FHWA/IN/JTRP-2001/6

Final Report

CONCRETE OVERLAYS AS A REHABILITATION OPTION FOR

DISTRESSED ASPHALT PAVEMENTS

Sudarshan Rajan

Jan Olek

December 2001 
Final Report

FHWA/IN/JTRP-2001/6

\title{
Concrete Overlays as a Rehabilitation Option for Distressed Asphalt Pavements
}

\author{
Sudarshan Rajan \\ Graduate Research Assistant \\ and \\ Jan Olek \\ Professor in Civil Engineering \\ Construction Materials Engineering \\ School of Civil Engineering \\ Purdue University \\ Joint Transportation Research Program \\ Project No. C-36-46Q \\ File Number: 6-14-25 \\ SPR-2340 \\ Prepared in Cooperation with the \\ Indiana Department of Transportation and the \\ U. S. Department of Transportation \\ Federal Highway Administration
}

The contents of this report reflect the views of the authors, who are responsible for the facts and the accuracy of the data presented herein. The contents do not necessarily reflect the official views and policies pf the Indiana Department of Transportation or Federal Highway Administration at the time of publication. The report does not constitute a standard, specification, or regulation.

Purdue University

West Lafayette, IN 47907

December 2001 


\section{TECHNICAL Summary}

INDOT Research

Technology Transfer and Project Implementation Information

TRB Subject Code: 40-6 Bituminous Pavement Maintenance

Publication No. FHWA/IN/JTRP-2001/06, SPR-2340

December 2001

Final Report

\section{Concrete Overlays as a Maintenance Option for Distressed Asphalt Pavements}

\section{Introduction}

The main objective of this study was to investigate the use of thin concrete overlays as a rehabilitation option for rutted asphalt pavements.

The scope of the research included characterization of the material properties of two concrete mixtures used for construction of the ultra-thin white topping (UTW) and evaluation of state of strains and stresses in the UTW installation exposed to slow moving heavy truck traffic.

The UTW concrete mixture was placed on the milled asphalt surface at the Accelerated Pavement Testing (APT) Facility of the Indiana Department of Transportation (INDOT) Research Division in West Lafayette, Indiana. Four different UTW lanes were constructed utilizing two different thicknesses of the overlay (2.5" and 4") and two different types of concrete (plain and fiber reinforced). The lanes were instrumented with various sensors to measure the strains, deflections and temperature changes in the pavement. The pavement was then subjected to varying wheel loads as well as temperature gradients. The strains and the deflections caused by the wheel load were monitored and the permanent strains and deflections of the pavement were recorded. The ultrasonic pulse velocity test was used in an attempt to detect the potential location of cracks and de-bonded zones in the pavement. In addition, cores were removed from the pavement and tested for shear strength using the Iowa Shear Test Method, to determine the quality of the bond between the overlay and the asphalt surface.

A finite element model was developed to predict the stress response of the composite pavement subjected to the wheel load. This model was used to verify the experimental test results obtained from the accelerated testing of the UTW.

\section{Findings}

The following conclusions can be drawn based on the results from this study:

- There was no significant damage to the UTW even after prolonged exposure to heavy slow moving wheel loads and elevated temperature. Overall, judging by the magnitudes of deflections and strains observed in various lanes, it could be concluded that the performance of the UTW was very satisfactory.
- The analysis of variation of strains as a function of the wheel position indicates that the overlay experiences significant stress reversal under the moving load.

- The pavement overlaid with UTW works as a composite section as indicated by the existence of a good bond between the overlay and the asphalt.

- Ultrasonic pulse velocity test is a promising technique that can be used to determine the 
areas where potential cracking may have occurred.

- The strain gage installation technique used on this project could be deemed satisfactory as seen from the low failure rates and the consistency of the readings over the whole period of the test. In addition, the concrete placement and curing techniques were satisfactory.

- Finite element modeling has proven to be a very useful tool for analysis of the complex state of stresses and strains that develop in a pavement under the wheel loads.

\section{Implementation}

The results of this investigation indicate that thin concrete overlays could be used as an effective rehabilitation technique to repair rutted asphalt pavements. However, before this technique can be widely implemented, field tests must be conducted and the pavement performance must be monitored over a sufficiently extended period to determine the effects of environmental conditions on the UTW installation.

Although the results of the current accelerated test can be used to develop preliminary design guidelines for the construction of the UTW overlays more extensive research needs to be conducted to develop a robust design methods. Specifically, there is a need to generate more data (through accelerated as well as field installations) that can help to develop empirical model for UTW performance prediction. Advanced finite element modeling of UTW pavements would provide further insight into the complex stresses that develop in the overlay under the moving wheel loads and help with selection of the optimum thickness and joint spacing.

\section{Contacts}

For more information:

\section{Prof. Jan Olek}

Principal Investigator

School of Civil Engineering

Purdue University

West Lafayette, IN 47907

Phone: (765) 494-5015

Fax: (765) 496-1364

\section{Purdue University}

School of Civil Engineering

Joint Transportation Research Project

West Lafayette, IN 47907-1284

Phone: (765) 494-9310

\section{Indiana Department of Transportation}

Division of Research

1205 Montgomery Street

P.O. Box 2279

West Lafayette, IN 47906

Phone: (765) 463-1521

Fax: (765) 497-1665 
TECHNICAL REPORT STANDARD TITLE PAGE

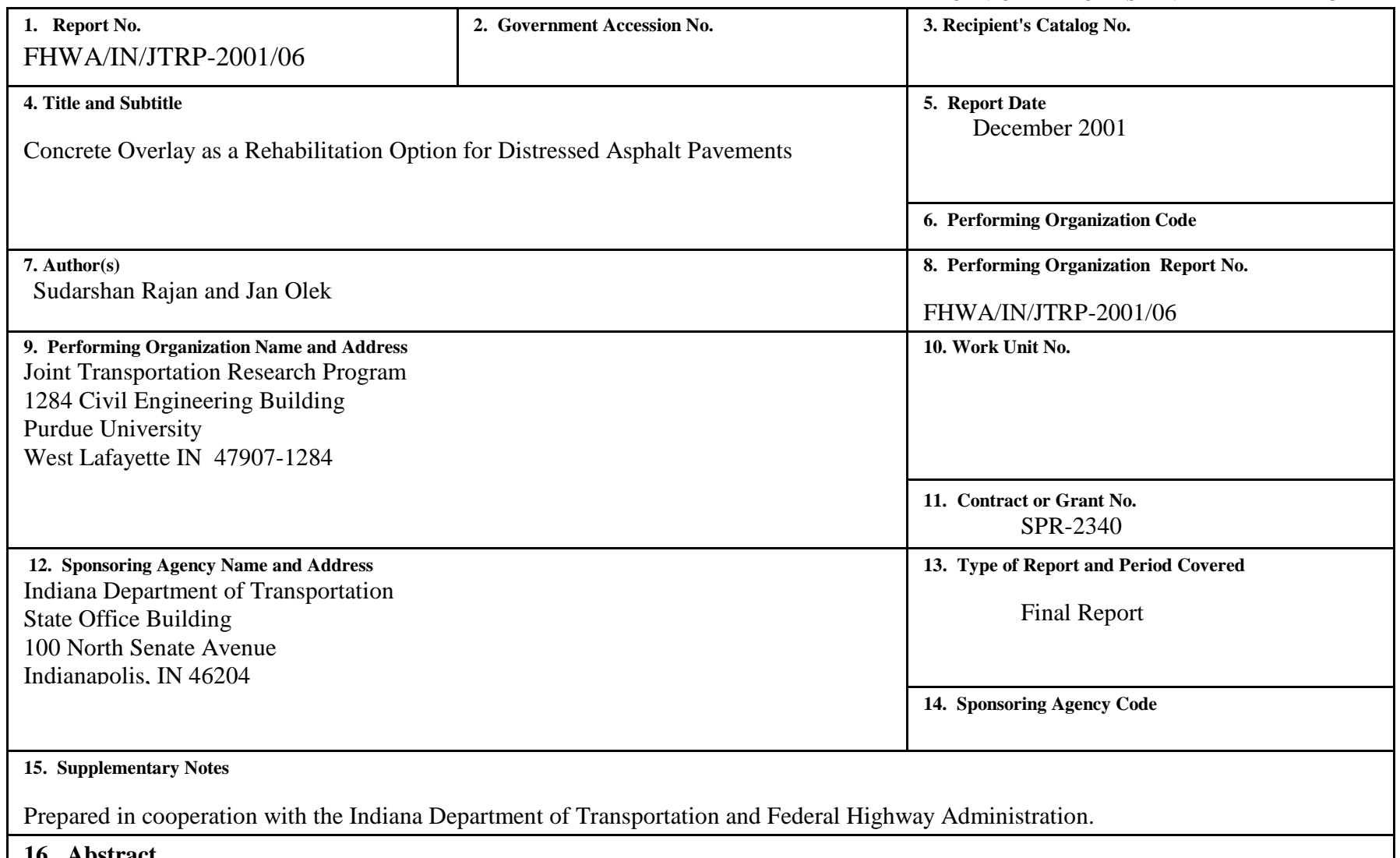

\section{Abstract}

Ultra-thin Whitetopping (UTW) involves placing a very thin concrete overlay $50 \mathrm{~mm}$ to $100 \mathrm{~mm}$ thick (2"-4") on the milled surface of a distressed asphalt pavement. To investigate the performance of UTW placed over a flexible pavement subjected to slow and heavy moving wheel loads, whitetopping mixes were placed over a milled pavement surface in the Accelerated Pavement Testing (APT) facility of the Indiana Department of Transportation (INDOT) Research Division in West Lafayette Indiana in the fall of 1999. The UTW installation experiment consisted of four test 'lanes' of two different thicknesses; each utilizing plain and fiber reinforced concrete. The test 'lanes' were instrumented using strain gages, Variable Differential Transducers (LVDTs) and thermocouples to measure the strains, deflections, and to monitor the pavement temperatures respectively. The test 'lanes' were subjected to both static and dynamic tandem wheel loads of varying magnitudes. In addition, one of the test 'lanes' was also exposed to thermal load by applying a temperature gradient to the pavement.

A mix design for the UTW was developed based on literature survey of previous UTW projects. The mechanical properties of concrete were evaluated in the laboratory before the UTW pavements were constructed at the APT facility. The pavements were monitored continuously during the testing period and the dynamic-load strains during the motion of the wheel, as well as the static strains due to the stationary wheel load were recorded. This data was analyzed to determine the maximum strains and their location, the degree of bonding between the UTW overlay and the underlying asphalt and the pavement performance under repeated loading. In addition, non-destructive test method was utilized to evaluate the pavement condition after the accelerated pavement testing was completed. In addition, cores obtained from the pavement were subjected to shear force to determine the quality of the bond.

A three-dimensional finite element model was developed using a general finite element code, ABAQUS, to conduct an analysis of the response of the composite pavement to the wheel loads. The principal goal was to develop a simple and reliable model using reasonable geometry, boundary conditions and material properties, to verify the pavement response observed experimentally. No significant differences were found between the predicted and the experimental pavement response.

\section{Key Words}

Ultra-thin white topping, plain concrete, fiber reinforced concrete, strain, deflection, stress, repeated wheel loading, pavement, temperature gradient, finite element model.
18. Distribution Statement

No restrictions. This document is available to the public through the National Technical Information Service, Springfield, VA 22161

\begin{tabular}{|c|c|c|c|}
\hline 19. Security Classif. (of this report) & 20. Security Classif. (of this page) & 21. No. of Pages & 22. Price \\
Unclassified & Unclassified & 149 & \\
\hline
\end{tabular}




\section{ACKNOWLEDGEMENTS}

This research study was funded by the Indiana Department of Transportation and the Federal Highway Administration through the Joint Transportation Research Program at Purdue University. The authors would like to thank both of these agencies for their financial support. Special acknowledgement also goes to the Study Advisory Committee members for their continued support and help throughout the project. 
TABLE OF CONTENTS

Page

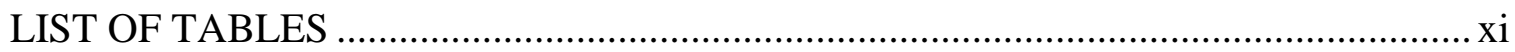

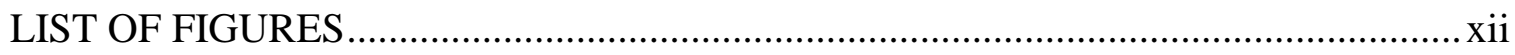

IMPLEMENTATION SUGGESTIONS ........................................................... xviii

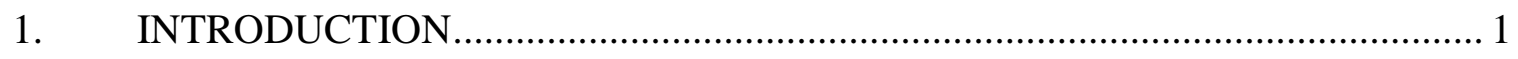

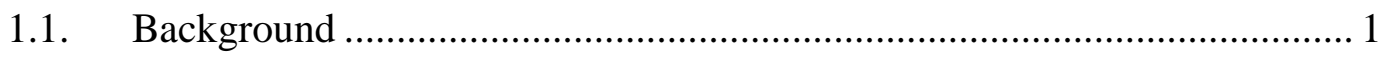

1.2. Problem statement ......................................................................... 3

1.3. Objective and scope of the present study .......................................... 3

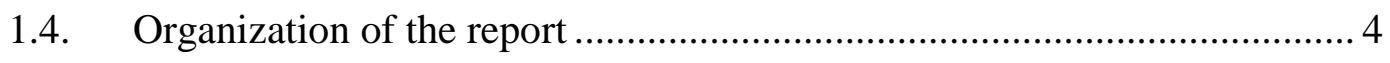

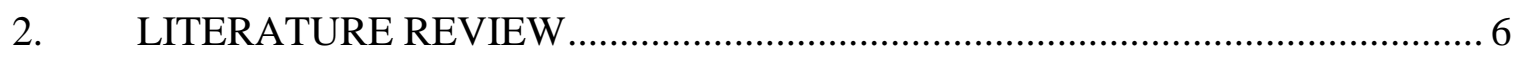

2.1. Definition and principles of UTW performance ................................. 6

2.2. Factors affecting UTW performance............................................... 11

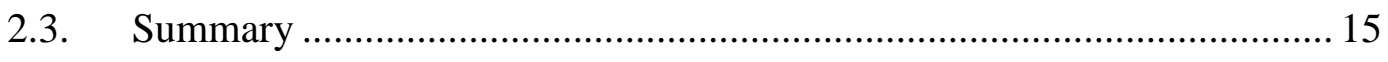

3. ACCELERATED PAVEMENT TESTING OF ULTRA-THIN

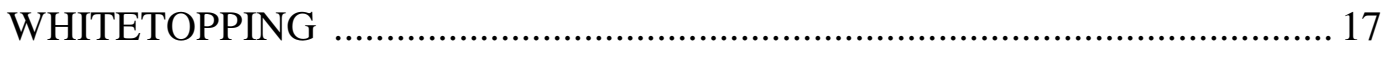

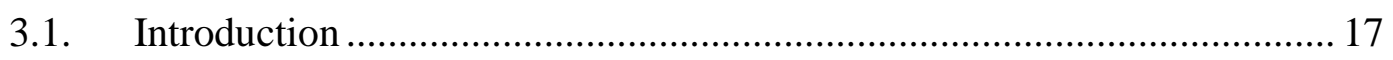


3.2. INDOT-Purdue University APT Facility ................................................ 18

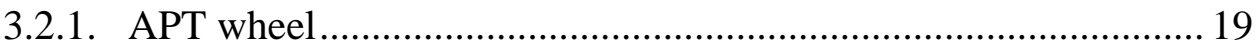

3.2.2. Data acquisition system............................................................. 20

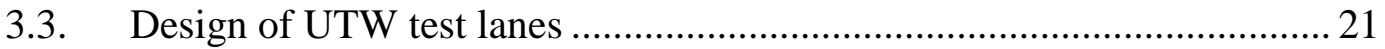

3.4. Concrete mixture design and test sample preparation............................... 23

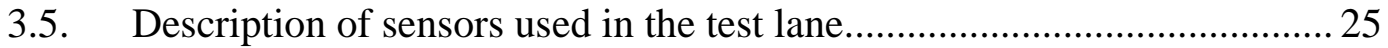

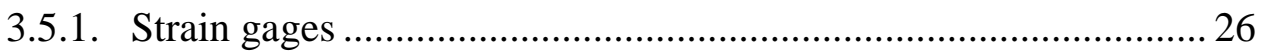

3.5.2. Linear Variable Differential Transducers (LVDT) ....................... 28

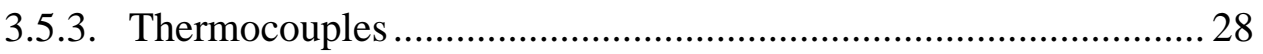

3.6. Instrumentation plan for accelerated testing of UTW .............................. 28

3.6.1 Location of single strain gages...................................................... 30

3.6.2 Location of strain gage rosettes..................................................... 30

3.6.3 Gage nomenclature ......................................................................... 31

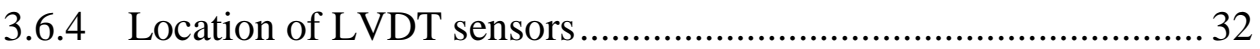

3.6.5 Location of thermocouple sensors.................................................... 33

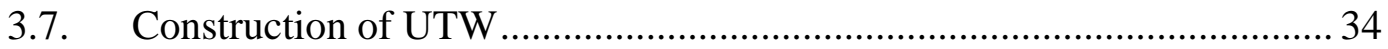

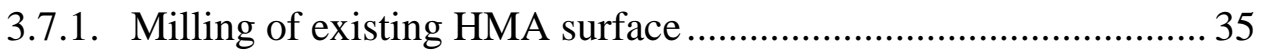

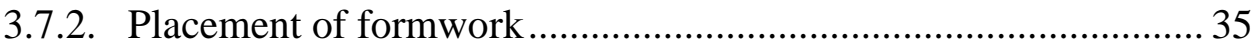

3.7.3. Placement of sensors .................................................................. 36

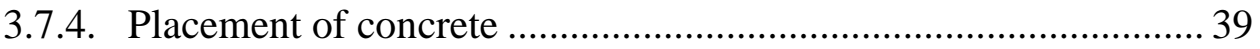

3.8 Mechanical properties of concrete ........................................................ 42

3.9 Test plan for accelerated testing of UTW ……......................................... 49 
4. ANALYSIS AND DISCUSSION OF THE RESULTS FROM THE

ACCELERATED PAVEMENT TEST .......................................................... 51

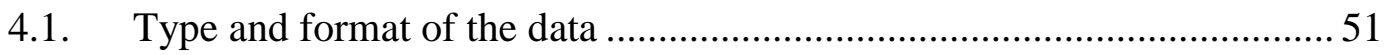

4.2. Analysis of data from dynamic wheel load tests.................................. 54

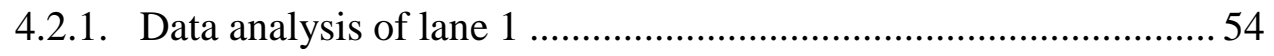

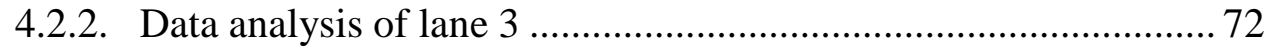

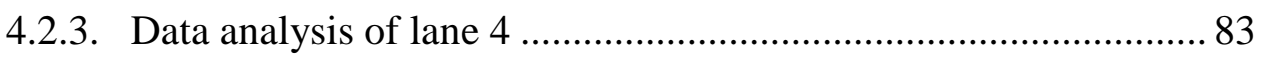

4.3. Analysis of data from the static wheel load tests .................................. 94

4.3.1 Summary of data analysis of lane 4 .................................... 102

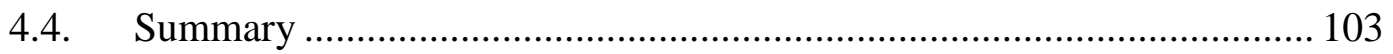

5. QUALITATIVE ASSESSMENT OF THE UTW PAVEMENT CONDITION 104

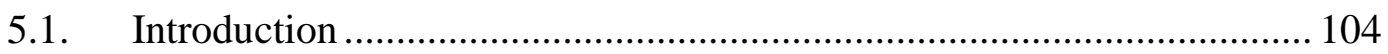

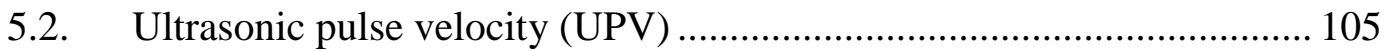

5.2.1. Description of the UPV method ......................................... 105

5.2.2. Test plan for the UPV tests ............................................... 106

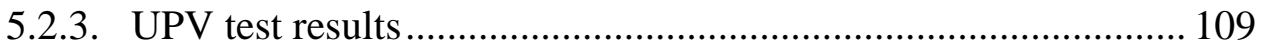

5.2.4. Summary of UPV test results ............................................ 114

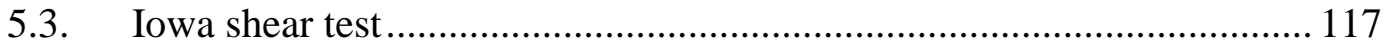

5.3.1. Test method and description .............................................. 117

5.3.2. Selection of location for test cores ........................................ 119

5.3.3. Discussion of shear test results............................................. 121

5.3.4. Summary of Iowa shear test data ......................................... 124 
6. FINITE ELEMENT MODELING OF ULTRA-THIN WHITETOPPING ........ 125

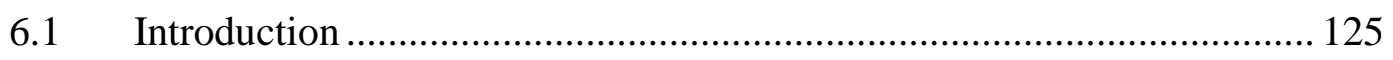

6.2 Description of the features of the finite element software and the graphical interface used in this study ...................................................... 126

6.3 Steps in creating the Finite Element Model (FEM) ........................... 127

6.3.1 Modeling of geometry of the UTW section ........................... 128

6.3.2 Model meshing .............................................................. 129

6.3.3 Element selection ....................................................... 130

6.3.4 Load and boundary conditions ........................................ 131

6.3.5. Material properties ........................................................... 133

6.4 Execution of the FEM program................................................... 134

6.5 Analysis of FEM results of UTW model ........................................ 134

6.5.1 Analysis of stresses and strains ........................................ 135

6.5.2 Comparison of FEM generated and experimental strain data.... 138

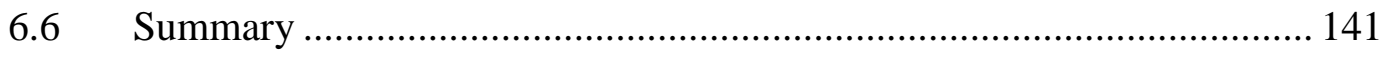

7. CONCLUSIONS AND RECOMMENDATIONS …................................ 143

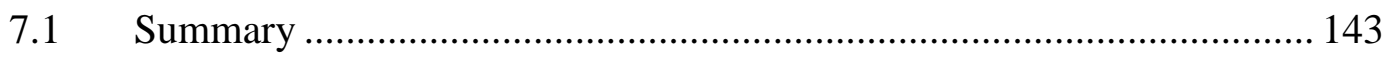

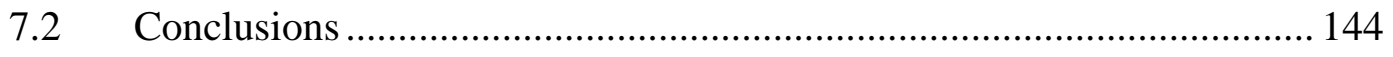

7.3 Suggestions for future research .............................................. 146

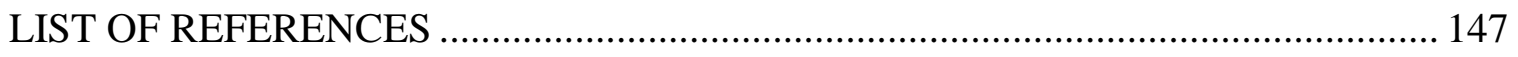




\section{LIST OF TABLES}

Table

Page

3.1. Summary of the material type and thickness information for the test lanes.....

3.2. Mixture composition for plain concrete

3.3. Mixture composition for fiber reinforced concrete

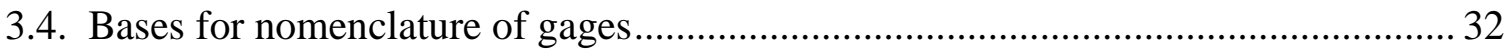

3.5. Nomenclature of instrumentation installed in a typical test lane 34

3.6. Laboratory-mix results for plain and fiber reinforced concrete

3.7. APT-mix results for plain and fiber-reinforced concrete 44 


\section{LIST OF FIGURES}

Figure $\quad$ Page

2.1. Stress distribution in unbonded and bonded overlays. .................................... 9

2.2. Load transfer mechanisms in conventional and UTW pavements. ...................... 10

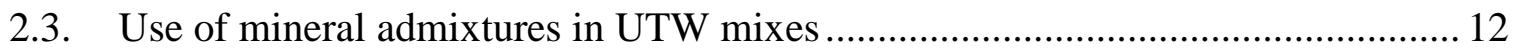

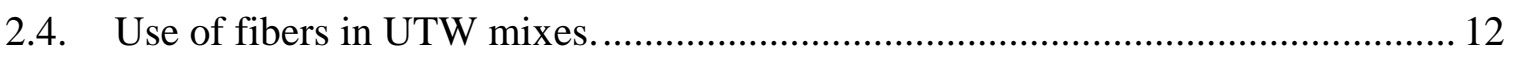

3.1. The INDOT-Purdue University APT facility. ................................................ 19

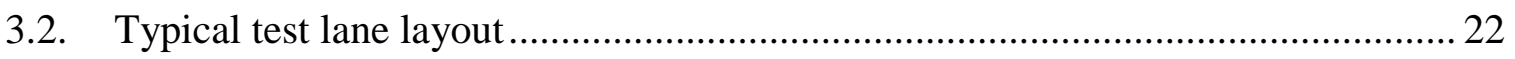

3.3. Non-encapsulated gage (WFLM-60-2LT) used on the asphalt surface................. 27

3.4. Concrete embedment gages (PML-60-2L) used in the UTW ............................. 27

3.5. Plan view of the instrumentation layout for a typical test lane........................... 29

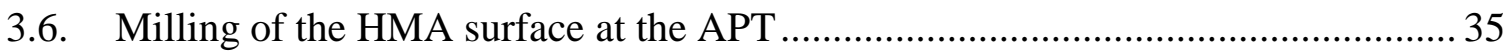

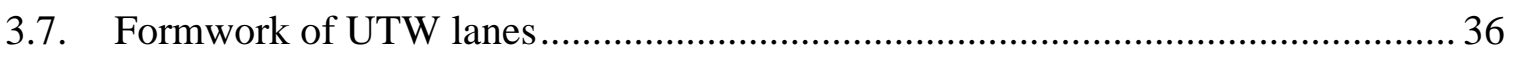

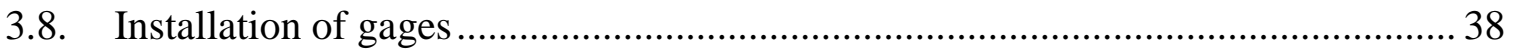

3.9. Top view of the gage setup on the milled asphalt prior to mounting of gages....... 38

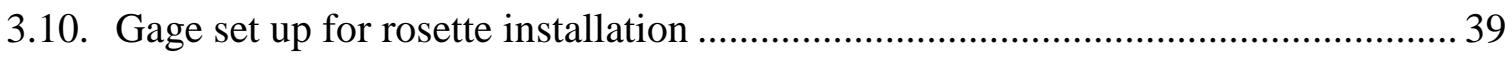

3.11. Concrete placement at the APT facility ..................................................... 40

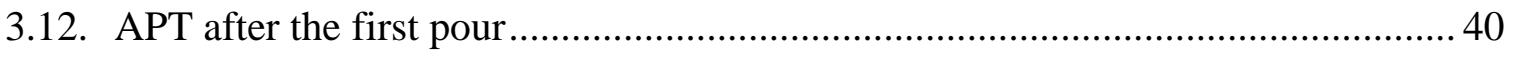

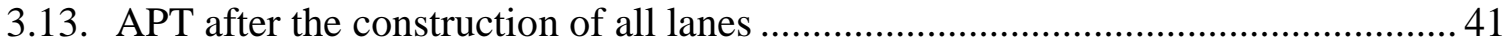

3.14. Comparison of compressive strength of plain concrete (lab and APT mixes) ....... 45 
Figure

3.15. Comparison of compressive strength of fiber reinforced concrete (lab and APT mixes)

3.16. Comparison of compressive strength of plain and fiber reinforced concrete (lab $\operatorname{mix})$

3.17. Comparison of compressive strength of plain and fiber reinforced concrete (APT $\operatorname{mix})$ 46

3.18. Comparison of flexural strength of plain vs. fiber concrete (APT mix) 47

3.19. Comparison of flexural strength of plain vs. fiber concrete (lab mix). 47

3.20. Comparison of flexural strength of plain concrete (lab and APT mixes) ..... 48

3.21. Comparison of flexural strength of fiber reinforced concrete (lab and APT mixes) 48

3.22. Schematic of the lane layouts and the test plan...... 50

4.1. Typical strain response of edge longitudinal gages under moving wheel during the first pass. 55

4.2. Relative motion of slabs causing dynamic strain reversal. 56

4.3. Typical strain response of edge longitudinal gages under the moving wheel during the $1000,000^{\text {th }}$ pass.

4.4. Dynamic strain response of longitudinal edge gages in the adjacent lane during the $100,000^{\text {th }}$ pass 58

4.5. Strain variation of transverse gages during the first pass. 59

4.6. Transverse gage strain variatons during the $100,000^{\text {th }}$ pass. 60

4.7. Strain response of the top rosette during the first pass. 61 
Figure

Page

4.8. Strain response of the top rosette during the $100,000^{\text {th }}$ pass 61

4.9. Strain response of the bottom rosette due to moving wheel at first pass 62

4.10. Deflection pattern of LVDTs at the first pass. 63

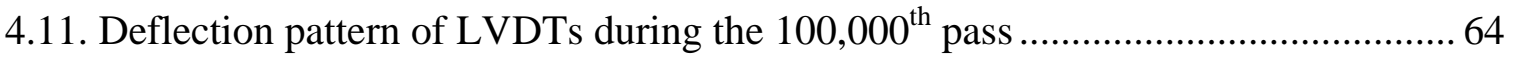

4.12. Increase in strain after load increase at 30,000 passes in gage 1-C-M-2 …...........6 65

4.13. Increase in strain after load increase at 30,000 passes in gage 1-C-M-1 ............... 66

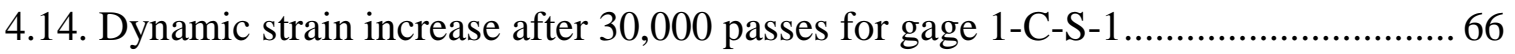

4.15. Change in maximum dynamic compressive and tensile strains (gage 1-C-S-1) after the increase in the load from $12,000 \mathrm{lbs}$ to $20,000 \mathrm{lbs}$.

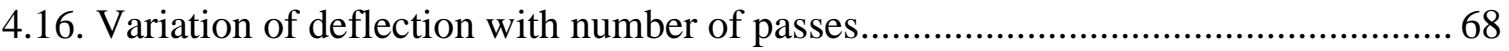

4.17. Variation of longitudinal mid-panel strain with number of passes ....................... 69

4.18. Variation of transverse strain with number of passes ..................................... 70

4.19. Variation of top rosette strain with number of passes ..................................... 70

4.20. Variation of longitudinal strain in adjacent lane with number of passes ................ 71

4.21. Comparison of permanent strains at the top and bottom of the concrete overlay in longitudinal gages in the test lane and the adjacent lane.

4.22. Typical strain response of edge longitudinal gages under the moving wheel during the first pass

4.23. Typical strain response of edge longitudinal gages under the moving wheel during the $100,000^{\text {th }}$ pass 74

4.24. Changes in maximum dynamic compressive and tensile strains in gage $3-\mathrm{C}-\mathrm{S}-1 \ldots 75$ 
Figure

4.25. Strain response of mid-panel longitudinal gages under the moving wheel at the first pass 76

4.26. Changes in maximum dynamic compressive and tensile strains in gage 3-C-M-1 . 76

4.27. Strain response of longitudinal gages in the adjacent unloaded lane under the moving wheel at the $100,000^{\text {th }}$ pass 77

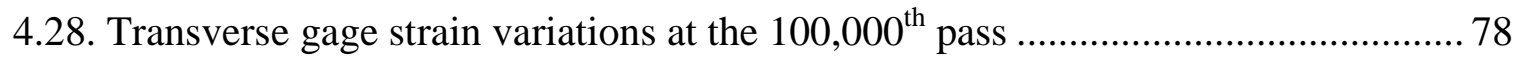

4.29. Strain response of bottom rosette in lane 3 due to moving wheel at first pass ........ 79

4.30. Strain response of bottom rosette in lane 3 due to moving wheel at the $100,000^{\text {th }}$ pass ........

4.31. Comparison of maximum dynamic strains in lane 1 and lane 3 81

4.32. Comparison of permanent strains in longitudinal edge gages in lane 3

4.33. Temperature variation in lane 4 ...... 84

4.34. Dynamic strain variation in longitudinal edge gages at the first pass .................... 85

4.35. Variation of dynamic strain in gage 4-W-S with number of passes....................... 86

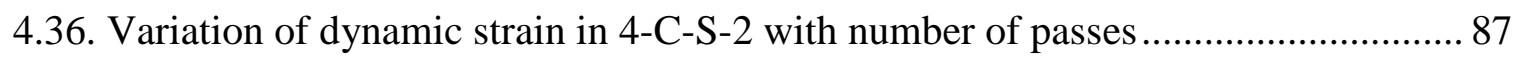

4.37. Variation of dynamic strain in gage 4-W-M with number of passes ...................... 88

4.38. Variation of dynamic strains in gage 4-C-M-1 with number of passes .................. 88

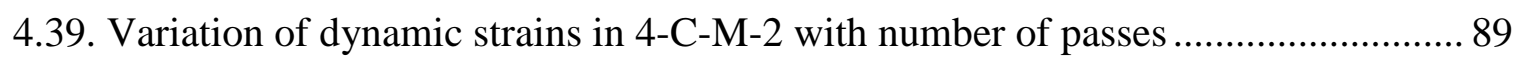

4.40. Variation of total dynamic strain in mid-panel gages with number of passes ........ 90

4.41. Variation of strain in the longitudinal gages in the adjacent lane at the first pass ...91

4.42. Variation of dynamic strain in transverse gages at the 100,000 th pass................... 92 
Figure

4.43. Variation of dynamic strain in rosette at the $100,000^{\text {th }}$ pass 93

4.44. Magnitude of total dynamic strain in strain gage rosette with number of passes ....93

4.45. Temperature and permanent strain variations for mid-panel gages in lane 4 95

4.46. Temperature and permanent strain variations for longitudinal edge gages in lane 496 4.47. Temperature and permanent strain variations for strain gage rosette in lane 4 ....... 97

4.48. Plan view of static test location in the UTW pavement

4.49. Initial strain response of longitudinal gages in lane 1 under 12,000 lbs. static load at position 1 100

4.50. Initial strain response of longitudinal gages in lane 1 under 12,000 lbs. static load at position 2 101

4.51. Static strain variation in edge gages with number of passes in lane 4 102

5.1. Cracks developed in lane 1 of the UTW pavement 104

5.2. Plan view of the grid layout for $\mathrm{V}$-meter tests 108

5.3. Distribution of $\mathrm{V}$-meter flight times between grid points in lane 1 110

5.4. Front view of flight times between grid points in lane 1 110

5.5. Distribution of V-meter flight times between grid points in lane 3 111

5.6. Frontal view of flight times between grid points in lane 3 112

5.7. Distribution of V-meter flight times between grid points in lane 4

5.8. Front view of flight times between grid points in lane 4 113

5.9. Cracks on and near the wheel path in lane 4 . 114

5.10. Distribution of flight times for the test lanes 1,3and 4 based on V-meter readings 116 
Figure

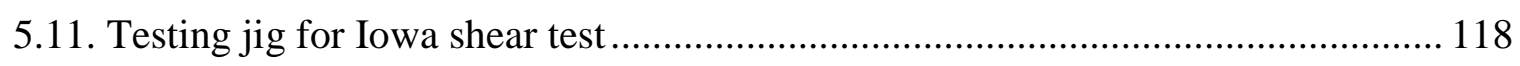

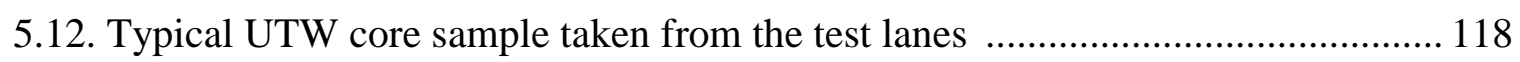

5.13. Drilling machine removing UTW cores at the APT facility .............................. 119

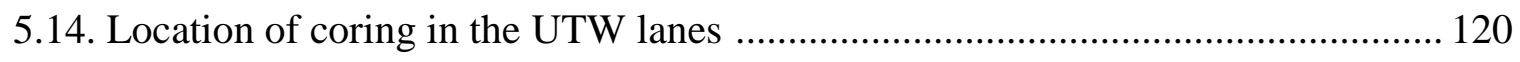

5.15. Comparison of average shear strengths for different lanes .............................. 122

5.16. Typical failure of a UTW specimen in the Iowa shear test............................... 122

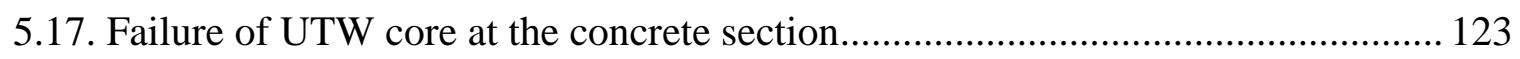

5.18. Failure of UTW core at the interface along with asphalt stuck to the surface ....... 123

6.1. Dimensions and cross section of the UTW pavement used in the FEM model ..... 129

6.2. Plan view of the loading area on the surface of the UTW panel......................... 132

6.3. Magnified image of the deflection pattern due to the wheel load......................... 135

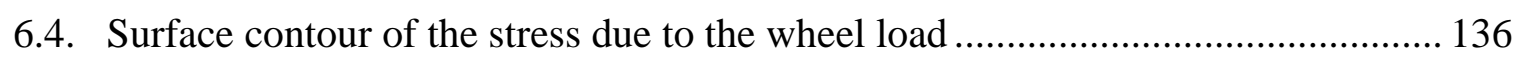

6.5. Surface contour of longitudinal strain distribution due to the wheel load ............. 137

6.6. Comparison of maximum calculated and experimental strains in the UTW

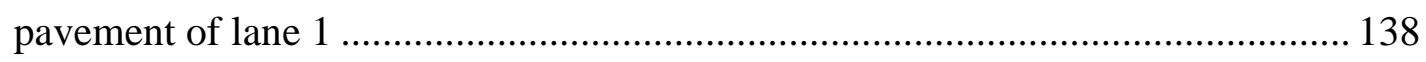

6.7. Dynamic strain variation at the asphalt surface under the 20,000 lbs wheel load in lane 1 139

6.8. Dynamic strain variation at the top of the concrete under the $20,000 \mathrm{lbs}$ wheel load in lane 1 140

6.9. Strain variation through the depth of the pavement for the FEM model and the experimental test 


\section{IMPLEMENTATION SUGGESTIONS}

Pursuant to findings presented in this report, the following suggestions are being provided as a means of implementing the Ultra-thin White-topping as a repair option for rutted asphalt pavements.

1. The construction guidelines developed for the experimental set up at the Accelerated Pavement Testing (APT) Facility could be used for the field implementation of the white topping. The instrumentation layout and its installation procedure could also be implemented in the field.

2. The results of the accelerated pavement test are valid only for the range of parameters used in the tests described in this report. These include the specified thickness (4" or $\left.2.5^{\prime \prime}\right)$ of the overlay, the fixed joint spacing (4') and the type of concrete mixture utilized (fiber vs. non-fiber).

3. The results of the finite element modeling could be used to develop further guidelines for the design of the UTW based on target values for stresses and strains in the pavement. 


\section{INTRODUCTION}

\section{$\underline{1.1 \text { Background }}$}

The significant increase in the number of automobiles observed in the recent years has created a need not only for the construction of new highways but also for the maintenance and rehabilitation of existing highway networks. Pavements are prone to damage due to the repeated wheel loads as well as temperature and other environmental effects. Millions of dollars are spent each year on rehabilitation of existing highways.

The three types of pavements used in the US include flexible or asphalt pavements, rigid or concrete pavements and composite pavements. A flexible pavement consists of three main layers, the bituminous layer, the aggregate or base layer and the sub-base layer. The bituminous layer is generally divided into wearing course and base course (or binder course), laid separately. A rigid pavement normally consists of two layers only, the concrete slab and the sub-base. Sometimes a base course is used when

the soil foundation is weak. A composite pavement generally consists of an asphalt overlay on top of a concrete pavement.

Paved surfaces for roadways, both portland cement concrete and asphalt, must withstand very harsh conditions. Wheel loads from moving vehicles cause strains, stresses and deflections in the paved surface and underlying roadbed. These loads are repetitive in nature and over an extended period of time will cause fatigue damage to the 
pavement. Additionally, the pavement must endure environmental effects. Climatic changes cause temperature variations through the depth of the pavement, inducing internal stresses.

Asphalt properties, especially the stiffness, changes with temperature. Moisture variations cause changes in foundation support. In many areas, freezing and thawing temperature cycles cause variations in foundation support and add additional stresses to the paved surface, particularly when moisture is also present.

Eventually, a pavement exhibits distress and requires rehabilitation. A variety of rehabilitation techniques has been developed. When properly applied at the appropriate time, rehabilitation techniques significantly extend the total life of concrete and asphalt pavements. One of the techniques for rehabilitating distressed asphalt pavements is the use of concrete overlay. In North America, this technique is often referred to as "whitetopping". Whitetopping has been routinely used in the United States since the mid-1970s. The first documented use of a concrete overlay over an existing asphalt roadway in the U.S. can be traced to 1918, when South 7th Street in Terre Haute, Indiana was whitetopped. It is a well-proven method of asphalt pavement rehabilitation [1].

A new method of rehabilitating asphalt pavements was developed in the early 1990s. This technique requires bonding of a relatively thin layer of concrete to the underlying asphalt to create a composite pavement section. This technique is called "ultra-thin whitetopping". While the technology is still developing, over 200 ultra-thin whitetopping sections have been built, primarily on low-volume roadways. 


\section{$\underline{1.2 \text { Problem statement }}$}

The deterioration of flexible pavements arises from deformation under traffic loading generally associated with heavy commercial vehicles. This is particularly evident at urban intersections where rutting, shoving and wash boarding are often observed. Similar problems are also encountered in exit/access ramps, busy intersections, parking areas and bus stops, which are prone to slow moving traffic. This leads to the deterioration of the surface of the asphalt pavements and a need to rehabilitate them before further damage could occur. Since the use of a thin concrete overlay is a relatively new concept in pavement rehabilitation, there is a need for evaluating its effectiveness. In particular, refined methods of design are needed along with long-term performance data.

\section{$\underline{1.3 \text { Objective and scope of the present study }}$}

The focus of the research described in this thesis was to investigate the use of thin concrete overlays as a rehabilitation option for rutted asphalt pavements. The objective of the research was to evaluate the state of strains and stresses in the UTW system exposed to slow moving heavy truck traffic. It is expected that the outcome of this research will help to improve the existing empirical methods of the UTW design by providing better understanding of the strain and stress fields created in such installations under heavy loads. The results of this research can also be used as a basis for the creation of preliminary design guidelines based on the pavement response to the wheel load as one of the major criterion. This approach would be based on the analysis of the strains and deflections produced by a slow moving load on the UTW pavement. 
To achieve this, the overlay was instrumented with a goal of analyzing the pavement response based on load strains, temperature strains and deflections. The main tasks undertaken during the course of this research are:

a) Literature Survey

b) Development and Testing of Laboratory Mixes

c) Instrumentation of the Ultra-Thin Whitetopping (UTW) test lanes at the Accelerated Pavement Testing Facility (APT)

d) Construction of UTW pavement

e) Monitoring and data collection during the accelerated testing of the UTW pavement.

f) Non-destructive testing on the UTW pavement.

g) Data analysis and modeling of the UTW system.

h) Development of future research recommendations.

\subsection{Organization of the report}

The thesis consists of seven chapters. The first chapter gives the background information and presents the problem statement and the objectives of the study. The second chapter presents literature review of the UTW. Chapter three describes the Accelerated Pavement Testing Facility. It also details the various steps taken to set up the experiment for conducting the accelerated testing of UTW. This involved preparing the APT test pad, instrumenting the lanes and finally placement of concrete to construct the UTW. In addition, the mechanical properties of the concrete are discussed in this chapter. Chapter four discusses the analysis of the data obtained from the accelerated 
testing of the UTW. The data consisted of strains, deflections and temperature readings from the sensors installed in the UTW pavement at the APT facility. Chapter five pertains to the various qualitative methods employed to assess the UTW pavement condition after the accelerated testing of the UTW pavement had been completed. This involved the use of non-destructive test method such as the ultrasonic pulse velocity method and the shear testing of the cores using the Iowa shear test method. Chapter six deals with the development of a finite element model for predicting the stresses and strains generated in the UTW pavement under the given loading conditions. The model was created and the results were compared to the experimental results obtained from the accelerated testing of the UTW pavement. Chapter seven lists the main findings from this research and gives the scope of further research in this field. 


\section{LITERATURE REVIEW}

\subsection{Definition and Principles of UTW Performance}

Ultra-thin White Topping (UTW) is a relatively new technique that is used mainly for the rehabilitation of deteriorated asphalt pavements. Typically, UTW is constructed by milling the distressed top portion of the asphalt pavement, and placing a thin ordinary or fiber reinforced concrete overlay, not more than $104 \mathrm{~mm}$ (4") in thickness on top of the milled surface. The normal thickness of a UTW pavement varies anywhere from 50 $\mathrm{mm}$ to $100 \mathrm{~mm}$ (2" to 4"). Based on U.S. experience, ultra-thin whitetopping can be defined as: "A concrete overlay $50 \mathrm{~mm}$ to $100 \mathrm{~mm}$ thick with closely spaced joints bonded to an existing asphalt pavement" [2].

Whitetopping is a pavement rehabilitation technique that has been evolving rapidly in the modern era of higher traffic volumes and heavier axle loading. The technique was used primarily to upgrade the load-carrying capacity (both volume and structural capacity) of existing highways and rural roads. Traditionally thick nonreinforced concrete overlays have been laid on existing asphalt highways. The performance studies conducted on these pavements concluded that these overlays provided excellent service [2]. Many were in service with little or no rehabilitation for well over 20 years. A dramatic increase in the popularity of whitetopping emerged in the mid-1970s and continues today. Whitetopping has been used to rehabilitate high-volume 
interstate expressways, rural highways, municipal streets, and rural county roadways. For example, since 1977, over $650 \mathrm{~km}$ of county roadways in the State of Iowa have been whitetopped. These roadways primarily serve as farm-to-market roadways in this agriculturally extensive region of the U.S. [2].

Until recently, most whitetopping projects did not purposely seek bond between the interface of the concrete overlay and the underlying asphalt surface. Rather, the existing asphalt served as base for the new concrete overlay. This technique is referred to as "conventional" or "classical" whitetopping, defined as: "A concrete overlay, usually of thickness of $100 \mathrm{~mm}$ or more, placed directly on top of an existing asphalt pavement" [2]. The UTW technology, which emerged in the early 1990s, however was based on the premise of development of bond between the concrete and the asphalt. This rehabilitation technique purposely seeks to bond the concrete overlay to the existing asphalt. As a result, the concrete overlay and the underlying asphalt act as a composite section rather than two independent layers as discussed previously. This composite action significantly reduces the load-induced stresses in the concrete overlay. Therefore, the concrete overlay can be significantly thinner for the same loading as compared to a whitetopping section with no bond to the underlying asphalt.

The first ever UTW project was undertaken in Louisville, Kentucky in September 1991 [3-6]. The experiment included construction of two thicknesses of concrete overlay (90 $\mathrm{mm}$ and $50 \mathrm{~mm}$ ) on the access road to a waste disposal landfill. The access road served 400 to 500 trucks daily throughout the working days in the week. This was viewed as a site where accelerated testing of the pavement could be done, as the truck loading was 20 to 100 times greater than that on an average low volume road. The 
success of this project led to a number of different projects in other states like Georgia, Tennessee, Virginia, Florida and Iowa, to name a few [2].

One of the major research projects undertaken is by the Federal Highway Administration and the American Concrete Pavement Association that is being conducted at the Turner-Fairbanks Test Facility in McLean, Virginia [7]. The purpose of this study is to evaluate design factors affecting the performance of the UTW. The main parameters to be analyzed were the UTW thickness, the joint spacing, as a function of concrete mixture proportions and different grades of HMA binder. An Accelerated Loading Facility (ALF) is being used to test the lanes, constructed for the different parameters, for repeated wheel loading. The lanes are being instrumented with strain gages, Linear Variable Differential Transducers (LVDTs) and thermocouples (temperature sensors) to monitor the response of the UTW system. The deflection and strain data obtained from the LVDTs and the strain gages is currently being used to evaluate finite element and other types of response models for the UTW [7]. Other research projects of a similar nature have been undertaken in Ohio University, Kansas State University and University of Florida [8, 9].

The performance of a UTW system is determined by the following factors.

a) Sufficient bond between the UTW overlay and the Hot Mix Asphalt (HMA) base. The milling of the HMA prior to constructing the overlay improves the bond between the UTW overlay and the existing HMA pavement. This is because the milling process exposes the aggregate of the HMA mix, which in turn establishes an interlocking effect between the milled HMA surface and the UTW overlay 
thereby improving the bond between them. The tensile load stresses in the concrete are reduced as solid bond at the concrete-asphalt interface creates a composite action and pushes the neutral axis away from the concrete layer (refer to Figure 2.1). As the neutral axis moves further down, the tensile stresses in asphalt also decrease, as the HMA layer is closer to the neutral axis.

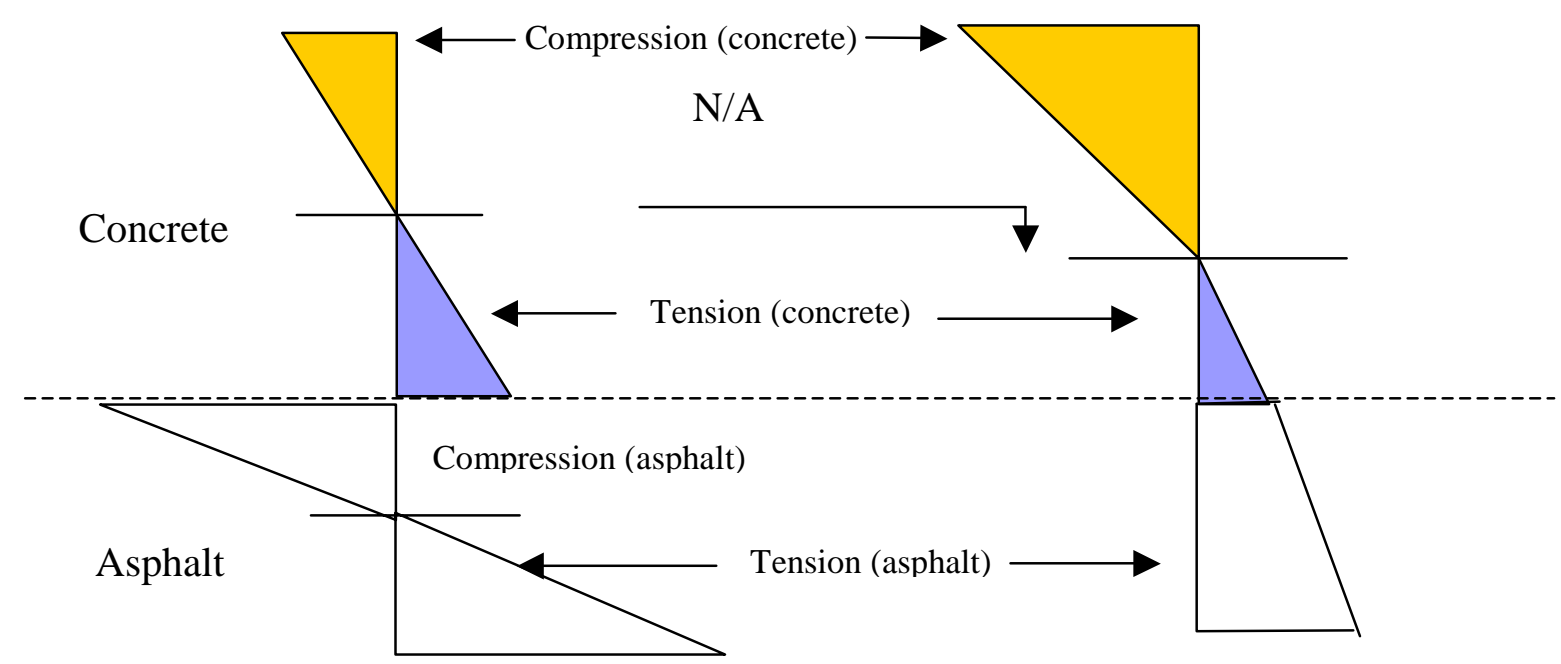

Unbonded

Bonded

Figure 2.1 Stress distribution in unbonded and bonded overlays

b) Shorter joint spacing or small panels. Smaller joint spacing helps to reduce the stresses generated by bending as well as curling and warping effects on the pavement due to temperature and moisture gradients. Traditionally, concrete pavements are designed to absorb energy by bending are thus are constructed thick enough to resist the bending stresses. Short joint spacing allows the load to 
be carried with lower deflection and the joint movement is minimized. With UTW, short joint spacings are used so that the energy is absorbed by deflection rather than by bending (refer to Figure 2.2). Typically the joint spacings for a UTW system are somewhere between $0.6 \mathrm{~m}$ and $1.5 \mathrm{~m}$ (2' to 6') [10].

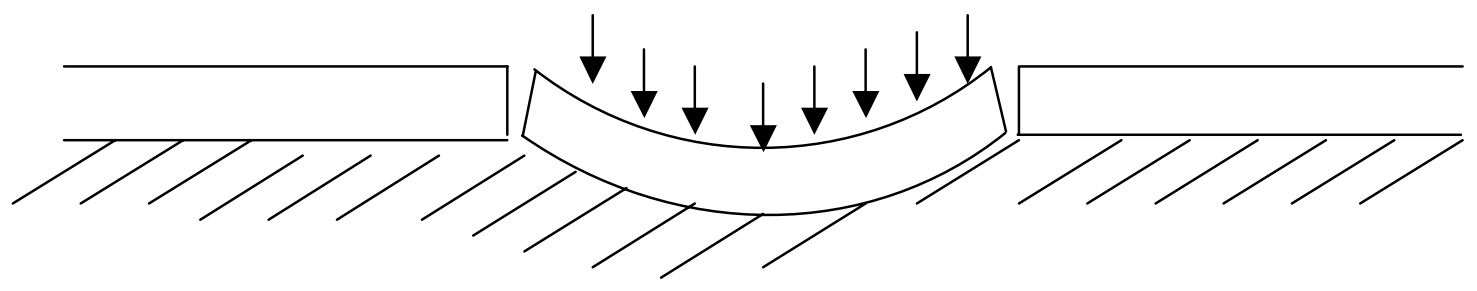

Conventional Concrete Pavement

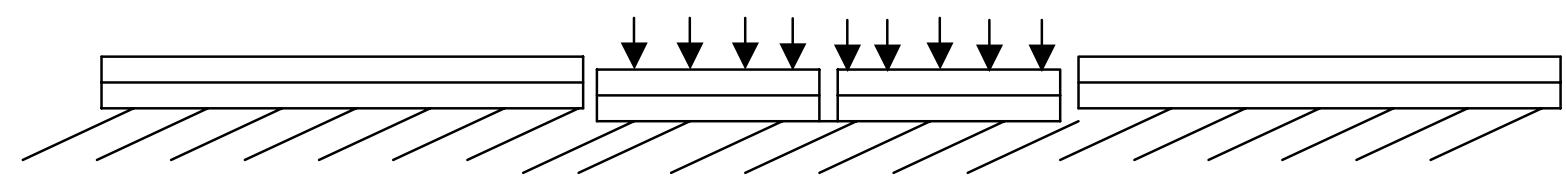

Ultrathin Whitetopping Overlay

Figure 2.2 Load transfer mechanism in conventional and UTW pavements

c) Sufficient thickness of the remaining asphalt. After surface preparation, (i.e., the milling of the asphalt surface) there should be enough asphalt remaining to form a sufficient composite section that can carry the load. There should be enough structural stability in the asphalt surface for the composite action in the UTW to develop. In addition, the thicker asphalt section carries more loads and helps the neutral axis to shift further down, thereby causing composite action. Thicker 
asphalt section increases the overall thickness of the pavement thereby decreasing the tensile stresses in concrete.

\subsection{Factors Affecting UTW Performance}

The UTW projects constructed in the last few years have provided promising results for further implementation and analysis of the white-topping as a rehabilitation measure for rutted and distressed asphalt pavements. The main points that have come about from the review, monitoring and construction of the UTW projects are:

a) Concrete Mixture Proportions

All of the UTW projects surveyed during the literature review were constructed with concrete of similar composition. The typical mix is characterized by low water-cement ratio $(<0.40)$. The slump requirement $(2.5 "-$ 4") for construction and placing is achieved by the use of high range water reducers. The mixes also have high cement content (typically greater than 350 $\left.\mathrm{kg} / \mathrm{m}^{3}\left(600 \mathrm{lb} / \mathrm{yd}^{3}\right)\right)$ and not much use of supplementary siliceous materials (except fly ash) has been observed. The use of fibers also has been observed in many mixes. The fibers are believed to delay the crack propagation after the onset of a crack on the concrete surface. The two main fibers used were fibrillated Polypropylene fibers and 3M 50/63 Polyolefin fibers. The average compressive strengths achieved by the mixes were well above $17.25 \mathrm{MPa}$ (2500 psi) after 1 day and some of the mixes showed strengths of over $60 \mathrm{MPa}$ (9000 psi) after 28 days. The flexural strength of typical mixes was around 5 to $5.5 \mathrm{MPa}$ (750 to 800 psi) after 28 days. Figure 2.3 below show the usage of mineral 
admixtures in UTW concrete mixtures. Figure 2.4 shows the extent and type of fibers used in typical UTW mixes. These figures are based on mixture design compositions surveyed in the literature for over 30 mixes.

\section{Use of mineral admixtures in UTW concrete mixes}

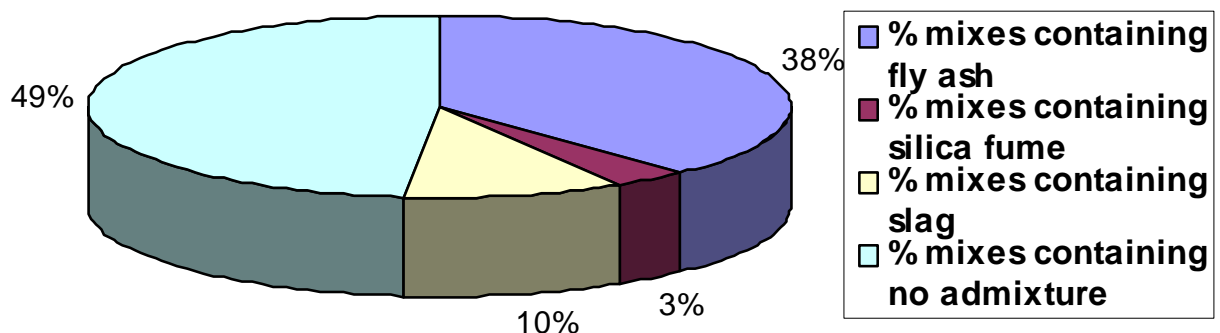

Figure 2.3 Use of mineral admixtures in UTW mixes

Fiber usage in UTW concrete mixes

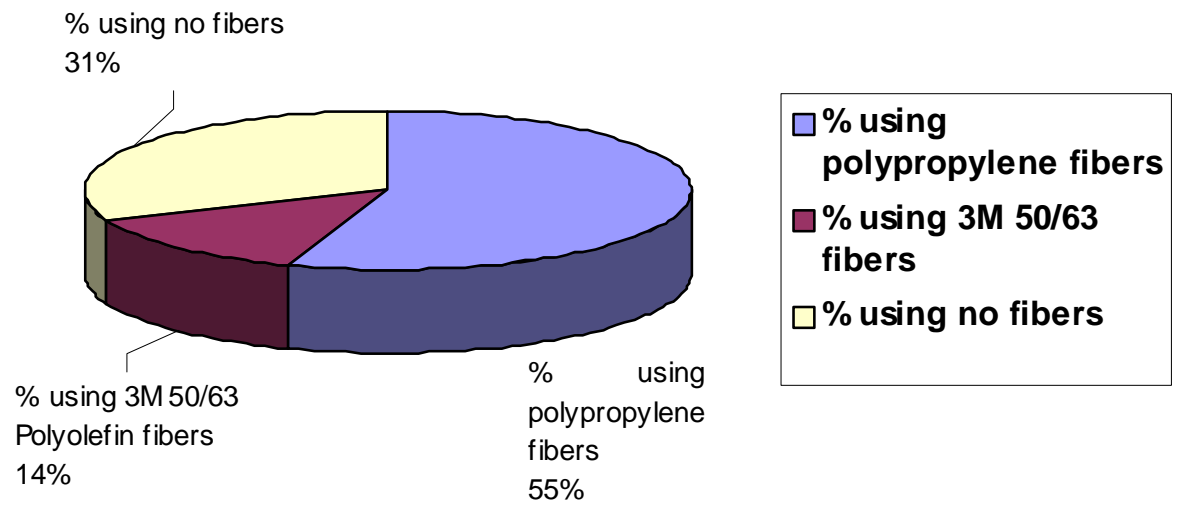

Figure 2.4 Use of fibers in UTW mixes 
b) Typical Construction Procedures

All of the UTW projects reviewed in the literature were constructed in a similar fashion. The existing asphalt was milled to produce the desired thickness of the overlay. The milled surface was flushed with a water jet or pressurized air to remove the debris before pouring concrete. Since the UTW is based on the premise that a bond forms between the asphalt and concrete, no bonding agent or a bond breaker was placed on the milled asphalt surface prior to pouring. Concrete produced in a commercial ready mix operation was placed directly on the milled asphalt. A vibrating screed was used to spread and consolidate the concrete and the finishing and texturing of the surface followed normal construction procedures. Early joint cutting using a mobile saw to prevent any shrinkage cracking emphasized the joint sawing operation.

c) Traffic loading

The axle load and the vehicular traffic count have a significant effect on the performance of the UTW system. For the UTW systems installed in the field, the traffic volume measurements, the percentage of truck traffic and the axle load gives an indication of the usage of the pavement. For the projects where these measurements were not made a constant factor of 0.75/ESAL (Equivalent Single Axle Load) per truck has been used to estimate the number of ESALs. For the UTW projects undertaken on Accelerated Loading Facilities such as the one in McLean Virginia, the axle load and the number of ESALs were easily available as the loaded wheel was running on the monitored experimental sections [7]. 
d) Pavement Monitoring

Most of the UTW projects implemented on the field have been subjected to periodic survey for assessing the damage caused to it by the flow of traffic. A large number of factors influence the performance of UTW pavements. Thickness of overlay, joint spacing, degree of bonding, thickness and condition of the remaining asphalt and pavement subgrade support conditions, all have been analytically proven to affect the stresses in the pavement. The survey mainly included visual inspection to detect cracking of the panels. In some cases, cores of the panels were taken to assess the remaining asphalt depths and finding the bond strength at the interface. In most of the projects, the foundation properties of the UTW pavement are not known which limit the further analysis of the performance of the pavement. In case of Accelerated Loading Experiments on UTW carried out in monitored facilities, the strains and deflections of the pavement have been monitored.

e) Design of UTW systems

From the literature survey, it was found out that no formal design guidelines for the design of UTW systems have been laid out. Most of the design procedure adopted for UTW systems is based on an empirical approach. It involves the selection of proper concrete thickness to carry the anticipated traffic. It also uses the existing asphalt properties and the choice of appropriate joint spacing. The main philosophy behind this approach is the evaluation of the critical load induced stress or strain caused by the wheel loads, the critical 
temperature induced stress and strains, and the critical location of the stresses and strains. A mechanistic design procedure has been developed through a comprehensive study involving extensive field load testing and theoretical analysis using a finite element model [10]. However, this design procedure is viewed as a first generation design method and needs to be verified after longterm performance data becomes available. Another empirical method to estimate the service life of the UTW based on the thickness of the overlay, the joint spacing, concrete mechanical strength, and subgrade characteristics was developed by FHWA.

\section{$\underline{2.3 \text { Summary }}$}

Since its inception in the early nineties, UTW use has increased throughout the United States. From literature survey of the various UTW projects undertaken, the following observations were made:

a) Most of the UTW projects undertaken in the last decade are field installations. The guidelines that are currently in use are based on empirical data and performance of the field installations. There is a need to study the mechanism of the UTW in further detail, to come up with a basis for laying down design guidelines of the UTW pavements.

b) Though from its conception, UTW systems have come a long way in terms of implementation and the research being carried out, there is still a lack of implementation of UTW as a rehabilitation measure for rutted asphalt pavements. 
This can be attributed to the lack of meaningful data and analysis generated from the UTW projects since most of the pavement monitoring in the field have been based on visual surveys, and not mechanistic analysis, based on stresses and strains in the pavements. 


\section{ACCELERATED PAVEMENT TESTING OF ULTRA-THIN WHITE TOPPING}

\section{$\underline{3.1 \text { Introduction }}$}

A critical problem for the pavement engineer is the design of heavy-duty pavements where traffic load may differ significantly in weight, number, or configurations from previous experience. The traditional method of establishing a satisfactory design may include building an experimental section of pavement and observing the behavior and performance of the pavement under in-service traffic. This may not provide sufficient guidance, as in-the-field pavement testing may not acquire enough data in a reasonable amount of time to enable accurate forecasts of pavement wear. Even where such an experiment can be built on a major route, it is still possible that the rate of growth of traffic load on the in-service pavements will exceed the loading accumulated by the experimental pavement so that no reliable predictive basis can be established.

Under these circumstances, a methodology is needed to allow exploration of new pavement configurations with controlled traffic load parameters that can accumulate damage faster than the anticipated growth of traffic or changes in vehicle technology. Ideally, the method also has to control non-traffic load factors, such as material variability and environmental parameters, to reduce the number of variables in any experiment. Many road organizations and academic researchers have sought to address 
these issues with "accelerated pavement testing facilities" (APT), allied to the development of theoretical models of pavement behavior.

\subsection{Indiana Department of Transportation (INDOT)-Purdue University} Accelerated Pavement Testing (APT) Facility

The APT Facility is a joint venture between INDOT, Purdue University (School of Civil, Mechanical and Electrical Engineering Technology) and the Industry and is located at the Division of Research in West Lafayette, Indiana. The INDOT-Purdue APT facility is housed in a $186 \mathrm{~m}^{2}$ environmentally controlled building and consists of a $6.1 \mathrm{~m}$ by $6.1 \mathrm{~m}(20 \mathrm{ft} \times 20 \mathrm{ft})$ test pit, a loading mechanism and control and monitoring equipment.

The APT building consists of three major areas: testing pit, operator control room and the boiler room. The test pit is a $6.1 \mathrm{~m} \times 6.1 \mathrm{~m}(20 \mathrm{ft} \times 20 \mathrm{ft})$ area pit that is $1.83 \mathrm{~m} \mathrm{(6}$ ft) deep. It consists of four $208 \mathrm{~mm}\left(8^{\prime \prime}\right)$ thick concrete slabs (1.52 m wide each) on top

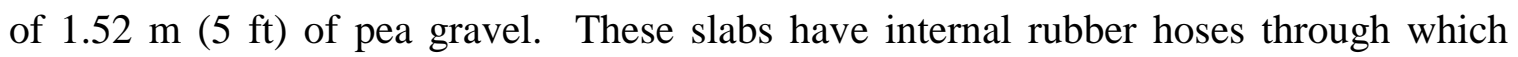
water may be circulated to heat or cool the slabs. A $104-\mathrm{mm}$ to $152-\mathrm{mm}$ (4 to 6 inch) layer of asphalt or concrete may be placed on top of this configuration in one or more layers. The boiler room houses a boiler, transformer and heating controls, and a water circulating system. These controls and water-circulating network allow heating of an individual slab or all slabs to a target test temperature.

The operator control room houses an interface to fully interact and control the APT operation. The room is currently equipped with three personal computers networked together. Currently, a 486-66 MHz computer and software written in Basic, 
control the APT operations. A second computer (Pentium - 5) is loaded with the software for the newly acquired data acquisition system for the UTW project and is used for data collection and reduction. There is also a third computer set up to assist the monitoring of the APT and the data acquisition system. The Figure 3.1 shows the general layout of the APT Facility.

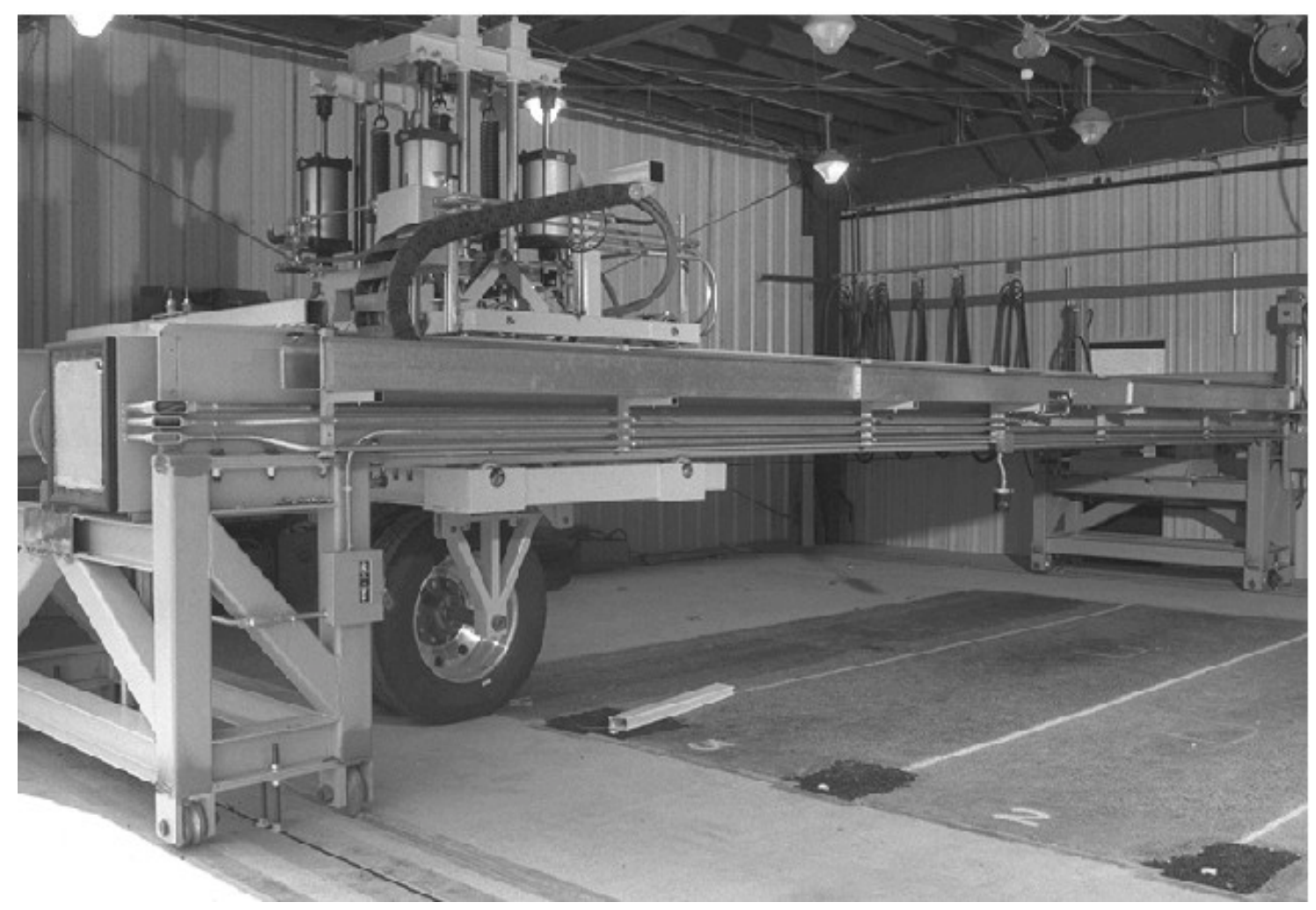

Figure 3.1 INDOT-Purdue University APT facility

\subsubsection{APT Wheel}

The APT is designed to apply a one half-axle load to a wheel assembly. Conventional dual or wide based single truck tires can be used. The wheel assembly is 
mounted on a carriage that is cable driven by a pull-lift motor and a drive. This set up allows for a maximum speed of $5 \mathrm{mph}$, which simulates a slow moving, truck at an intersection. The loading mechanism consists of a set of tension and compression springs connected through a scissors type linkage. To overcome the effect of the constant force mechanism during return, four pneumatic cylinders are used, which allow the wheel to be raised for the return of to the start-up position in one direction traffic testing is required.

\subsubsection{Data Acquisition System}

A new data acquisition system was acquired for data acquisition from the APT testing of the UTW installation. The system was purchased in February 2000 from Vishay Measurements Group and is called the System 6000. It consists of Windows based software called StrainSmart, a scanner with different channels and the various input cards for the instrumentation hardware. System 6000 hardware is designed to incorporate all the features required for precision strain measurement under a variety of loading conditions. A system can be configured with 1 to 1200 sensors. Strain gages, strain-gage-based transducers, thermocouples, LVDTs, potentiometers, accelerometers, piezoelectric sensors and other transducers can be intermixed by choosing the appropriate sensor card. All System 6000 components can be easily configured for each test requirement. The Model 6100 Scanner (holding up to 20 input cards) functions independently. The other features of the System 6000 include analog-to-digital conversion on each channel and simultaneous data acquisition for all channels, System 6000 's Model 6100 Scanners record test data at rates of upto 10000 samples per second per channel of instrumentation hardware. The PCI hardware interface between the 
scanners and a PC running StrainSmart software in the Windows NT environment enables a combined throughput of up to 200000 samples per second for all channels. (For example, 20 channels at 10000 samples per second per channel or 40 channels at 5000 samples per second per channel). Selectable, digital FIR low-pass filtering is incorporated into each instrumentation channel to meet a variety of testing requirements.

StrainSmart is an extensive, Windows-based software package, included with the System 6000, and is a complete system for collection and formatting of data. The most significant feature of StrainSmart is that it addresses virtually every variable that must be considered in stress analysis testing - from initial data entry, to data acquisition and conditioning, to on-line and off-line correction, reduction and presentation of results.

\section{$\underline{3.3 \text { Design of UTW test lanes }}$}

The APT test pad is nominally $6.1 \mathrm{~m}(20 \mathrm{ft})$ long and $6.1 \mathrm{~m}(20 \mathrm{ft})$ wide. For the purposes of the current project, it was decided to divide the test pad into four test lanes (each $1.2 \mathrm{~m}(4 \mathrm{ft})$ wide) thus leaving a $0.6-\mathrm{m}(2 \mathrm{ft})$ wide shoulder along the two sides of

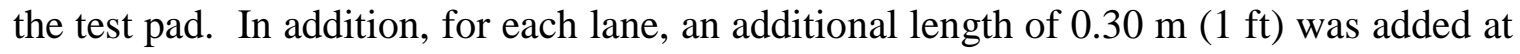
each end to accommodate the formwork for the construction of the concrete overlay. The resulting total length of the overlay for each lane was thus $7 \mathrm{~m}(22 \mathrm{ft})$. Based on the design parameters to be considered (thickness of overlay, joint spacing, and type of concrete (plain vs. fiber reinforced)) and the limitation on having only four lanes, it was decided to construct the four lanes having different thicknesses and a different type of

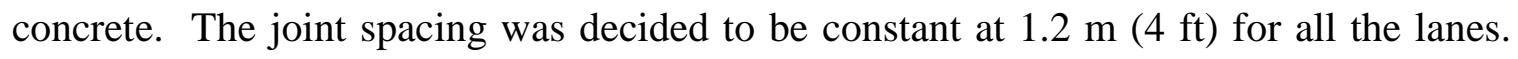
Figure 3.2 shows the layout of a typical test lane including the position of the transverse 
joints. Table 3.1 contains the summary of material type and thickness information for each lane.

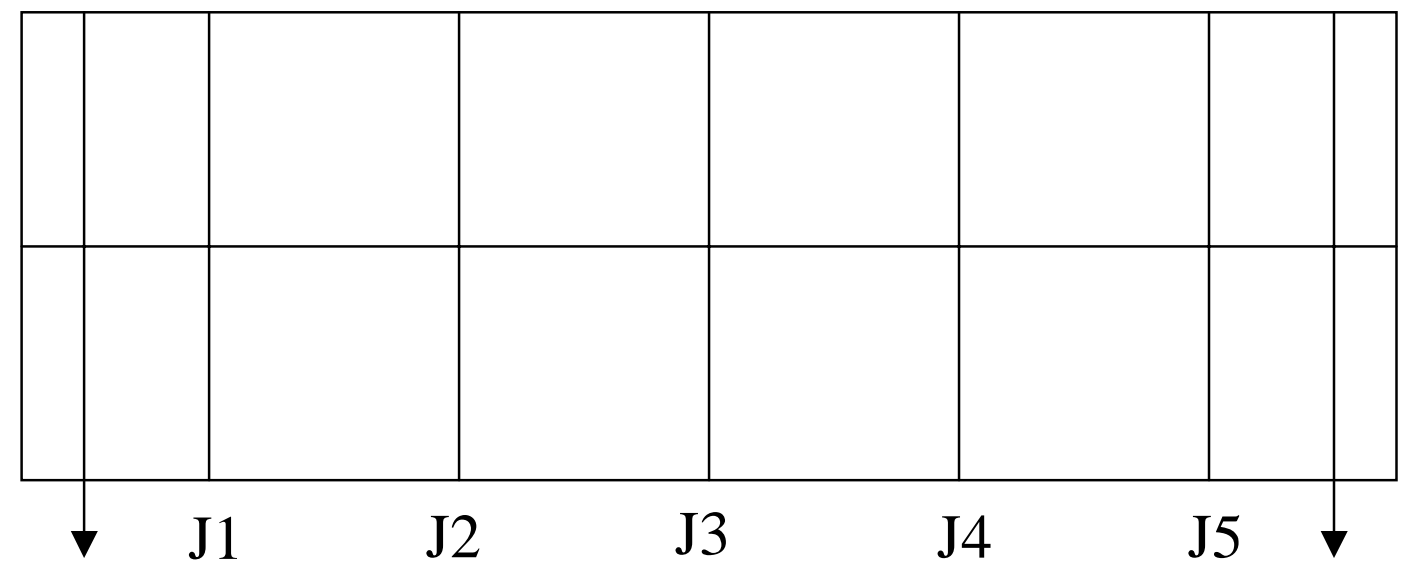

Pit begins

Pit ends

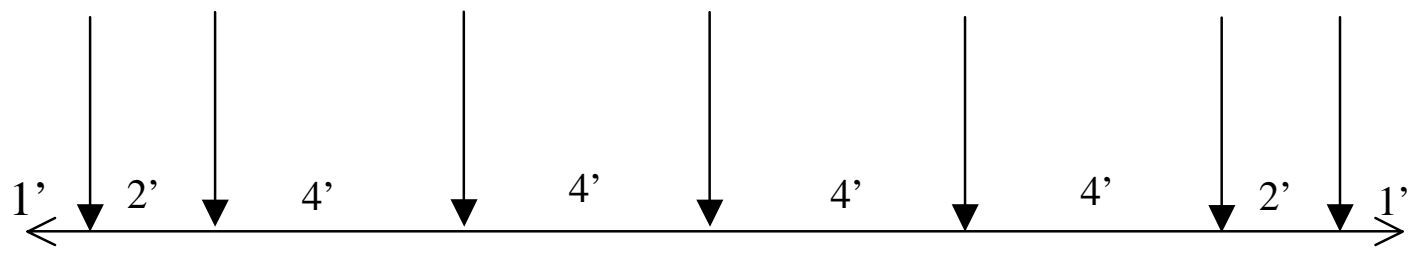

Concrete Slab (22')

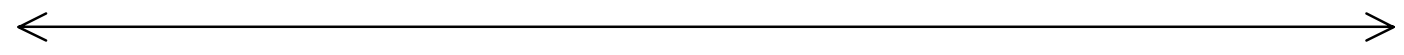

Figure 3.2 Typical test lane layout

Table 3.1 Summary of the material type and thickness information for the test lanes

\begin{tabular}{|c|c|c|}
\hline Lane Number & Material Type & Thickness \\
\hline 1 & Plain concrete & $104 \mathrm{~mm}\left(4{ }^{\prime \prime}\right)$ \\
\hline 2 & Fiber-reinforced concrete & $63.5 \mathrm{~mm}(2.5 ")$ \\
\hline 3 & Plain concrete & $104 \mathrm{~mm} \mathrm{(4")}$ \\
\hline 4 & Fiber-reinforced concrete & $63.5 \mathrm{~mm}(2.5 ")$ \\
\hline
\end{tabular}




\section{$\underline{3.4 \text { Concrete mixture design and test sample preparation }}$}

The mixture designs for the UTW lanes were developed in the laboratory at Purdue University. The initial proportions were chosen based on information collected from the literature. Two mixes were designed, one for plain concrete mix and one for the fiber reinforced concrete mix. The fiber reinforced concrete mix was very similar to the plain concrete mix except for the addition of 50/63 3M Polyolefin fibers. Tables 3.2 and 3.3 show the mixture composition of the UTW mixes tested in the laboratory. Mixtures of the same composition were used to construct the UTW overlay at the APT facility.

The criteria selected for the concrete mixture included the option of using or not using fibers, use of low water cement ratio $(<0.40)$ and achievement of good workability by using high range water reducers (this involved setting the minimum slump requirement to be at least $\left.63 \mathrm{~mm}\left(2.5^{\prime \prime}\right)\right)$. The samples cast included standard $104 \mathrm{~mm}$ by $208 \mathrm{~mm}$ (4" x 8") cylinders for compressive strength, $152 \mathrm{~mm}$ x $304 \mathrm{~mm}$ (6” x 12”) cylinders for split tensile strength and $152 \mathrm{~mm}$ x $152 \mathrm{~mm}$ x $533 \mathrm{~mm}$ (6" x 6" x 21") beams for modulus of rupture tests (flexural strength). The specimens were cast in accordance to the ASTM specification C192. After casting, the laboratory mixes were kept in molds for 24 hours and covered with a wet burlap and subsequently cured in the moist room at $100 \%$ relative humidity after they were removed from the molds, until tested. The samples prepared at the APT facility during the construction of the lanes were cured with wet burlap at ambient temperature for the first three days after which they were transported to the curing room in the laboratory and were subjected to moist curing at $100 \%$ relative humidity. 
Table 3.2 Mixture composition for plain concrete

\begin{tabular}{|c|c|c|c|c|}
\hline Material & Type & Sources & $\mathrm{kg} / \mathrm{m}^{3}$ & $\mathrm{lb} / \mathrm{yd}^{3}$ \\
\hline $\begin{array}{l}\text { Lonestar } \\
\text { Cement }\end{array}$ & Cement & $\begin{array}{c}\text { IMI, } \\
\text { Lafayette }\end{array}$ & 375 & 632 \\
\hline Fly Ash & Fly ash & $\begin{array}{c}\text { IMI, } \\
\text { Lafayette }\end{array}$ & 70 & 118 \\
\hline \#11 stone & $\begin{array}{c}\text { Coarse } \\
\text { aggregate }\end{array}$ & $\begin{array}{l}\text { Delphi, } \\
\text { Indiana }\end{array}$ & 1000 & 1684 \\
\hline Sand & $\begin{array}{c}\text { Fine } \\
\text { aggregate }\end{array}$ & $\begin{array}{l}\text { Delphi, } \\
\text { Indiana }\end{array}$ & 750 & 1263 \\
\hline Water & Water & & 160 & 270 \\
\hline HRWR & Admixtures & W.R. Grace & $3-41 / m^{3}$ & $2.3-3$ liters $/ \mathrm{yd}^{3}$ \\
\hline
\end{tabular}

Table 3.3 Mixture composition for fiber reinforced concrete

\begin{tabular}{|c|c|c|}
\hline Material & $\mathrm{kg} / \mathrm{m}^{3}$ & $\mathrm{lb} / \mathrm{yd}^{3}$ \\
\hline Cement: & 375 & 632 \\
\hline Fly Ash & 70 & 118 \\
\hline \#11 stone & 995 & 1676 \\
\hline Sand & 745 & 1255 \\
\hline Water & 160 & 270 \\
\hline 3M 50/63 Polyolefin fibers & $10(0.45 \% \mathrm{v} / \mathrm{v})$ & $17(0.45 \% \mathrm{v} / \mathrm{v})$ \\
\hline HRWR & $3.9-4.6$ liters $/ \mathrm{m}^{3}$ & $3-3.5 \mathrm{liters} / \mathrm{yd}^{3}$ \\
\hline
\end{tabular}




\subsection{Description of sensors used in the test lane}

The Accelerated Pavement Testing of the Ultra-thin White topping lanes, constructed in the fall of 1999, began in the end of March 2000. This delay in the start of the test program was caused by the high levels of electrical noise in the APT facility and the inability of the previously existing data acquisition system to filter out the low frequency noise and record the low level signals generated by the sensors. After several unsuccessful attempts to enhance the sensitivity and resolution of the existing instrumentation, a new data acquisition system (System 6000) was acquired from Vishay Measurements Group and installed.

Since the APT wheel had been previously never been used to test concrete overlays on an asphalt base, there was a need to upgrade the wheel loading mechanism for the testing of the UTW lanes. The wheel load was upgraded from the existing testing capability of $12000 \mathrm{lbs}$ to $20000 \mathrm{lbs}$. Four pneumatic cylinders were added to the wheel set up to the already existing spring loading mechanism to achieve a downward force of 20000 lbs. The APT wheel is mounted in a carriage, which is cable driven, by a motor and a control drive. This set up allows the wheel to move on the test path at speeds up to $8 \mathrm{kmph}(5 \mathrm{mph})$. The whole test of the UTW at the APT was carried at this speed.

Before the acquisition of the actual test data began, a number of test runs were performed in which the CPU clock of the computer that operates the APT wheel and that of the computer operating the data acquisition system were synchronized. The data was obtained at various scan rates to determine which would provide an optimum balance between accuracy and memory requirements. In addition, the validity of the data obtained from the system was verified before the start of the actual test. 


\subsubsection{Strain gages}

The strain gages, used in the UTW test at the APT facility, were manufactured by Tokyo Sokki Limited, Japan and purchased from Texas Measurements Group. Three different types of strain gages were purchased:

a) $\mathrm{PML}-60-2 \mathrm{~L}$

PML-60-2L is a concrete embedment gage, and is embedded in concrete at various depths in the slab, both transversely as well as longitudinally. There are oriented along one axis only. It is polymer encapsulated to protect moisture intrusion and perform effectively under varying environmental conditions.

b) WFLM-60-2LT

WFLM-60-2LT is a non-encapsulated gage that is installed at the milled surface of asphalt. However, it has a moisture proof sealing. It is also a uniaxial gage.

c) PMR-60-2L

PMR-60-2L is a strain rosette that consists of three gages fixed together. These gages are aligned in the transverse, longitudinal and an inclined 45-degree angle axis. Each of these gages is separately attached with lead wires. Therefore, they are in effect concrete embedment gages fixed together to form a rosette.

All these gages have a gage length of $60 \mathrm{~mm}$ and are resistance type gages with a resistance of $120 \Omega$. The excitation voltage used for these gages was $6.66 \mathrm{~V}$. (The maximum prescribed voltage to be used was $10 \mathrm{~V}$. However, taking into account the long duration of the test and the heating effects caused by a higher excitation voltage a lower voltage of $6.66 \mathrm{~V}$ was used). 
Figures 3.3 and 3.4 show the different types of strain gages (the gage at the asphalt surface and the concrete embedment gage) used in the instrumentation.

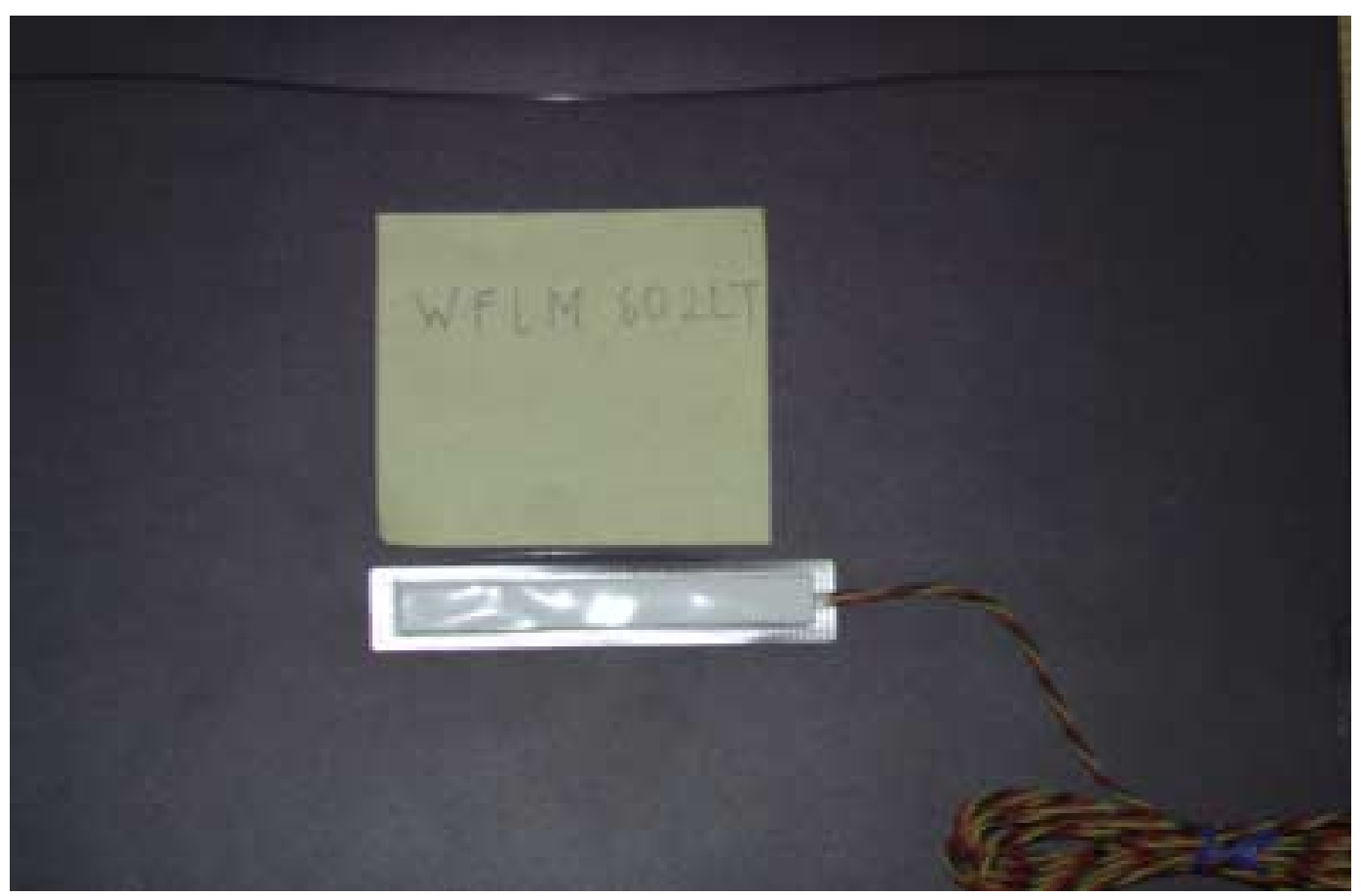

Figure 3.3 Non-encapsulated gage (WFLM-60-2LT) used on the asphalt surface

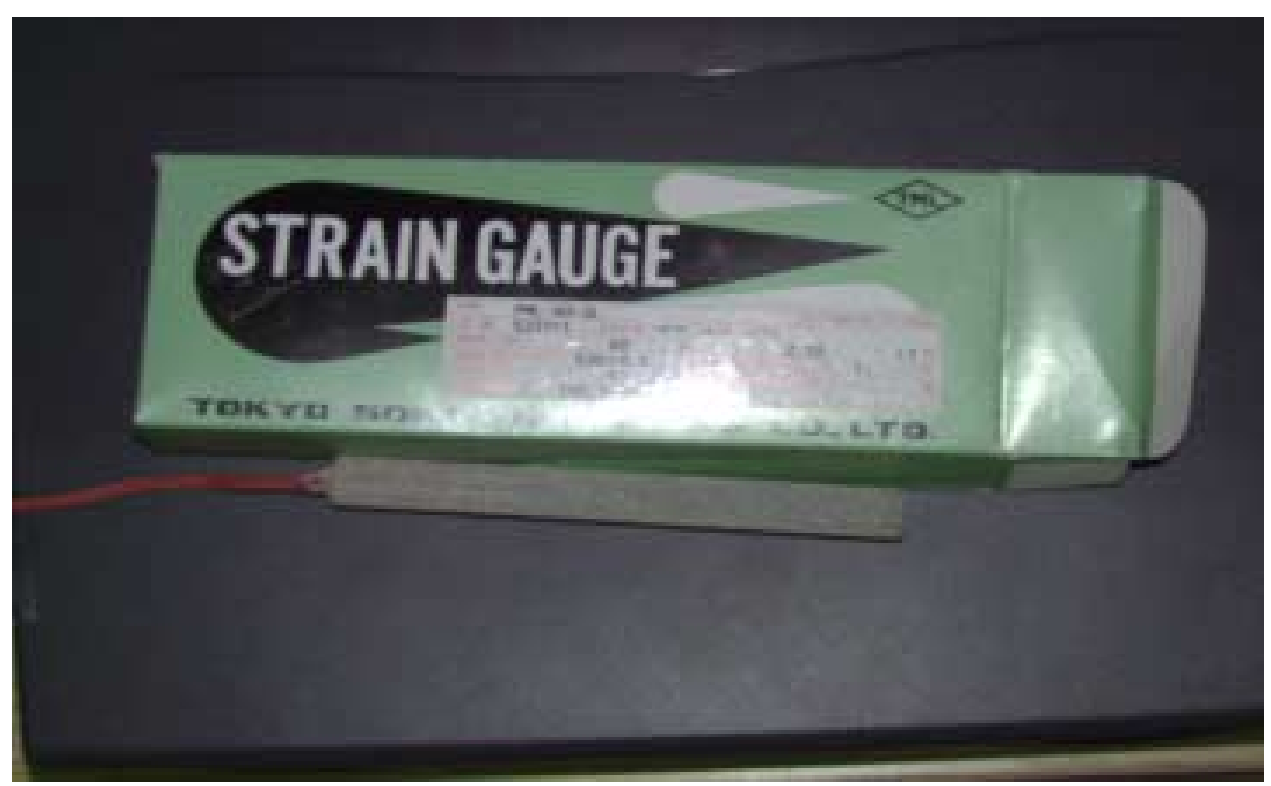

Figure 3.4 Concrete embedment gages (PML-60-2L) used in UTW 


\subsubsection{Linear Variable Differential Transducer (LVDT)}

The surface deflection of the UTW pavement was measured by LVDT. The LVDTs used in the present study had a stroke of $12.7 \mathrm{~mm}( \pm 0.5$ ") in each direction. The excitation voltage for the LVDTs was 10 volts. The accuracy of these LVDTs was $0.0025 \mathrm{~mm}(0.0001 ”)$.

\subsubsection{Thermocouples}

The thermocouples used for instrumentation were purchased from Omega Engineering. They were ' $T$ ' type thermocouples made of copper-constantan alloy. Special connectors, also made of copper constantan leads, were used to connect it to the thermocouple wires. The temperature range of the sensors was from $-25^{\circ} \mathrm{C}$ to $100^{\circ} \mathrm{C}$.

\subsection{Instrumentation plan for accelerated testing of UTW}

The instrumentation installed in the slabs of the test lane included nine strain gages ( 3 transverse ( $\mathrm{T}$ series) and 6 longitudinal (M and $\mathrm{S}$ series)) one or two strain gage rosettes ( $\mathrm{R}$ series) and two Linear Variable Differential Transducers (LVDTs). In addition, three gages ( $\mathrm{S} 2$ series) were also located in one of the slabs of the adjacent (not loaded) lane. The specific location and the nomenclature of all the gages are shown in the Figure 3.5. Please note that in order to help with the identification of the locations of the sensors the panels in the test lanes were numbered consecutively starting with panel 1 which was adjacent to the starting point shown in the figure. 


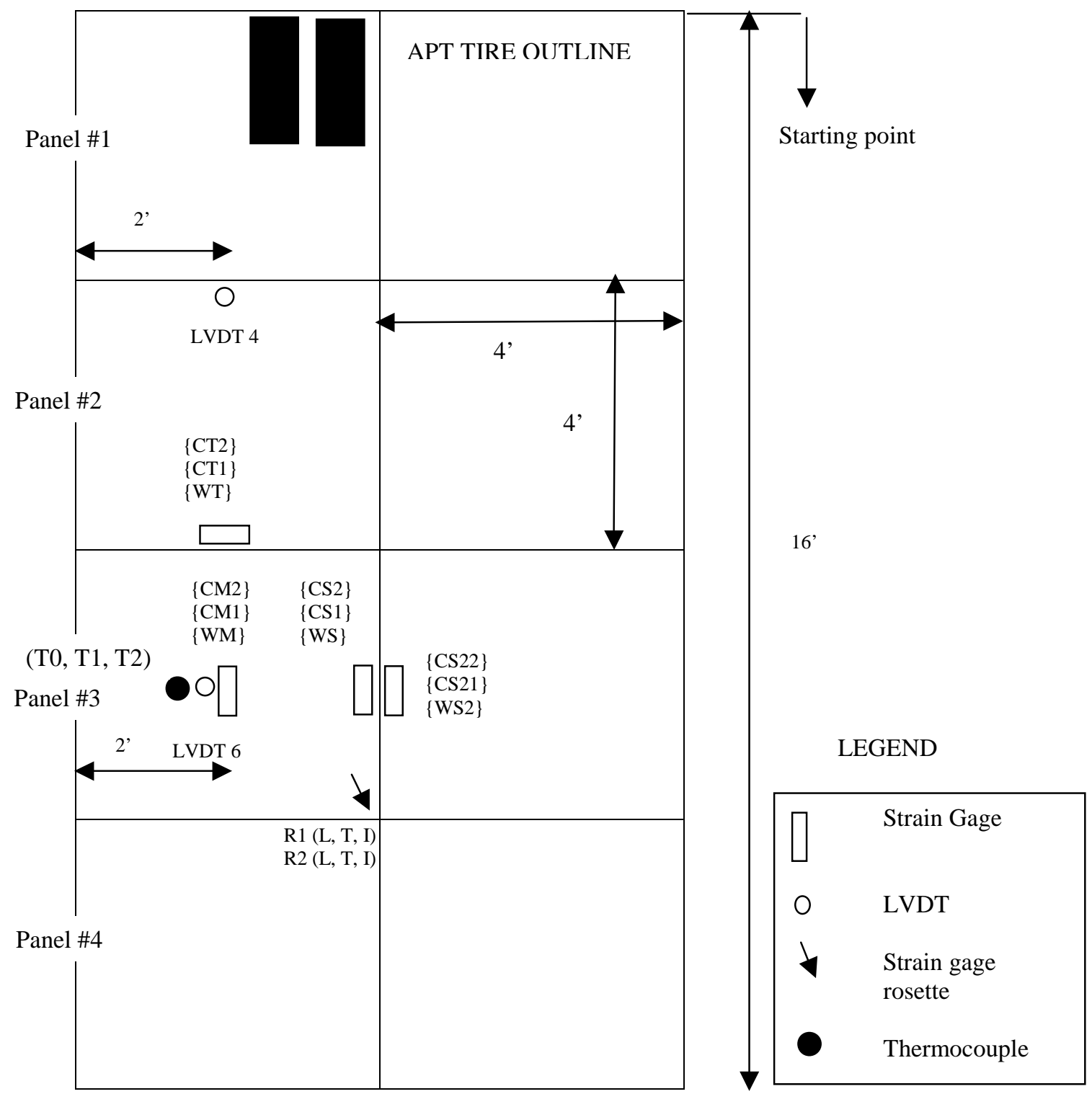

Figure 3.5 Plan view of the instrumentation layout for a typical test lane

The specific location and the nomenclature of the sensors for a typical lane is discussed in the following section. 


\subsubsection{Location of single strain gages}

a) Three transverse gages at the center of the panel near the transverse joint; two in the UTW overlay and one on the milled asphalt surface. The gages were located $12 \mathrm{~mm}(1 / 2 ")$ from the bottom of the overlay (CT1), about $12 \mathrm{~mm}(1 / 2 ")$ from the top of the overlay (CT2) and on the milled asphalt surface (WT).

b) Three longitudinal gages at the center of the panel at similar depths. The bottom gage in concrete was about $12 \mathrm{~mm}(1 / 2 ")$ from the bottom of the overlay (CM1), the top gage in concrete was about $12 \mathrm{~mm}(1 / 2 ")$ from the top of the overlay (CM2) and one gage was on the top of the milled asphalt (WM).

c) Three longitudinal gages near the longitudinal joint in the center of the panel on the wheel path. The bottom gage in concrete was $12 \mathrm{~mm}(1 / 2$ ") from the bottom of the overlay (CS1), the top gage in concrete was $12 \mathrm{~mm}(1 / 2$ ") from the top of the overlay (CS2) and one gage was on the top of the milled asphalt (WS).

d) Three longitudinal gages on the other side of the longitudinal joint in the adjacent (unloaded) lane. The bottom gage in concrete was $12 \mathrm{~mm}(1 / 2$ ") from the bottom of the overlay (CS21), the top gage in concrete was $12 \mathrm{~mm}(1 / 2 ")$ from the top of the overlay (CS22) and one gage was on the top of the milled asphalt (WS2).

\subsubsection{Location of strain gage rosettes}

a) Two strain gage rosettes each consisting of three gages each in the transverse, (T) longitudinal (L) and inclined $\left(45^{\circ}\right)$ (I) direction were located at the corner of the panel. The bottom rosette was designated as rosette 1 (R1) and the top was the rosette 2 (R2). The R2 rosette was located $12 \mathrm{~mm}(1 / 2$ ") from the top of the 
concrete overlay. The R1 rosette was located $12 \mathrm{~mm}(1 / 2$ ") (from the bottom of the overlay. Only one rosette (R1) was installed in the thinner $63 \mathrm{~mm}\left(2^{1 / 2 "}\right)$ overlay.

\subsubsection{Gage nomenclature}

All the labels used for strain gage identification follow the general pattern: \#, X, Y (or Y\#), \# (digit, alphabet, alphabet(s), digit (or no digit)) The first digit in each gage corresponds to the lane corresponding to which readings must be taken. The first character $\mathrm{X}$ would be $\mathrm{C}, \mathrm{W}$ or $\mathrm{R}$, which corresponds to the type of gage (concrete embedment gage, non-encapsulated gage on asphalt or concrete embedment rosette, respectively). The next character(s) identifies the location of the gage.

a) ' $\mathrm{T}$ ' transversely installed near the transverse joint in panel 2.

b) 'M' longitudinally installed in the center of the slab. $\left(3^{\text {rd }}\right.$ Panel $)$

c) 'S' longitudinal gages installed parallel to the longitudinal joint of the slab within the loaded lane $\left(3^{\text {rd }}\right.$ Panel).

d) ' $\mathrm{S} 2$ ' longitudinally installed near the other side of the longitudinal joint on the adjacent (unloaded) lane. (Even though this gage is located on the unloaded lane, its output would be recorded to the loaded lane) ( $3^{\text {rd }}$ panel of the adjacent lane)

e) ' $R$ ' Rosette installed on the corner $3^{\text {rd }}$ panel. In the rosette, the symbols ' $L$ ', ' $\mathrm{T}$ ', and ' $\mathrm{I}$ ' correspond to the longitudinal, transverse and inclined gages respectively. Finally, the last number on the gage (if any) corresponds to the depth at which the gage is located. ' 1 ' means the gage is nearer to the asphalt 
surface. '2'means the gage is nearer to the surface of the concrete. No number at the end corresponds to the gage located on the surface of the asphalt. (This is seen only in the gages that are of the type ' $\mathrm{W}$ ').

Eighteen strain gages were installed in the $100 \mathrm{~mm}$ thick UTW overlay (test lanes 1 and 2) while fifteen strain gages were installed in the $63 \mathrm{~mm}$ thick UTW overlay (lanes 3 and 4). The schematic in Table 3.4 shows the basis of the nomenclature of the gages.

Table 3.4 Bases for nomenclature of gages

\begin{tabular}{|c|c|c|c|}
\hline Lane & Type & Location & Depth or orientation \\
\hline $\begin{array}{l}\text { Could } \\
\text { be } \mathbf{1 , 2} \\
3 \text { or } 4\end{array}$ & $\begin{array}{l}\text { Concrete embedment gage }(\mathbf{C}) \\
\text { Non-encapsulated gage }(\mathbf{W}) \\
\text { Rosette at the corner }(\mathbf{R}) \\
\text { L: Longitudinal leg of the } \\
\text { rosette } \\
\text { T: Transverse leg of the rosette } \\
\text { I: Inclined leg of the rosette }\end{array}$ & $\begin{array}{l}\text { M: near the side of } \\
\text { the mid panel } \\
\text { S: Longitudinal joint } \\
\text { of the loaded lane } \\
\text { S2: longitudinal joint } \\
\text { adjacent lane } \\
\mathbf{T} \text { : near the transverse } \\
\text { joint }\end{array}$ & $\begin{array}{l}\text { 1: } 12 \mathrm{~mm} \text { above the } \\
\text { bottom of the UTW } \\
\text { concrete overlay } \\
\text { 2: } 12 \mathrm{~mm} \text { below the } \\
\text { top of the UTW } \\
\text { concrete overlay }\end{array}$ \\
\hline
\end{tabular}

\subsubsection{Location of LVDT sensors}

a) One LVDT at the center of panel 3. (LVDT 6)

b) One LVDT near the center of the transverse joint of panel 2. (LVDT 4) 


\subsubsection{Location of thermocouple sensors}

a) Three thermocouples in each lane located at the center of panel 3 at various depths. The first thermocouple was placed at the bottom of the overlay (top of the milled asphalt surface), next one was $19 \mathrm{~mm}(3 / 4$ ") from the top of the overlay and the third one was placed in the slab center depending on the thickness of the overlay. Table 3.5 shows the list of the instrumentation used at the APT facility.

\subsection{Construction of UTW}

The construction of the UTW experiment at the APT started after the conclusion of a prior test involving the use of the APT facility. Since testing of the asphalt had already taken place at the APT and the lanes were rutted, it provided a perfect opportunity to mill the surface of the HMA and place a thin concrete overlay. The lanes were also instrumented with strain gages, LVDTs and thermocouples to monitor the strains and deflections in the pavement. (The details of the instrumentation are given in section 3.6). The various steps undertaken during this process are described below. 
Table 3.5 Nomenclature of instrumentation installed in a typical test lane

\begin{tabular}{|c|c|c|c|c|}
\hline Instrumentation Type & \multicolumn{3}{|l|}{ Location } & Symbol \\
\hline \multirow[t]{9}{*}{ Longitudinal Strain Gage } & \multirow{3}{*}{$\begin{array}{llr}\text { Center } & \text { of } & \text { th } \\
\text { loaded } & \text { slab } & \text { il } \\
\text { panel 3 } & & \end{array}$} & \multicolumn{2}{|c|}{$12 \mathrm{~mm}$ from top of UTW } & C-M-2 \\
\hline & & \multicolumn{2}{|c|}{$12 \mathrm{~mm}$ from bottom of UTW } & C-M-1 \\
\hline & & \multicolumn{2}{|c|}{ Top of milled asphalt } & W-M \\
\hline & \multirow{3}{*}{$\begin{array}{l}\text { Longitudinal joint } \\
\text { of loaded slab in } \\
\text { panel } 3\end{array}$} & \multicolumn{2}{|c|}{$12 \mathrm{~mm}$ from top of UTW } & C-S-2 \\
\hline & & \multicolumn{2}{|c|}{$12 \mathrm{~mm}$ from bottom of UTW } & C-S-1 \\
\hline & & \multicolumn{2}{|c|}{ Top of milled asphalt } & W-S \\
\hline & \multirow{3}{*}{$\begin{array}{l}\text { Longitudinal joint } \\
\text { of adjacent } \\
\text { (unloaded) slab } \\
\text { adjacent to panel3 }\end{array}$} & \multicolumn{2}{|c|}{$12 \mathrm{~mm}$ from top of UTW } & C-S2-2 \\
\hline & & \multicolumn{2}{|c|}{$12 \mathrm{~mm}$ from bottom of UTW } & C-S2-1 \\
\hline & & \multicolumn{2}{|c|}{ Top of milled asphalt } & W-S2 \\
\hline \multirow[t]{3}{*}{ Transverse Strain Gage } & \multirow{3}{*}{$\begin{array}{l}\text { Center of loaded } \\
\text { slab near } \\
\text { transverse joint in } \\
\text { panel } 2\end{array}$} & \multicolumn{2}{|c|}{$12 \mathrm{~mm}$ from top of UTW } & C-T-2 \\
\hline & & \multicolumn{2}{|c|}{$12 \mathrm{~mm}$ from bottom of UTW } & C-T-1 \\
\hline & & \multicolumn{2}{|c|}{ Top of milled asphalt } & W-T \\
\hline \multirow[t]{6}{*}{ Strain Gage Rosette } & \multirow{6}{*}{$\begin{array}{l}\text { Corner of loaded } \\
\text { slab in panel } 3\end{array}$} & \multirow{3}{*}{$\begin{array}{l}12 \mathrm{~mm} \text { from } \\
\text { top of UTW }\end{array}$} & Longitudinal & R-2-L \\
\hline & & & Transverse & $\mathrm{R}-2-\mathrm{T}$ \\
\hline & & & Inclined & R-2-I \\
\hline & & \multirow{3}{*}{$\begin{array}{ll}12 \mathrm{~mm} & \text { from } \\
\text { bottom } & \text { of } \\
\text { UTW }\end{array}$} & Longitudinal & R-1-L \\
\hline & & & Transverse & R-1-T \\
\hline & & & Inclined & R-1-I \\
\hline \multirow[t]{2}{*}{ LVDT } & \multicolumn{3}{|c|}{ Edge of transverse joint on panel 2} & LVDT 4 \\
\hline & \multicolumn{3}{|l|}{ Center of panel 3} & LVDT 6 \\
\hline \multirow[t]{3}{*}{ Thermocouples } & \multirow{3}{*}{$\begin{array}{l}\text { Center of panel } \\
3\end{array}$} & \multicolumn{2}{|c|}{ Top of milled asphalt } & T0 \\
\hline & & \multicolumn{2}{|c|}{$19 \mathrm{~mm}$ from bottom of UTW } & T1 \\
\hline & & \multicolumn{2}{|c|}{$\begin{array}{l}19 \mathrm{~mm} \text { from the top of the } \\
\text { UTW }\end{array}$} & $\mathrm{T} 2$ \\
\hline
\end{tabular}




\subsubsection{Milling of existing HMA surface}

The milling of the HMA was done over the whole APT test pad. The initial thickness of HMA was estimated to be between $125 \mathrm{~mm}$ and $175 \mathrm{~mm}$ (5" to7"). It was decided to mill about 2 to 3 inches of asphalt so that the remaining asphalt thickness would be greater than $75 \mathrm{~mm}$ which is the minimum thickness as recommended by the literature. Figure 3.6 shows the milling of the HMA surface at the APT.

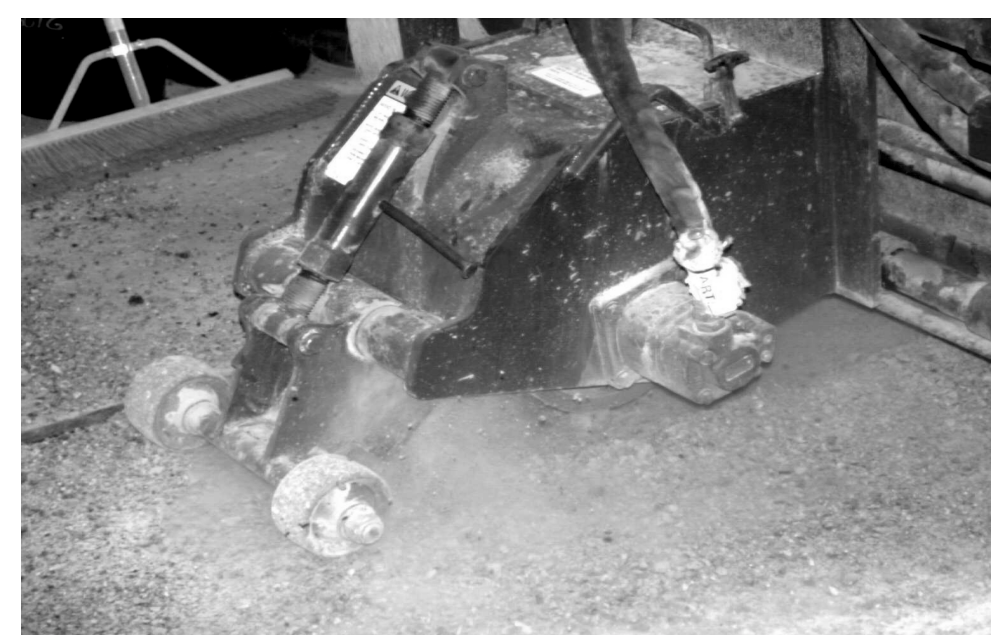

Figure 3.6 Milling of the HMA surface at the APT

\subsubsection{Placement of formwork}

After the milling, all the four lanes were marked out using string lines and chalk. The exact locations where the strain gages and the thermocouples were to be placed were marked. The milled asphalt surface was polished at those locations using a grinding machine. Once this was done, based on the thickness of the lanes, a wooden formwork was placed on the APT test pad, clearly demarcating the four lanes. The first two lanes (lanes 1 and 2) were designed to be $100 \mathrm{~mm}$ (4") thick, each having plain and fiber reinforced concrete, respectively. The latter two lanes (lanes 3 and 4) were designed to 
be $63.5 \mathrm{~mm}(2.5$ ") thick each having plain and fiber reinforced concrete respectively. Figure 3.7 shows the formwork as it was placed on the APT test pad.

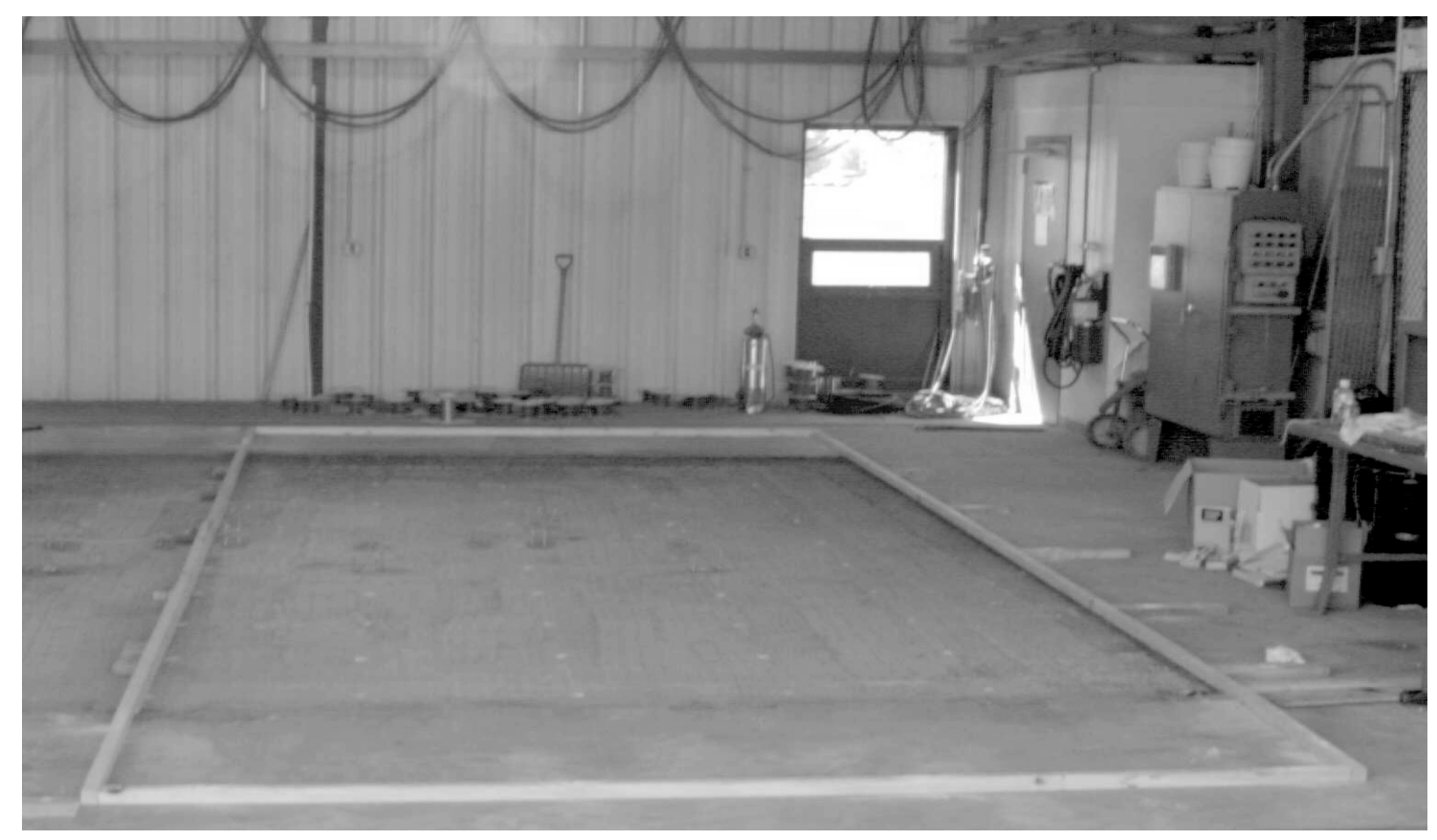

Figure 3.7 Formwork of UTW lanes

\subsubsection{Placement of sensors}

The gages were mounted prior to the placement of the concrete. The locations of the gages would be shown in the instrumentation layout shown in the following section. For the concrete embedment gages (PML 60 2L), two holes for \# 6-32 x $100 \mathrm{~mm}$ (4") long machine screws were drilled into milled asphalt concrete at each end of the gages. Each pair of screws was connected with two pieces of perforated sheet metal strap and secured in place with \#6-32 nuts, one on top and the other on the bottom of the strap (refer Figure 3.8), on either side to allow for the adjustment of the strap at the required elevation. The bolts were inserted into the holes in the asphalt concrete to a depth of 
about $12.5 \mathrm{~mm}(1 / 2 ")$. Friction in the holes was adequate to hold the screws upright and keep the gages aligned correctly during the placement of concrete. The plumbing straps were adjusted to hold the strain gage level at the depth of about $12 \mathrm{~mm}(1 / 2$ ") from the top and bottom of the UTW overlay, respectively. Nuts on the screw were tightened to secure the straps and the strain gages were fastened to the straps with fine wire. The screw heads and excess screw length were cut off just above the top of the nut. Figure 3.9 shows the set up on which the strain gages were mounted.

The strain gage rosettes (PMR 60 2L) were installed in a similar manner with both straps being placed perpendicular to the R45 gage, and positioned as far apart as possible while still supporting all the three legs of the rosette (refer to Figure 3.10). The nonencapsulated gages (WFLM 60 2LT) at the asphalt concrete surface were placed directly below the embedment gages. A small area on the milled asphalt surface was ground smooth. The gage was epoxied to this surface and covered with duct tape to prevent moisture intrusion.

The lead wires from all the gages were cut short and soldered to an insulated strain gage wire, which was taped down on the milled asphalt surface to prevent any movement during placement of concrete. These wires were extended into the control room through a utility duct where they could be hooked up to the data acquisition system. The alignment of the embedment strain gages was checked using a level and the position of the nuts was adjusted accordingly to make the gage lie horizontal and parallel relative to the surface of the asphalt. Also, the gages, the lead wires and the connections between the lead wires and the strain gages were coated with layers of epoxy to prevent moisture intrusion and damage during the placement and subsequent testing. The electrical 


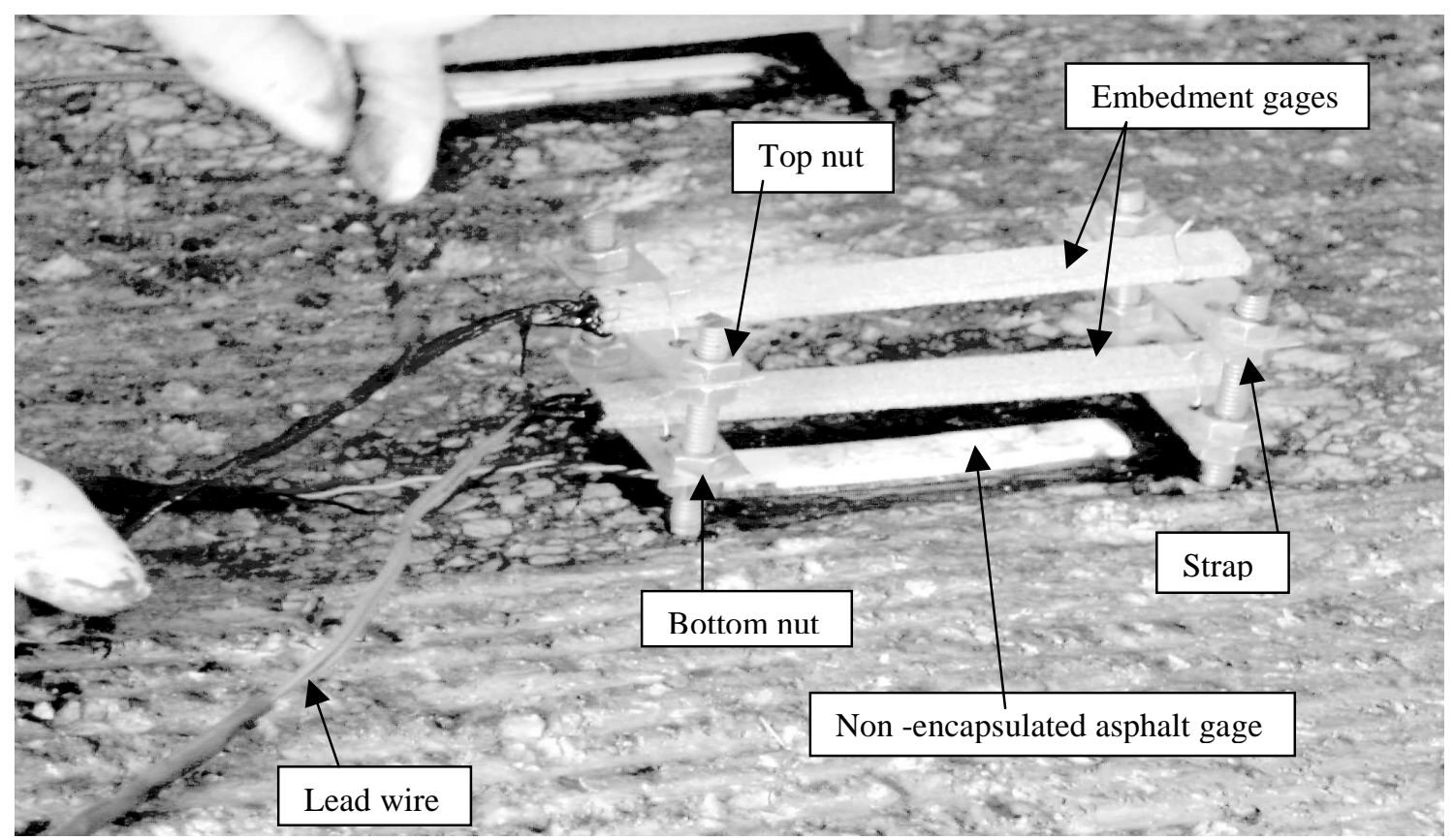

Figure 3.8 Installation of gages

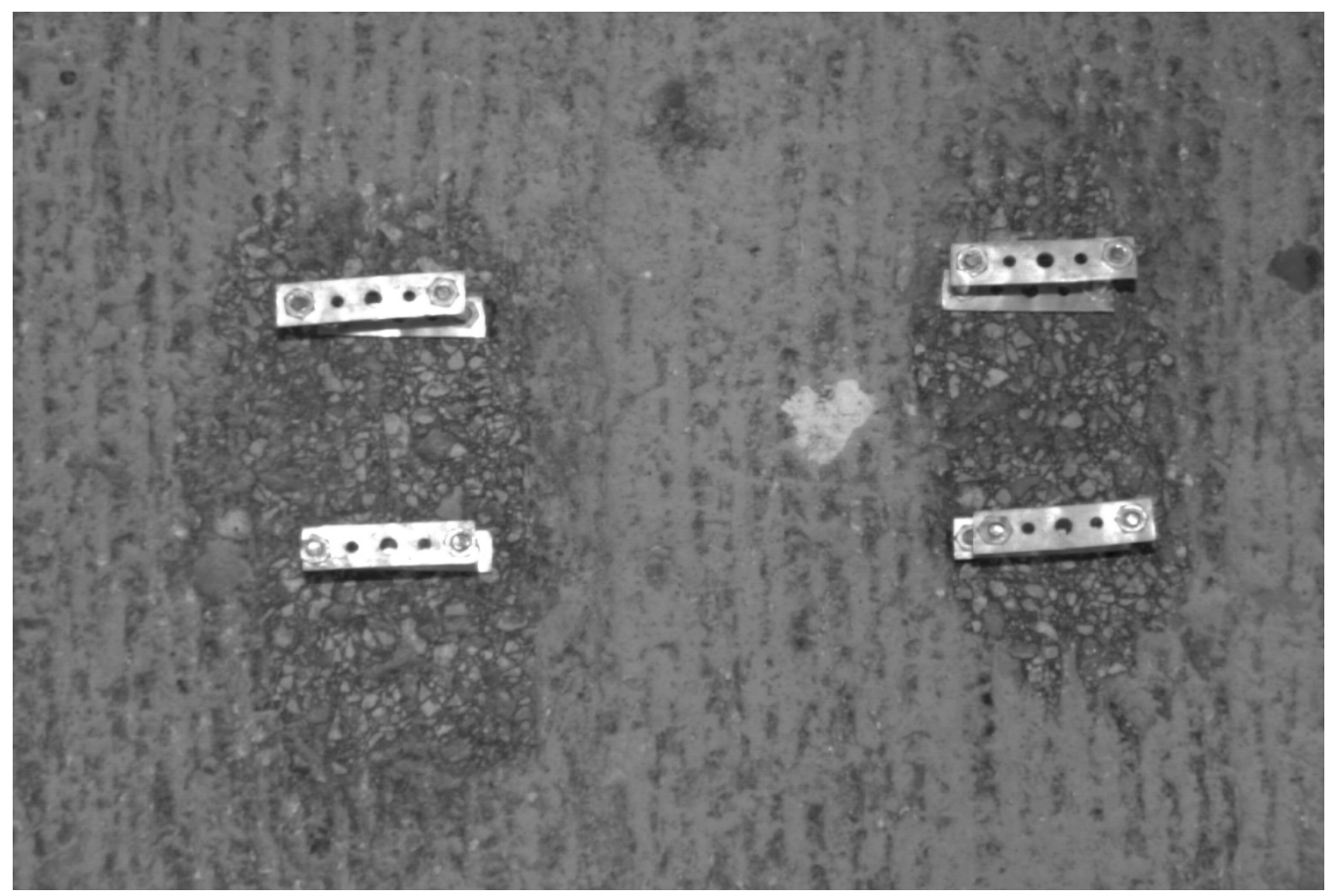

Figure 3.9 Top view of the gage setup on the milled asphalt prior to mounting of gages 


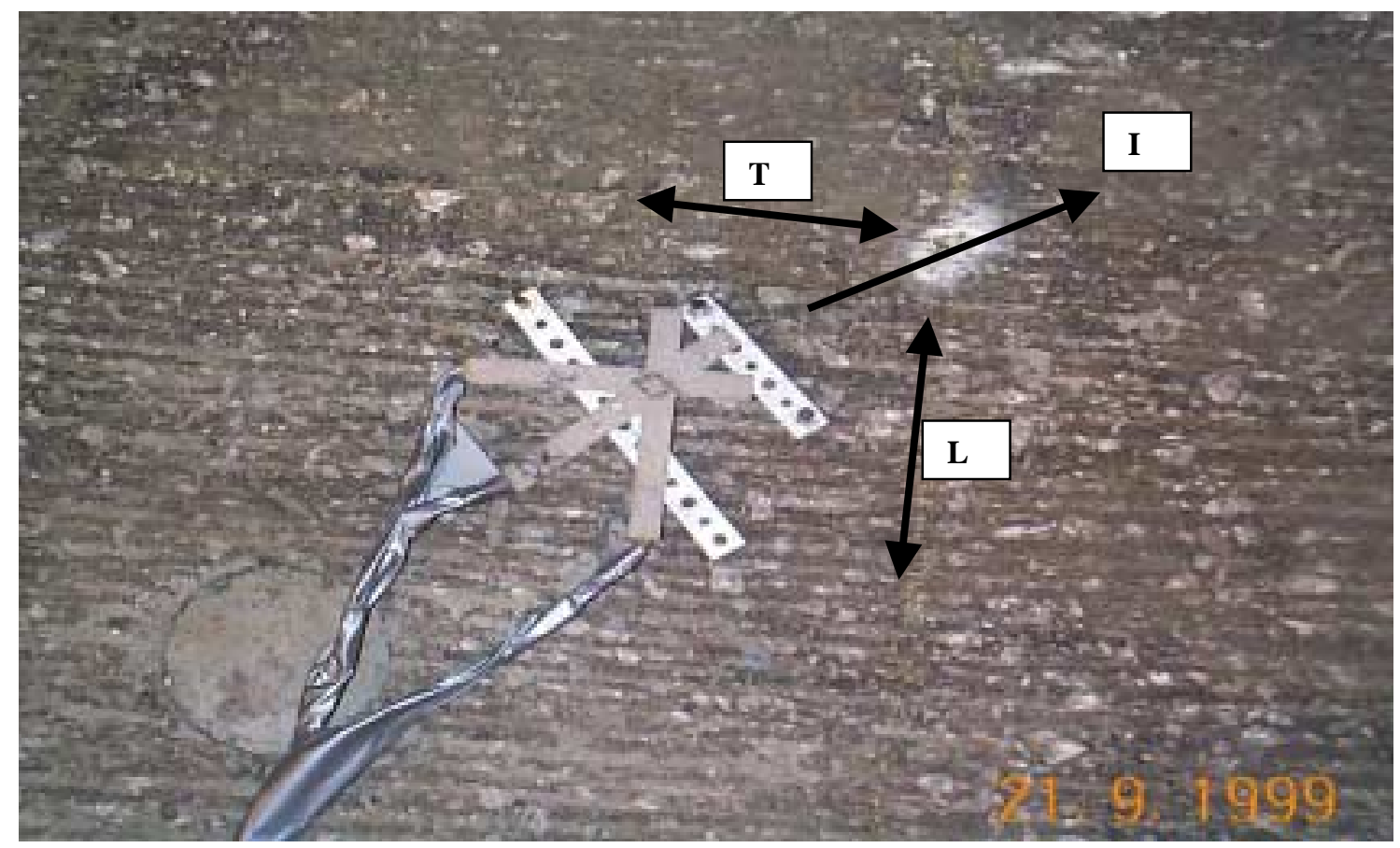

Figure 3.10 Gage set up for rosette

functionality of the gages was checked manually using a switch and balance unit and the defective gages were replaced. In addition, the gage alignment was made uniform to ensure that compressive strains produced a negative strain value and a tensile strain produced a positive one.

\subsubsection{Placement of concrete}

The four lanes instrumented at the APT Facility in INDOT were placed on two different days. On the first day, plain concrete was delivered and was placed in lanes 1 and 3, which were plain concrete overlays of $100 \mathrm{~mm}(4 ")$ and $63.5 \mathrm{~mm}\left(2.5^{\prime \prime}\right)$ thickness, respectively. The fiber concrete was poured in lanes 2 and 4 two days later. Irving Materials Incorporated, a ready mix company in West Lafayette, supplied the concrete. 
The concrete truck was brought to the end of the APT building. The concrete was poured into wheelbarrows and taken into the lanes for placement. The placement of concrete started in the center of the lanes and proceeded to the ends. Extreme caution was exercised during placement to avoid damage to the sensors. To avoid accidental damage to the wires, all wires were firmly tied into bundles and pinned to the milled surface of the asphalt. A small vibrator was used around the sensors to ensure good mechanical bonding and consolidation of the concrete (refer Figure 3.11). As soon as the concrete had set sufficiently for a person to walk on it without marring the surface, a hand held cutting saw was used to cut the joints at the prescribed locations. The transverse

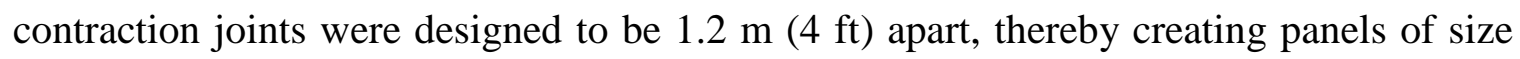
$1.2 \mathrm{~m}$ by $1.2 \mathrm{~m}(4 \mathrm{ft} \times 4 \mathrm{ft})$ in the test lanes. The joints were cut about $6.5 \mathrm{~mm}(1 / 4$ ") deep. The entire lane was covered with wet burlaps and no curing compound was used. Figure 3.12 and 3.13 show the pictures of the APT after the first and the second concrete placement operation, respectively. 


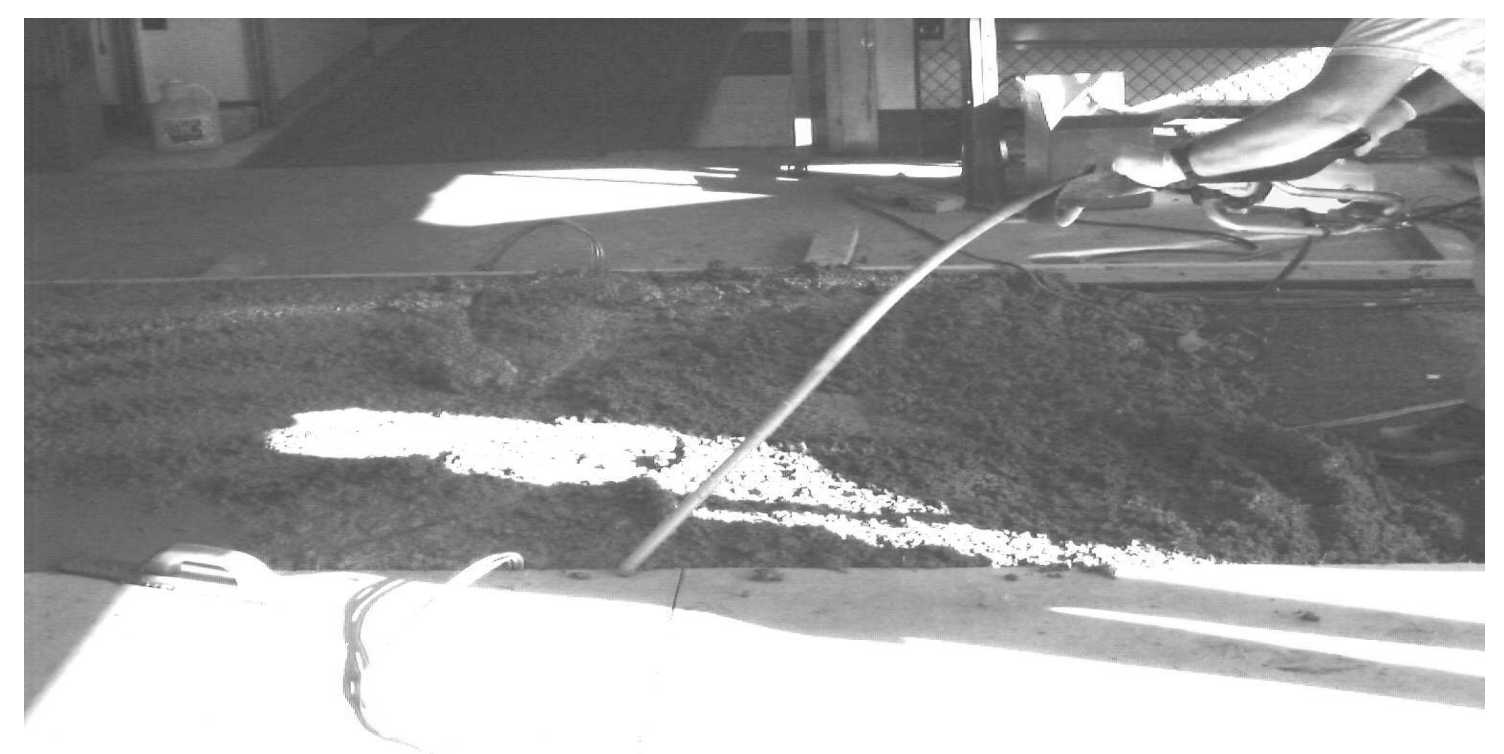

Figure 3.11 Concrete placement at the APT facility

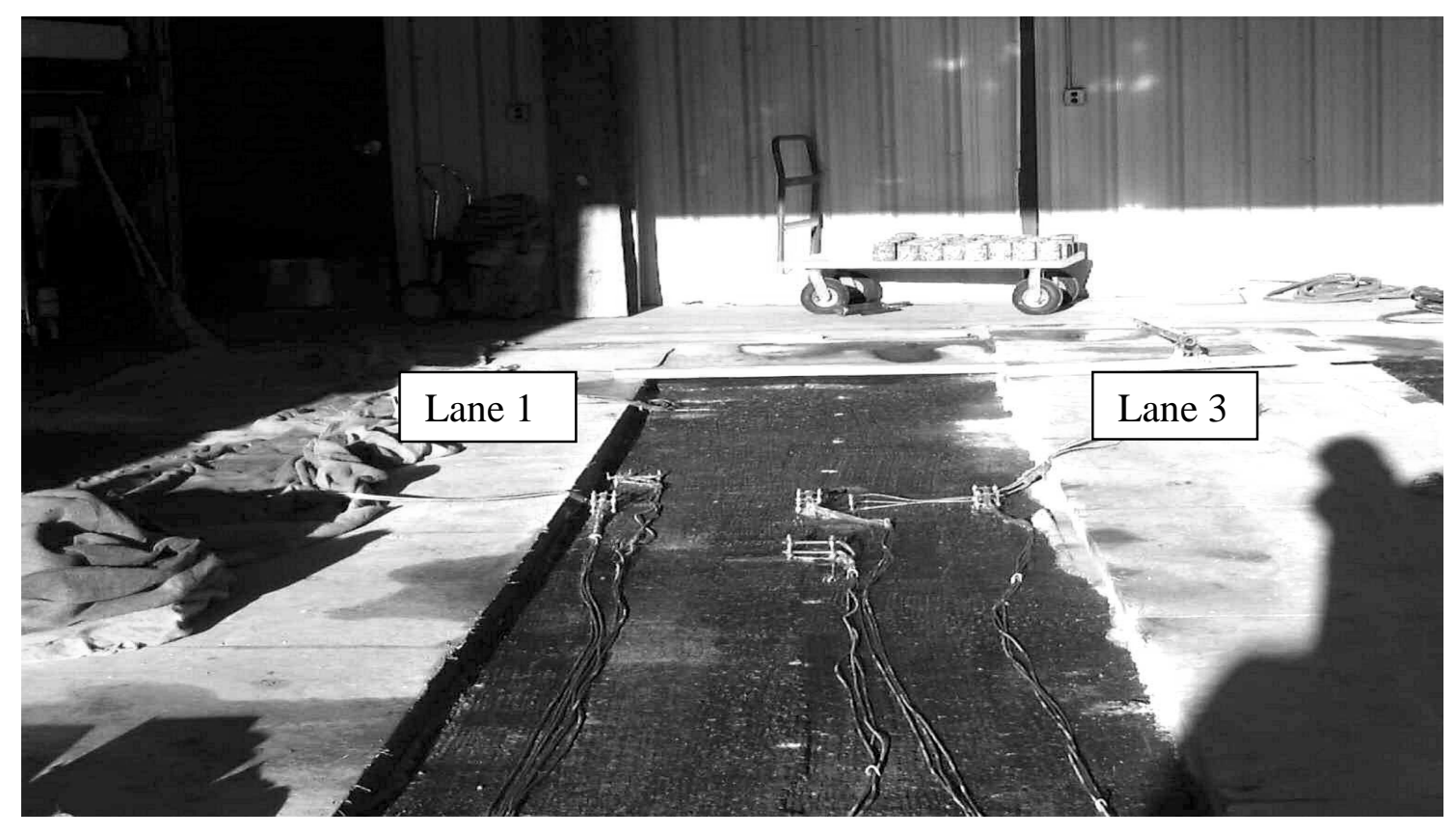

Figure 3.12 APT after the first pour 


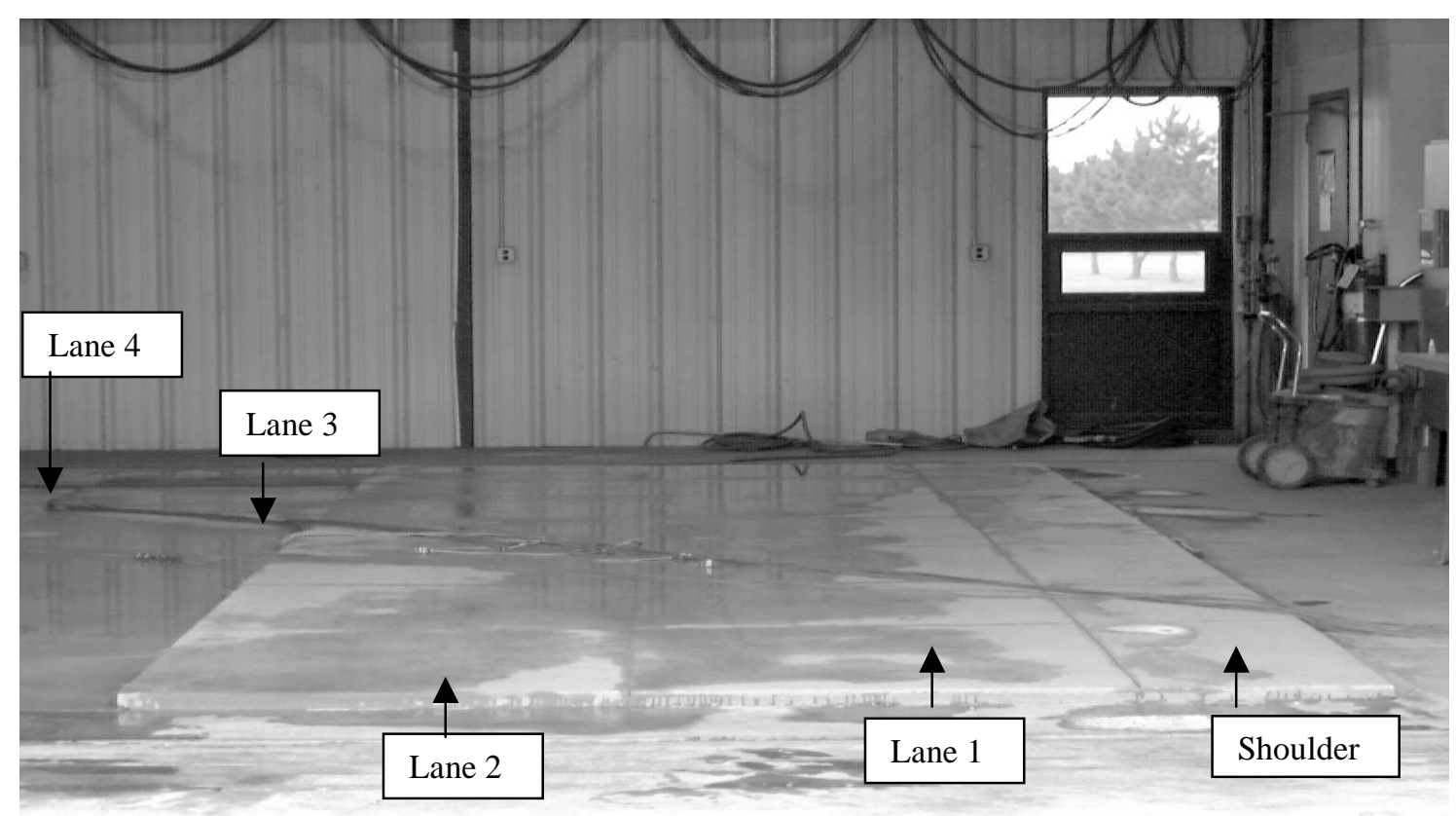

Figure 3.13 APT after construction of all lanes

\subsection{Mechanical properties of concrete}

The mechanical tests conducted on the concrete specimens included, compressive strength, split tensile test, three point loading on concrete beams to determine the flexural strength of concrete. The tests were conducted in specification to the current ASTM standards. A minimum slump requirement of $63 \mathrm{~mm}(2.5$ ") was set for the concrete. This was achieved using high range water reducers. The concrete mix placed at the APT had a slump of $89 \mathrm{~mm}$ (3.5") for the plain concrete and a slump of $63 \mathrm{~mm}(2.5$ ") for the fiber reinforced concrete mix. The Tables 3.6 shows the test results of the concrete produced in the laboratory. 
Table 3.6 Laboratory mix test results of plain and fiber reinforced concrete

\begin{tabular}{|c|c|c|c|c|}
\hline \multirow{2}{*}{ Property (MPa) } & \multicolumn{5}{|c|}{ Age (Days) } \\
\cline { 2 - 5 } & 1 Day & 3 Day & 7 Day & 28 Day \\
\hline \multicolumn{5}{|c|}{ Plain concrete } \\
\hline $\begin{array}{c}\text { Compressive } \\
\text { (ASTM C39) }\end{array}$ & 18.75 & 39.72 & 49.14 & 73.57 \\
\hline $\begin{array}{c}\text { Split Tension } \\
\text { (ASTM C496) }\end{array}$ & 1.95 & 3.05 & 3.35 & 4.51 \\
\hline $\begin{array}{c}\text { Flexural Stress } \\
\text { (ASTM C78) }\end{array}$ & 3.97 & 4.77 & & 6.91 \\
\hline \multicolumn{2}{|c|}{ Fiber reinforced concrete } & 62.44 \\
\hline $\begin{array}{c}\text { Compressive } \\
\text { (ASTM C39) }\end{array}$ & 19.95 & 41.09 & 51.52 & 4.48 \\
\hline $\begin{array}{c}\text { Split Tension } \\
\text { (ASTM C496) }\end{array}$ & 1.49 & & 2.27 & 6.99 \\
\hline $\begin{array}{c}\text { Flexural Stress } \\
\text { (ASTM C78) }\end{array}$ & 4.41 & & 5.95 & \\
\hline
\end{tabular}

(Note: All results obtained from an average of 3 or 4 samples)

The flexural strength of the concrete was over $3.8 \mathrm{MPa}(550 \mathrm{psi})$ after 1 day, which is the minimum requirement for the pavement opening to traffic according to INDOT specifications. In addition, the 28-day compressive strengths were way over 55 $\mathrm{MPa}$ (8000 psi), (more than $70 \mathrm{MPa}(10000 \mathrm{psi})$ in case of plain concrete). Based on the results it was decided to use the same mixture composition for the concrete to be placed at the APT. The Table 3.7 shows the results of the mechanical tests on the samples of concrete taken from the APT site. 
Table 3.7 APT mix test results of plain and fiber reinforced concrete

\begin{tabular}{|c|c|c|c|c|}
\hline \multirow{2}{*}{ Property (MPa) } & \multicolumn{4}{|c|}{ Age (Days) } \\
\cline { 2 - 5 } & 1 Day & 3 Day & 7 Day & 28 Day \\
\hline \multicolumn{5}{|c|}{ Plain concrete } \\
\hline $\begin{array}{c}\text { Compressive } \\
\text { ASTM C39) }\end{array}$ & 19.18 & 35.95 & 45.16 & 83.21 \\
\hline $\begin{array}{c}\text { Flexural Stress } \\
\text { (ASTM C78) }\end{array}$ & 3.04 & 4.07 & 4.76 & 71.83 \\
\hline \multicolumn{5}{|c|}{ Fiber reinforced concrete } \\
\hline $\begin{array}{c}\text { Compressive } \\
\text { (ASTM C39) }\end{array}$ & 16.56 & 31.84 & 44.51 & 5.83 \\
\hline $\begin{array}{c}\text { Flexural Stress } \\
\text { (ASTM C78) }\end{array}$ & 2.62 & 4.55 & 5.59 & \\
\hline
\end{tabular}

(Note: All results obtained from an average of 3 or 4 samples)

The mechanical properties of the APT field mixes were comparable to those achieved from the laboratory mixes for both plain as well as fiber-reinforced concrete. The compressive strength of the mixes was above $17.25 \mathrm{MPa}$ (2500 psi) after 24 hours for all the mixes except for the fiber reinforced concrete mix placed at the APT (refer to Figures 3.14 and 3.15, respectively). This reduction in strength may be attributed to the extra addition of high range water reducers to achieve sufficient workability for consolidation and placement. The lab mixes typically showed a higher strength at early ages but the field mix showed a higher compressive strength after 28 days for both the plain as well as the fiber mix. 


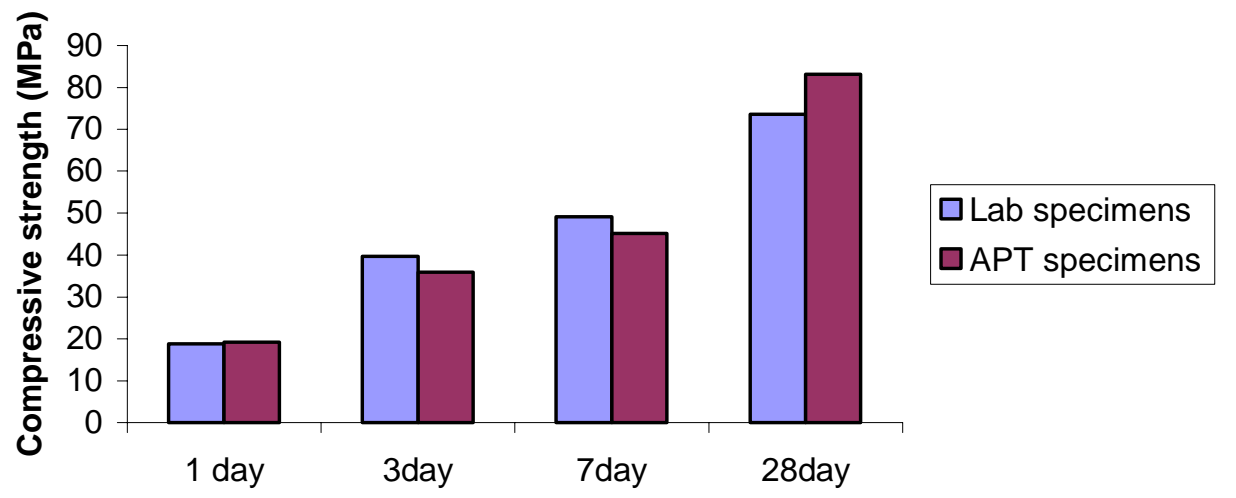

Figure 3.14 Comparison of compressive strength of plain concrete (lab and APT mixes)

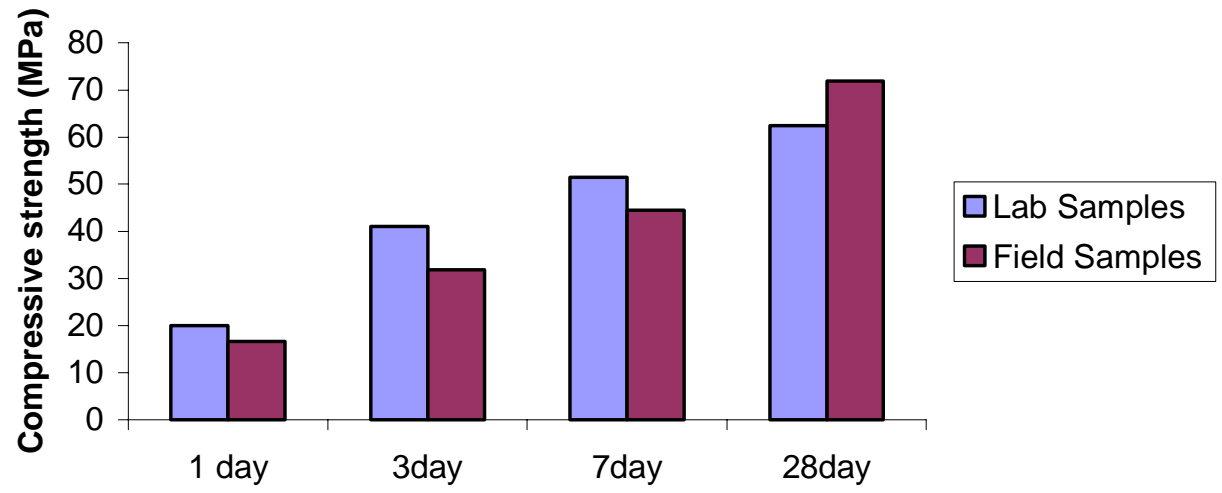

Figure 3.15 Comparison of compressive strength of fiber reinforced concrete (Lab and APT mixes)

The compressive strength of the fiber reinforced concrete mixes showed a comparable value as the plain concrete mix. For the lab and the APT specimens the fiber and the plain concrete showed similar strengths at early ages (1, 3 and 7 day) but plain concrete showed a significantly higher strength compared to the fiber-reinforced concrete after 28 days (refer to Figures 3.16 and 3.17). 

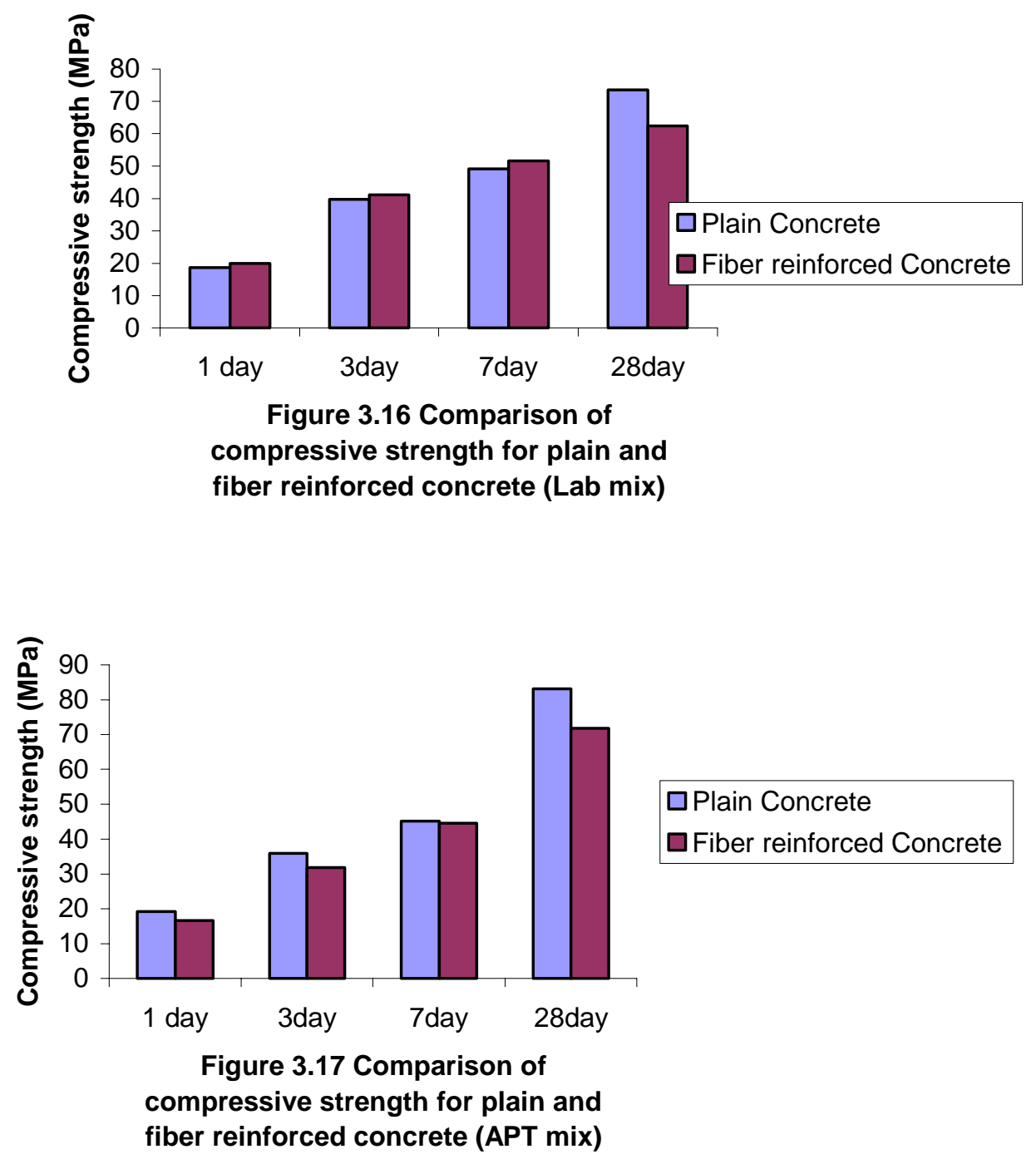

From the Figures, 3.18 and 3.19 it can be inferred that the flexural strength of the laboratory mixes was well above $3.8 \mathrm{MPa}$ (550 psi) after 24 hours for both the plain and fiber reinforced concrete. For the lab mix, the fiber reinforced concrete showed a slightly higher strength at early ages (up to 7 days) but the 28 -day strengths are very similar. For the APT mix the fiber reinforced concrete showed a lower 1-day strength but the 28-day results were slightly higher than plain concrete. Also, the failure of the fiber reinforced 
concrete specimens was much slower and the specimen showed markedly higher deformation than the plain concrete mixes, which failed suddenly under the loading. The use of fibers cannot be perceived to increase the flexural strength of concrete greatly. It only leads to a different failure mechanism as indicated above.

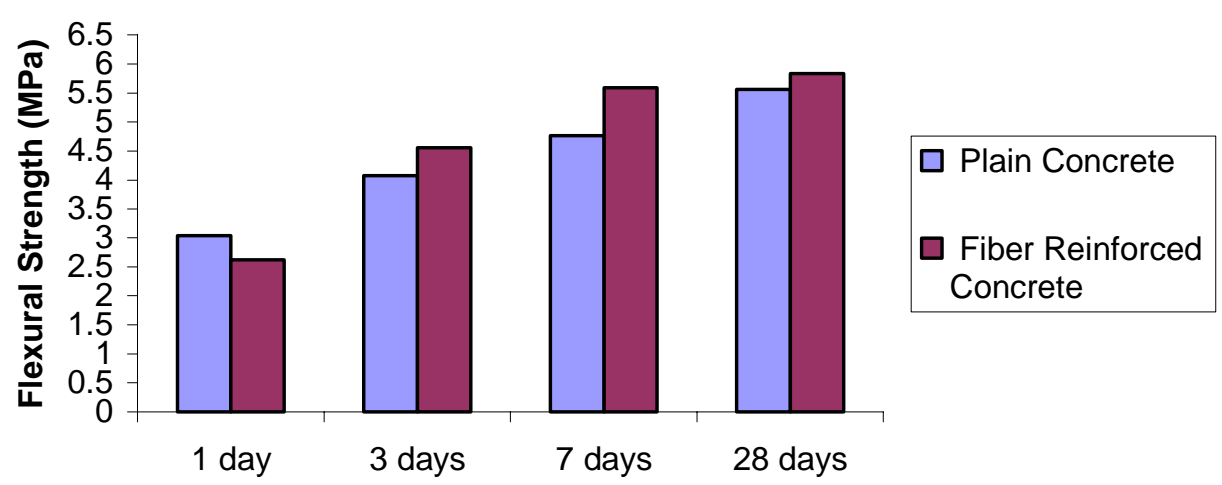

Figure 3.18 Comparison of flexural strength of plain vs fiber concrete (APT mix)

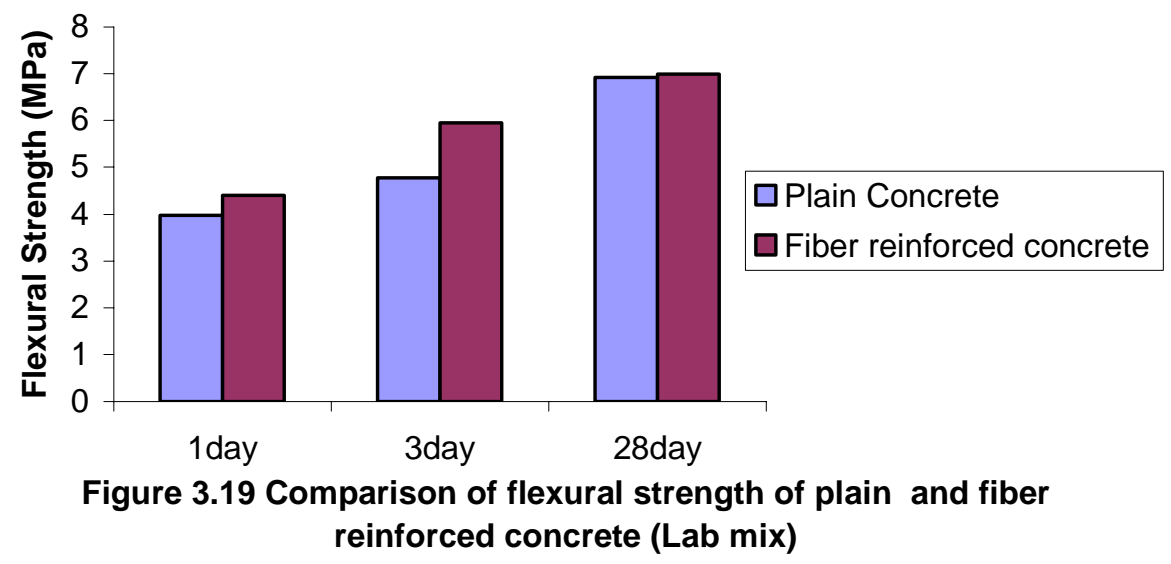

The Figures 3.20 and 3.21 show the comparison of the flexural strengths of the lab and the APT mixes for the plain and fiber reinforced concrete respectively. In both 
cases the APT mix shows a slightly lower flexural strength at all ages. The higher strength of laboratory mixes could be attributed to better consolidation of the concrete.

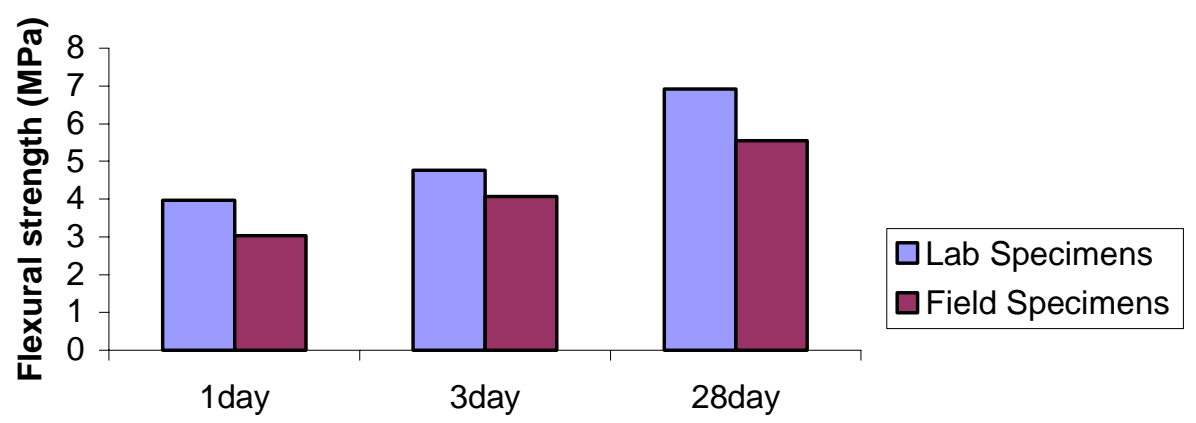

Figure 3.20 Comparison of flexural strength of plain concrete (Lab and APT mixes)

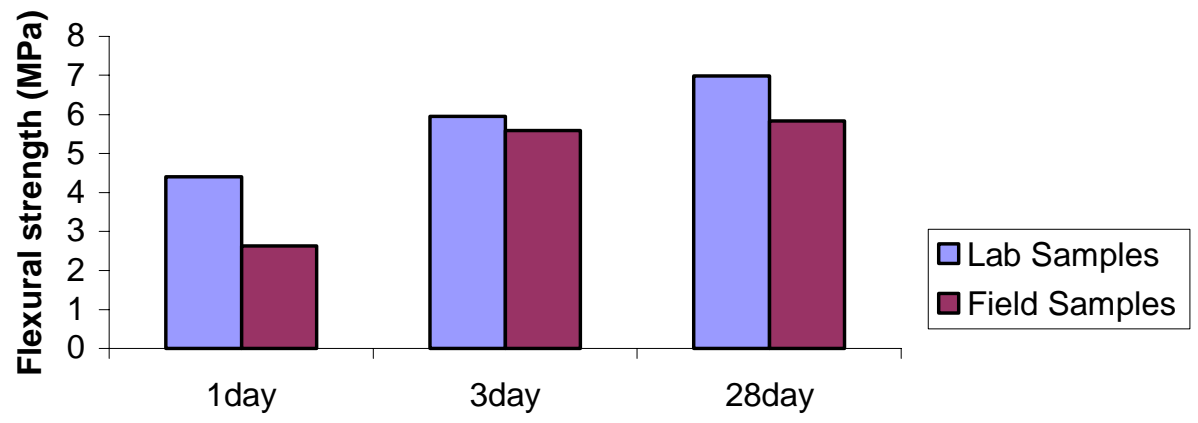

Figure 3.21 Comparison of flexural strength of fiber reinforced concrete (Lab and APT mixes) 


\subsection{Test plan for accelerated testing of UTW}

The initial test plan consisted of testing the lanes until some sort of mechanical, physical or visible failure is detected in the forms of cracking, faulting or debonding. However the time constraint led to testing the lanes at elevated loads and temperature conditions, to accelerate the damage, for a specified number of passes or failure whichever happened earlier. Lane 1 was tested for 100,000 passes. The first 30,000 passes were tested using a $12000 \mathrm{lbs}$ loading. The remaining 70,000 passes were tested after the APT wheel load was hiked to $20000 \mathrm{lbs}$. This was done to observe whether the elevated loading had any effect on accelerating the damage to the pavement. Even after a 100,000 passes, not much visible damage was observed and the strains stabilized. Therefore, the test was shifted to Lane 3. Lane 3 was then tested for 150,000 passes under a uniform load of $12000 \mathrm{lbs}$, since it was a thinner overlay. The performance of Lane 3 to the $12000 \mathrm{lbs}$ load was similar to Lane 1. This led to the testing of Lane 4 at a $20000 \mathrm{lbs}$ load and at elevated temperature to aggravate the damage. The slabs were heated from below to a temperature up to $130^{\circ} \mathrm{F}$ after 60,000 passes and two cycles of heating and cooling were maintained. Figure 3.22 shows the test plan for the testing of the UTW at the APT facility. 


\begin{tabular}{|c|c|c|c|c|}
\hline $\begin{array}{l}2.5 \text { " Thick } \\
\text { Fiber Concrete }\end{array}$ & $\begin{array}{l}2.5 " \text { Thick } \\
\text { Plain Concrete }\end{array}$ & $\begin{array}{l}\text { 4" Thick } \\
\text { Fiber Concrete }\end{array}$ & $\begin{array}{l}\text { 4" Thick } \\
\text { Plain Concrete }\end{array}$ & \\
\hline $\begin{array}{l}\text { Load of } \\
20000 \mathrm{lbs} \text { for } \\
250,000 \\
\text { passes } \\
\text { Tested at } \\
\text { Elevated } \\
\text { Temperature } \\
\text { after } 60000 \\
\text { passes } \\
\text { 2Cycles of } \\
\text { heating and } \\
\text { cooling the } \\
\text { slab (85- } \\
\text { 130F) }\end{array}$ & $\begin{array}{l}\text { Load of } \\
12000 \mathrm{lbs} \text { for } \\
150,000 \\
\text { passes }\end{array}$ & $\begin{array}{l}\text { Was not } \\
\text { tested }\end{array}$ & $\begin{array}{l}\text { Load of } \\
12000 \mathrm{lbs} \text { for } \\
\text { first } 30,000 \\
\text { passes } \\
\text { Load of } \\
20,000 \mathrm{lbs} \text { for } \\
\text { next } 70,000 \\
\text { passes } \\
\text { Tested for a } \\
\text { total of } \\
100,000 \\
\text { passes }\end{array}$ & $\begin{array}{c}\mathrm{O} \\
\mathrm{F} \\
\mathrm{F} \\
\mathrm{I} \\
\mathrm{C} \\
\mathrm{E}\end{array}$ \\
\hline
\end{tabular}

\section{LANE 4 \\ LANE 3 \\ LANE 2 \\ LANE 1}

Figure 3.22 Schematic of the lane layouts and the test plan 


\section{ANALYSIS AND DISCUSSION OF THE RESULTS FROM THE ACCELERATED PAVEMENT TEST}

\section{$\underline{4.1 \text { Type and format of the data }}$}

The data recorded by the system consisted of strains recorded from 4 sets of gages (with 3 gages in each set) and 2 sets of rosettes, deflections from 2 LVDTs and temperature from 3 thermocouples installed at various depths in the pavement. StrainSmart (System 6000 software from Vishay Measurements Group) calculates the strains from the gages and the deflection of the LVDTs directly from the voltage readings supplied by the sensors. The strain generated in the specimen (gage) is relayed through the base of the gage to the fine wire or foil where the expansion or contraction occurs. As a result, the fine wire or foil experiences a variation in resistance. This variation is directly proportional to the strain. It is given by:

$$
\begin{gathered}
\varepsilon=\Delta \mathrm{l} / \mathrm{l}=(\Delta \mathrm{R} / \mathrm{R}) / \mathrm{K} \\
\varepsilon: \text { Strain measured } \\
\text { 1: length of specimen (gage) }
\end{gathered}
$$

$\Delta \mathrm{l}$ : change in length of the specimen (gage)

$$
\begin{gathered}
\mathrm{K}: \text { Gage factor } \\
\mathrm{R}: \text { resistance of the gage } \\
\Delta \mathrm{R}=\text { change in resistance of the gage }
\end{gathered}
$$


Normally this resistance change is very small and requires a Wheatstone bridge circuit to convert it into a voltage output. From Kirchoff's law the relation between the voltage and resistance is given by:

$$
\begin{gathered}
\mathrm{V}=\mathrm{I}^{*} \mathrm{R} \\
\mathrm{V} \text { : voltage } \\
\mathrm{I} \text { : current in the circuit } \\
\mathrm{R} \text { : resistance }
\end{gathered}
$$

Hence, the resistance is proportional to the voltage change and the relationship between the excitation voltage of the circuit and strain measured can be given by:

$$
\begin{gathered}
\Delta \mathrm{e}=(\mathrm{E} / 4)^{*} \mathrm{~K}^{*} \varepsilon \\
\Delta \mathrm{e}: \text { voltage change } \\
\text { E: excitation voltage for the Wheatstone circuit } \\
\mathrm{K}: \text { gage factor } \\
\varepsilon: \text { strain }
\end{gathered}
$$

(The gage factor for the gages used for instrumenting the APT lanes was 2.0.)

At the beginning of the test for all the lanes tested, the data was scanned and recorded after every 200 passes of the wheel over the sensor. As the test progressed the frequency of recording was decreased to one in 500 passes and finally to one in 1000 passes. Synchronizing the clocks of the computer, which controls the travel of the APT carriage and that of the computer that runs the data acquisition system, enabled the real time recording of the instrumentation data by the system. The data was saved in the form of an ASCII text file, which could be opened by any standard spreadsheet program. 
The three types of strains recorded by the data acquisition system were:

a) Dynamic strains: These strains were recorded by the strain gages, as the wheel was moving along the test lane. The frequency of sampling for the gages was 200 Hz. This, when translated to the wheel moving at $8 \mathrm{~km} / \mathrm{h}(5 \mathrm{mph})$ corresponds to one reading every $1.1 \mathrm{~cm}(0.44$ ") of the wheel traverse. The trends in dynamic strain indicate how the strains changed at a particular gage location, as the wheel moves towards, passes over the gage and moves away from the gage. For all the sensors, these strains were recorded every 500 to 1000 passes.

b) Permanent strains: These strains were recorded daily before the beginning of the test (with the wheel completely outside the test lane). The trends observed in static strains and deflections were used as indicators of permanent deformations accumulating in the pavement with increasing number of load repetition.

c) Static load strains: Periodically static load strains in the overlay were recorded in order to determine if they increased with the increased number of load repetitions. It was assumed that an increase in the strain caused by the static load would be a good indicator of pavement fatigue damage. The measurement of static strains included bringing the wheel to predetermined locations on the pavement (typically over gages located in panel 3 near the longitudinal joint), parking it at this location and statically loading the area with the wheel. The wheel load was removed after 15 seconds and the strain response on those gages was monitored for up to 45 seconds after the removal of the load. 
The typical output data file included the strains, the deflections, the temperature data and the wheel position data that were recorded by different channels of the system. The strains were reported in microstrains, deflections and wheel position was recorded in inches and the temperature data in degrees Fahrenheit.

\subsection{Analysis of data from the dynamic wheel load tests}

\subsubsection{Data analysis of lane 1}

\subsubsection{Analysis of dynamic strains and deflections}

The analysis presented in this section includes the data collected during testing of Lane 1 up to a 100,000 passes. During the first 30,000 passes, the load applied to the wheel was $12000 \mathrm{lbs}$. The load was then increased to 20,000 lbs for the remaining 70,000 passes. This section discusses the trends in the variation of dynamic strains and deflections at the first wheel pass of the test and at the $100,000^{\text {th }}$ pass of the test. (The analysis of the effect of increasing the load after 30,000 passes is discussed in section 4.2.1.2)

a) Longitudinal gages at the edge of the longitudinal joint within the test lane. (1-C-S-1, 1-C-S-2, 1-W-S) 


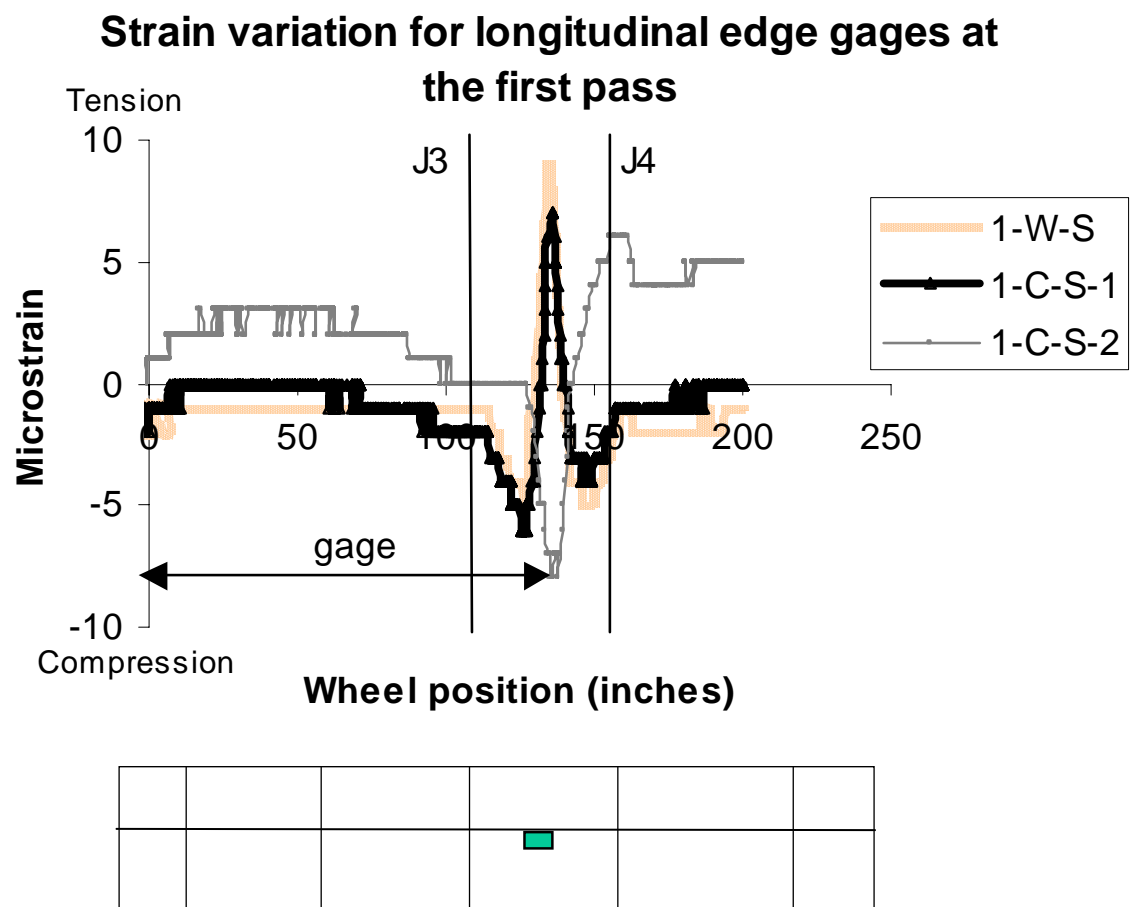

Figure 4.1 Typical strain response of edge longitudinal gages under the moving wheel during the first pass

Figure 4.1 shows the typical response of all the three gages as the wheel passes over it for the first time. This set of gages is the ones on which the wheel directly passes over. The top gage in concrete (1-C-S-2) shows a compressive strain and the bottom two gages (bottom of concrete (1-C-S-1) and top of milled asphalt (1-W-S)) show tensile strains as the wheel passes exactly on top of them. The strains recorded have a very low magnitude (of the order of about 10 microstrains). It can also be seen from the Figure 4.1 that as the wheel position approaches the gage location; the top of the panel experiences tensile strain and the bottom of the panel experiences a compressive strain. This could be because the panel curls upwards. As the wheel reaches the position exactly on top of the gage, the strains quickly reverse and the top gage goes into compression and while the 
bottom gage goes into tension indicating that, the panel curls downward under the wheel load. The phenomenon reverses again as the wheel leaves the panel and moves on to the next panel. This phenomenon can be explained by the fact that there is a relative vertical motion of the pavement structure as the wheel moves from one panel to another. This relative movement causes a wave like deformation of the slabs. The schematic shown in Figure 4.2 represents the slab movement with respect to the wheel motion.
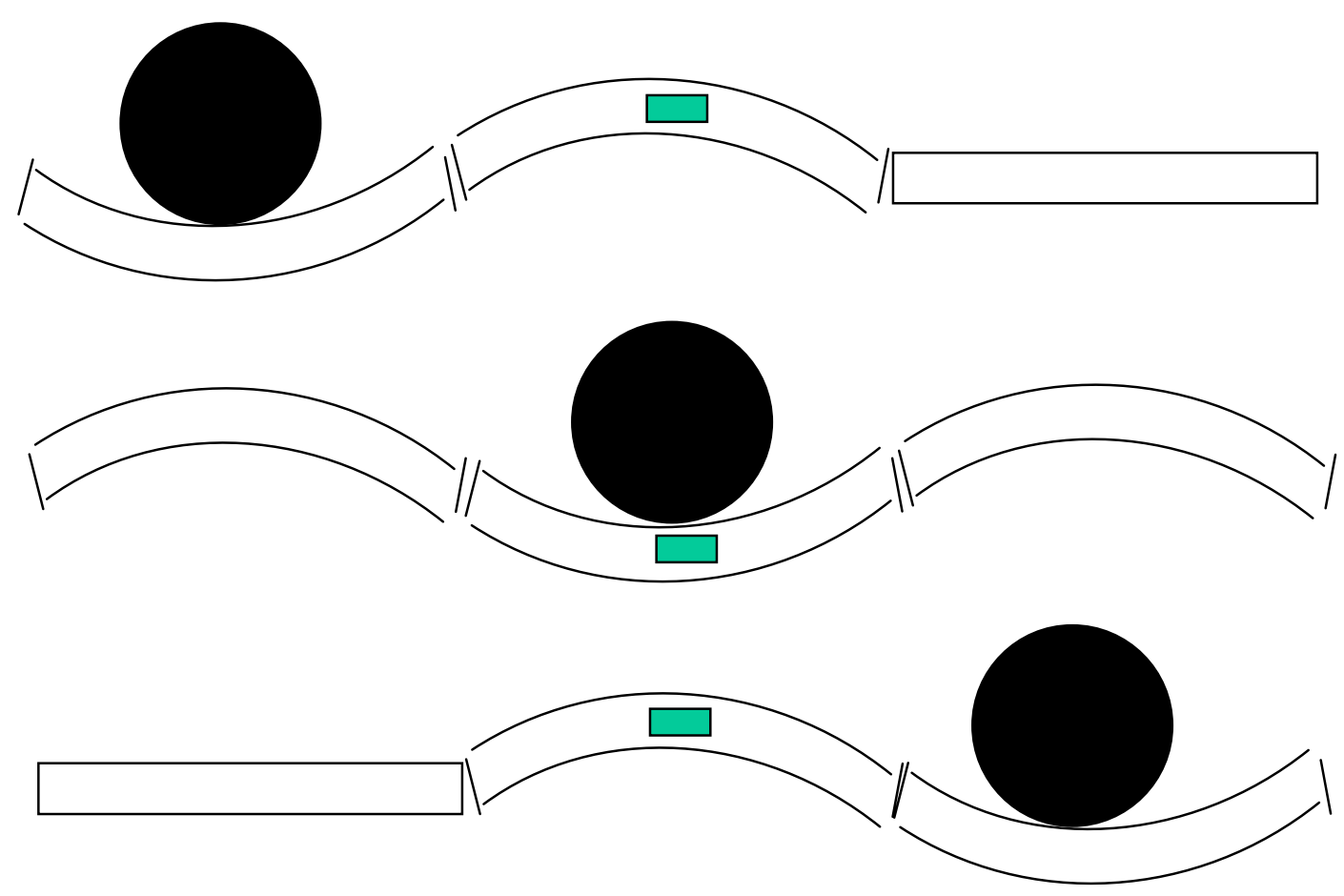

Figure 4.2 Relative motion of slabs causing dynamic strain reversal

Figure 4.3 shows the longitudinal edge gages response during the 100,000 passes. The magnitude of strain variation due to the motion of the wheel over the lane is higher after 100,000 passes. The base strains have also increased which indicate a permanent strain formation in the gages. The gage at the top of the concrete (1-C-S-2) shows a maximum dynamic compressive strain of 25 microstrain whereas the gages at the bottom 
of the concrete (1-C-S-1) and top of the asphalt (1-W-S) show a maximum dynamic tensile strain of 25 microstrains and 20 microstrains, respectively. The maximum strains caused in the gages, due to the reversal phenomenon discussed above, are much greater in magnitude than the strains generated when the wheel load is directly on top of the gages. This was not observed during the first pass.

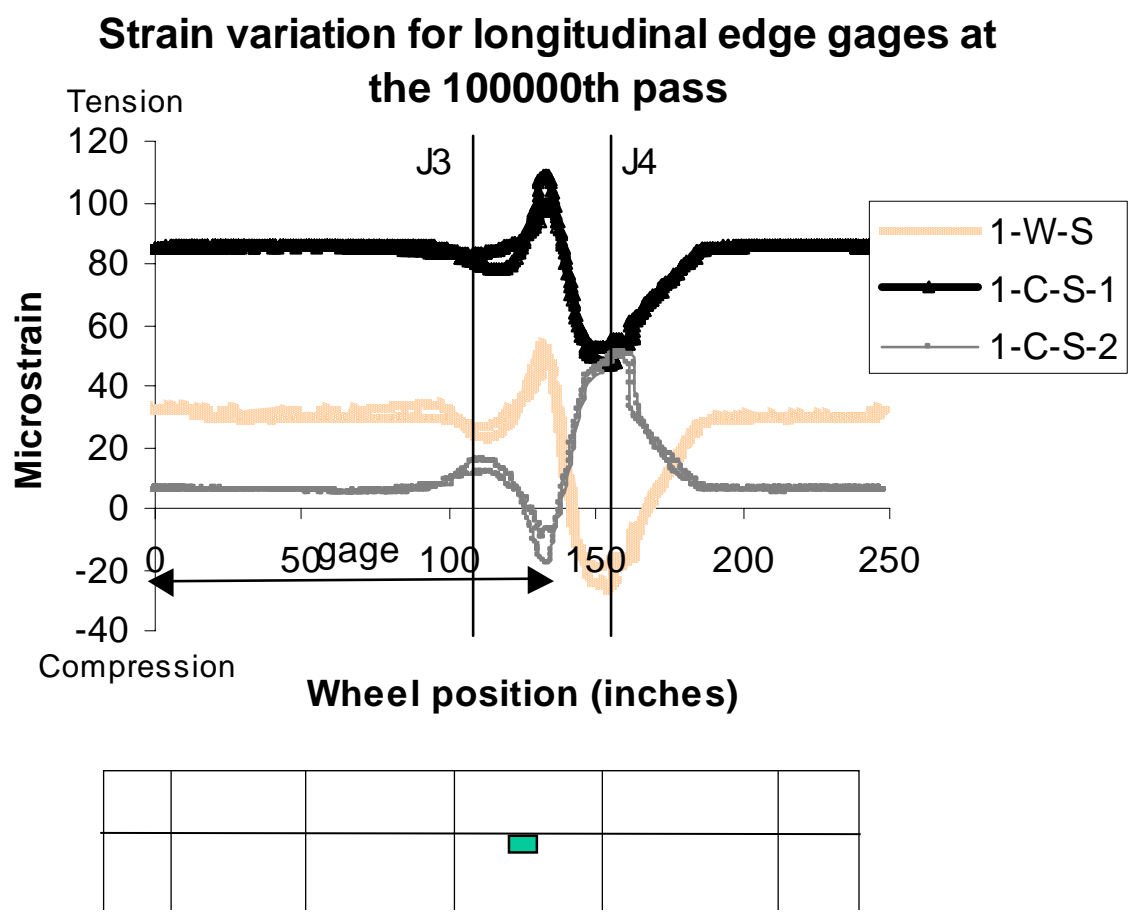

Figure 4.3 Typical strain response of edge longitudinal gages under the moving wheel during the $100000^{\text {th }}$ pass

b) Longitudinal gages at the edge of the longitudinal joint in the lane adjacent to loaded test lane (1-W-S2, 1-C-S2-1, and 1-C-S2-2).

Unlike the response from the gages in the loaded lane, after the initial pass, the response in the gages located in the adjacent lanes does not follow a distinctive pattern. The strains were low and scattered when the load was 12,000 lbs. However, when the load was increased to $20000 \mathrm{lbs}$, the gage at the top of the concrete showed a 
compressive strain and the gage at the top of the asphalt showed a tensile strain as the wheel passed over them (see Figure 4.4).

\section{Strain variation for longitudinal edge gages in the adjacent lane at the 100000 th pass}
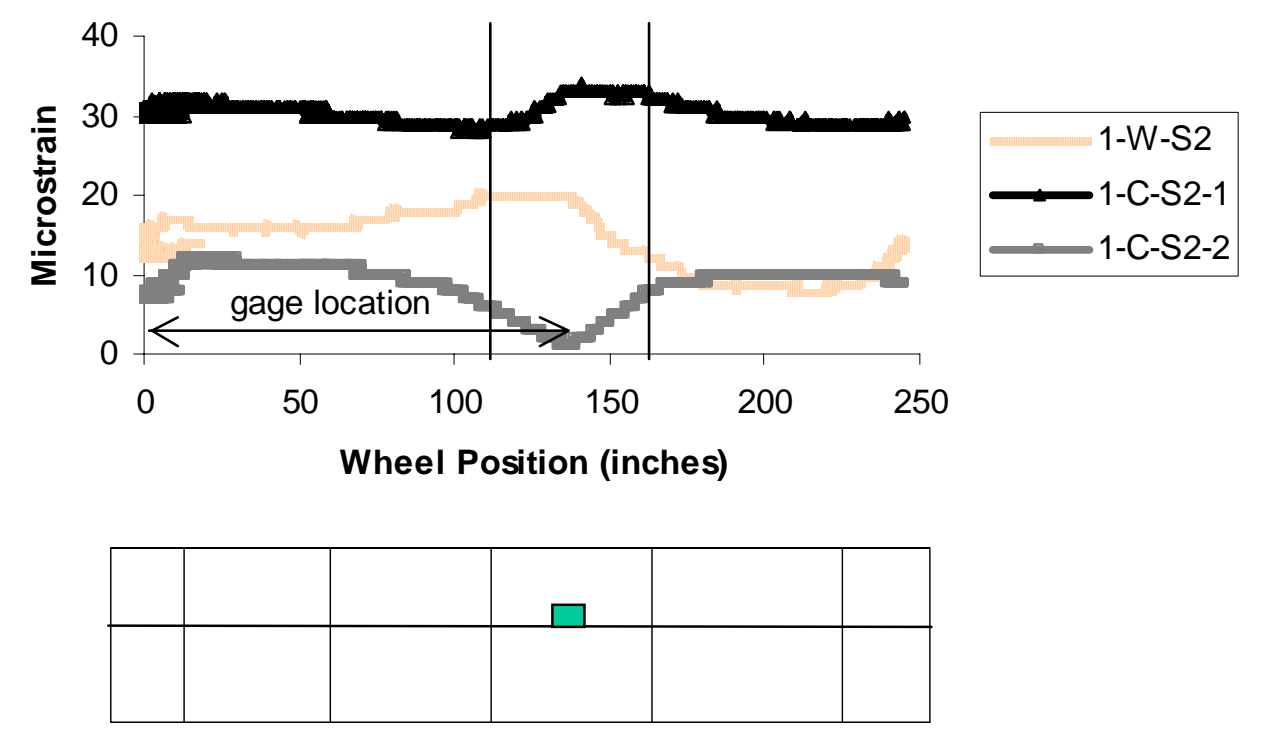

Figure 4.4 Dynamic strain response of longitudinal edge gages in the adjacent lane during the $100,000^{\text {th }}$ pass

c) Transverse gages at the edge of the transverse joint in the middle of the panel

(1-W-T, 1-C-T-1, 1-C-T-2)

The results obtained from these gages after the first pass are presented in Figure

4.5. The top gage in concrete (1-C-T-2) shows a tensile strain as the wheel passes across the position of the gage and the gage on the top of the asphalt (1-W-T) shows a compressive strain. This may be attributed to the fact the gages are not in the wheel path that may cause the upheaval of the remaining panel that is not under the wheel load, hence causing the slab to curl upward. This causes a compressive strain at the bottom of the slab and a tensile strain on the top of the slab. 

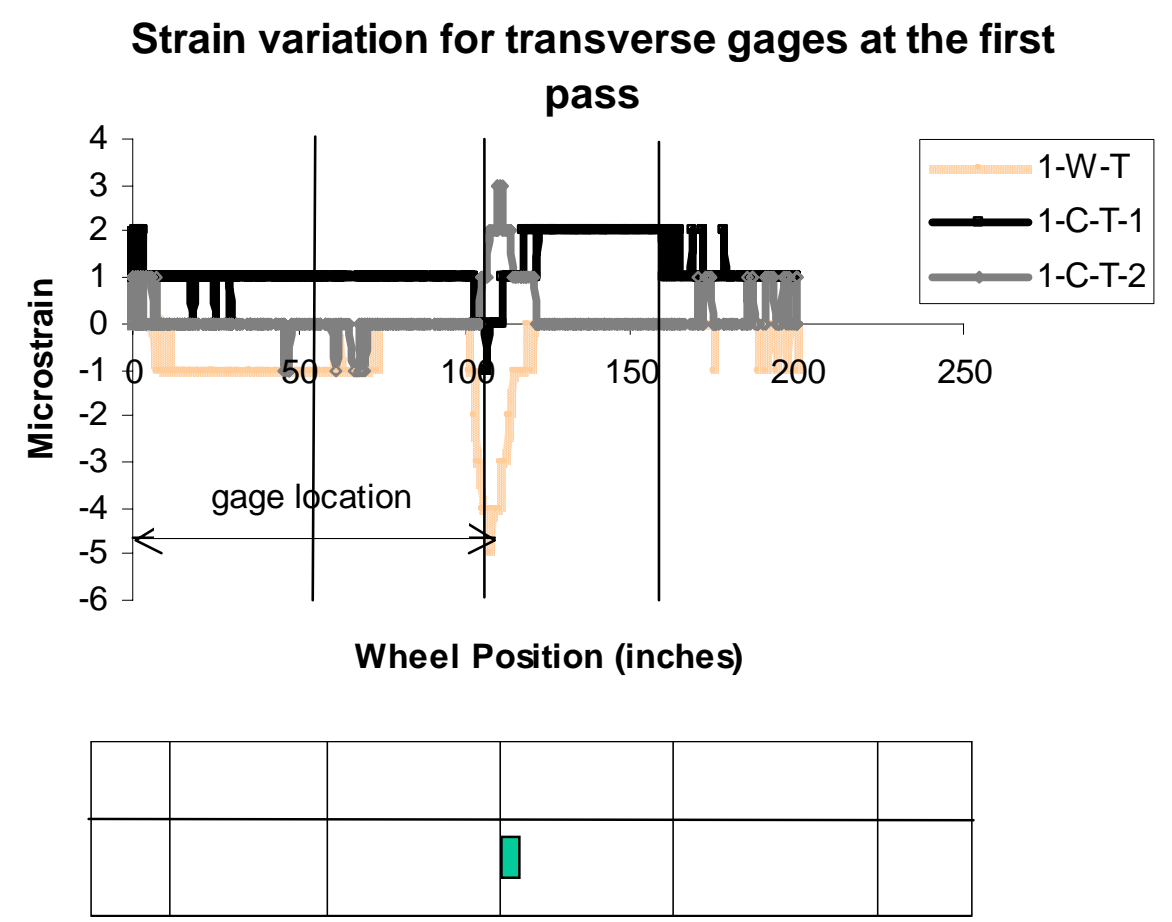

Figure 4.5 Strain variations of transverse gages during the first pass

After a 100,000 passes, the changes in strain registered by these gages were still very low (on the order of 10 microstrain). The gage on the surface of asphalt showed some response to the wheel load whereas the gage on the top of the concrete showed almost no response to the load, (refer Figure 4.6). The bottom gage in concrete in the set of transverse gages was rendered useless earlier in the test (after approximately 3000 passes) when it started showing abnormally high strain values, which did not correspond to the location of the wheel. Hence, the data from that gage has been excluded from the analysis. 


\section{Strain variation for transverse gages at the 100000th pass}

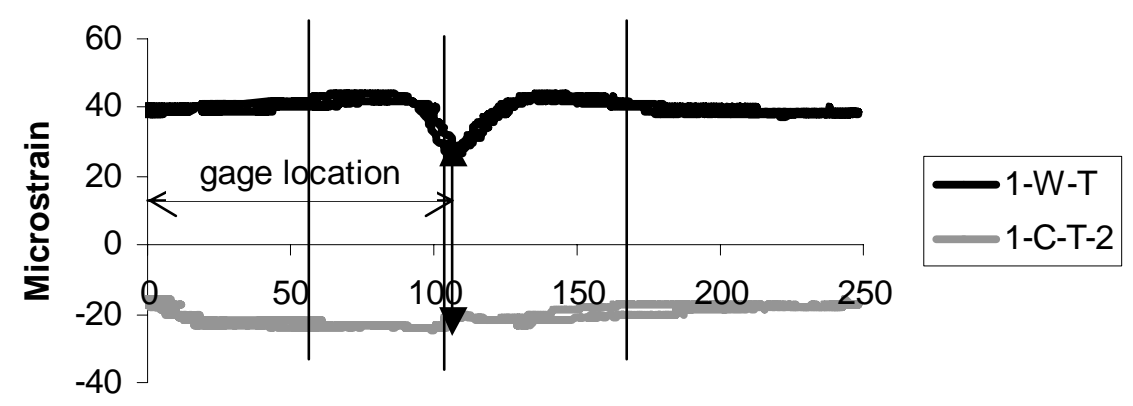

Wheel Position (inches)

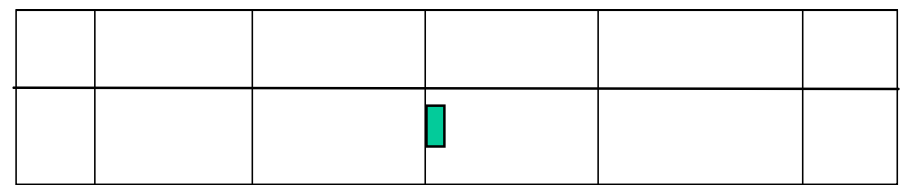

Figure 4.6 Transverse gage strain variations during the $100,000^{\text {th }}$ pass

d) The top rosette at the corner of the panel (1-R-2-L, 1-R-2-T, 1-R-2-I)

The data for the top rosette are shown in Figure 4.7 and 4.8 for the $1^{\text {st }}$ and the $100,000^{\text {th }}$ pass, respectively. These figures show the strain response of the top rosette with respect to the position of the wheel using gage location as the datum point. During the first pass of the wheel, the top rosette showed a complex strain response in the pavement. The longitudinal gage in the rosette (1-R-2-L) showed a compressive strain as the wheel passed exactly over the gage. The transverse (1-R-2-T) and the inclined (1-R2-I) legs of the strain rosette however showed tensile strains as the wheel passed over them. This correlates with the trends shown by the longitudinal gages installed in the lane. The inclined gage of the rosette showed similar trends as the transverse gages. 


\section{Strain response of the top rosette during the 100000th pass}

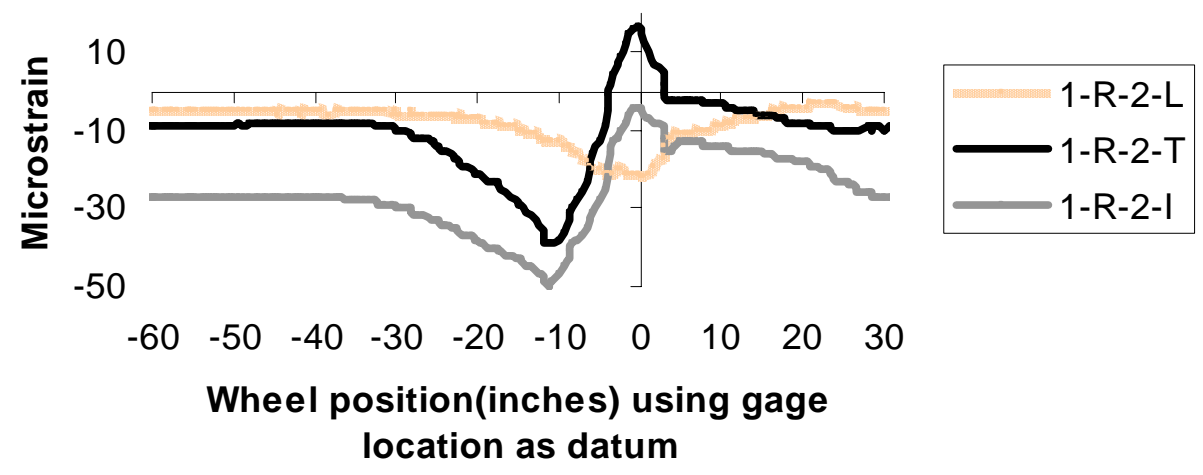

Figure 4.7 Strain response of the top rosette during the first pass

From Figure 4.7, it can be observed that there is a strain reversal in the inclined (1-R-2-I) as well as the transverse gages (1-R-2-T) in the rosette. However, the longitudinal gage (1-R-2-L) however shows only a compressive strain as the wheel passes over it. This is more pronounced after a 100,000 passes as shown in Figure 4.7. It could be noted from Figures 4.7 and 4.8 that the top rosette strains did not show any substantial increase even after the lane was subjected to a 100,000 passes of the wheel.

\section{Strain response of the top rosette during the 100000th pass}

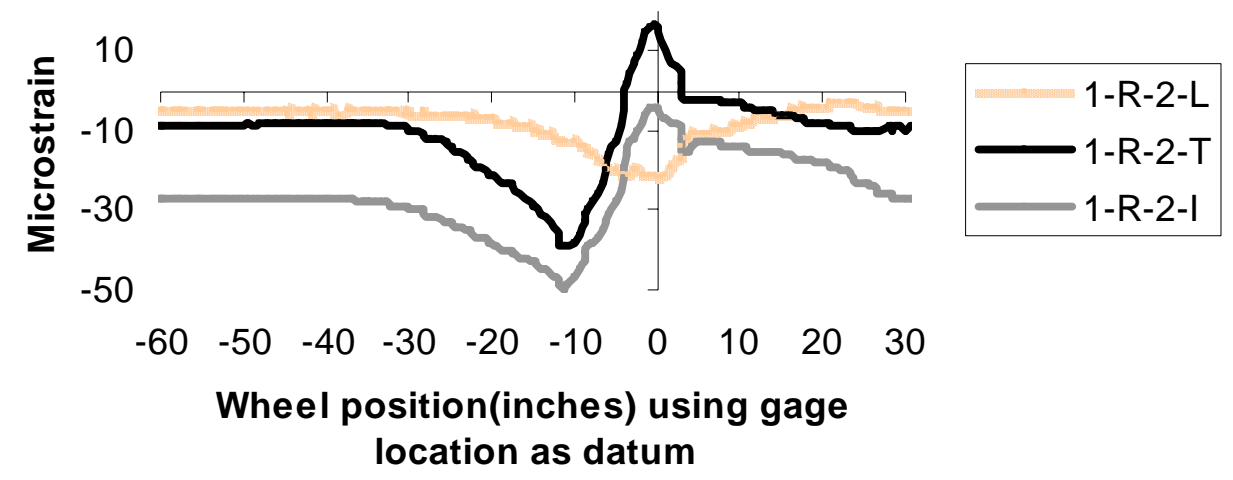

Figure 4.8 Strain response of the top rosette during the $100000^{\text {th }}$ pass 
e) Bottom rosette at the corner of the panel (1-R-1-L, 1-R-1-T, 1-R-1-I)

The strain variation in the bottom rosette during the first pass is shown in Figure 4.9. It could be seen that all the gages of this rosette show tensile strains when the wheel passed over them. However the gages in this rosette, started showing drifting strains after a couple of thousand passes. The tensile strains progressively increased (to the level of a few hundred microstrains in all the legs of the rosette) and then the rosette stopped responding to the changing wheel position. As a result, later data (beyond the first wheel pass) collected by this rosette are not included in the analysis.

\section{Strain response of the bottom rosette during the 1st pass}

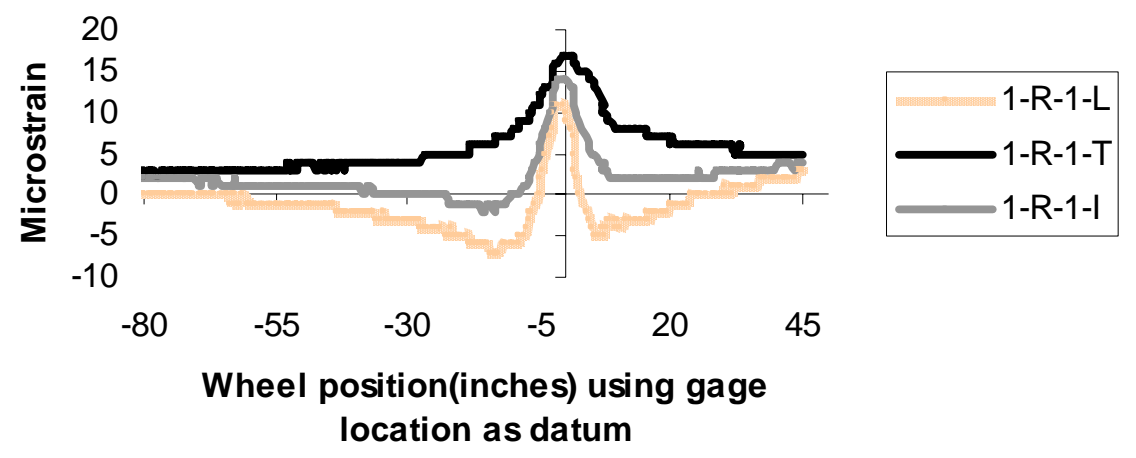

Figure 4.9 Strain response of bottom rosette due to moving wheel at first pass

f) Deflection at the center of the transverse joint of the panel 2 (LVDT 4)

Figures 4.10 and 4.11 show the variation of pavement deflection as recorded by LVDT 4 after the $1^{\text {st }}$ and the $100,000^{\text {th }}$ pass, respectively. During the first pass of the wheel, the average deflection of the panel that contained the LVDT 4 sensor was about 0.004. This deflection was induced by a load of $12,000 \mathrm{lbs}$. When the load was increased to $20,000 \mathrm{lbs}$, the deflection change increased to about 0.015 ". After 100,000 
passes, the average deflection increased from $0.004 "$ to about $0.015 "$. The deflection kept increasing with the increase in the number of load cycles and reached an average value of about 0.04 " after 100,000 passes of the wheel.

g) Deflection of LVDT at the center of the panel (LVDT 6)

LVDT 6 also shows a similar deflection values with a maximum deflection registered at the time when the wheel passes near the sensor. The average deflection value observed after the few initial passes was about 0.003 ". When the wheel load was increased to $20,000 \mathrm{lbs}$, the value almost doubled. The deflection values increase steadily from a near zero value at the beginning of the test to about 0.045 " after a 100000 passes. The magnitude of deflections of both the LVDTs was very small.

\section{LVDT deflections during the first pass}

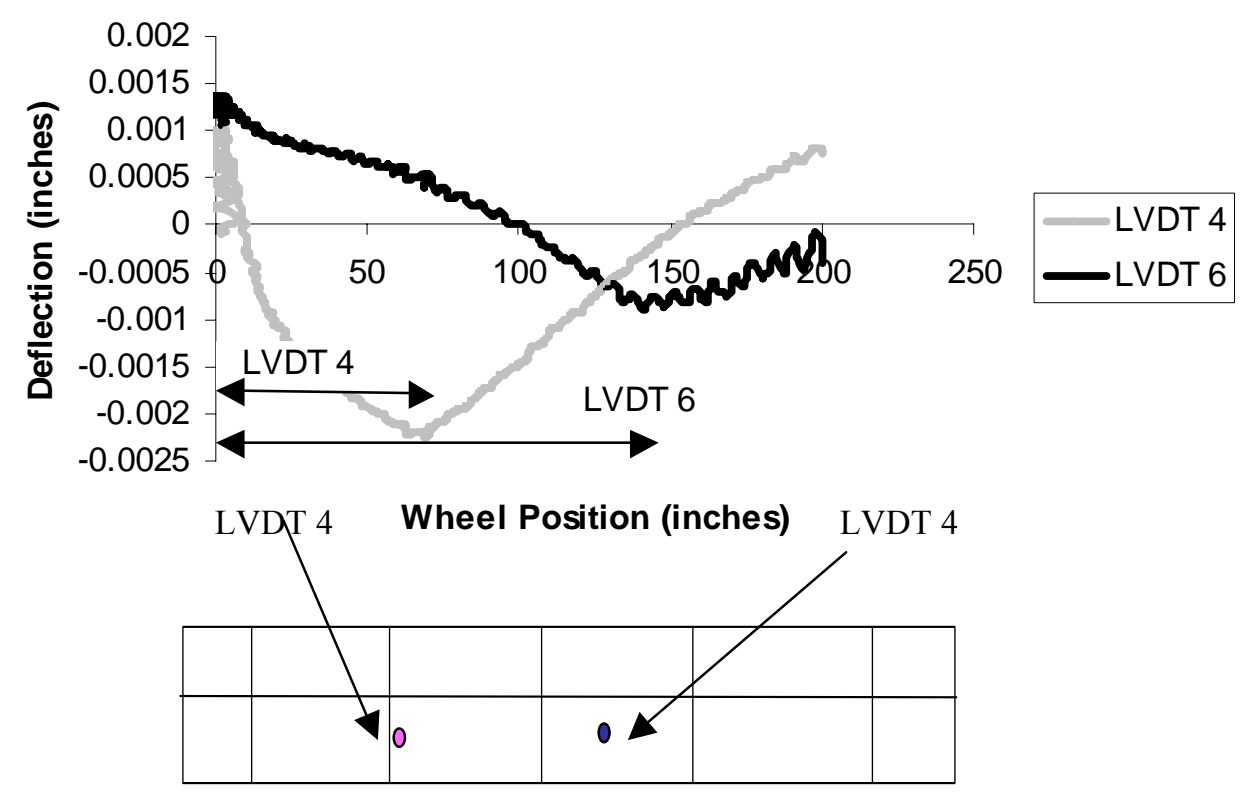

Figure 4.10 Deflection values of LVDT's at the first pass 


\section{LVDT deflection during the 100000th Pass}

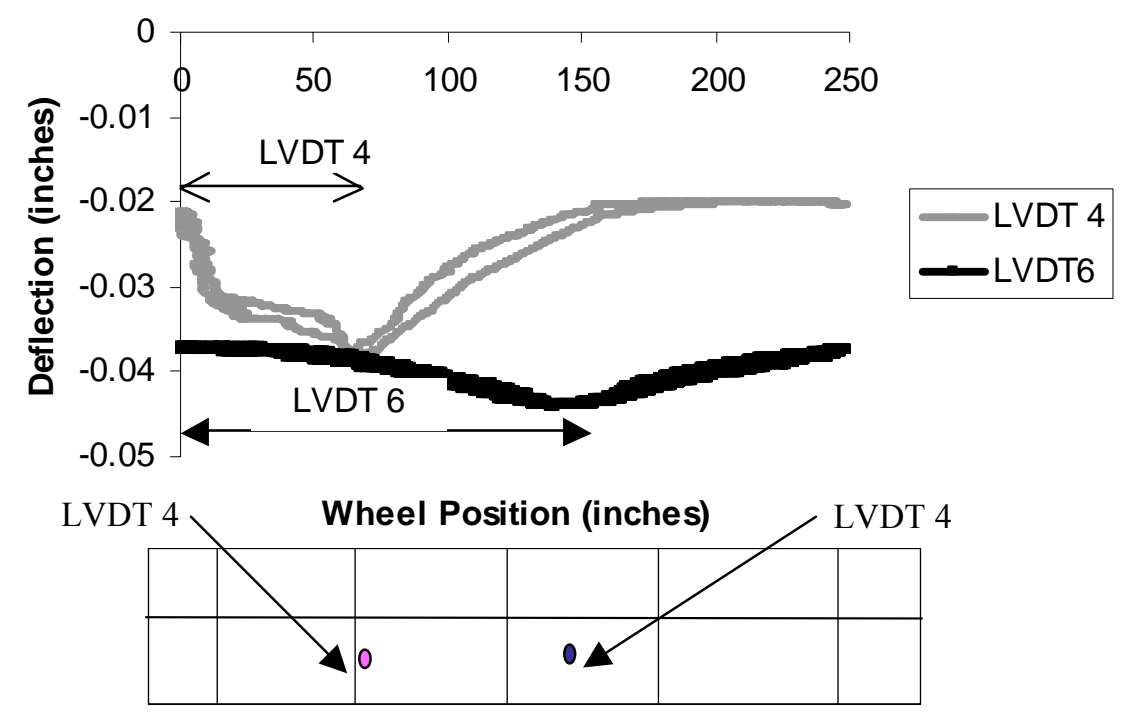

Figure 4.11 Deflection values during the $100,000^{\text {th }}$ pass

\subsubsection{Analysis of the effect of load increase}

The following sub section discusses the effect of the load increase from 12,000 lbs (used for the first 30,000 passes) to $20,000 \mathrm{lbs}$ (used for the next 70,000 passes). The increase of the load caused an increase in the dynamic strains and deflections. The most noticeable changes were observed in the two sets of longitudinal gages located in the center and edge of the slabs. The dynamic strain changes recorded almost a two-fold increase. This increase was related to the increase in the load and was a linear function of the load. In the transverse gages and the rosettes, the changes were very negligible and the average strain values remained low. The deflection recorded by the LVDTs was very small as well. Even after the load was increased to $20,000 \mathrm{lbs}$, the deflection did not exceed $0.05 "$ even after 100,000 passes. 
In addition, the increase in the load caused the increase in the strains associated with the strain reversal phenomena discussed in the previous sections. As discussed previously, a reversal in strain was observed as soon as the wheel load passed the gage location. The magnitude of this strain increased to almost about 4 to 5 times the strain that was observed for the lower $(12000 \mathrm{lbs})$ load. This indicates that the relative motion between the adjoining panels increased greatly with the increase of the load. This was mainly observed in the two sets of gages at the center (M-series) and the edge (S-series) of the panel. The Figures 4.12 and 4.13 show the increase in the magnitude of the strain reversal after the loading was increased from $12,000 \mathrm{lbs}$ to $20,000 \mathrm{lbs}$ for the M-series gages. It could also be observed from both the figures that the load increase resulted in the change of both the magnitude and the location of the critical (tensile) strain. The critical strain location shifted from the bottom of the slab to the top of the slab. The increase in magnitude is shown clearly in the S-series gages as shown in Figure 4.14.

\section{Strain reversal due to load increase after 30000 \\ Passes in gage 1-C-M-2}

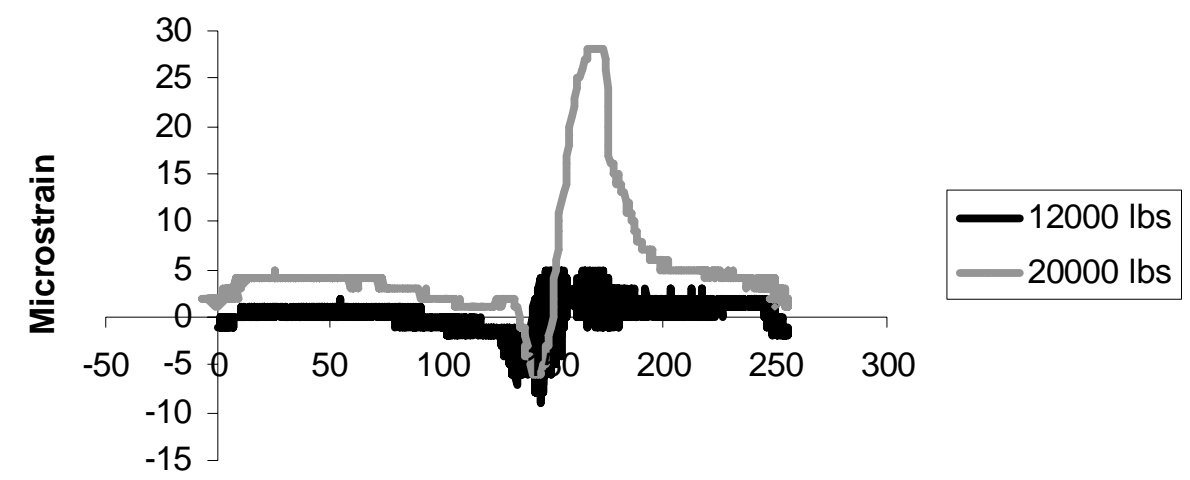

Wheel Position (inches)

Figure 4.12 Increase in strain after load increase at 30000 passes in gage1-C-M-2 


\section{Strain reversal due to load increase after 30000}

Passes in gage 1-C-M-1

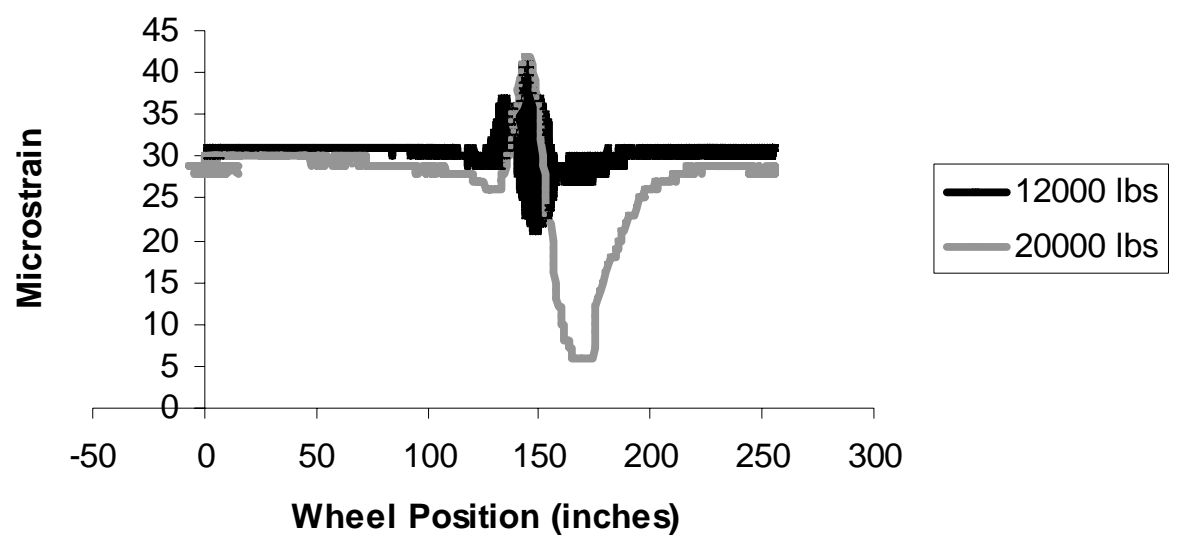

Figure 4.13 Increase in strain after load increase at 30000 passes in gage1-C-M-1

Strain increase due to load increase from 12000 to $20000 \mathrm{lbs}$ load for gage1-C-S-1

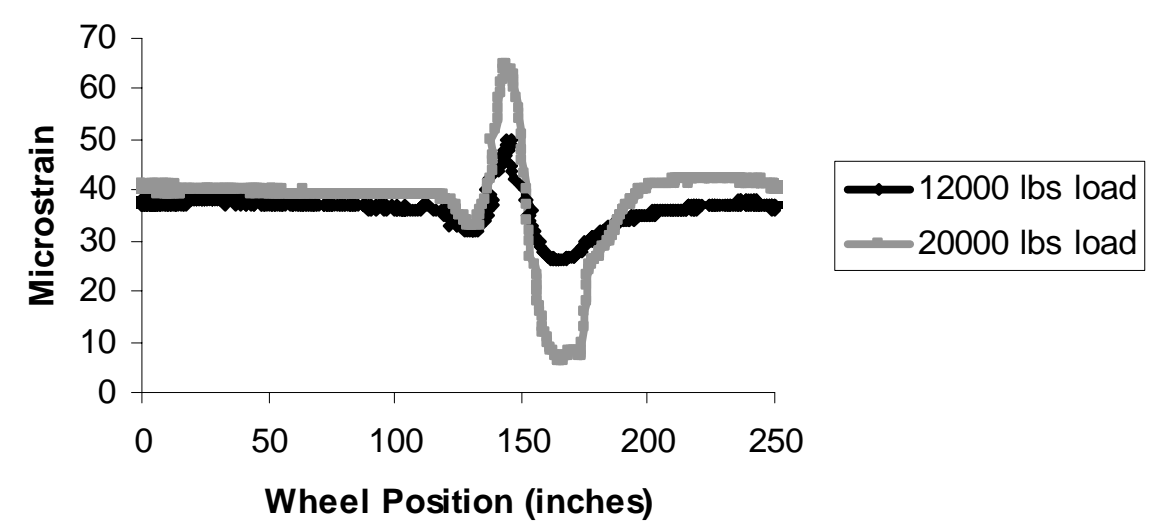

Figure 4.14 Dynamic strain increase after 30000 passes for gage1-C-S-1

From Figure 4.15 it can be observed that the strains increased largely after the loading was increased to $20,000 \mathrm{lbs}$ after 30,000 passes. Also it can be noted that the magnitude of the compressive strains caused by the reversal were greater than the tensile strains caused when the wheel load was directly on top of the gage location. 


\section{Maximum dynamic tensile and compressive strain in gage 1-C-S-1}

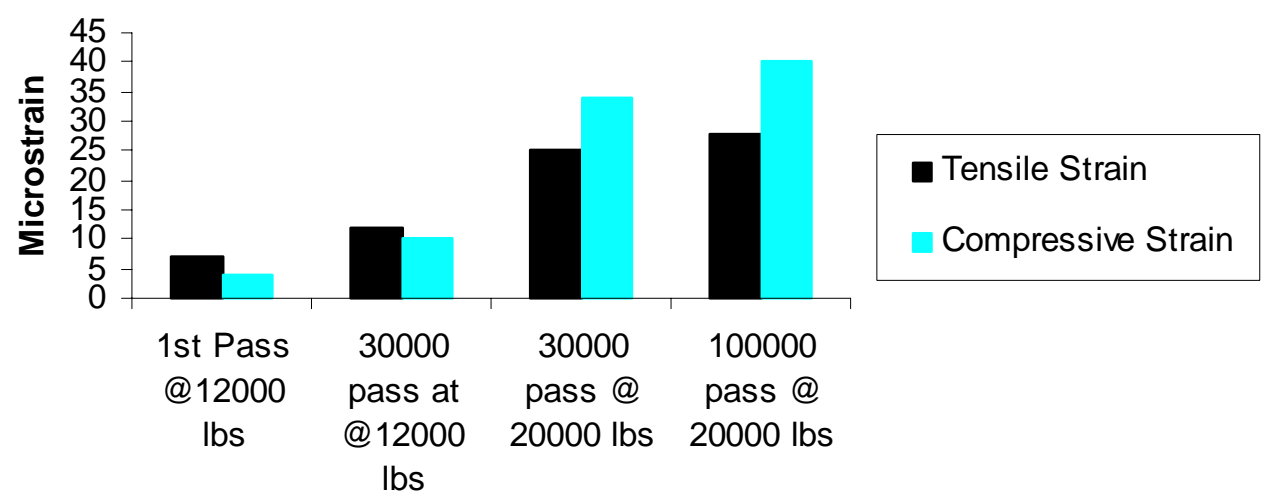

Figure 4.15 Change in maximum dynamic compressive and tensile strains (gage 1-C-S1) after increase in the load from $12,000 \mathrm{lbs}$ to $20,000 \mathrm{lbs}$

\subsubsection{Analysis of permanent strains and deflections}

Initially the test lane 1 was loaded with $12,000 \mathrm{lbs}$ load and it was observed that the strains and deflections increased with the number of passes. At 30,000 passes, the wheel load was increased from $12,000 \mathrm{lbs}$ to $20,000 \mathrm{lbs}$. This caused an additional increase in the strain and the deflection readings. In this subsection, trends for permanent strains and deflections would be discussed. Lane 1 was tested at ambient (room) temperature. The maximum temperature gradient across the thickness of the slab was about $3^{\circ} \mathrm{F}$. This corresponds to a maximum strain variation of about 15 microstrain (assuming linear coefficient of expansion for concrete to be $5 \times 10^{-6} /{ }^{\circ} \mathrm{F}$ ). The strain variations near the bottom of the concrete overlay and at the top of the asphalt layer were higher than this value, suggesting that permanent strains were accruing in the pavement due to repeated load applications. However, the increase could also be attributed to the fact that the wheel load was increased to $20,000 \mathrm{lbs}$ after the first 30,000 passes for the remaining test. The increase in wheel load and the increase in the number of load 
repetitions can not be isolated from each other in discussing the effects of the permanent strains and deflections and the extent to which each of these is affecting the fatigue damage of the pavement can not be determined quantitatively. The following graphs show the variation of permanent strains and deflections with respect to the number of cycles.

Figure 4.16 shows the variation in deflection for both LVDTs. It can be observed from the graphs that the relative slope of the deflection curves starts to stabilize after about 60,000 passes. Also the values of the permanent deflections show an increase after 30,000 passes due to the increase in the load.

\section{LVDT deflections vs number of passes}

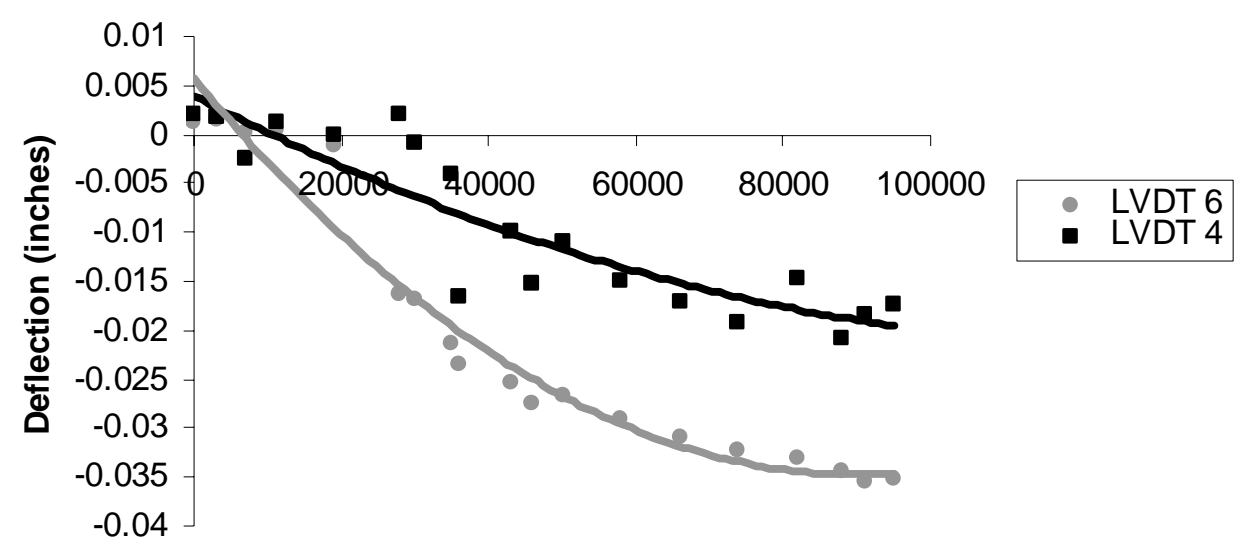

number of passes

Figure 4.16 Variation of deflection with number of passes

Figure 4.17 shows the permanent strain variation in the gages located in the center of panel 3 in lane 1 . The strains at the bottom of the concrete (1-C-M-1) and the top of the asphalt layer (1-W-S) show an increase with the increase in the number of passes. The strains on the asphalt layer however tend to stabilize after 70,000 passes. There is not much change in the strains at the top of the concrete (1-C-M-2). 


\section{Strain variation of longitudinal gages in the mid panel vs number of passes}

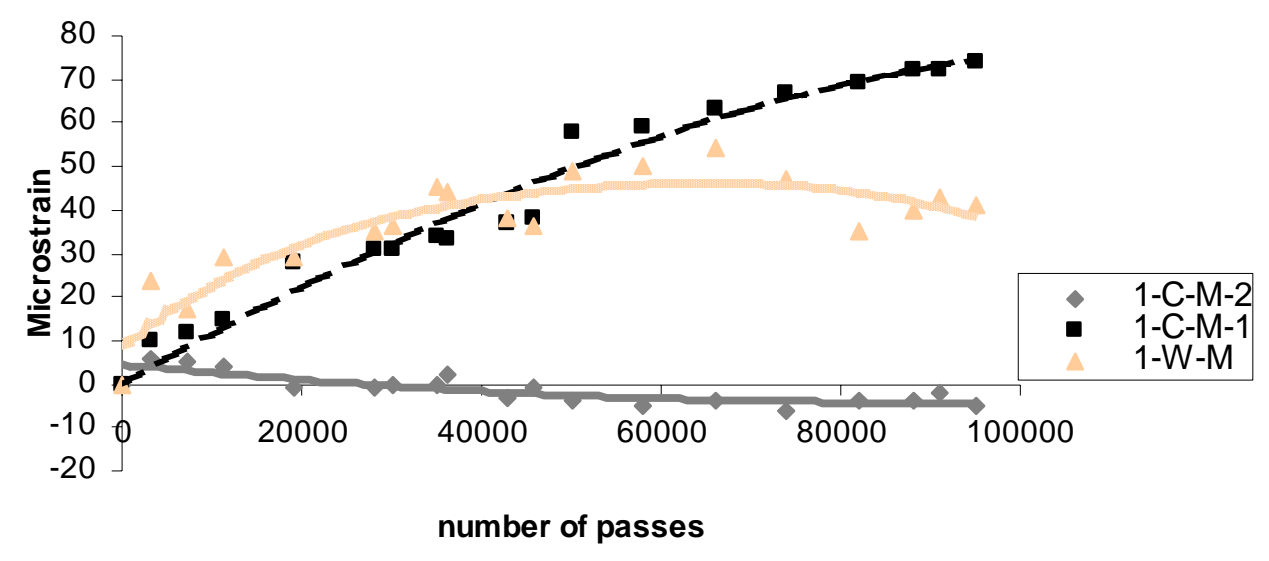

Figure 4.17 Variation of longitudinal mid-panel strain with number of passes

As shown in Figure 4.18 the transverse gages show a very symmetric response. The top gage in concrete (1-C-T-2) shows a compressive strain and the gage on top of the asphalt layer (1-W-T) shows corresponding tensile strains. The strains tend to stabilize after 50,000 passes. Unfortunately, the bottom gage in concrete (1-C-T-1) stopped functioning after a few thousand passes and therefore its results could not be included in the graph. The maximum permanent strain at the asphalt surface was about 40 microstrain whereas the strain at the top of the concrete was around 25 microstrains. 


\section{Transverse strain variation vs number of passes}

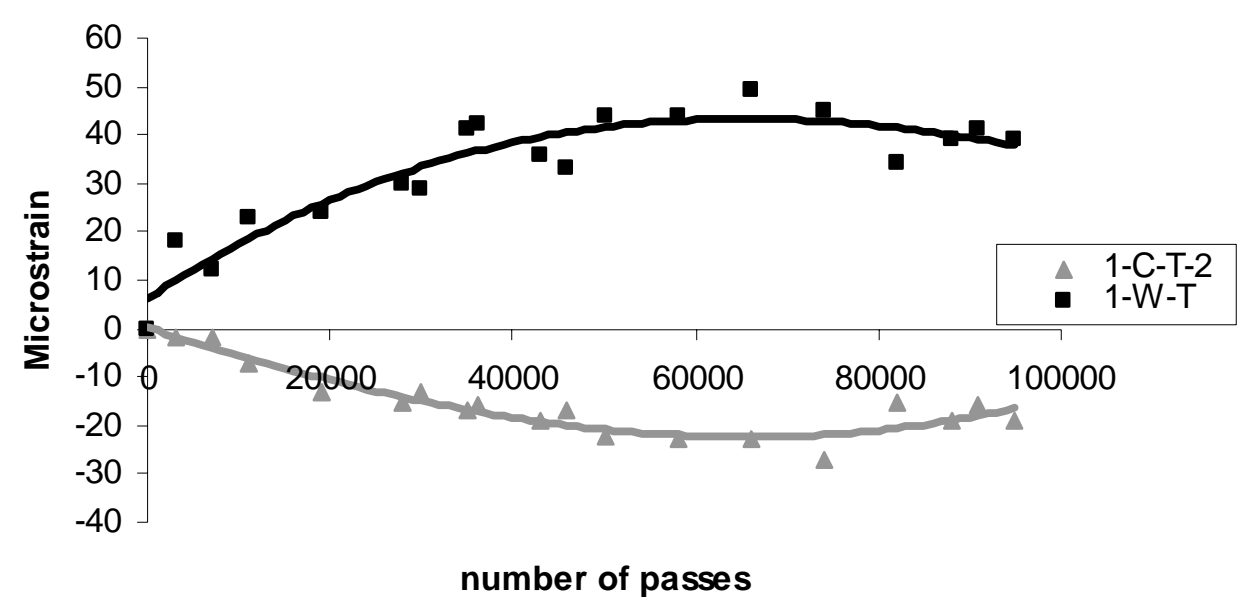

Figure 4.18 Variation of transverse strain with number of passes

Figure 4.19 shows the variation of the permanent strains in the rosette located at the top of the slab. All the gages show a permanent compressive strain. After about 70,000 passes the magnitude of compressive strains start to decrease a little. The trends in the permanent strain variation in the longitudinal gages in the adjacent lanes show a lot of scatter (refer to Figure 4.20).

Top rosette strain variation vs number of passes

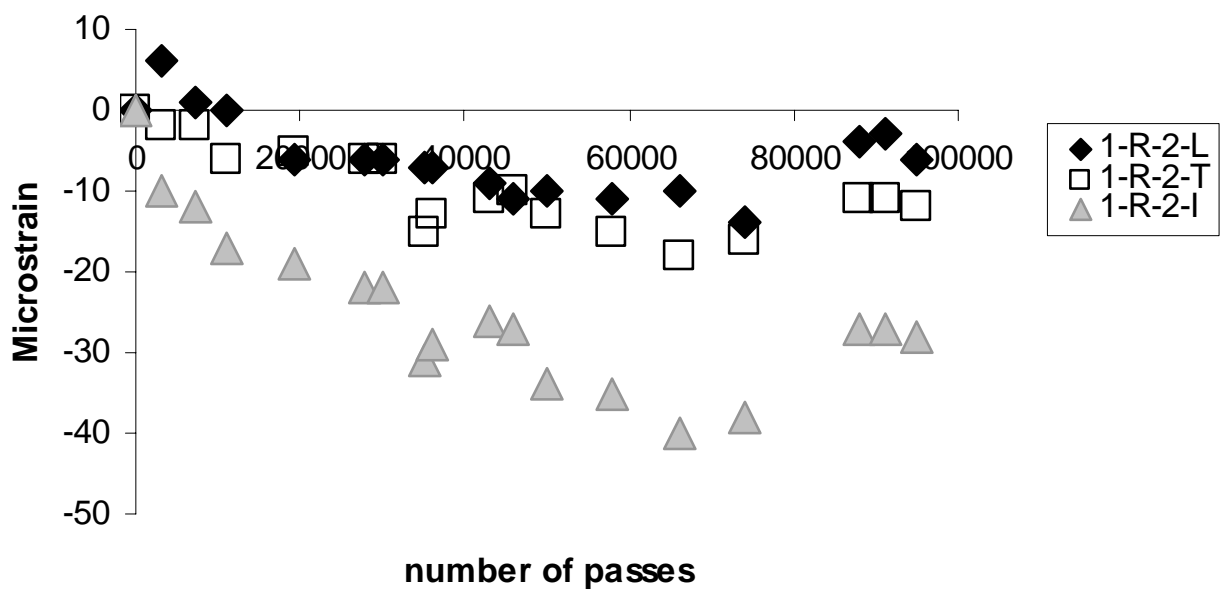

Figure 4.19 Variation of top rosette strain with number of passes 


\section{Variation of strains vs number of passes for longitudinal strain gage in adjacent lane}

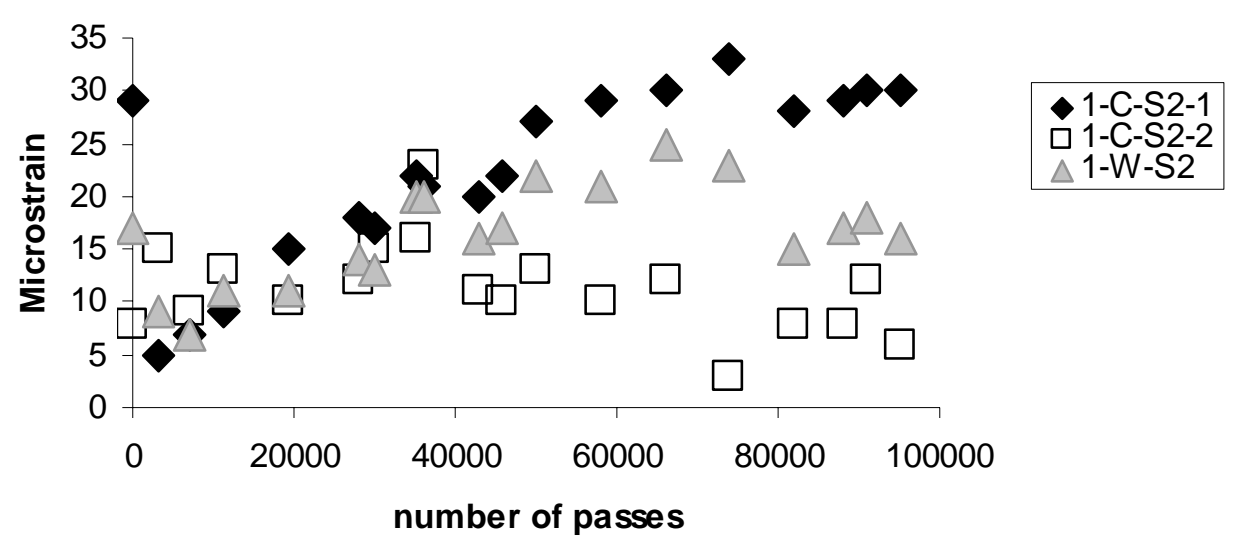

Figure 4.20 Variation of longitudinal strain in the adjacent lane with number of passes

From Figure 4.21 it can be observed that the trends in the permanent strains in the longitudinal gages installed in both the test lane as well as the adjacent lane is very similar. The magnitude of the strains in the top of the concrete is almost equal for both the gages. However, the strains at the bottom of concrete are higher for the gage located on the test lane. This may be attributed to the fact that the gage in the test lane was subjected to the wheel load more directly than the gage in the adjacent lane. 


\section{Comparison of permanent strains in the test lane and the adjacent lane}

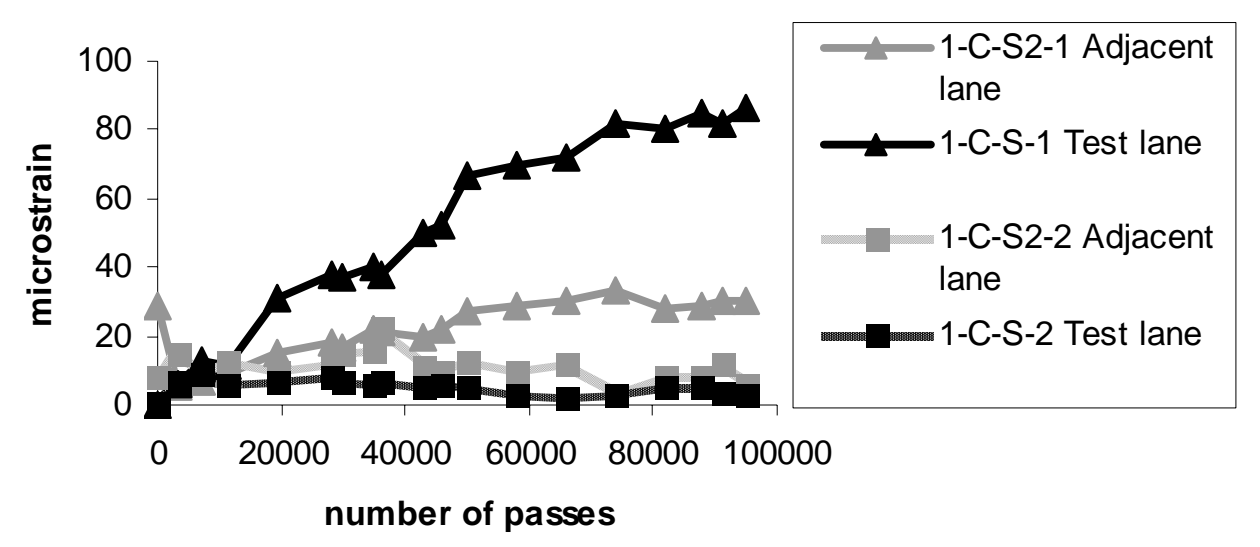

Figure 4.21 Comparison of permanent strains at the top and bottom of the concrete overlay in longitudinal gages in the test lane and the adjacent lane

\subsubsection{Summary of analysis of lane 1}

The analysis of data from lane 1 indicates that the magnitudes of the strains and deflections were not very high. The permanent strains and deflections accrued after 100,000 passes were also low. There was an increase in the magnitude of the dynamic strains after the increase in load from $12,000 \mathrm{lbs}$ to $20,000 \mathrm{lbs}$. The dynamic strains also showed the phenomenon of reversal of strains due to the motion of the wheel across the gage in the wheel path.

\subsubsection{Data analysis of lane 3}

\subsubsection{Analysis of Dynamic Strains and Deflections}

The strains and deflections produced in lane 1 were low. It was therefore decided to test the thinner overlay to observe the effects of accelerated loading on it. After the test of the $100 \mathrm{~mm}$ (4") thick overlay in lane 1 was completed, the loading wheel was 
moved to lane 3 to test the $63 \mathrm{~mm}\left(2^{1 / 2}\right.$ ") thick overlay. Due to the reduced thickness of the overlay, it was decided to use the lower $(12,000 \mathrm{lbs})$ load during the entire testing period. Although 150,000 passes of the wheel were applied to lane 3, the data for the last 50,000 passes was lost due to operator error. Therefore, the section below presents only the analysis of the results for the first 100000 passes.

a) Longitudinal gages at the edge of the longitudinal joint within the test lane.

\section{(3-C-S-1, 3-C-S-2, 3-W-S)}

The data recorded by the gages at the edge of the longitudinal joint in lane 3 during the first pass are shown in Figure 4.22. The top gage in concrete (3-C-S-2) was found defective at the beginning of the test and did not register any strains. The bottom
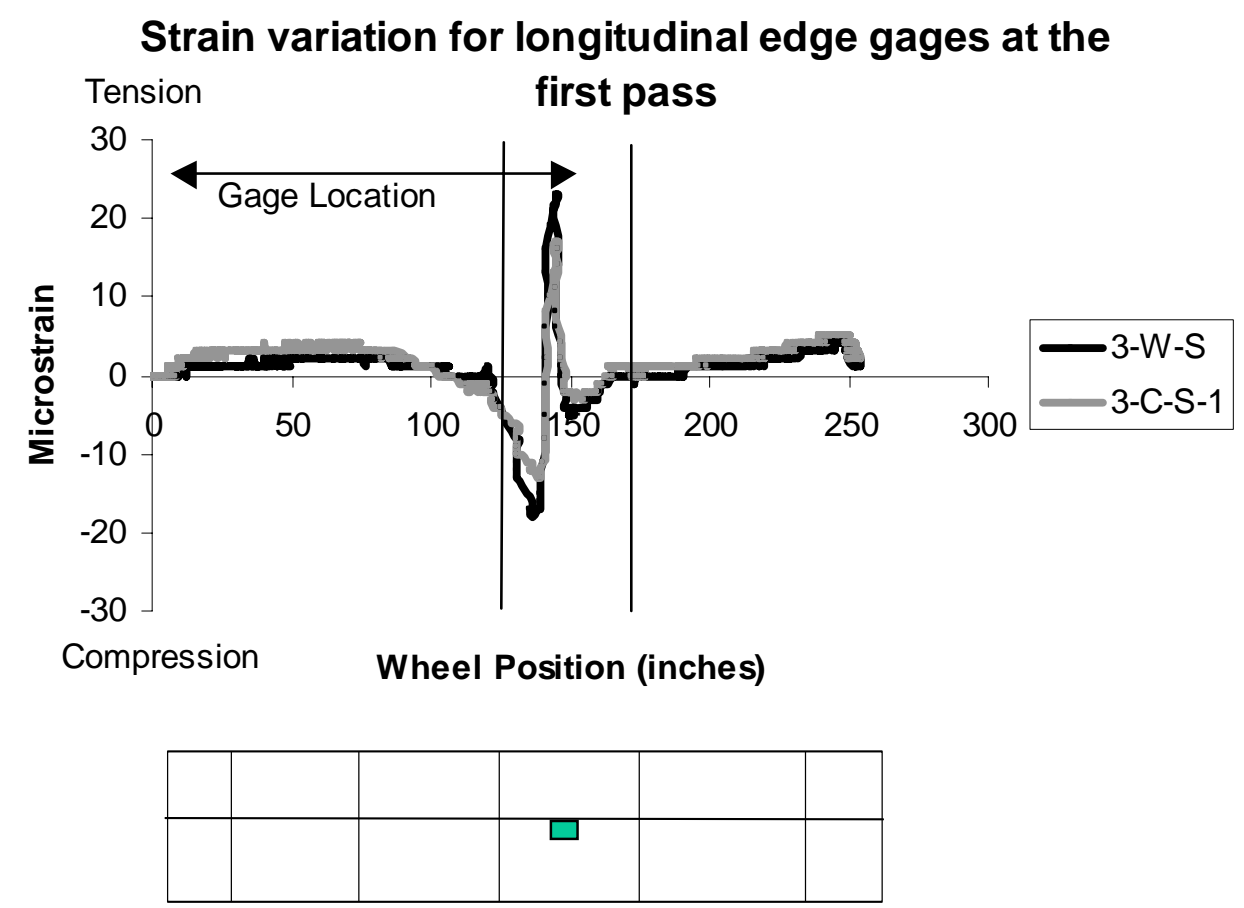

Figure 4.22 Typical strain response of edge longitudinal gages under the moving wheel during the first pass 
gage in concrete (3-C-S1) and the gage at the top of milled asphalt (3-W-S) show tensile strains as the wheel passes exactly on top of them. These gages show a compressive strain, just before the wheel passes exactly on top of the gage. This is similar to the reversal response of the corresponding gages in lane 1. However, the reversal immediately after the wheel passes over the gage is not as pronounced as that in lane 1 . The strains recorded by both gages were very similar in magnitude, the gage at the asphalt (3-W-S) showing a slightly higher strain value than the gage at the bottom of the concrete (3-C-S-1). Figure 4.23 shows the gage response of the above gages at the $100,000^{\text {th }}$ pass. The dynamic strains did not change very much after 100,000 passes and was very similar in magnitude.

\section{Strain variation for longitudinal edge gages at the 100000th pass}
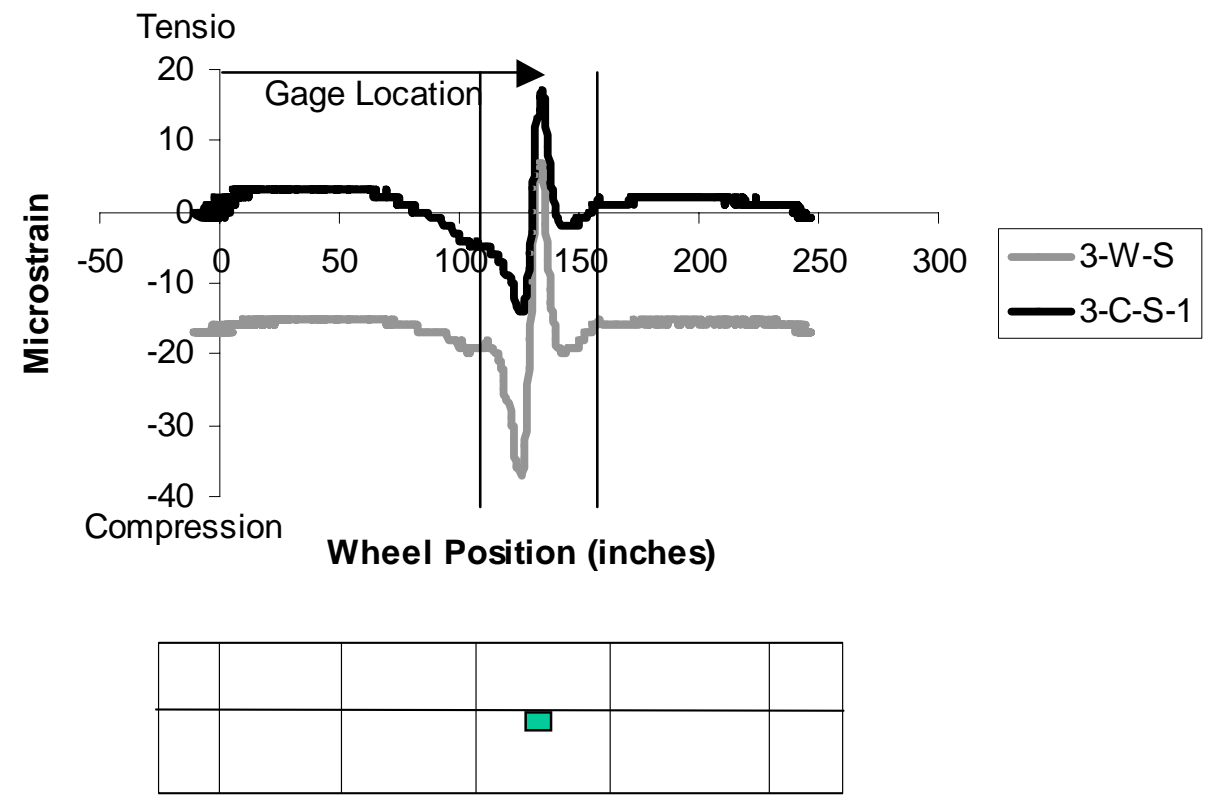

Figure 4.23 Typical strain response of edge longitudinal gages under the moving wheel during the $100000^{\text {th }}$ pass 


\section{Magnitudes of maximum dynamic tensile and compressive strain in 3-C-S-1}

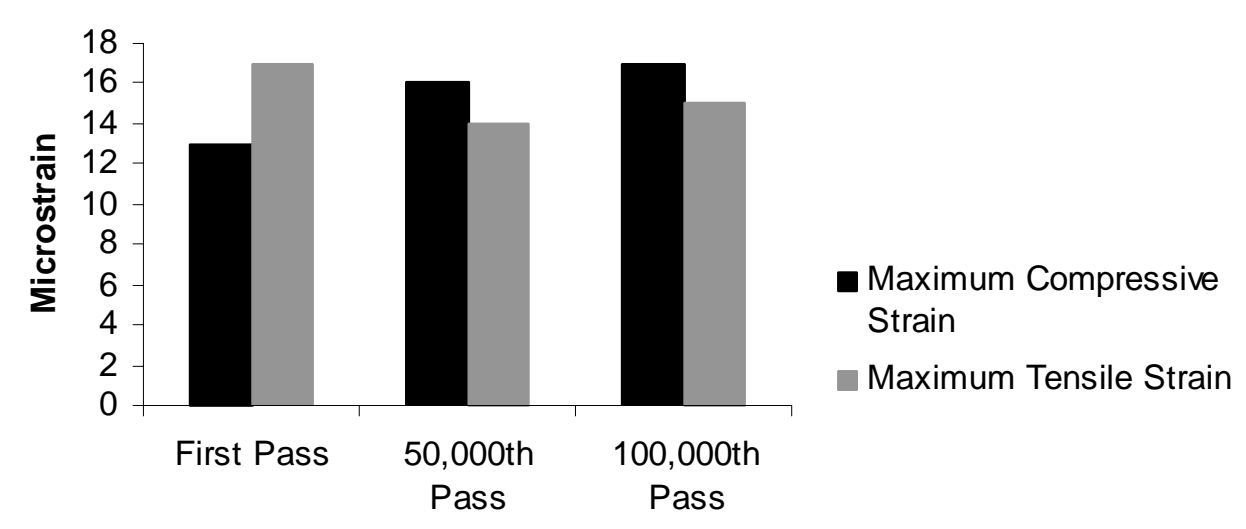

Figure 4.24 Change in maximum dynamic compressive and tensile strains in gage $3-\mathrm{C}-\mathrm{S}-1$

Figure 4.24 shows the magnitudes of the maximum dynamic tensile and compressive strains recorded by the gage at the bottom of the concrete. The magnitudes of the strains are almost constant with the increasing number of repetitions of the wheel loads. The tensile strains show a slight decrease after 50,000 passes. The dynamic compressive strain however exceeds the tensile strain, which indicates the accentuated effects of the strain reversal.

b) Longitudinal gages in the middle of the slab (3-C-M-1, 3-C-M-2, 3-W-M)

The typical response of these gages is shown in Figure 4.25. It can be seen that this response was similar to the response of the gages at the edge of the longitudinal edge described in part "a" above. 


\section{Strain variation for longitudinal mid-panel gages at first pass}

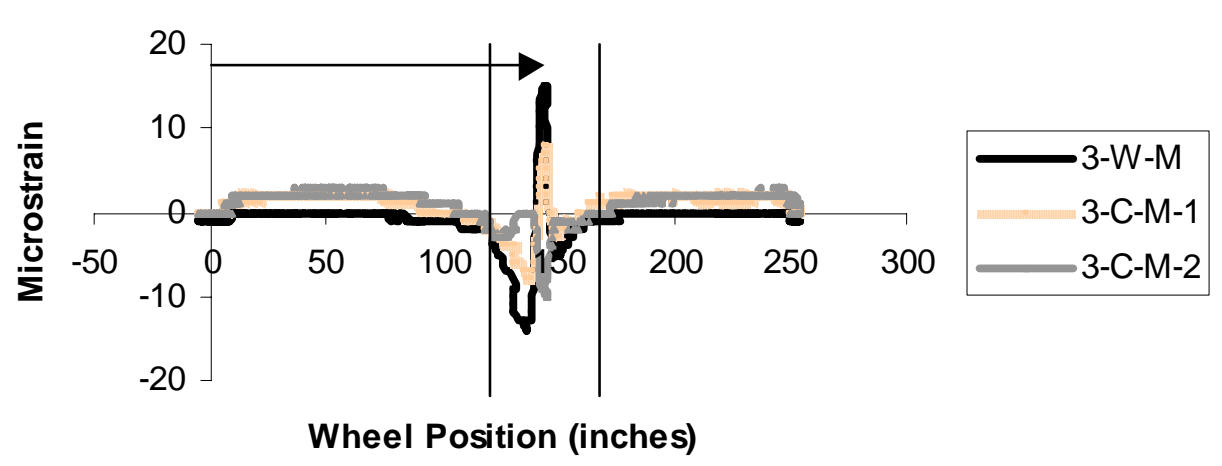

Figure 4.25 Strain response of mid-panel longitudinal gages under the moving wheel at the first pass

Figure 4.26 shows the magnitudes of the maximum dynamic tensile and compressive strains recorded by the gage at the bottom of the concrete. The magnitudes of the tensile strains are seen to be almost constant with the increasing number of repetition of the wheel load. The compressive strains show a slight increase after 50,000 passes and exceeds the tensile strain, which again indicates the pronounced effects of the phenomenon of strain reversal.

\section{Maximum dynamic tensile and compressive strain in gage 3-C-M-1}

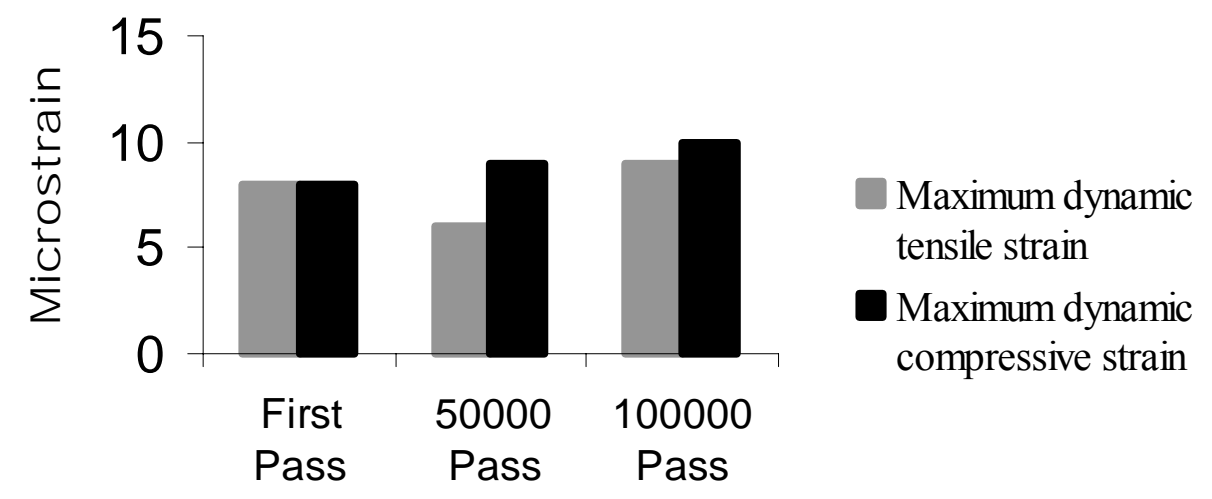

Figure 4.26 Change in maximum dynamic compressive and tensile strains in gage 3-C.-M-1 
c) Longitudinal gages at the edge of the longitudinal joint in the lane adjacent to loaded test lane (3-W-S2, 3-C-S2-1, and 3-C-S2-2)

Figure 4.27 shows the dynamic strain response of these gages after 100,000 passes. These gages registered a very scattered response during the initial passes primarily because the strain values were low and comparable in magnitude to the signal due to the noise in the instrumentation. Therefore, the graph showing the strain response after the first pass has been discarded. After about 50000 passes the pattern of the response was much more, clear. All the gages showed a compressive dynamic strain as the wheel was passing across the location of the gages. Since the gages were located on the adjacent (unloaded) lane, the wheel did not physically pass over the gages.

\section{Dynamic strain response of longitudinal edge gages in the adjacent lane at the 100000 th pass}

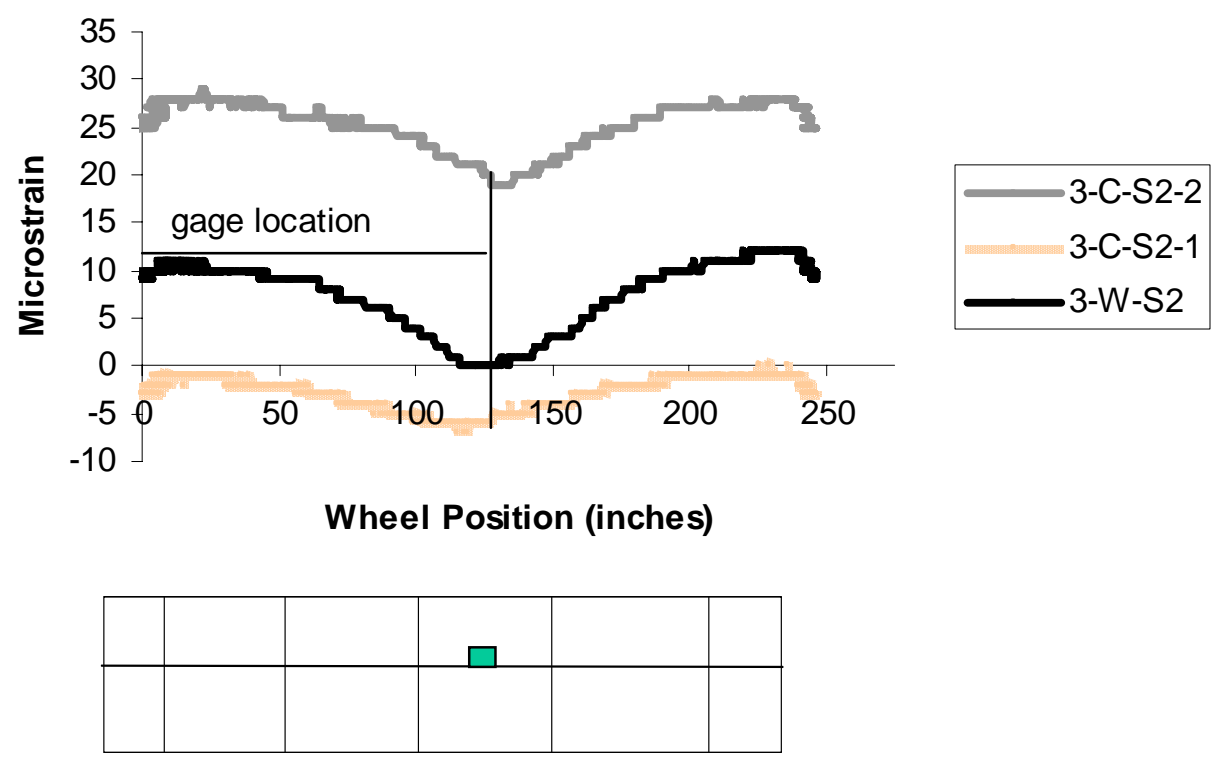

Figure 4.27 Strain response of longitudinal gages in the adjacent unloaded lane under the moving wheel at the $100,000^{\text {th }}$ pass 
d) Transverse gages at the edge of the transverse joint in the middle of the panel (3-W-T, 3-C-T-1, 3-C-T-2)

Figure 4.28 shows the strain response of the transverse gages at the $100,000^{\text {th }}$ pass. The response for these gages was very scattered in the beginning of the test because of low strain values. The response stabilized after around 70,000 passes. The top gage in concrete (3-C-T-2) showed a compressive strain whereas the bottom gage in concrete (3-C-T-1) and the gage on the asphalt surface (3-W-T) showed a tensile strain as the wheel passed across the location of the gage. A strain reversal was observed in the gage on the asphalt surface.

\section{Dynamic strain response of transverse gages at the 100000th pass}

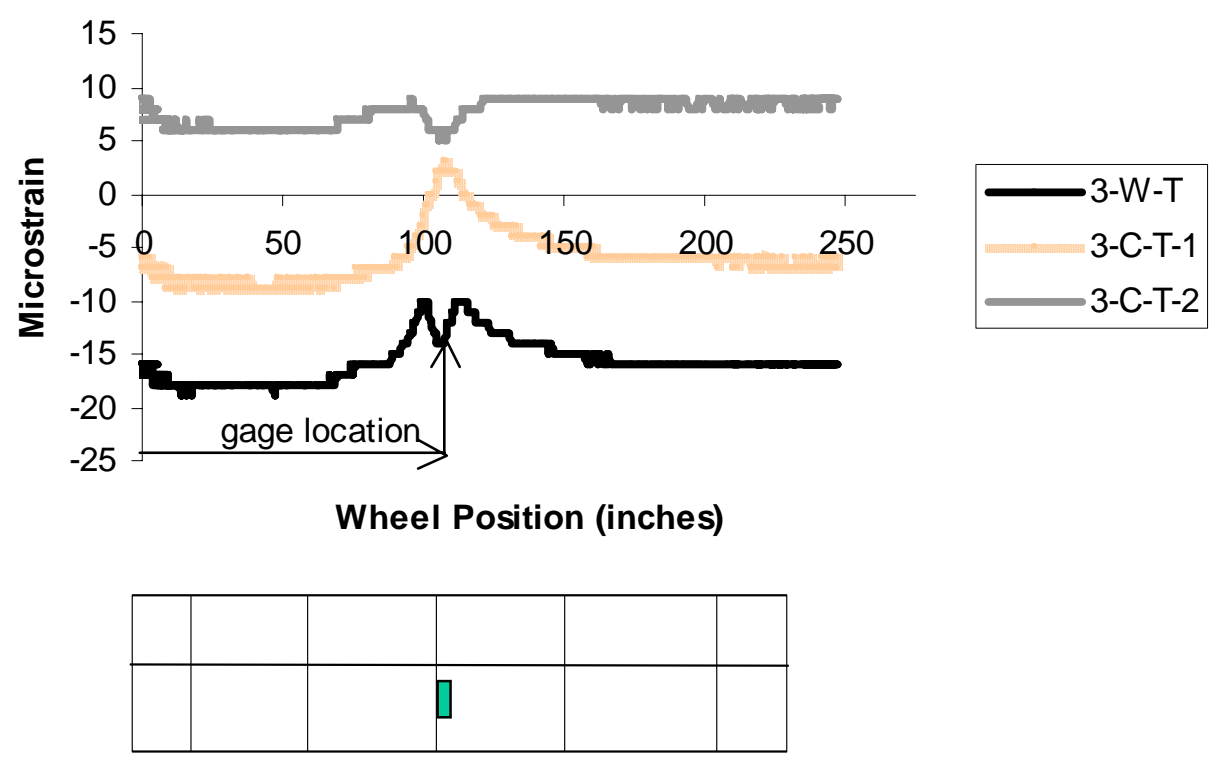

Figure 4.28 Transverse gages strain variation at the $100,000^{\text {th }}$ pass 
e) Bottom rosette at the corner of the panel (3R1L, 3R1T, 3R1I)

During the initial pass of the wheel, all three legs of the rosette show tensile strains when the wheel load passes over them (see Figure 4.29). The rosette data also show a strain reversal. The gages record a compressive strain just before the wheel passes over them. The strains become tensile when the wheel is immediately over the rosette and as the wheel moves on to the next panel, all three legs of the rosette again register a tensile strain. The longitudinal leg of the rosette (3-R-1-L) was damaged after about 3000 passes. However, the transverse (3-R-1-T) and the inclined (3-R-1-I) legs of the rosette were functional until the end of the test.

\section{Dynamic strain response of bottom rosette at the corner of the panel 3 at first pass}

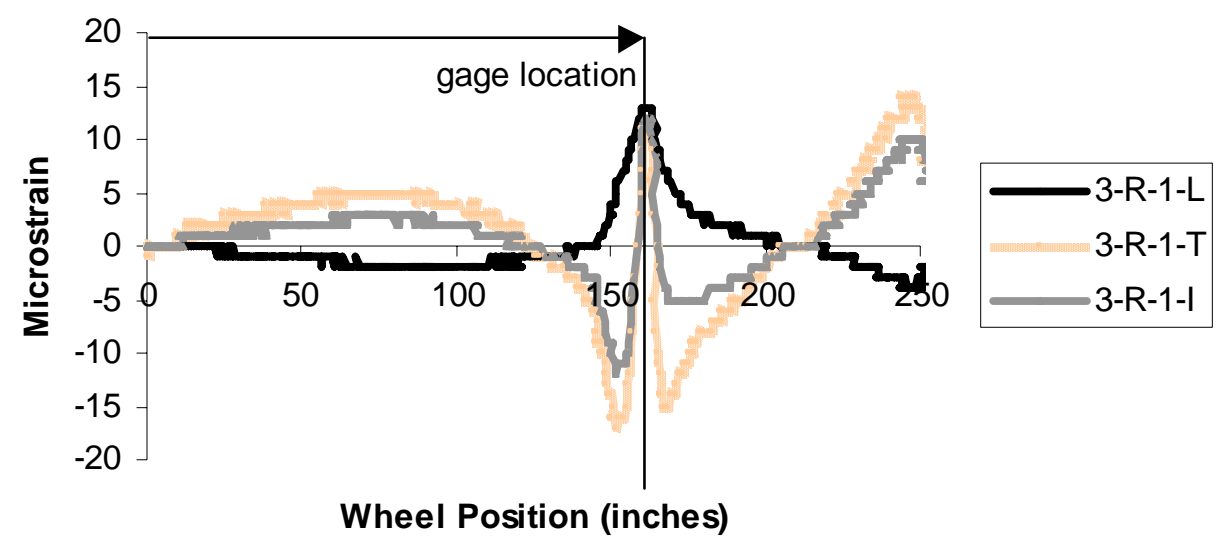

Figure 4.29 Strain Response of the bottom rosette in lane 3 due to the moving wheel at the first pass

Figure 4.30 shows the strain response of the rosette at the $100,000^{\text {th }}$ pass. The magnitudes of the maximum dynamic strains do not show much change compared to the first pass. There is shift in the base strain for the inclined gage (3-R-1-I). This could be 
attributed to an electrical shift in the response of the gage. The reversal in strains observed in these gages is not very large in magnitude.

\section{Dynamic strain response of bottom rosette at the corner of panel 3 at the 100000th pass}

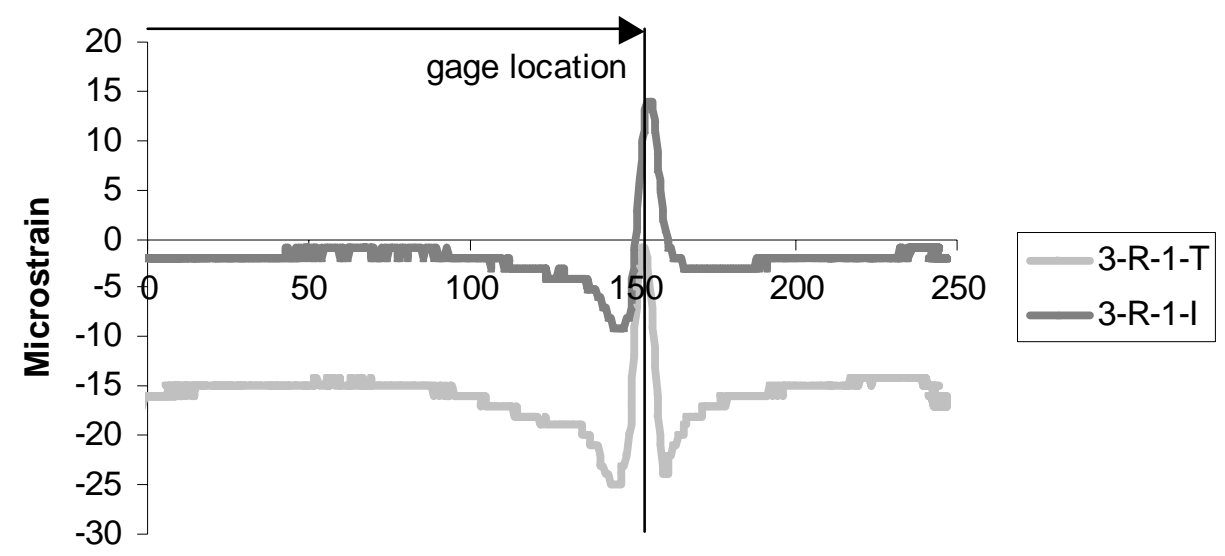

Figure 4.30 Strain response of bottom rosette in lane 3 due to moving wheel at the $100,000^{\text {th }}$ pass

\section{f) Deflections}

The deflection data obtained from the LVDT sensors was very scattered and the deflections measured values were very small (to the order of 0.0001 "). This was later attributed to the malfunctioning of the LVDT's measurement set up and as a result, the data from the LVDT's have been excluded from this analysis.

\subsubsection{Comparison of strains in Lane 1 and Lane 3}

The data from lane 1 and lane 3 can only be compared for the first 30,000 passes as the test was carried out at $12,000 \mathrm{lbs}$ for both lanes. After 30,000 passes, however the load was increased to 20,000 lbs for lane 1 . The comparison of dynamic strains from both lanes is shown in Figure 4.31. For the particular graph, the corresponding gages 
being compared were near the longitudinal joint in panel 3 , located at the bottom of concrete. From the Figure it can be observed that the strains in lane 3 were correspondingly higher than those in lane 1. This was because of the difference in thickness of the overlays in the lanes. Also the compressive strains in lane 3 were greater than those in lane 1 indicating that the phenomenon of strain reversal was more pronounced on the thinner overlay.

\section{Comparison of dynamic strains in lane1and lane 3}

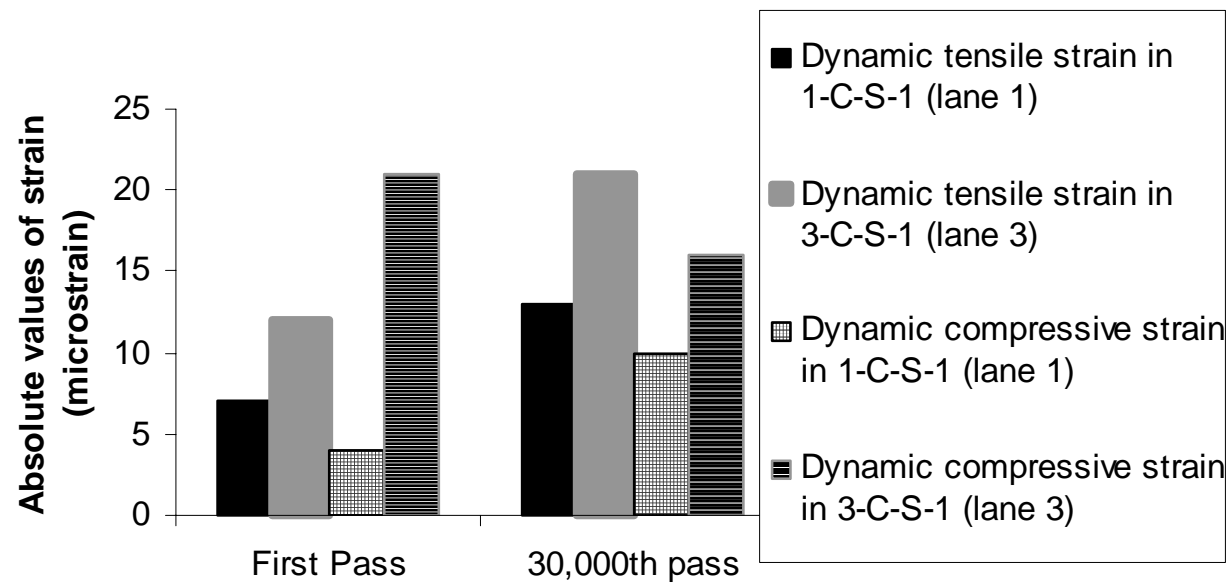

Figure 4.31 Comparison of maximum dynamic strains in lane 1 and lane 3

\subsubsection{Permanent Strains and Deflections}

The permanent strains measured in lane 3 were very scattered and did not follow any explainable trends. As a representative sample, Figure 4.32 shows the variation of permanent strains in the gages located at the longitudinal edge. These gages showed the maximum dynamic strains and the corresponding gages showed the maximum permanent strains in lane 1. The response shows very low magnitude of strains and lot of scatter. 
The response of the other gages in lane 3 showed similar scatter and low magnitudes which leads to the conclusion that there were no permanent strains formed in lane3.

The strains in lane 3 were caused only because of the temperature change in the slab during the course of the test. This is in contrast to lane 1, where permanent strains accrued due to repeated loading. From the residual strains observed in all the gages in Lane 3, it could be concluded that no permanent strain was caused because of the repeated wheel loading.

\section{Permanent strain variation for gages at the longitudinal edge}

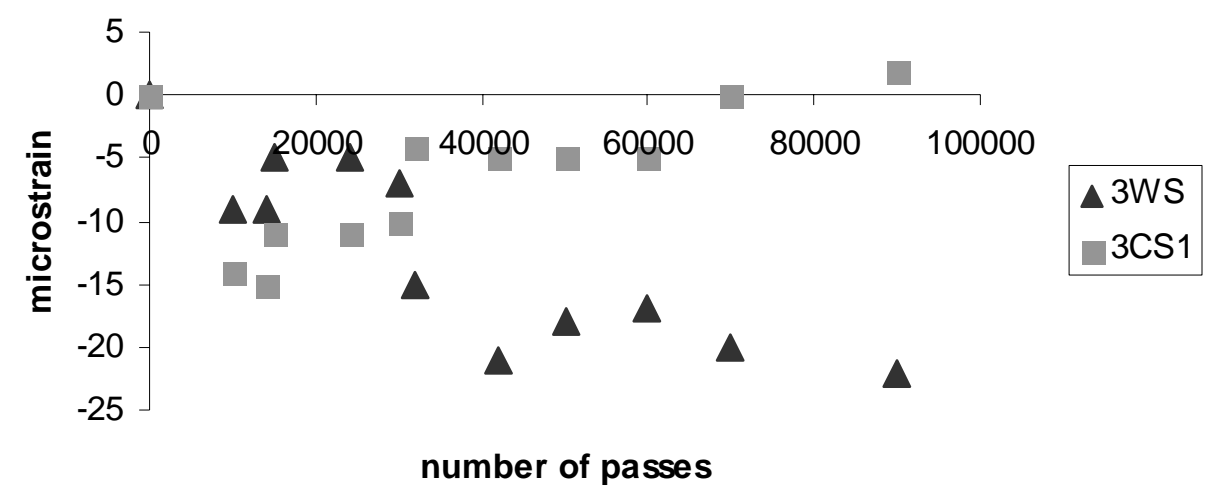

Figure 4.32 Comparison of permanent strains in longitudinal edge gages in lane 3

\subsubsection{Summary of data analysis of lane 3}

The data analysis of lane 3 showed that that there was not much variation in dynamic strains with increase in load repetitions. This is in contrast to what was observed in lane 1 . It could be therefore concluded that the $12,000 \mathrm{lbs}$. load did not cause much distress to the pavement. In addition, there was no development of permanent strains in lane 3. The corresponding dynamic strains in lane 3 were higher than the ones measured for the same gages in lane1, which could be explained by the presence of a 
thinner overlay in lane 3. The phenomenon of strain reversal was observed in this lane also.

\subsubsection{Data analysis of lane 4}

After testing lane 3 at 12,000 lbs, it was decided to test lane 4 under the increased load of 20,000 lbs. This was because the strains and deflections produced in lane 3 were very low and the effect of repeated loading did not cause much distress to the pavement. Lane 4 was tested at ambient temperature for the first 100,000 passes. Since the loading did not cause much increase in strains, it was decided to increase the temperature of the slab to accelerate the distress caused to the pavement. The details of the elevated temperature testing are discussed in section 4.2.3.1.

\subsubsection{Elevated temperature testing}

The increase in the temperature of the pavement was accomplished by circulating hot water. The heating continued until the pavement reached the temperature of $130^{\circ} \mathrm{F}$. The loading also continued while the pavement was being heated. Thus by the time the temperature reached $130^{\circ} \mathrm{F}, 140,000$ passes of wheel load had been applied to the pavement. The heating was then turned off for the next 20,000 passes. During this time, the temperature of the pavement dropped to about $95^{\circ} \mathrm{F}$. After 160,000 passes, the heating was turned on again and remained on until 200,000 passes was reached. The heating was then turned off again. This procedure resulted in two cycles of heating and cooling that were applied to lane 4 . The temperature variation with the number of passes is shown in Figure 4.33 . 
Temperature variation vs number of passes

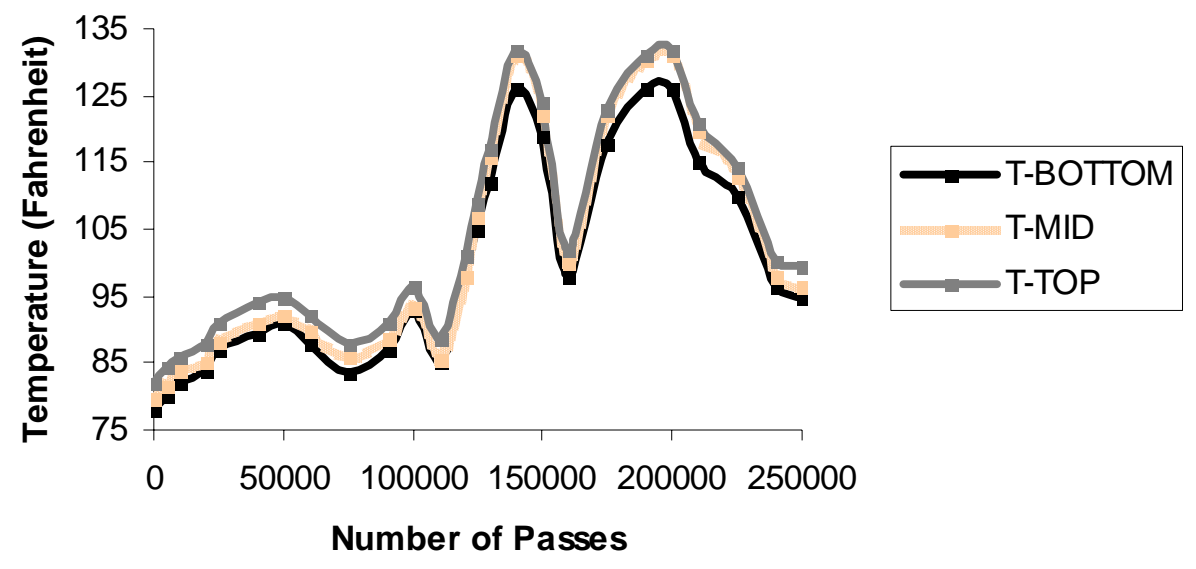

Figure 4.33 Temperature variation in lane 4

\subsubsection{Analysis of Dynamic Strains and Deflections}

a) Longitudinal gages at the edge of the longitudinal joint within the test lane.

(4-C-S-1, 4-C-S-2, 4-W-S)

The response of these gages after the first pass is shown in Figure 4.34. It can be observed that this response is similar to the response of the corresponding gages in the other two previously described lanes (1 and 3). The gages showed a strain reversal both before and after the wheel passed over the gage location. This was especially pronounced in the gage on the asphalt surface $(4-\mathrm{W}-\mathrm{S})$. The initial dynamic strains were higher than those observed in lane 3 because of the application of 20,000 lbs wheel load. 


\section{Dynamic variation of longitudinal edge gages under $20000 \mathrm{lbs}$ at the first pass}

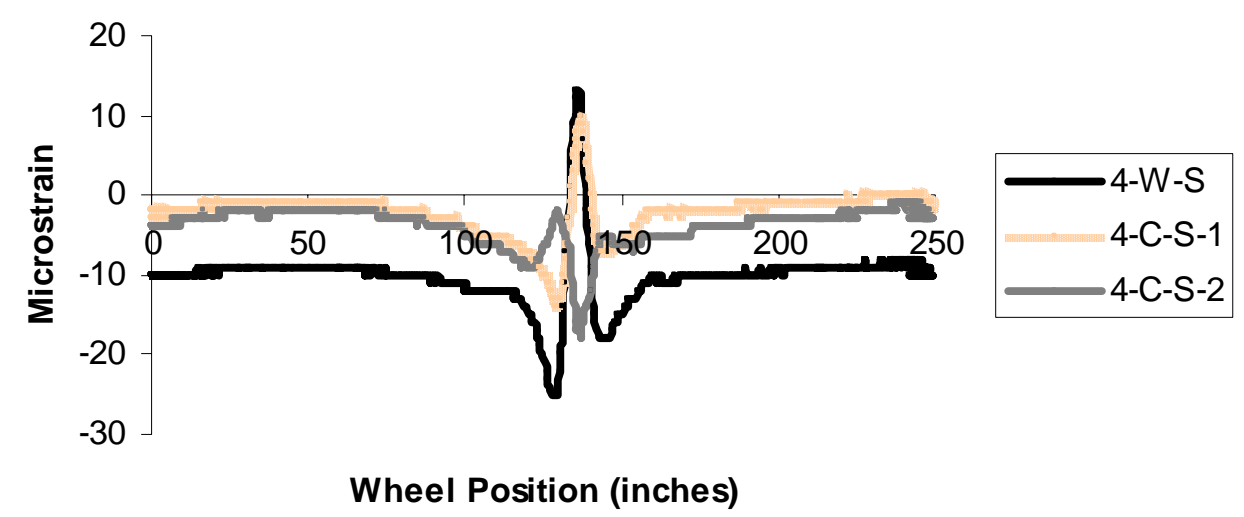

Figure 4.34 Dynamic strain variation in longitudinal edge gages at the first pass

Figure 4.35 shows the variation of the dynamic strains at the top of the asphalt surface (recorded by gage 4-W-S) at the edge of the longitudinal joint. The dynamic strains for the gages have been represented only by the absolute values of strain (the negative sign associate with compressive strain has been discarded). As indicated by the Figure 4.35 , the departure of the strain values from the base value occurs at about 110,000 passes. The dynamic strains increased considerably with increase in the temperature of the slabs. The strain reversal was also accentuated due to the increase in the slab temperature. The second peak in Figure 4.35 indicates this point, as the maximum compressive strain (caused by strain reversal) is greater than the maximum dynamic tensile strains. 


\section{Variation of dynamic strains in gage 4-W-S with number of passes}

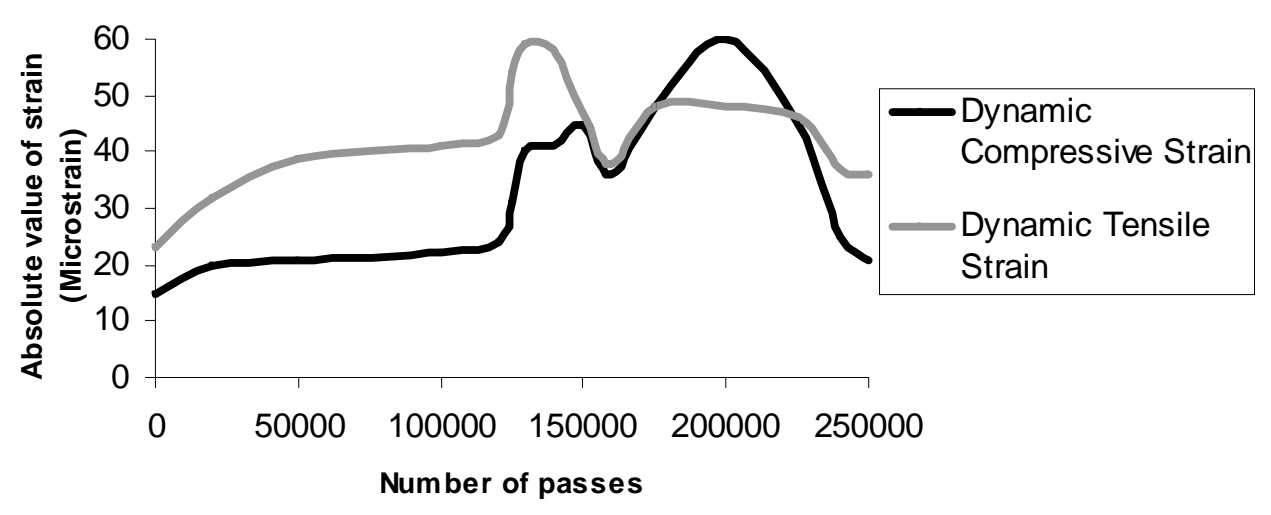

Figure 4.35 Variation of dynamic strains in gage 4-W-S with number of passes

Figure 4.36, which shows the dynamic strain variation for the gage at the top of the slab located at the edge of the longitudinal joint (4-C-S-2). By comparing the curves shown in Figure 4.36 and the temperature variation shown in Figure 4.33, it can be observed that the trend in the strains follows the trend in the temperature variation. As the temperature increased, the values of the dynamic strains also increase and vice a versa. The dynamic tensile strain shown by this gage exceeds the dynamic compressive strain after the number of passes corresponds to the first and second heating cycles. As a result, the critical strain in the slab shifts from the bottom of the slab to the top of the slab due to the increase in the dynamic tensile strain at the top. 


\section{Variation of dynamic strains in gage 4-C-S-2 with number of passes}

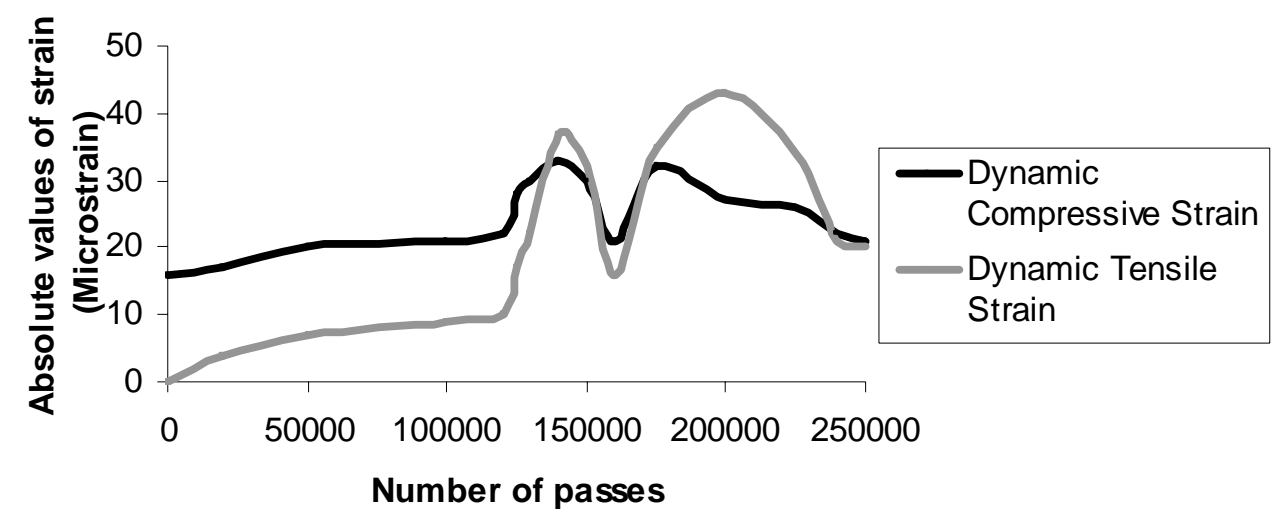

Figure 4.36 Variation of dynamic strain in 4-C-S-2 with number of passes

b) Longitudinal gages at the mid panel within the test lane.

(4-C-M-1, 4-C-M-2, 4-W-M)

The Figures 4.37 and 4.38 show the variation of the dynamic strains with the number of passes for the gages located on the asphalt surface and at the bottom of the concrete overlay, respectively. The response of these gages was similar to the gages along the longitudinal edge, discussed above. These gages also showed increasing strains as the temperature of the slab increased. The strain reversal phenomenon was observed in these gages as well. Since the magnitude of the tensile strains was greater than the compressive strains, it could be concluded that the tensile strains are the critical strains at this location. The increase in the compressive strains as the wheel moves is an indication of the pronounced effect of the strain reversal phenomenon. Also, by comparing the data shown in Figures 4.37 and 4.38 it can be seen that the dynamic strains have higher magnitude at the asphalt surface than at the bottom of the concrete overlay. 


\section{Variation of dynamic strain with number of passes in gage 4-W-M}

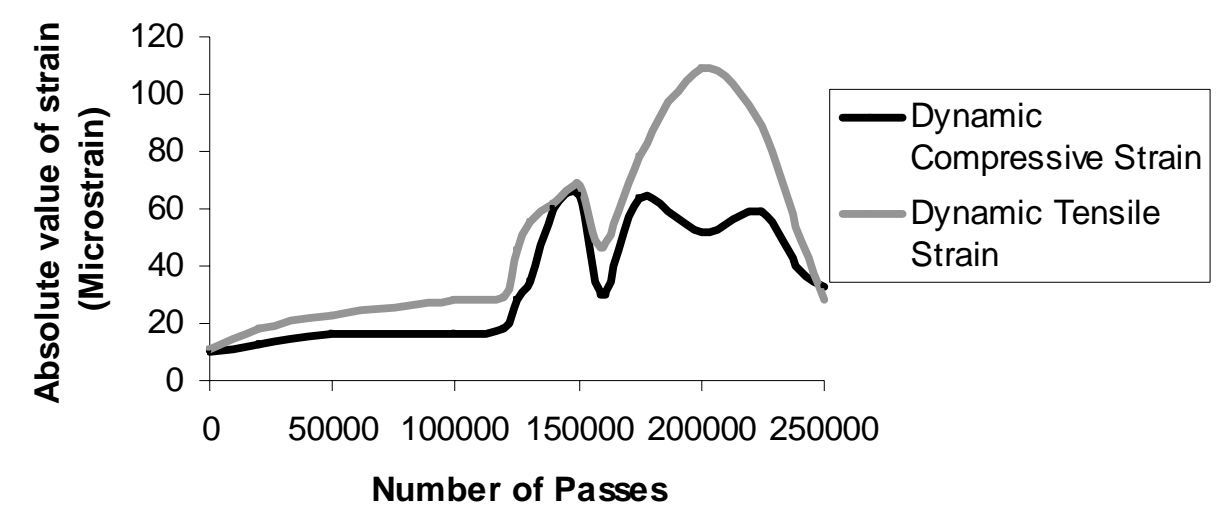

Figure 4.37 Variation of dynamic strains in gage 4-W-M with number of passes

\section{Variation of dynamic strains with number of passes in gage 4-C-M-1}

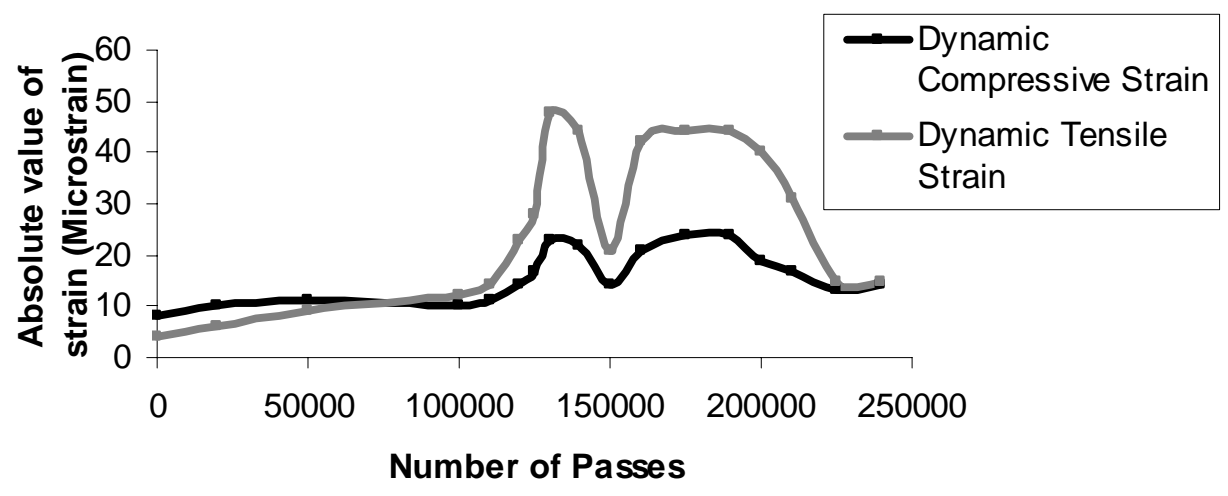

Figure 4.38 Variation of dynamic strains in gage 4-C-M-1 with number of passes

Figure 4.39 shows the variation of the dynamic strains shown by the gage located in the top of the slab (4-C-M-2). This gage registers a compressive strain as the wheel passes over the gage location. During the initial part of the test carried out at room temperature, the phenomenon of strain reversal was not observed, as the dynamic tensile 
strains are almost zero. As the slab is heated, the tensile strains increase rapidly to over 100 microstrains. The critical (tensile) strain shifts from the bottom to the top of the slab in the mid panel. It can also be seen that the reversal strains (tensile strains) exceed the compressive strains caused by the load when the wheel is exactly over the location of the gage.

\section{Variation of dynamic strain with number of passes in gage 4-C-M-2}

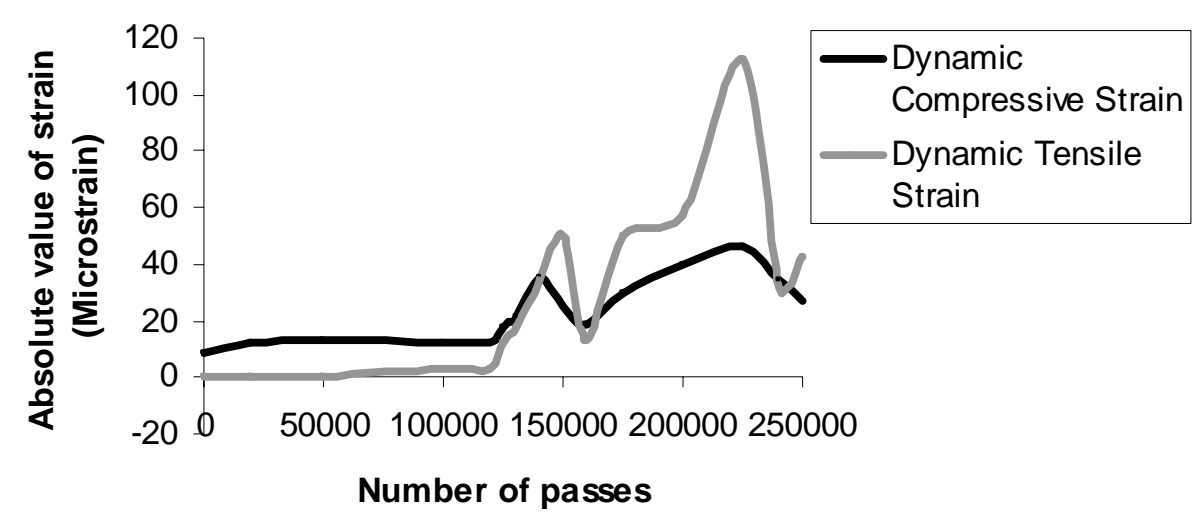

Figure 4.39 Variation of dynamic strain in 4-C-M-2 with number of passes

Figure 4.40 shows the variation of the total dynamic strain for the gages located at the center of the slab. The total dynamic strain can be defined as the algebraic sum of the absolute values of maximum (tensile) and the minimum (compressive) values of dynamic strains. From Figure 4.40 it can be observed that the strains indicated by the gage located at the bottom of the concrete (4-C-M-1) do not vary as much as the strains indicated by gages located at the top of the asphalt (4-W-M) and the top of the concrete (4-C-M-2). The low magnitude and the low variation of the total dynamic strain indicated by the 
bottom gage (4-C-M-1) could be a result of the neutral axis shifting down. This indicates that the UTW slab and the underlying asphalt are acting as a composite section.

\section{Total dynamic strain variation for mid-panel gages with number of passes}

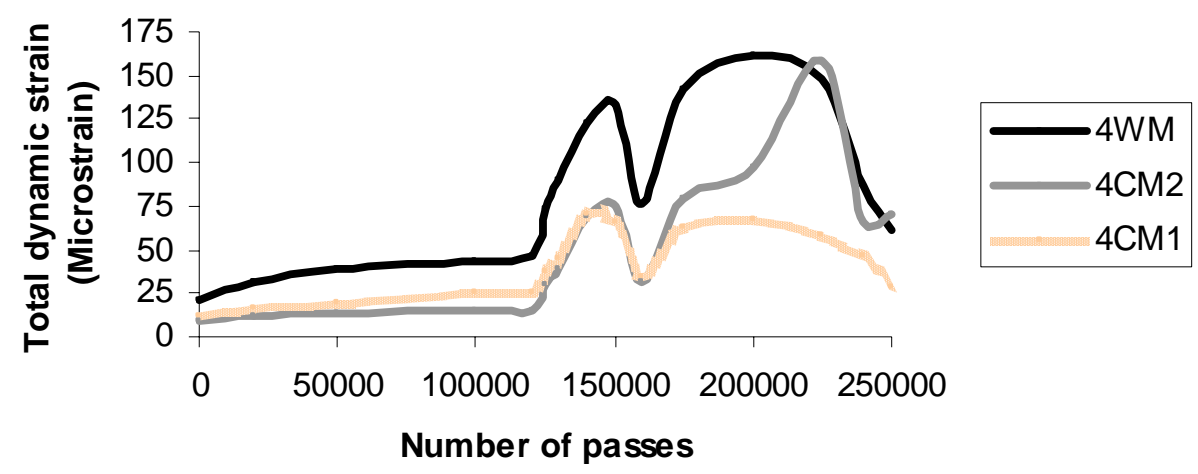

Figure 4.40 Variation of total dynamic strain in mid panel gages with number of passes

c) Longitudinal gages at the edge of the longitudinal joint in the lane adjacent to loaded test lane (4-W-S2, 4-C-S2-1, and 4-C-S2-2)

These gages showed similar response as the gages on the edge of the longitudinal joints as discussed previously. A representative sample of strain data obtained from these gages is shown in Figure 4.41 (the variation was similar all throughout the test). The figure shows the variation in strains during the first pass. The bottom gage in concrete (4-C-S2-1) and the gage on top of the asphalt (4-W-S2) show tensile strains whereas the top gage in concrete (4-C-S2-2) shows compressive strains as the wheel passes near the gages. 


\section{Dynamic strain variation of longitudinal gages in the adjacent lane at the first pass}

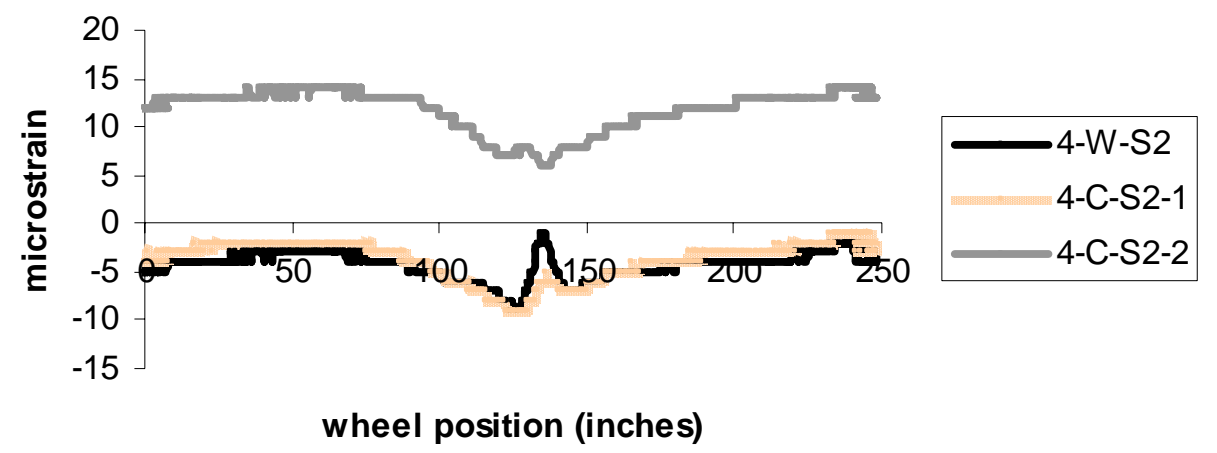

Figure 4.41 Variation of strain in the longitudinal gages in the adjacent lane at the first pass

d) Transverse gages at the edge of the transverse joint in the middle of the panel (4-W-T, 4-C-T-1, 4-C-T-2)

Figure 4.42 shows the strain response of the transverse gages during the $100,000^{\text {th }}$ pass. The variation of strain in these gages was similar to that shown by the other gages located in the same lane. The bottom gage in concrete (4-C-T-1) and the gage on the asphalt surface (4-W-T) showed a tensile strain as the wheel passed across the location of the gages. A strain reversal was observed in the gage on the asphalt surface only. The top gage in concrete (4-C-T-2) showed a compressive strain as the wheel passed across the gage location. 


\section{Dynamic strain variation of transverse gages in Lane 4 at the 100000th pass}

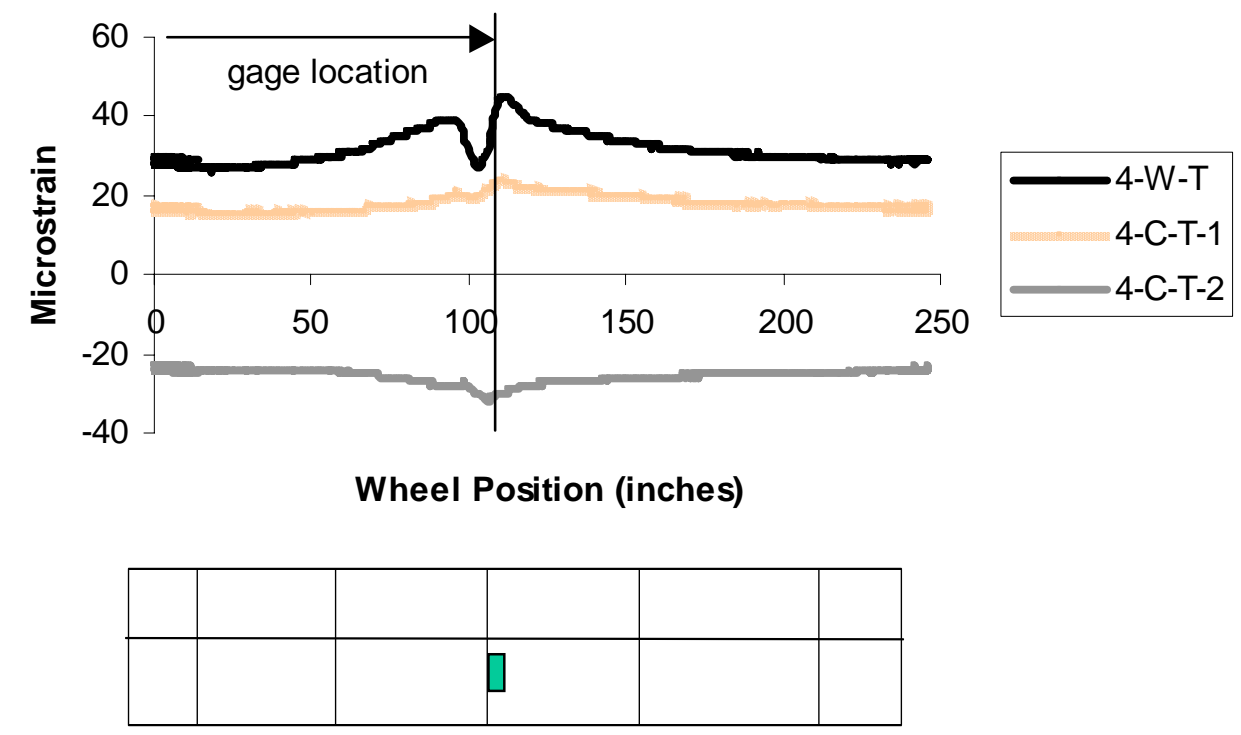

Figure 4.42 Variation of dynamic strain in transverse gages at the $100,000^{\text {th }}$ pass

e) Bottom rosette at the corner of the panel (4-R-1-L, 4-R-1-T, 4-R-1-I)

The variation of strains recorded by this rosette (shown in Figure 4.43) is similar to the variation in strains recorded by rosettes in other lanes. A tensile strain developed in all legs of the rosette as the wheel was passing over the corner of the panel. All gages of the rosette show the maximum magnitude of strain as the wheel passes over the gage location. This trend remained constant throughout the test. The strain reversal phenomenon was observed only in the longitudinal leg of the rosette (4-R-1-L). The transverse (4-R-1-T) and the inclined legs (4-R-1-I) of the rosette show a higher strain than the longitudinal leg of the rosette. The stresses that develop at the corner of the panel are very complex and lead to the high strain values. 


\section{Strain response of rosette at the 100000th pass}

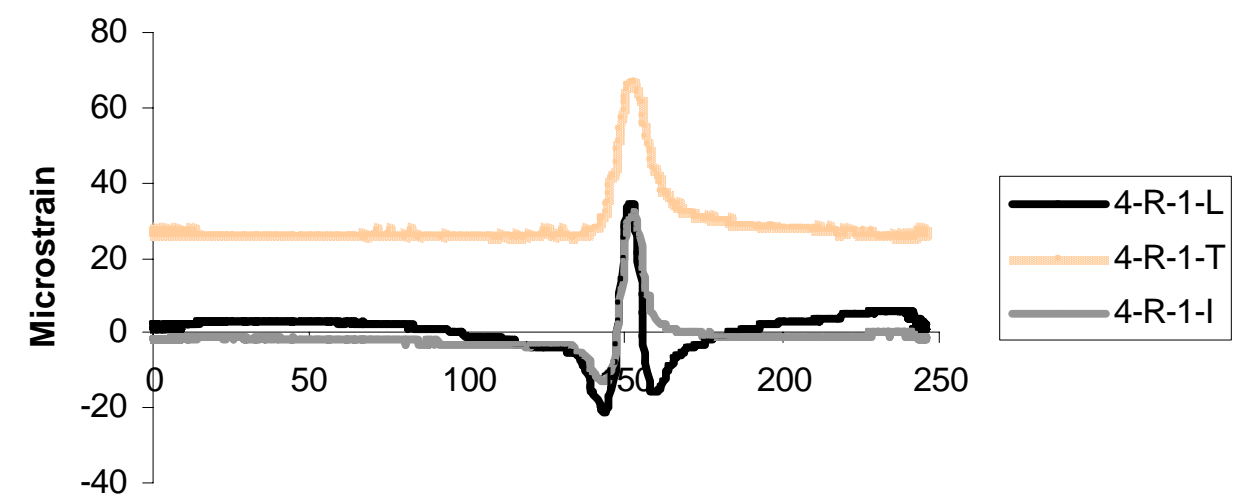

Wheel Position (inches)

Figure 4.43 Variation of dynamic strain in rosette at the $100000^{\mathrm{tn}}$ pass

The variation in total dynamic strain was high (in the order of a few hundred microstrain) as shown in Figure 4.44. The transverse leg of the rosette showed the maximum value and the longitudinal leg showed the minimum value of total dynamic strain. The increase in the strains corresponds with the increase in the temperature of the slabs.

\section{Variation of total dynamic strain with number of passes for strain gage rosette}

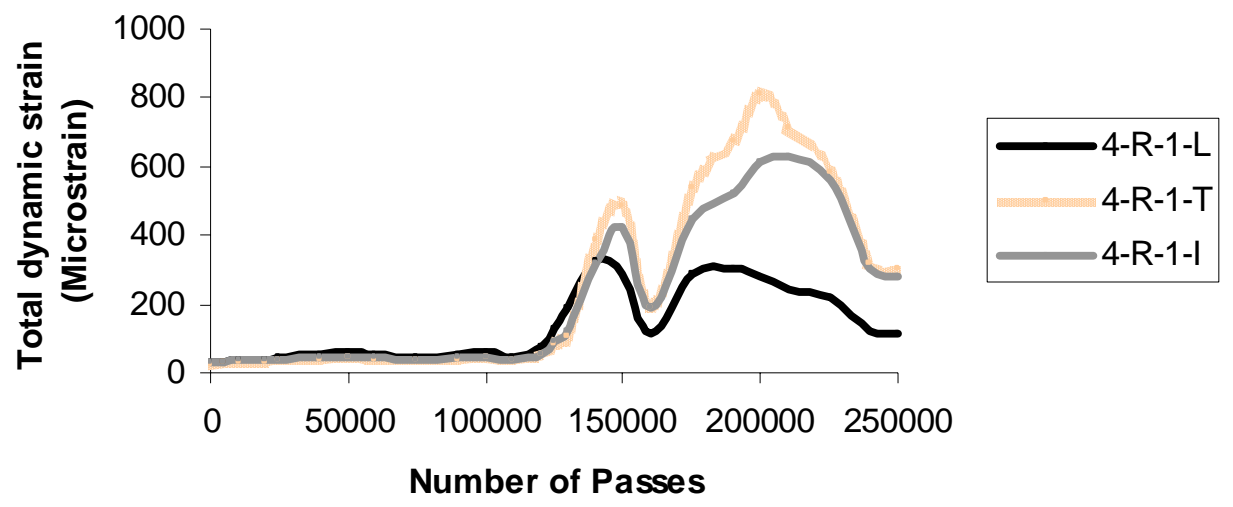

Figure 4.44 Magnitude of total dynamic strain in strain gage rosette with number of passes 


\section{$\underline{\text { 4.2.3.3 Permanent Strains and Deflections }}$}

The variation of the permanent strains with the number of wheel passes is seen Figures 4.45 - 4.47 for the mid-panel gages, longitudinal edge gages and the rosette, respectively. The strains generated by the increase in the temperature of the slab increased did not disappear when the temperature of the slab was lowered. The strains on the asphalt surface were the highest among all strains shown in Figures 4.45 and 4.46. In Figure 4.45, the permanent strain at the asphalt surface was about 375 microstrains after 250,000 passes. For other gages at the same location, the strains in the top and the bottom of the concrete overlay were around 175 microstrains. For the gages at the longitudinal edge (as seen in Figure 4.46) the asphalt surface gage recorded a maximum strain of over 330 microstrains, whereas the gages in concrete showed values of around 120 microstrain and 30 microstrain at the bottom and top of the overlay, respectively. The permanent strain on the asphalt surface was around 500 microstrains. As shown in Figure 4.47, in case of the rosette, the strains in all the gages in concrete stabilized around 380 microstrain. As can be seen from all the figures (Figures $4.45-4.47$ ), a significant increase in the permanent strains occur at the time when the temperature of the slab is increased indicating that the permanent strains were affected more by the temperature increase than by the cycles of load application.

\subsection{Analysis of data from the static wheel load tests}

As already discussed in section 4.1, in addition to the dynamic load testing of the

UTW lanes, static load tests were also conducted on lanes 1, 3 and 4. Static load tests included stationing the wheel load at predetermined locations on the test slab and 
Variation of permanent Strain with temperature and number of passes for mid-panel gages (lane 4)

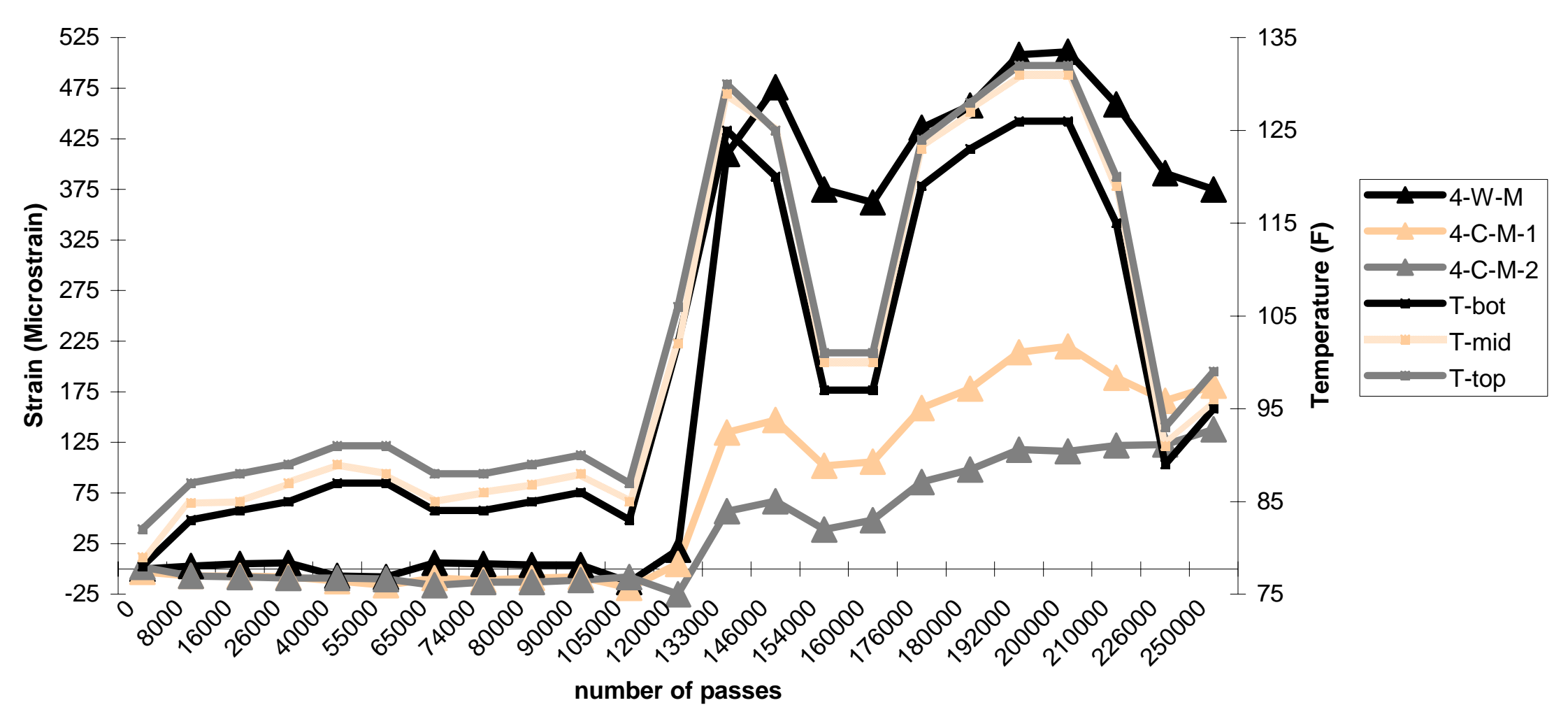

Figure 4.45 Temperature and permanent strain variation for mid-panel gages in Lane 4 


\section{Variation of Permanent Strain and Temperature with Number of Passes for} Longitudinal Edge Gages

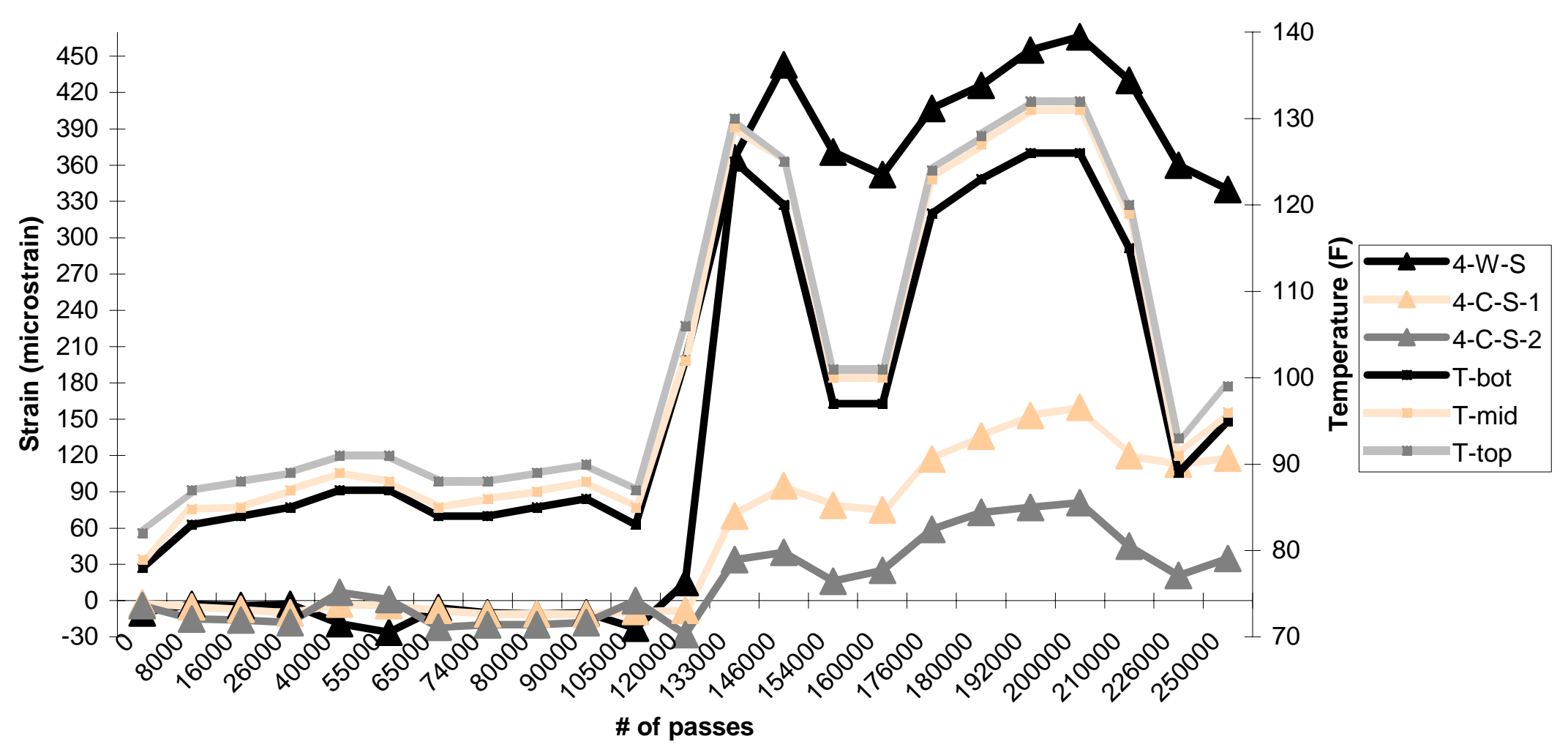

Figure 4.46 Temperature and permanent strain variation for longitudinal edge gages in Lane 4 


\section{Variation of Permanent Strain and Temperature with Number of Passes for Rosette}

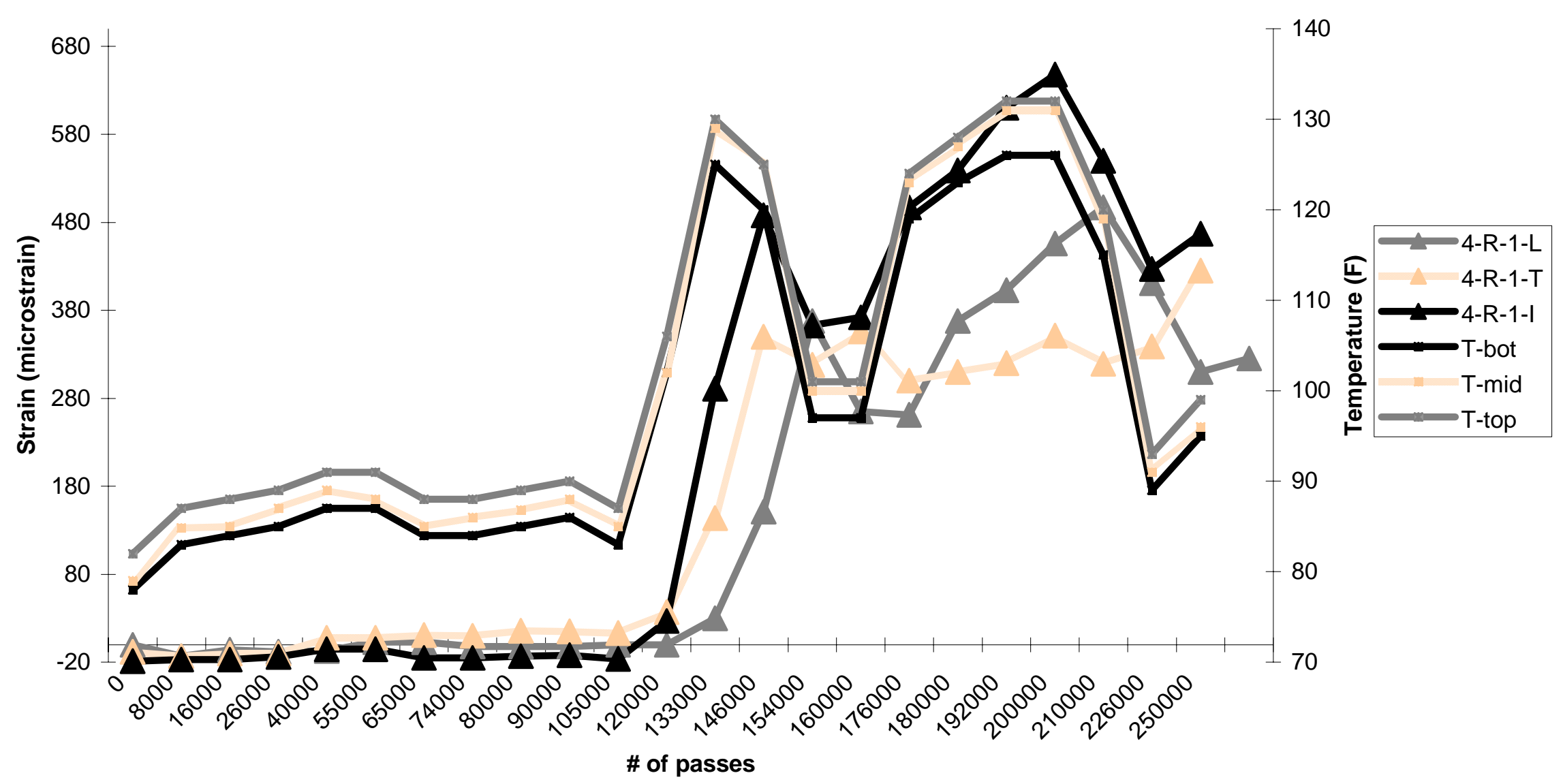

Figure 4.47 Temperature and permanent strain variation for strain gage rosette in Lane 4 
monitoring the strain response as the wheel load was placed and removed from the spot. It has been reported that for a given number of passes, the static strain is always greater than the dynamic strain observed in the pavement [7]. Therefore, static load tests were performed to estimate the maximum strains that would be caused due to the static wheel load. The static loading was carried out at two locations in each lane. These were:

a) Position 1: Longitudinal joint edge in the middle of the third panel. The wheel was located just over the strain gage assembly embedded in the pavement.

b) Position 2: Corner of the third panel. The wheel was placed directly over the strain gage rosette assembly.

Figure 4.48 shows the location of the static load tests conducted for a typical lane. The wheel was moved longitudinally to the position of the gages. The wheel load was applied to the pavement for 15 to 20 seconds after which time it was raised above the pavement. The data acquisition system measured the strains for approximately 45 - 60 seconds after the wheel was removed. The test was performed at both locations shown in Figure 4.48 at two different loadings of $12000 \mathrm{lbs}$. and $20000 \mathrm{lbs}$, respectively. The phenomenon of strain reversal did not take place when the wheel is lowered on to the pavement for making static measurements. 
Static Test Locations (Plan View)

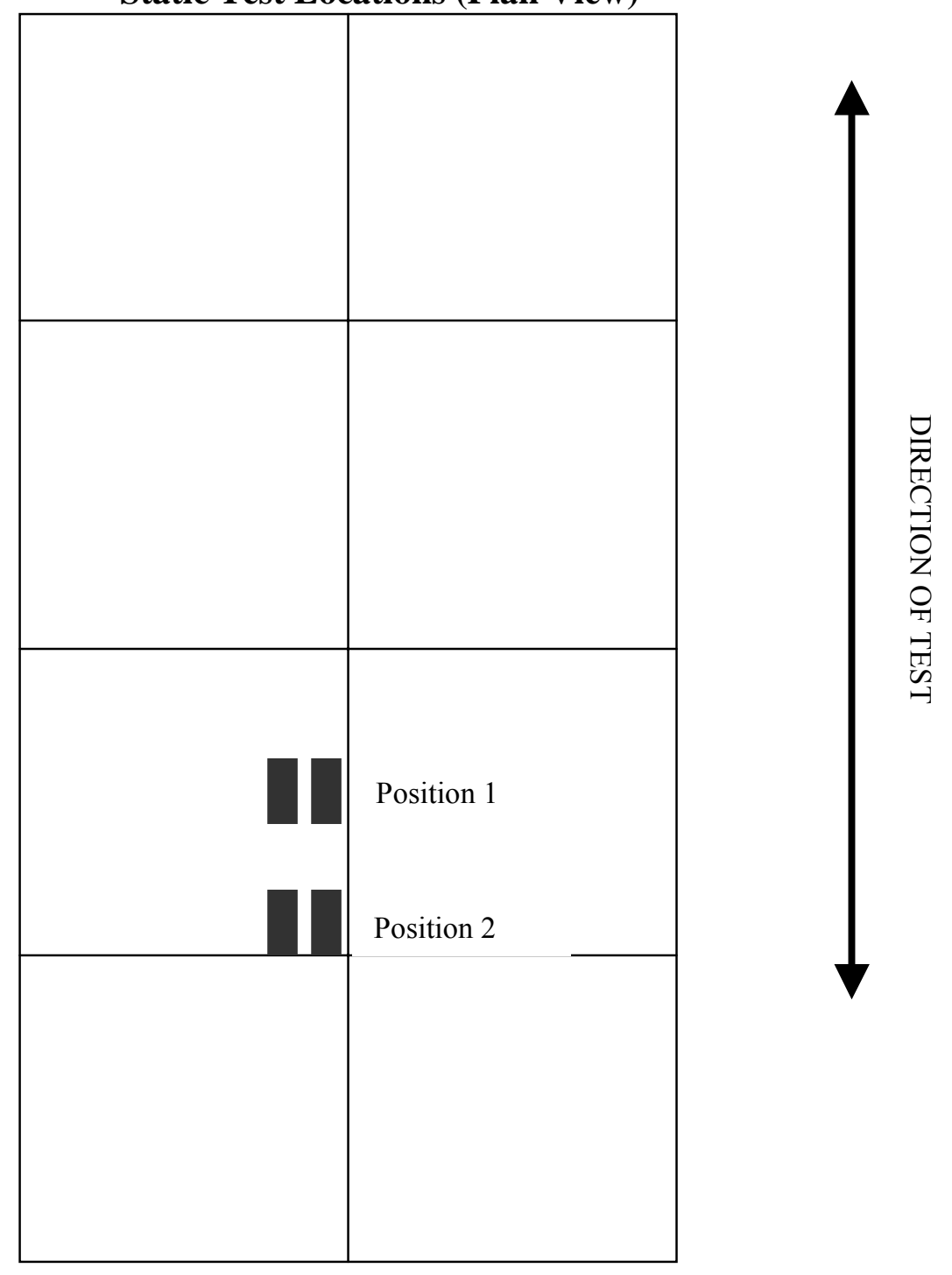

Figure 4.48 Plan view of static test location in the UTW pavement 
The highest value of strains due to the static tests were recorded on the gages at the longitudinal edge (wheel in position 1), the rosette at the corner of the panel (wheel in position 2) and the mid panel gages (wheel in position 1). The Figures 4.49 and 4.50 show the strains recorded by the longitudinal edge gages under static loading in lane 1 with the wheel in position 1 and 2, respectively. As expected, the gages located along the longitudinal edge responded differently to the change in the position of the loading wheel. When the wheel was positioned along the longitudinal edge of the panel (position 1), the gages under the wheel at the edge show a tensile strain at the bottom (1-W-S and 1-C-S-1) and a compressive strain at the top (1-C-S-2) (refer to Figure 4.49). When the wheel was positioned at the corner of the panel (position 2), the edge gages show a compressive strain at the bottom of the slab (1-W-S and 1-C-S-1) and a tensile strain at the top of the slab (1-C-S-2) (refer to Figure 4.50).

\section{Strain distribution at the longitudinal edge due to initial static loading at the edge @ 12000 lbs}

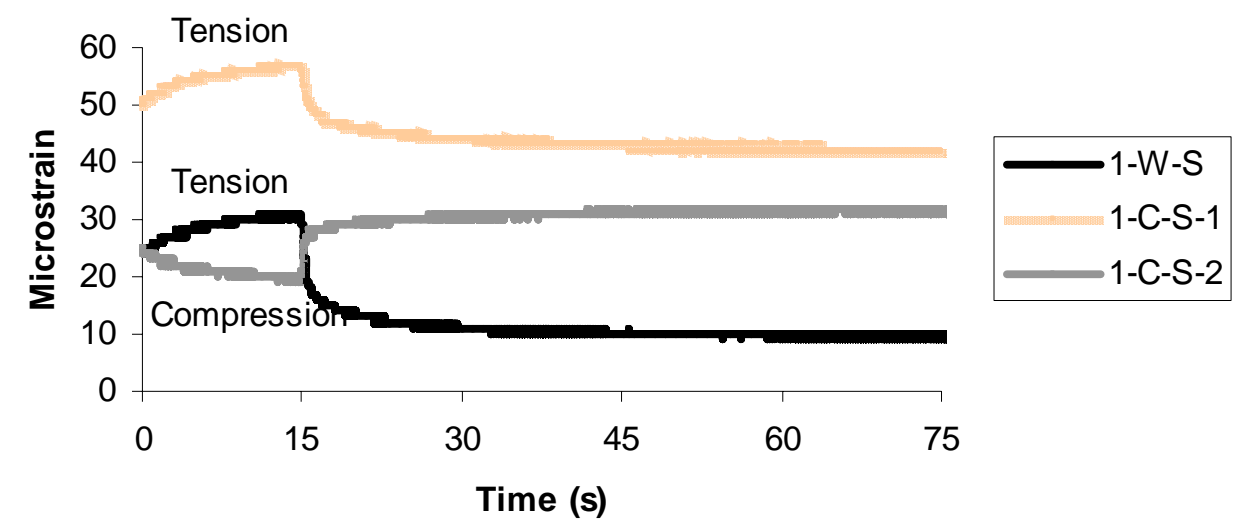

Figure 4.49 Initial strain response of longitudinal gages in lane 1 under 12000 lbs static load at position 1 


\section{Strain distribution at the longitudinal edge due to initial loading at position $2 @ 12000$ lbs}

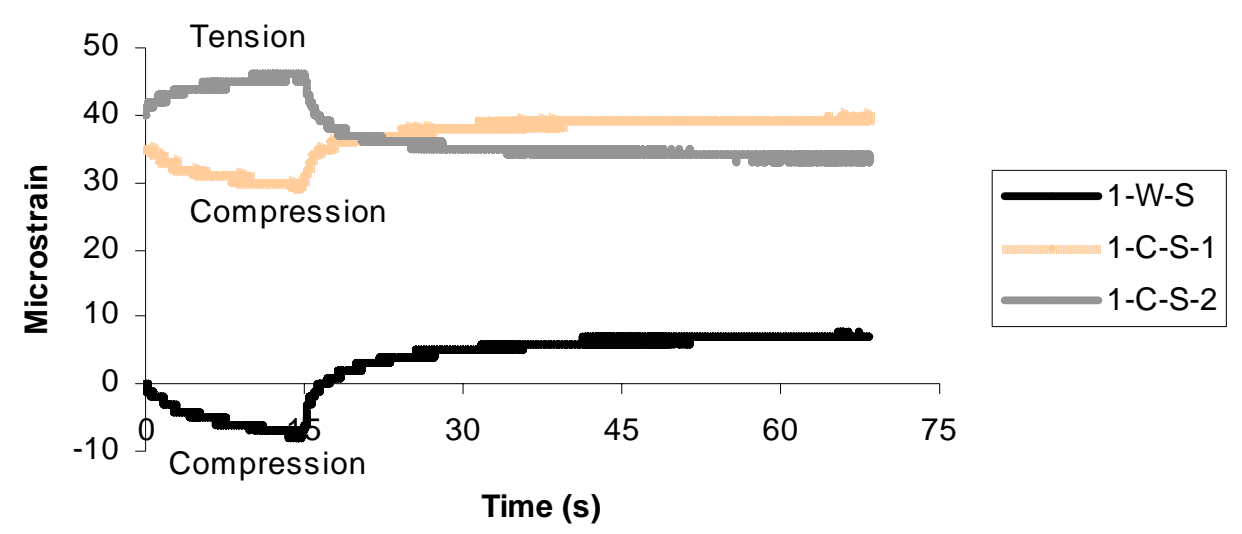

Figure 4.50 Initial static strain response of longitudinal gages in lane 1 under $12000 \mathrm{lbs}$ static load on position 2

Figure 4.51 shows the reduction of static strain as the accelerated testing progressed in lane 4. The reduction of strains in the bottom of concrete (4-C-S-1) and top of the asphalt (4-W-S) is an indication of the possible shift in the location of the neutral axis and thus providing an indirect evidence that the pavement is acting as a composite layer. The compressive strains at the top of the slab (4-C-S-2) remain almost unchanged, whereas the tensile strains in the bottom of the slab reduce. The change is largest at the bottom of the concrete, which suggests that the neutral axis could have shifted down due to the composite action. 


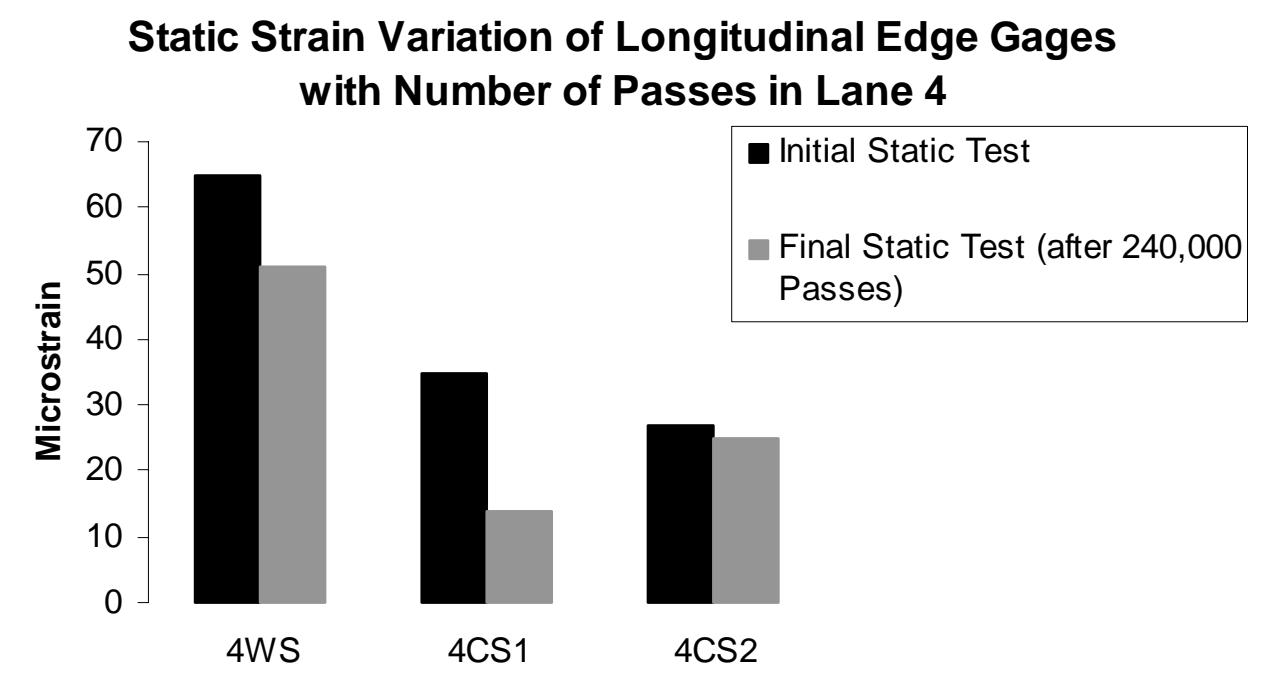

Figure 4.51 Static strain variation in edge gages with number of passes in lane 4

\subsubsection{Summary of data analysis of lane 4}

The analysis of data from lane 4 indicates a significant increase in the magnitudes of strains with the number of cycles. Both the dynamic strains as well as permanent strains showed an increase. The strains do not show an increase during the initial 100,000 passes when the test was carried out at ambient (room) temperature. The increase in the strains corresponds to the increase in the temperature of the pavement. This leads to the conclusion that the elevated temperature was the primary cause of the strain increase. The increase in temperature caused the magnitude of the reversal strain to increase in most cases. In those cases, it led to the shift of the critical tensile strains from the bottom of the slab to the top of the slab. The strains did not return to the original values even after the heating was turned off and the temperature dropped to ambient temperature. 


\section{$\underline{4.4 \text { Summary }}$}

The analysis of the data generated by the Accelerated Pavement Testing on Ultrathin Whitetopping led to the following observations and conclusions.

1) There was a phenomenon of strain reversal observed in the gages near the longitudinal joint (S-series), the mid panel gages (M-series) and the strain gage rosette (R-series) for all lanes. This was characterized by a sudden reversal in strains before and after the wheel passed over or near the location of the gage.

2) The dynamic strains and deflections in lane 1 were very low in magnitude initially when the lane was loaded with $12,000 \mathrm{lbs}$ load. When the load was increased to $20,000 \mathrm{lbs}$, there was a significant increase in strains and deflections. Some permanent strains were observed after 100,000 passes of the wheel.

3) The $12,000 \mathrm{lbs}$ load produced greater dynamic strains in lane 3 compared to lane 1. This was because of the thinner overlay used in lane 3. However, no significant permanent strains developed after 100,000 passes of loading.

4) The elevated temperature testing of lane 4 caused the significant increase in the dynamic strains in the pavement. The strains did not drop indicating that even after the slab was cooled to ambient temperature elevated temperature testing induced permanent strains in this lane. 


\section{QUALITATIVE ASSESSMENT OF THE UTW PAVEMENT CONDITION}

\section{$\underline{5.1 \text { Introduction }}$}

The accelerated testing of the UTW pavement did not lead to the obvious failure of any of the lanes. There were virtually no signs of visible distress on the pavement (except for some cracks in lane 1 and lane 4 (refer Figure 5.1)).

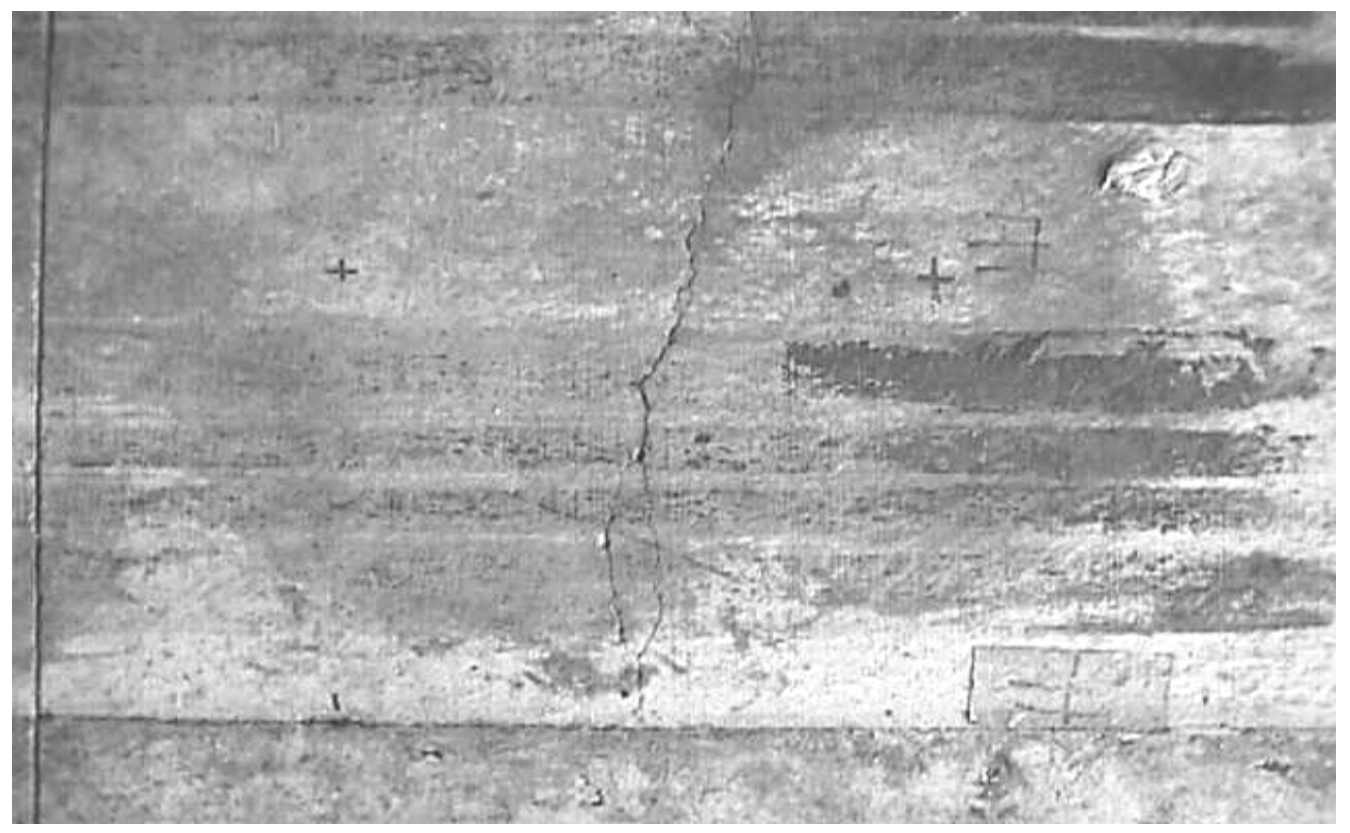

Figure 5.1 Cracks developed in lane 1 of the UTW pavement

However, the analysis of strains and deflections presented in chapter 4 showed that there might be some damage to the pavement at the micro level, perhaps in the form of either cracks that had developed in the pavement near the joints or the delamination of the interface between the overlay and the asphalt surface. It is postulated that the 
presence of such distress could explain the phenomenon of strain reversal. For this reason, there was a need to investigate the potential damage in more details. There was also a need to evaluate the feasibility of using non-destructive test methods such as ultrasonic pulse velocity, impact echo and acoustic emission for determining the degree of damage in the pavements. Such tests are relatively easy to perform and if successful may prove to be a useful tool to monitor the condition of UTW installations in the future. The impact echo and the acoustic emission tests were performed on the UTW pavement, but failed to produce robust data. As the result, the data produced from these tests could not be interpreted and only the results from the ultrasonic pulse velocity are presented and discussed in the following sections.

\section{$\underline{5.2 \text { Ultrasonic Pulse Velocity }}$}

\subsubsection{Description of the Ultrasonic Pulse velocity (UPV) method}

This non-destructive test method is based on determining the velocity of the ultrasonic wave in a given medium. The velocity of an ultrasonic pulse through a material is a function of the elastic modulus and the density of the material. In case of concrete as the quality of concrete deteriorates because of some distress, its elastic modulus decreases. The pulse velocity can therefore be used to assess the quality and uniformity of the material. The method is also useful in estimating crack depth and direction, and determining the thickness of surface layers. The ultrasonic pulse velocity (UPV) of a material can be determined by placing a piezo electric pulse transmitter on one face of the sample of the material, and a receiver on the opposite (or the same) face. A timing device measures the transit time of the ultrasonic pulse through the material. If 
the length of the path is known, the velocity of the pulse can be calculated by dividing the path length by the transit time. The accuracy of the method will depend on the geometry of the test, the width of the contact faces of the transducers and the frequency of the transducers. A degree of uncertainty is introduced by flat-faced transducers because the precise point of contact for maximum pulse transmission and reception is not known. For such transducers, the actual transmission and reception could happen anywhere within the area of the contact face.

The method is most accurate in direct transmission mode, where the transmitter and the receiver are placed directly opposite each other on parallel faces of the test piece, and the path length can be measured or calculated with a high degree of accuracy. A lesser degree of accuracy is achieved when the transmitter and the receiver are placed on mutually perpendicular faces of the test piece, such as the corner, due to the uncertainty of the true contact point. This is known as the semi-direct transmission. The method is least accurate when both the transmitter and the receiver are applied to the same face of the test piece. This is called the indirect transmission method. Due to the technical impossibility of accessing both sides of the pavement, the indirect method was used in this study.

\subsubsection{Test plan for the UPV tests}

The UPV testing at the APT facility was performed using the Ultrasonic Pulse Velocity Meter (subsequently referred to as the V-meter). The apparatus consists of two transducers, one that emits the ultrasonic wave (transmitter) and the other, which receives the wave (receiver). The two transducers are connected to a display unit which has a 
built in timing device which provides a direct read out of the time required for a pulse to travel from the transmitter to the receiver (pulse flight time). Before the measurements were made, the test lanes were divided into grids of size $300 \mathrm{~mm}$ x $300 \mathrm{~mm}$ (12” x 12”). The V-meter's transmitter and receivers were placed on the grid points and the flight times of the ultrasonic waves were recorded. Since lane 2 was not tested, it was excluded from the UPV evaluation. For the sake of convenience, the grid points were numbered using numbers and letters (as shown in Figure 5.2). None of the grid points was located closer than $150 \mathrm{~mm}$ (6") from the joints. This enabled the measurements of the flight times across the joints. The measurements were taken in both the transverse as well as the longitudinal directions. The longitudinal measurements along the length of the lane were used to determine the locations of the transverse cracks. Similarly, the transverse measurements gave an indication of the longitudinal cracks. In most cases, the transverse readings failed to give an indication of longitudinal cracking. Therefore, the transverse readings were not used in this analysis. Figure 5.2 shows the grid points in lanes 1, 3 and 4 and the coding system used. The thick dotted line indicates the discontinuity at lane 2 that was not included in the grid layout. The thick dark lines correspond to the locations of the transverse and longitudinal points. The points of intersections of the small dotted lines are the grid points and each is denoted by a letter followed by a number as shown in the Figure 5.2. 


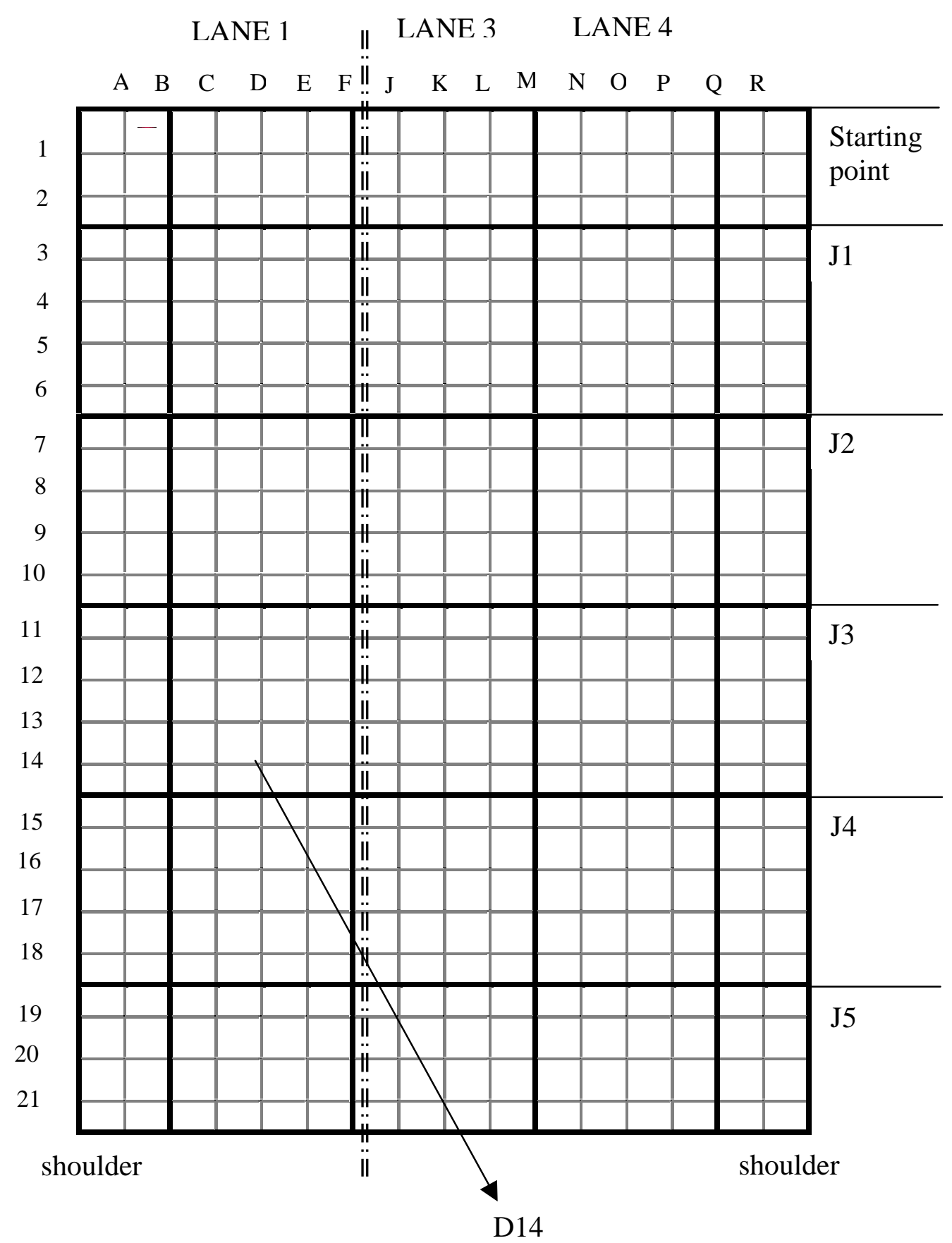

Figure 5.2 Plan view of grid layout for V-meter tests 


\subsubsection{UPV test results}

The V-meter tests were conducted at each of the grid points and yielded flight time data. This data was then used to create three-dimensional graphs with the pavement surface (length and width) being the first two dimensions and the flight time being the third dimension. In preparation for these plots, the flight time of $70 \mu \mathrm{s}$ was chosen to represent the reference plane for the lanes 1 and 3. Since all the values of the flight of time for lane 4 were higher than $70 \mu$ s, a value of $75 \mu$ s was selected as a reference value when plotting the results for this lane. The plot gave a variation of flight times over the surface of the pavement.

Figures 5.3 and 5.4 show the surface profile and front view of the flight time surface plot for lane 1. A significant increase in the flight times could be observed on the first, second and to a lesser extent on the fourth transverse joint on the lane. The third joints showed the lowest magnitude of the flight time. This can be clearly seen in the front view plot (Figure 5.4). The values of flight times ranged between $65 \mu$ s and $75 \mu \mathrm{s}$. The deviation from these values is observed only on the joint locations. The increase in the time of flight could be due to the potential existence of cracks at the locations. 


\section{Lane 1 V-Meter Time (Surface Profile)}

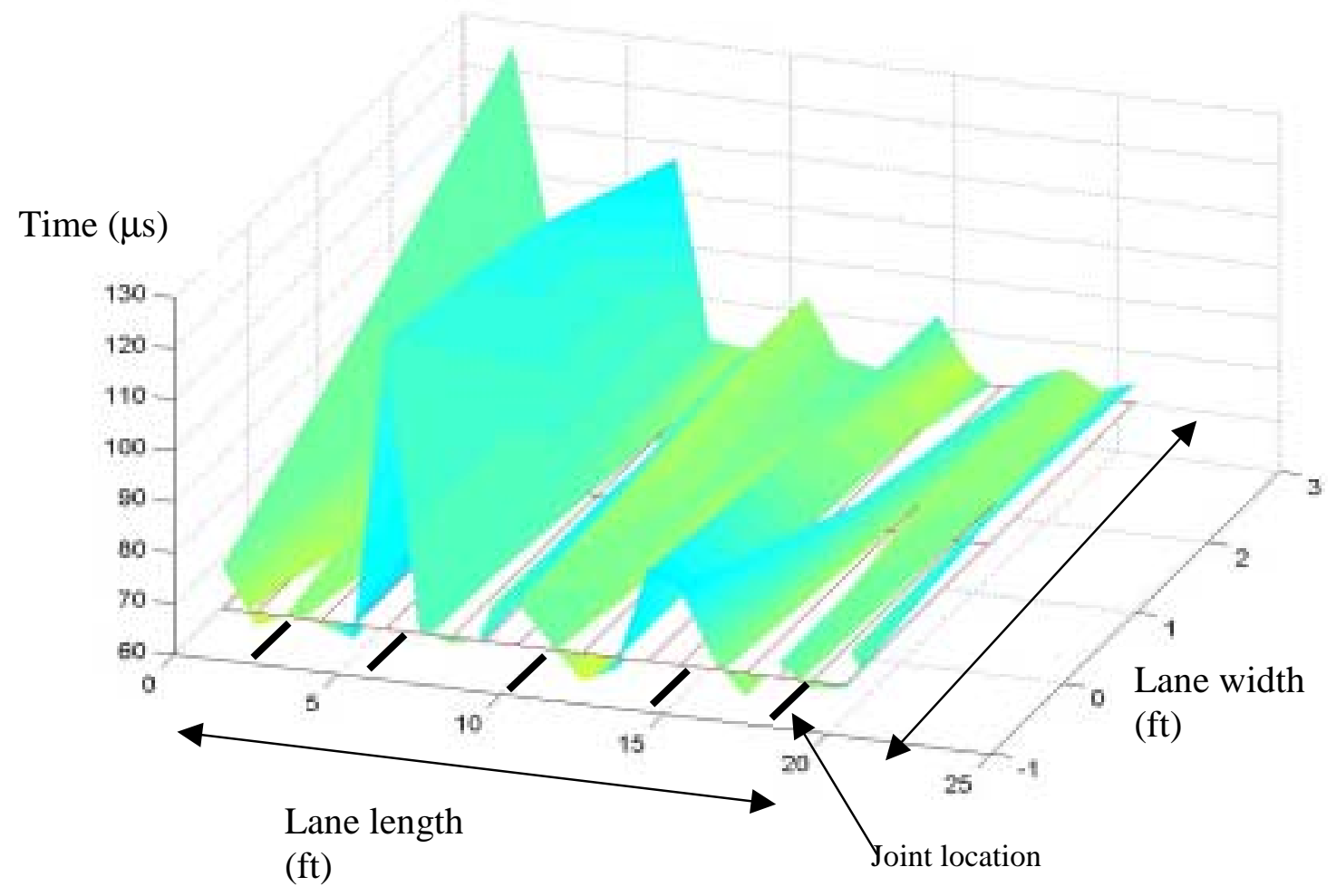

Figure 5.3 Distribution of V-meter flight times between grid points in lane 1

\section{Lane 1 V-Meter Time (Front View)}

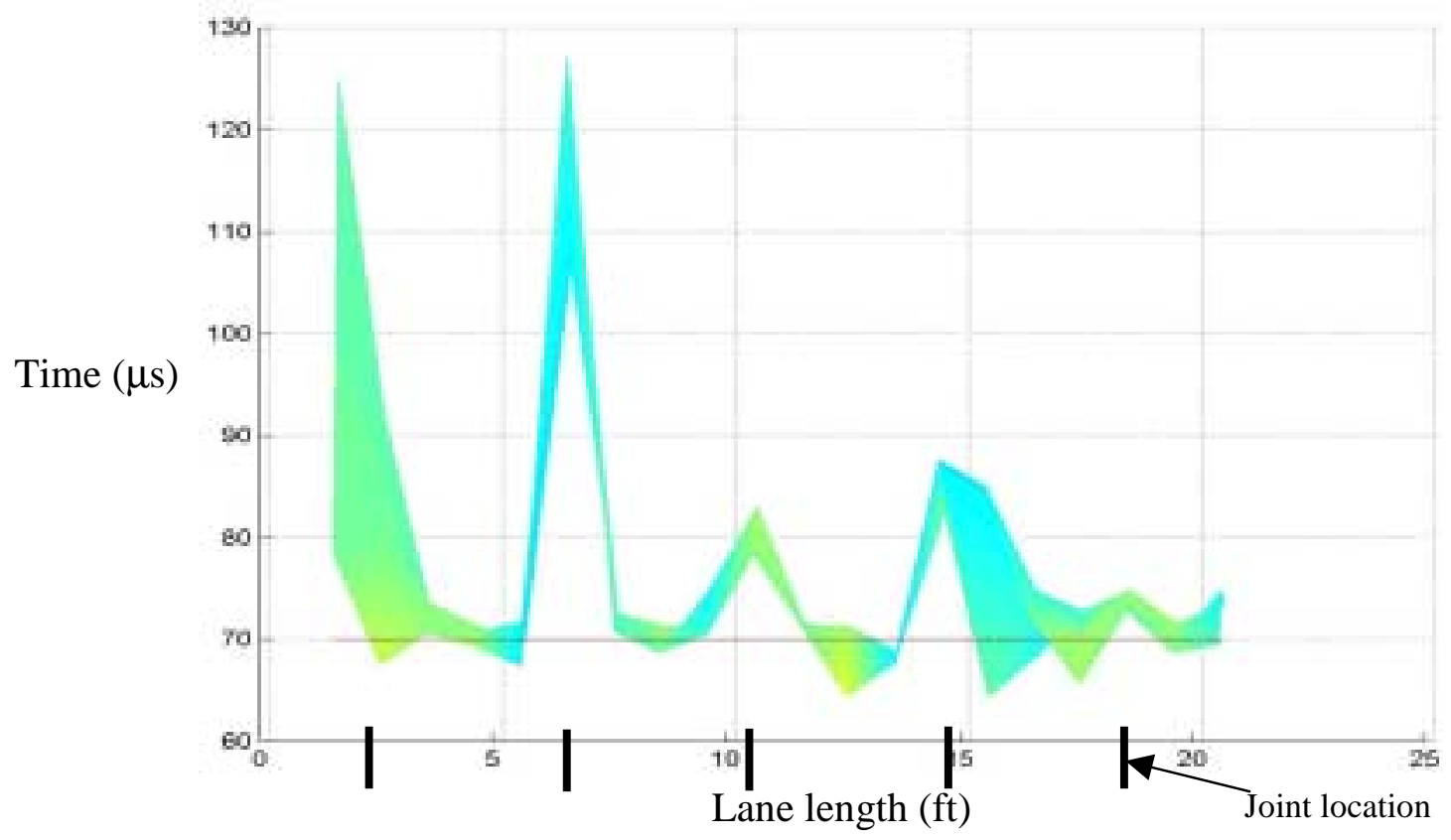

Figure 5.4 Front view of flight times between grid points in lane 1 
Figures 5.5 and 5.6 show the lane 3 surface profile and the front view of the flight time data, respectively. It could be observed that for the areas of the UTW pavement located between the joints, the value of the time of flight was consistently between $60 \mu \mathrm{s}$ and $70 \mu \mathrm{s}$. However, the values were higher between the first and the second transverse joints. The first joint was located over the original APT facility floor joint and the overlay in this area was less than $50 \mathrm{~mm}$ (2") thick. This point of the overlay was not considered a part of the test lane and as a result, the deviant values of the time of flight at the first joint can be neglected. The only significant increase the time of flight was found near the second joint. The consistently low values of the flight times in the areas between the joint suggest that the degree of damage to these areas was probably insignificant.

\section{Lane 3 V-Meter Time (Surface Profile)}

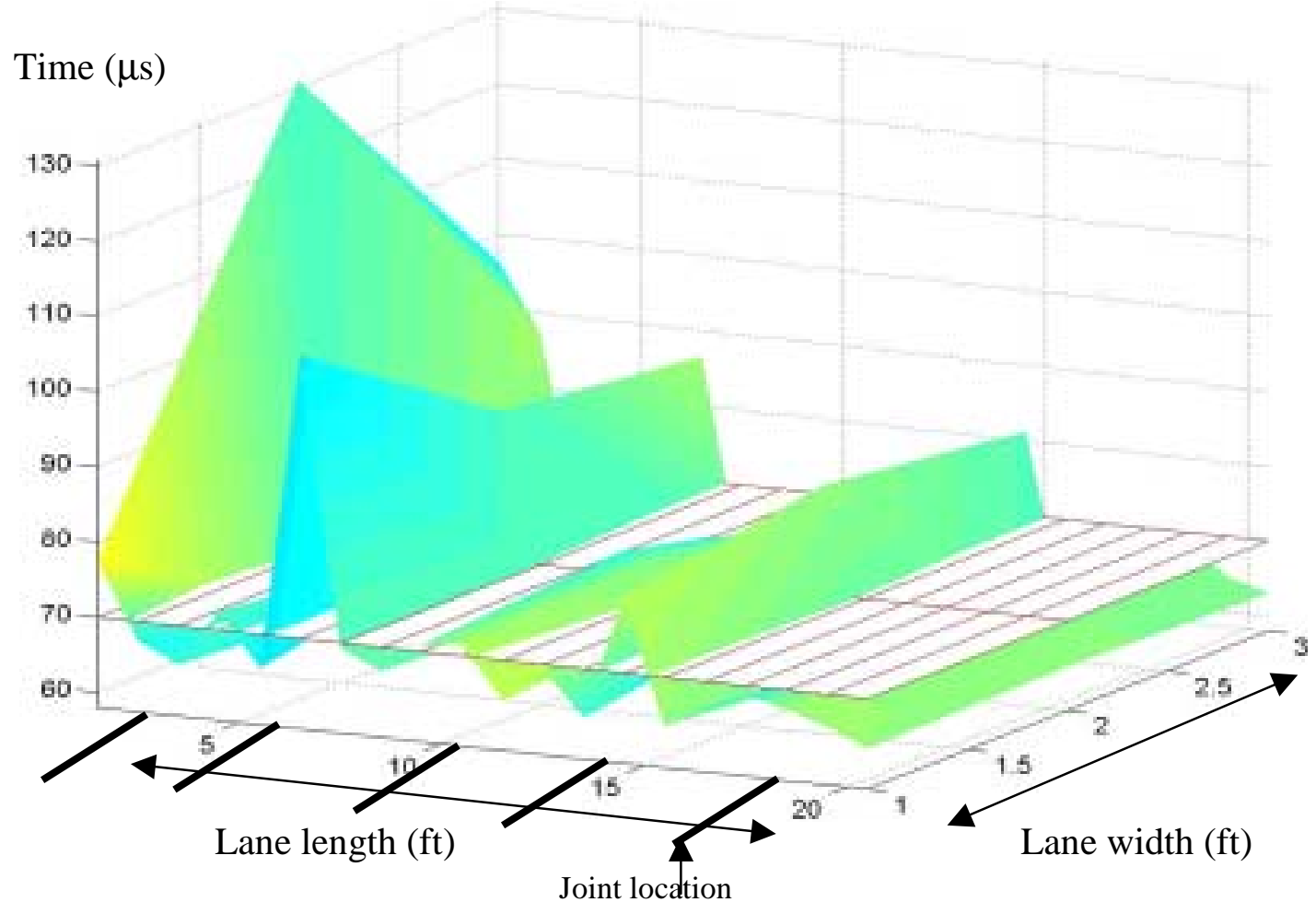

Figure 5.5 Distribution of V-meter flight times between grid points in Lane 3 


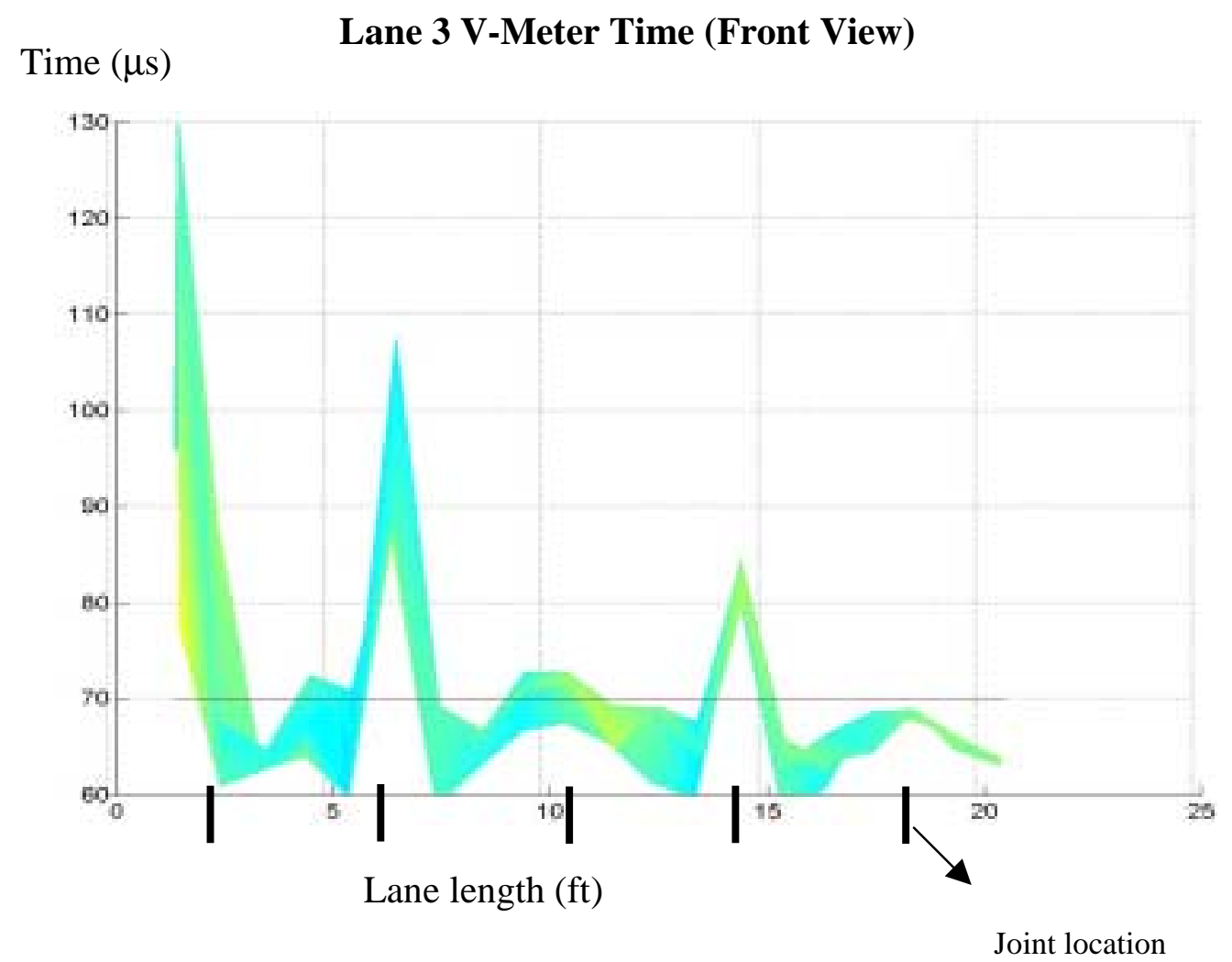

Figure 5.6 Frontal view of flight times between grid points in Lane 3

The surface profile and the front view of the time of flight for lane 4 is very rugged indicating the potential for existence of many cracks along the wheel path of the lane, (see Figures 5.7 and 5.8). The values of the flight times are also higher than the ones observed in previous lanes, the average being about $90 \mu$ s as compared to the average values of about $65 \mu$ s and $70 \mu$ s in lane 3 and lane 1, respectively. The high values of flight times observed in the figures indicate the possibility of intensive cracking. This can be supported by the fact that some transverse cracks were visually observed in lane 4(see Figure 5.9). These cracks started to develop at the edge of the panel and as testing progressed, spread towards the center of the lane. Although no 


\section{Lane 4 V-Meter Time (Surface Profile)}

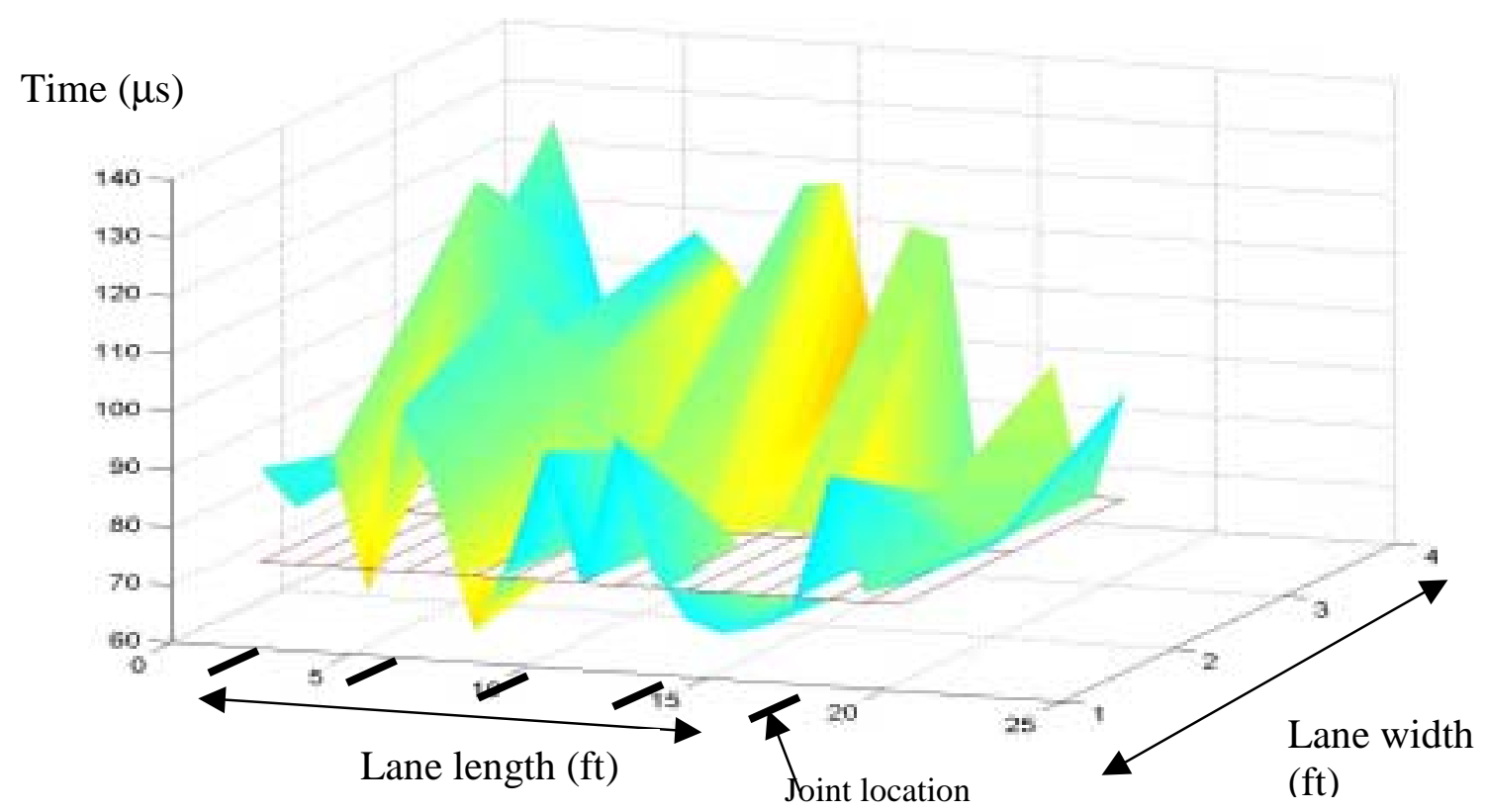

Figure 5.7 Distribution of V-meter flight times between grid points in lane 4

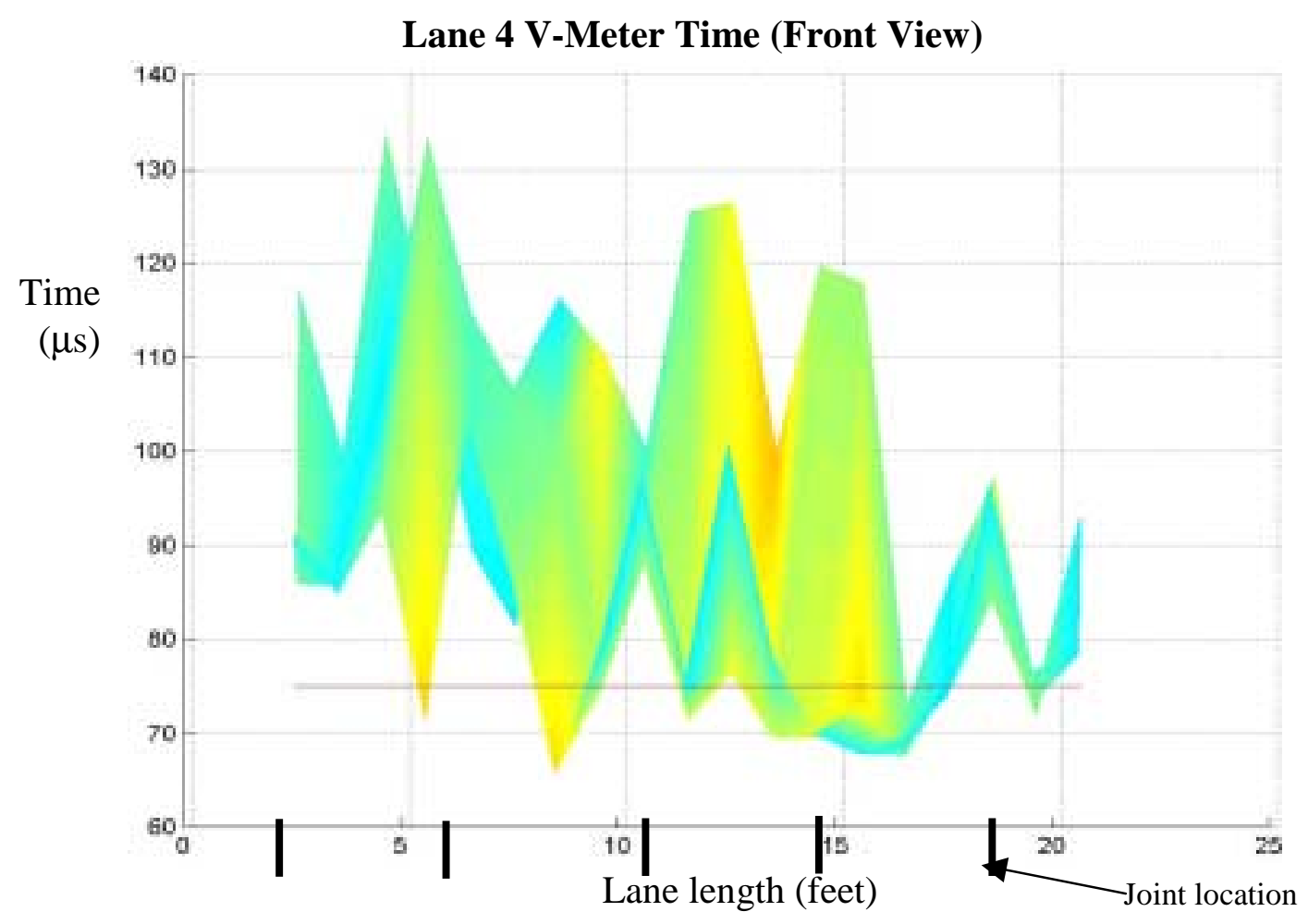

Figure 5.8 Front view of flight times between grid points in Lane 4 


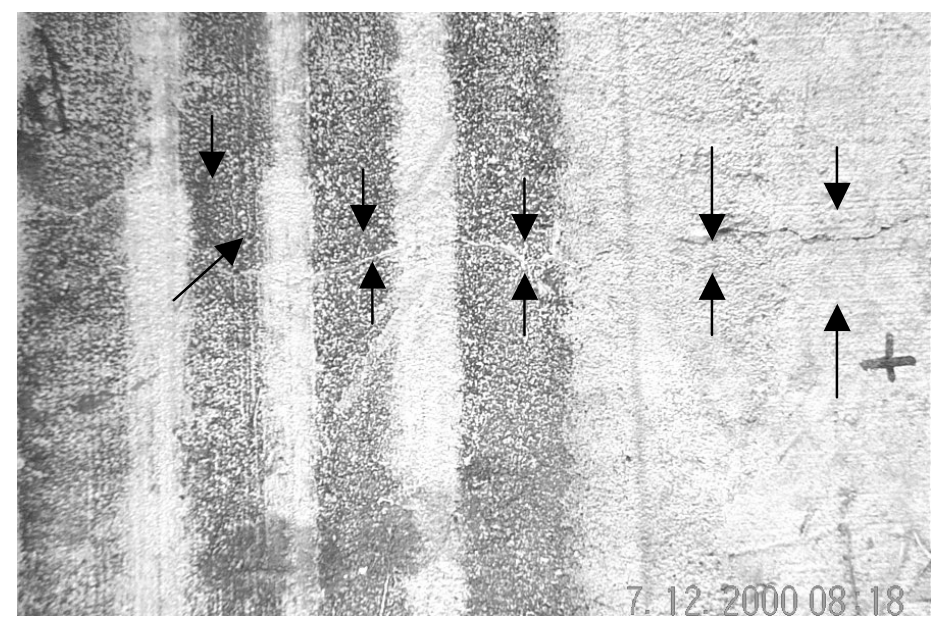

Figure 5.9 Cracks on and near the wheel path in lane 4

excessive faulting or delamination was observed in the UTW, the presence of the numerous cracks indicated that this lane was the most severely distressed of all lanes.

\subsubsection{Summary of UPV test results}

In summary, it could be seen that the flight times vary with the location in the pavement. In most cases, there was a sharp change in the times when the readings were taken across a transverse joint. This was not noticeable for the readings taken across the longitudinal joints. There was no increase in the time of flight along the transverse joints in the shoulder next to lane 1. It was therefore assumed that the shoulder was not cracked at all.

The average range of the times of flight varied from $65 \mu$ s to around $90 \mu$ s. The values were the lowest in lane 3 , which had an average, flight time of about $65 \mu \mathrm{s}$. In Lane 1 an average flight time between grid points was $70 \mu$ s. The highest average flight 
time (about $90 \mu \mathrm{s}$ ) was recorded in lane 4 . The low value of the time of flight and the relatively low strains and deflections observed in lane 3 indicate that the lane was probably the least damaged of all the lanes. On the contrary, the high values of the time of flight in lane 4 and the relatively higher strains measured in lane 4 tend to suggest that lane 4 was probably the most distressed of all the lanes tested. The damage in lane 4 could be attributed to the elevated temperature testing of lane 4, in addition to the higher wheel load. From the results of the V-meter tests, lane 1 also did not show much damage. This could be attributed to the fact that the thickness of the overlay in lane 1 $(100 \mathrm{~mm})$ was greater than the overlay thickness in lanes 3 and $4(63 \mathrm{~mm})$.

Based on the values of the time of flight a summary plot was developed as shown in Figure 5.10. In developing this plot, the entire test area of the UTW panels was divided into four regions with the following arbitrary chosen values of the time of flight:
a) $\quad t^{\prime} 63 \mu \mathrm{s}$
b) $\quad 63 \mu \mathrm{s}\left[\mathrm{t}^{\prime} 75 \mu \mathrm{s}\right.$
c) $\quad 75 \mu \mathrm{s}\left[\mathrm{t}^{\prime} 90 \mu \mathrm{s}\right.$
d) $\quad \mathrm{t} / 90 \mu \mathrm{s}$

The bin values for the above plot are based on the frequency distribution of the time of flight. This plot helped to determine the potential locations where the cores from the lanes could be taken for conducting bond tests, the details of which are discussed in section 5.3. 

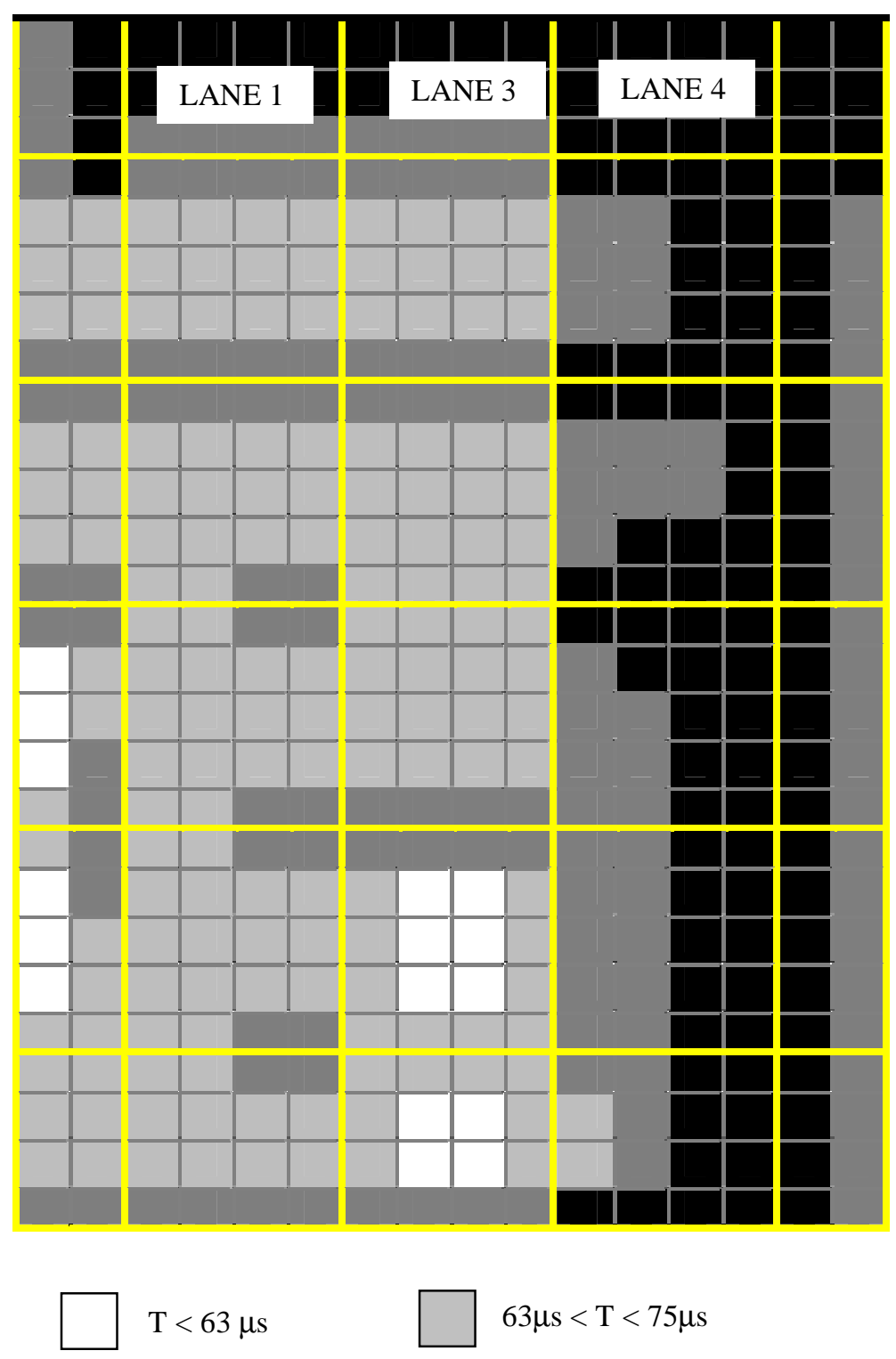

$63 \mu \mathrm{s}<\mathrm{T}<75 \mu \mathrm{s}$

$75 \mu \mathrm{s}<\mathrm{T}<90 \mu \mathrm{s}$

$\mathrm{T}>90 \mu \mathrm{s}$

Figure 5.10 Distribution of flight times for the test lanes 1, 3 and 4 based on Vmeter readings 


\section{$\underline{5.3 \text { Iowa shear Test }}$}

\subsubsection{Test method and description}

The test method used for determining the bond strength of the interface of the UTW was called the Iowa shear test [11]. This test method covers the procedure used to determine the shear strength of the bond between new and old concrete. The test is normally conducted on cores drilled from completed structures or pavements. The test apparatus consists of a loading jig to accommodate a 4" nominal diameter specimen. The jig is designed to provide a direct shearing force at the bonded interface. The load should be applied using a testing machine capable of applying a smooth and uniform tensile load. Figure 5.11 and 5.12 show the testing jig and a typical UTW core used for testing in this study.

The specimen is placed in the testing jig in such a manner that the bonded interface is placed in the space between the main halves of the jig. The testing jig is then carefully aligned in the testing machine with the central axis of the jig in the center of the testing machine. A uniform tensile load is applied at the rate of $2.75-3.45 \mathrm{MPa}$ (400 to $500 \mathrm{psi}$ ) per minute, until the specimen fails. The maximum load carried by the specimen during the test is recorded and the shear bond strength of the specimen is calculated by dividing the maximum load carried by the specimen during the test by the cross-sectional area of the sample. The results are reported to the nearest psi.

Cores from the UTW pavement section were collected from various locations in test lanes 1,3 and 4, both from the wheel path area as well as outside the wheel path. Within a panel, cores were taken from the center of the panel, near the longitudinal edge of the panel and at the corner of the panel to ensure a representative sample. The cores 
taken from lane 2 served as a benchmark for comparison with the cores taken from the other lanes, since lane 2 had not been exposed to repetitive cycles of the wheel, and the cores could be assumed undamaged. Figure 5.13 shows the coring of the UTW pavement at the APT facility.

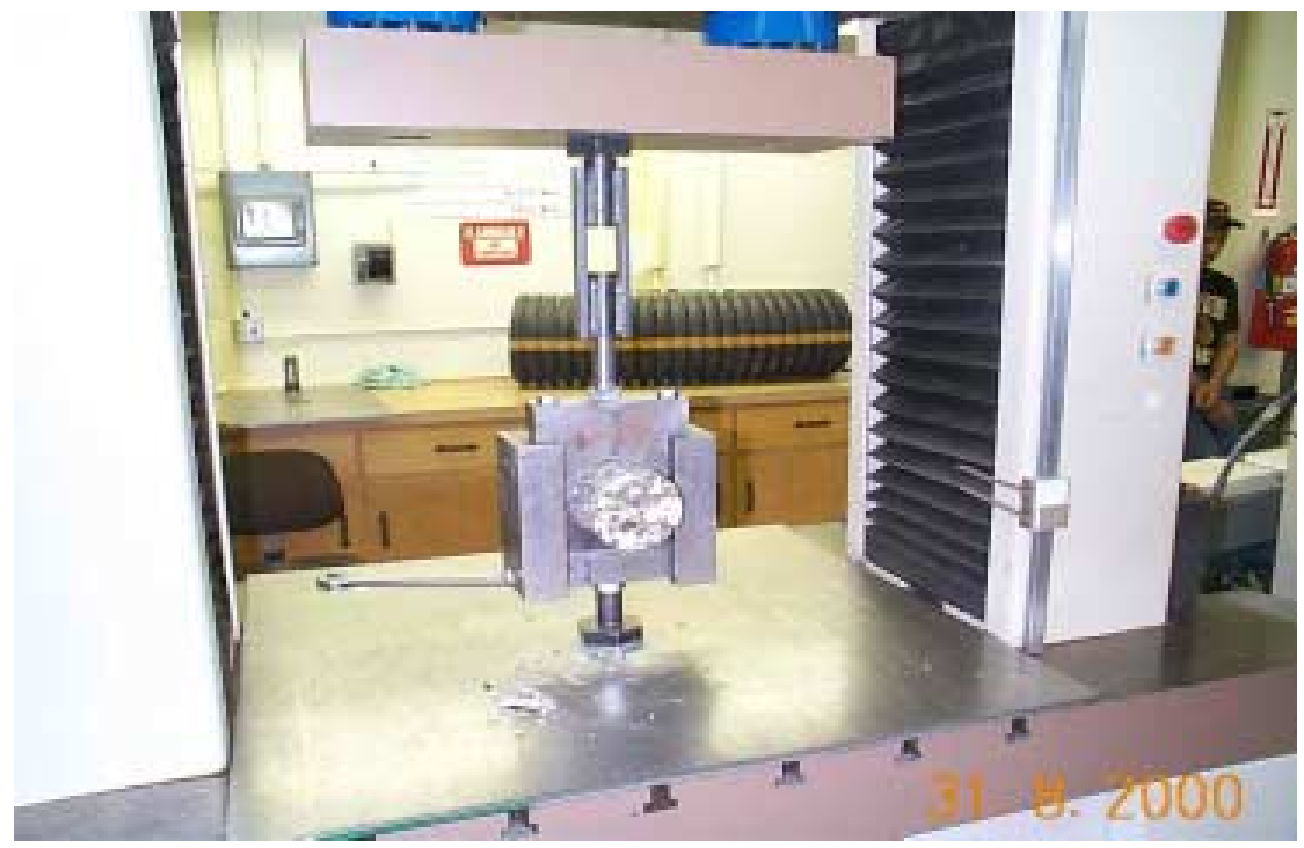

Figure 5.11 Testing jig for Iowa shear test

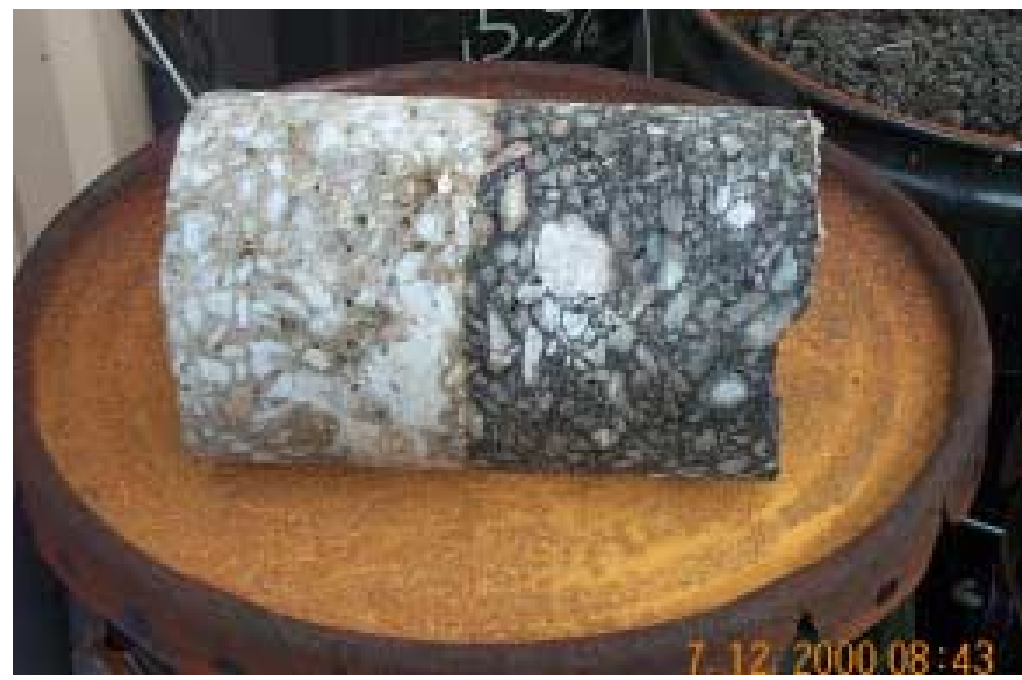

Figure 5.12 Typical UTW core sample taken from the test lanes 


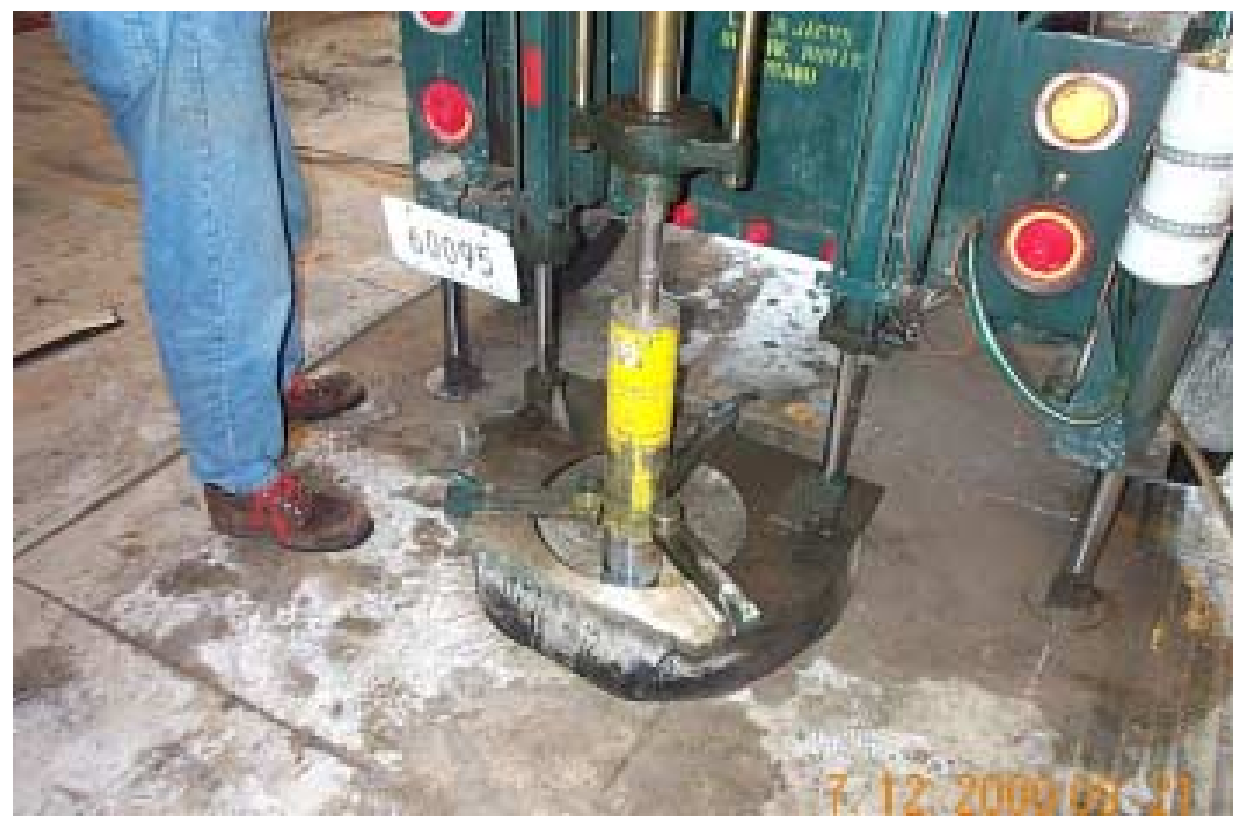

Figure 5.13 Drilling machine removing UTW cores at the APT facility

\subsubsection{Selection of location for test cores}

Based on the results of the ultrasonic pulse velocity tests conducted on the UTW pavement, a summary plot was developed (as shown in Figure 5.10) which identifies locations having potential damage. This was used to identify the locations from where the cores were taken for the bond strength tests. Figure 5.14 shows the location of the cores from the various lanes. 


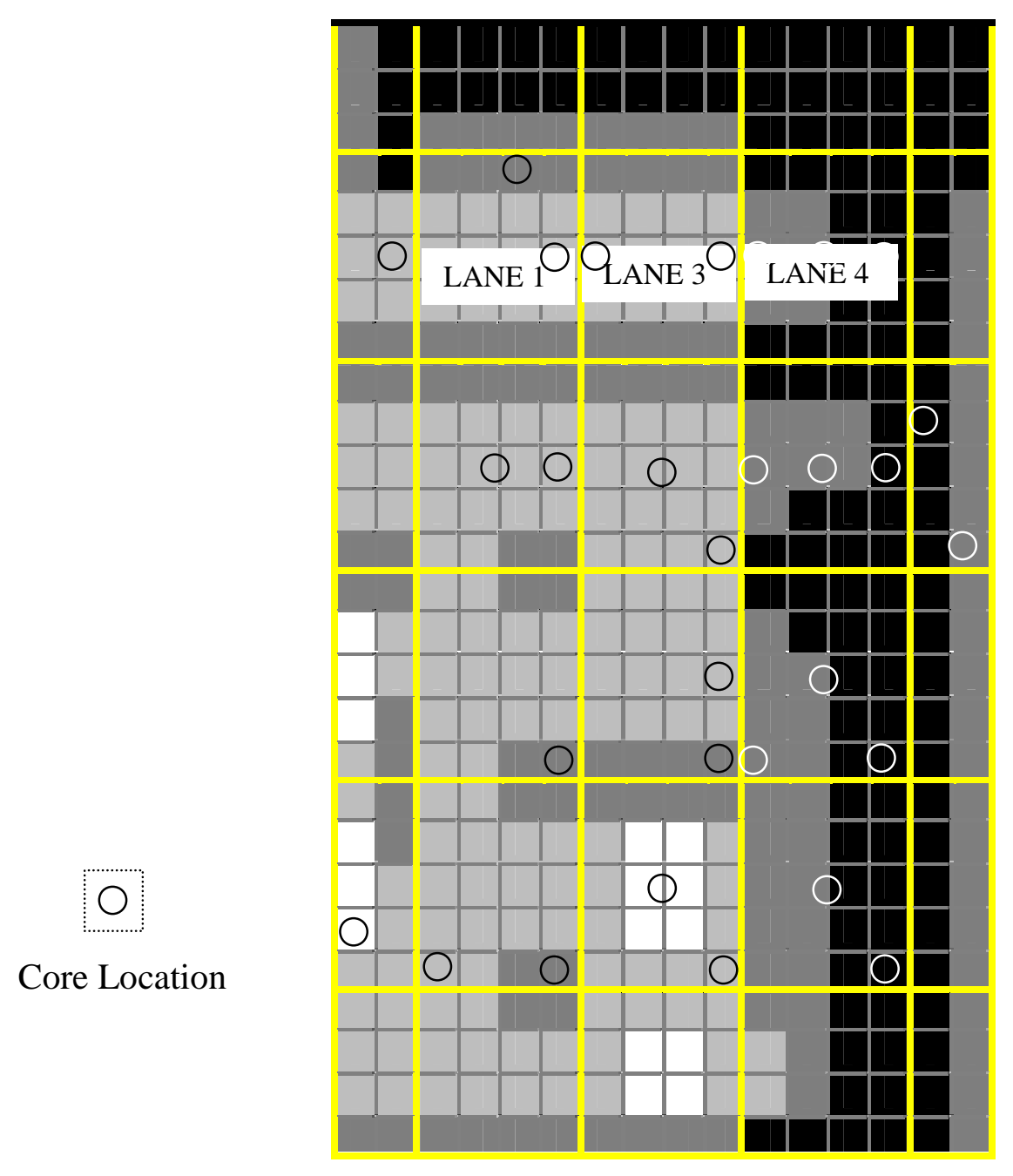

Figure 5.14 Location of coring in the UTW lanes 
Either single of multiple cores were taken from the location. In lane 2 three cores were taken, one from the center of the panel, one at the edge and one at the corner of the panel. These cores were set to be the benchmark, as this lane had not been tested.

\subsubsection{Discussion of shear test results}

Figure 5.15 shows the comparison of the average shear strength of the UTW cores for all the lanes. The average values of all the lanes were greater than equal to $1.5 \mathrm{MPa}$. It was surprising to note that lane 2 cores had the lowest average strength (1.42 MPa) and lane 4 cores tested the maximum average strength $(1.75 \mathrm{MPa})$. This could be attributed to the fact that the asphalt mixes in the lanes were different. Since there was no comparable data for UTW shear strength tests, the performance of the bond could not be determined in quantitative terms using the absolute values of the shear strengths. All the specimens showed almost similar bond strengths. The typical mode of failure of the UTW cores is shown in Figure 5.16. Most of the cores sheared at the interface of the asphalt and concrete as shown in the figure. However, some of the cores showed slightly different modes of failure. Figure 5.17 shows the failure of a UTW specimen at the concrete interface. Some cores also sheared at the interface but some asphalt stuck to the interface that suggests a very good bond between the concrete and the asphalt. This is shown in Figure 5.18. 


\section{Comparison of average shear strength of cores in different lanes}

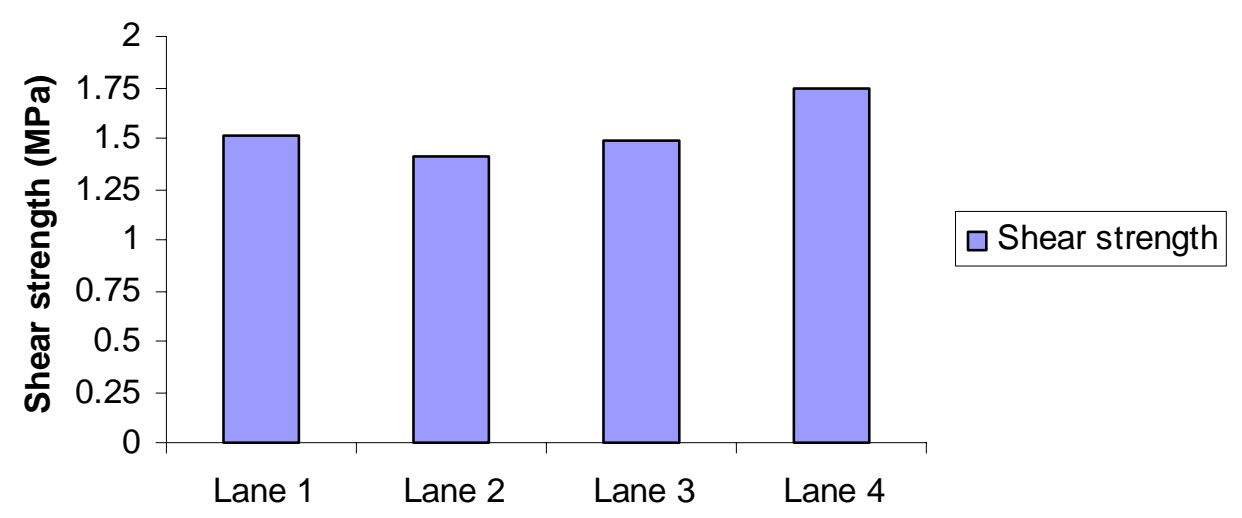

Figure 5.15 Comparison of average shear strengths for different lanes

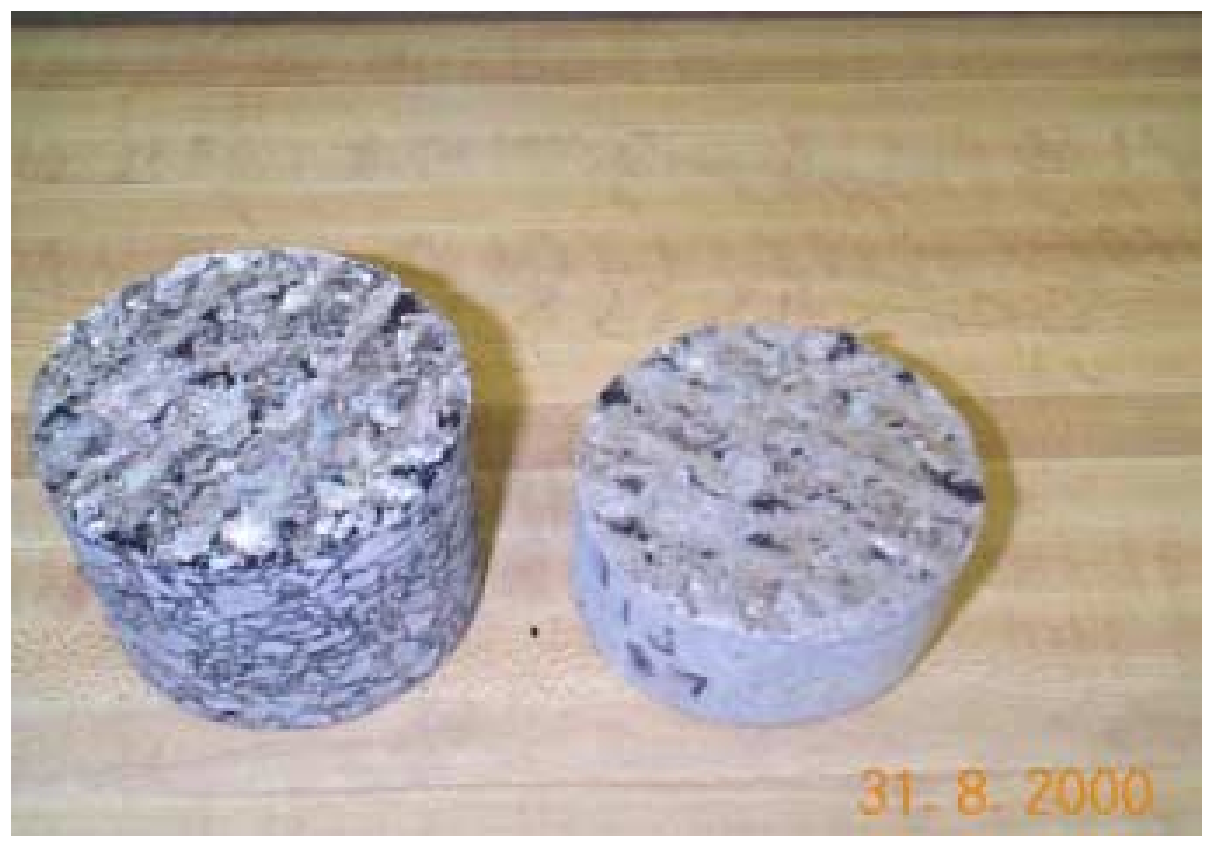

Figure 5.16 Typical failure of a UTW specimen in the Iowa shear test 


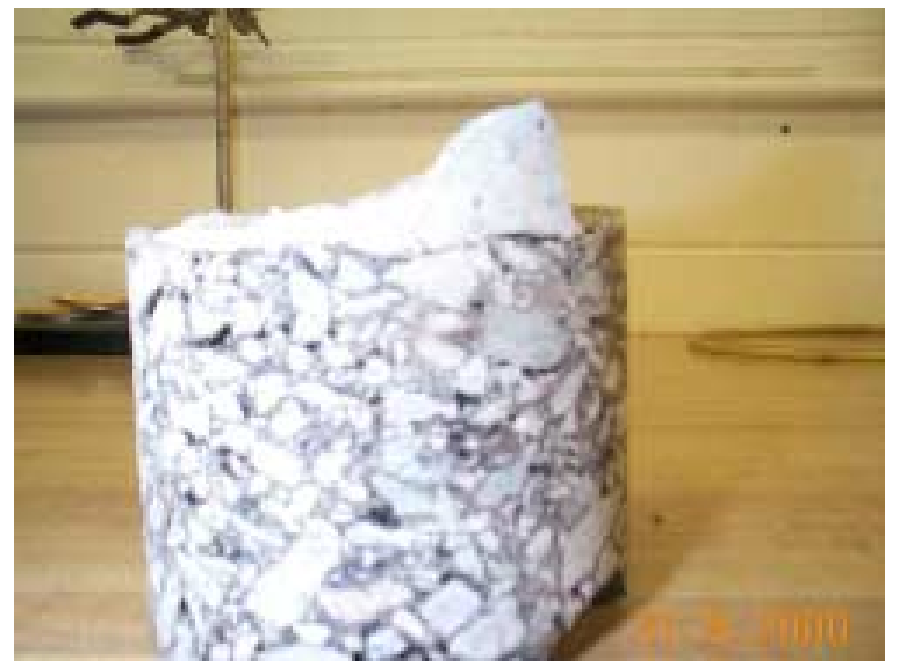

Figure 5.17 Failure of UTW core at the concrete section

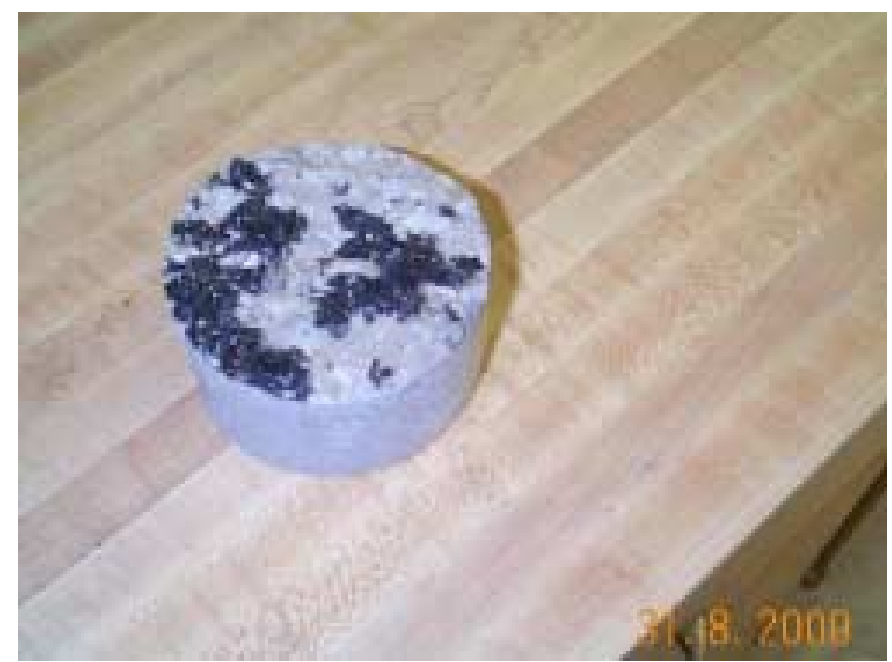

Figure 5.18 Failure of UTW core at the interface along with asphalt stuck to the surface 


\subsubsection{Summary of Iowa shear test data}

The results from the shear test give an indication that the bond between the overlay and the asphalt was quite strong. Due to lack of previous data on the performance of UTW specimens subjected to Iowa shear test, the performance of the UTW cores from the APT can not be quantitatively estimated. Most of the cores performed well under the shear tests. The average value of the bond strength computed using the test method was around 1.5 MPa for all the test specimens (except for lane 2 specimens ). Lane 4 showed a bond strength of about $1.75 \mathrm{MPa}$ which indicated that even the elevated temperature testing and the high wheel load (20,000 lbs) did not lead to the delamination of the bond. Thus the performance of the UTW pavement at the APT could be deemed satisfactory. 


\section{FINITE ELEMENT MODELING OF ULTRA-THIN WHITETOPPING}

\section{$\underline{6.1 \text { Introduction }}$}

This chapter describes the development of the finite element model for the analysis of stresses and strains in the UTW overlay used in this project. In addition, the results from the finite element model are discussed and compared to the experimental results obtained from the testing of the UTW at the APT facility.

The main need for developing a finite element model for the UTW arose because an attempt to verify the measured strains in the pavement using the closed form analytical solutions (Westergaard's theory) resulted in the overestimation of the stresses and strains. This is because the Westergaard's theory has a number of simplifying assumptions such as including use of infinite size panel to approximate the actual finite size panel, and assuming a homogenous base (Winkler's system) to be represented by a set of springs. The essential difference between a concrete and an asphalt pavement is the manner in which they distribute the load-induced stresses to the subgrade. A rigid concrete pavement, because of its high modulus and rigidity, tends to distribute the stresses over a wide area of its support, in effect providing the major structural capacity through the slab. In addition, there was a need to verify the degree of bonding in the pavement based on the analysis of the experimental results obtained from the accelerated testing of UTW. A properly developed finite element model can also provide the basis for designing an 
overlay without the need for expensive experimental set-ups and data collection systems. The task of model development and verification included the following steps:

1. Assessment of the applicability of general-purpose finite element code ABAQUS, for development of stress as well as strain prediction model for composite UTW pavements.

2. Simulation of dynamic response of the pavement under APT wheel loads.

3. Prediction of strains in the overlay at the interface of concrete and asphalt. The predicted values were compared with the experimental data obtained from the APT test thereby providing a basis for future detailed finite element modeling of the UTW.

\subsection{Description of the features of the finite element software and the graphical interface used in this study}

An all purpose finite element program; ABAQUS has been used to conduct analysis in this study. This program is capable of modeling any combination of static, steady state, dynamic, impulse or user defined loading. Pavement support, bonding between layers and a wide range of material behavior can be implemented through this program.

Since ABAQUS is a batch program, the objective is to assemble a data deck (or an input file) that describes the problem for analysis. Input files for complex simulations can be very large but can be managed efficiently by using the features built into the program's structure. A convenient way to simplify the task of building a complex model and generating an input file is to use a graphical user interface for preprocessing. The 
interface used in this study was MSC/PATRAN (Version 8). MSC/PATRAN is a graphical software used to create the model geometry. After the geometry is created, this software can be used to mesh the model for further finite element analysis. Even load cases and boundary conditions can be generated graphically using PATRAN. After the model is developed and the finite element mesh generated, the model can be exported as an input file to ABAQUS, using the built in links in PATRAN.

In the present study, the procedure involving finite element modeling included:

1. Model generation using PATRAN.

2. Finite element meshing using PATRAN.

3. Creating load cases and boundary conditions graphically using PATRAN.

4. Creating input file in PATRAN and transferring model data into ABAQUS.

5. Adding material properties into input file.

6. Selecting analysis procedure (linear static displacement method was used).

7. Running ABAQUS code for analysis.

8. Post processing of the results using ABAQUS /POST

\section{$\underline{6.3 \text { Steps in creating the Finite Element Model (FEM) }}$}

The first step in developing the finite element model of the structure is to create a geometrical representation of the structure. The geometrical model should include all the major features of the actual structure in reasonable detail to provide a reliable solution. The geometrical model is constructed using the appropriate type of finite elements such as brick elements, beam elements etc. After the geometrical element model has been 
constructed, it is then discretized into a mesh. The material properties and the boundary conditions (including the loading conditions) are defined. The model is subsequently analyzed using ABAQUS.

\subsubsection{Modeling of geometry of the UTW section}

The UTW pavement at the APT facility consisted of a concrete overlay on top of a flexible milled asphalt surface supported by a stiff concrete base. The level of bonding between the concrete overlay and the asphalt is a major factor in the performance of this composite pavement. The FEM model developed in this study was for the $100 \mathrm{~mm}(4$ ") thick overlay. To simplify the calculations, four of the individual $1.2 \mathrm{~m}$ x $1.2 \mathrm{~m}$ (4' $\mathrm{x} 4^{\prime}$ ) panels was represented in the model as a continuous (joint less) strip of pavement $4.8 \mathrm{~m}$ (16') long, $1.2 \mathrm{~m}$ (4') wide and $200 \mathrm{~mm}$ (8”) thick. The top $0.1 \mathrm{~m}$ (4”) thick layer represented the concrete overlay while the bottom $0.1 \mathrm{~m}$ (4") thick layer represented the asphalt base. The overall dimensions and the cross section of the model UTW pavement are shown in Figure 6.1. It was assumed that the asphalt layer below the concrete had a uniform thickness of $0.1 \mathrm{~m}(4$ "). (Actual coring results revealed that this was not the case and the thickness of the asphalt surface varied between $63 \mathrm{~mm}\left(2 \frac{1}{2}\right.$ ") and $100 \mathrm{~mm}(4 ")$. Also, the thickness of concrete overlay varied from $100 \mathrm{~mm}(4 ")$ to $\left.115 \mathrm{~mm}\left(4^{1 / 2 "}\right)\right)$. 


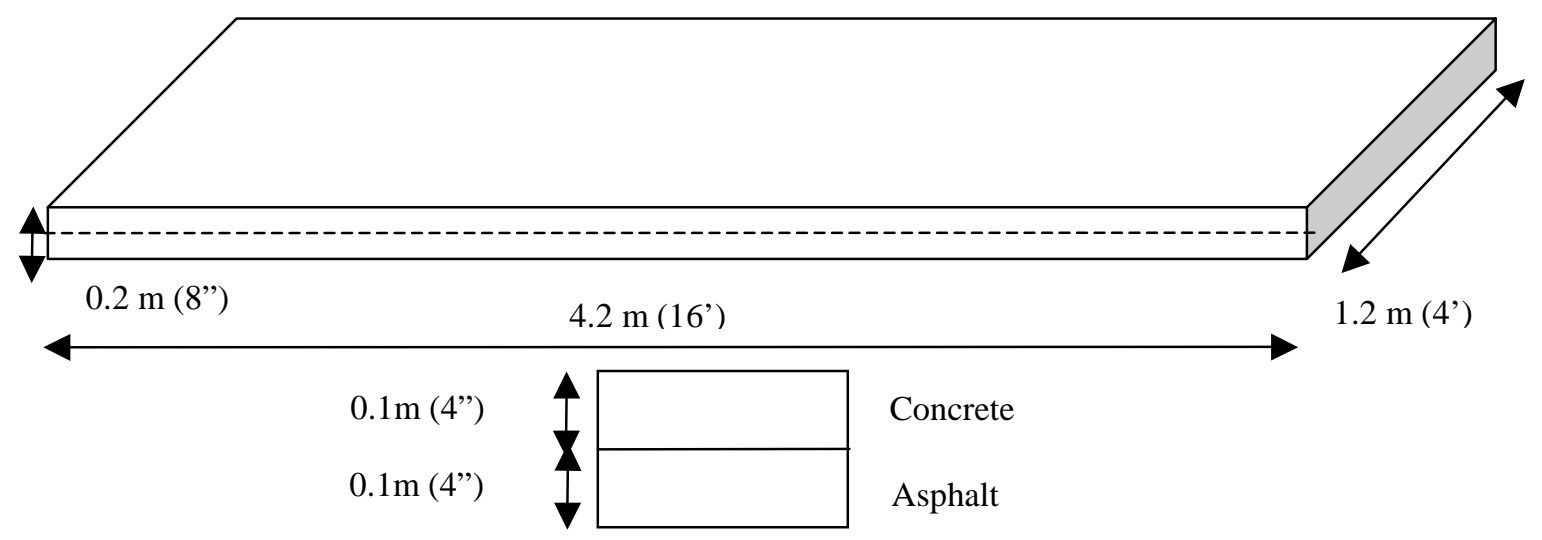

Figure 6.1 Dimensions and cross section of the UTW pavement used in the FEM model

\subsubsection{Model meshing}

After the geometrical model was created, it was meshed for further analysis.

When selecting the size of the mesh, one should strive to achieve an optimum balance between the accuracy of the solution and the size of the FEM model. The mesh size should be small enough to allow detailed modeling and analysis of the pavement section. However, a uniform fine mesh results in a large number of nodes and elements, which requires significant computing capacity and time. On the other hand, coarse meshing may not provide the necessary level of accuracy. The usual approach to the problem is to use multiple mesh sizes. The coarser mesh is used in areas where a low stress gradient is expected and a finer mesh is used in the areas where high stress gradients are expected. In case of the present study, it was possible to use a fine mesh throughout the model. This was because the model size was not too large. In addition, since only a linear finite element analysis was planned to be carried out, computational 
time was not going to be the constraint as only a single iteration was required for the analysis. The mesh size chosen was $50 \mathrm{~mm}$ (2") x $50 \mathrm{~mm}$ (2") on the surface. The total thickness of $200 \mathrm{~mm}$ (8") was divided into eight parts each being $25 \mathrm{~mm}$ (1") thick. Thus the size of each solid element was $50 \mathrm{~mm}$ x $50 \mathrm{~mm}$ x $25 \mathrm{~mm}$ (2" x 2" x 1").

\subsubsection{Element selection}

ABAQUS provides a complete modeling capacity through its element library. Since a 3D analysis was planned, solid continuum stress/displacement elements, which are the standard volume elements in ABAQUS, were chosen. The solid element library includes first order (linear) interpolation elements and second order (quadratic) interpolation elements in all dimensions. For the current model first order, linear interpolation, solid continuum elements were chosen.

In selecting an element type, there is also a trade off between the level of accuracy and the computational efficacy. Second order elements (quadratic elements) provide more accurate results than first order elements assuming that the same number of elements is used in both cases. However, the quadratic elements require a significantly longer computational time. Based on successful application in previous pavement analysis, the eight-node linear brick element with reduced integration (C3D8R) was used in this current study. Reduced integration uses a lower order of integration to form the stiffness matrix. The reduced integration method using standard elements produces accurate results provided the mesh size is fine enough and there are no distortion in the elements. Use of the reduced integration elements also significantly reduces the required amount of computing memory, especially for three-dimensional problems. 


\subsubsection{Load and Boundary Conditions}

When developing the model, the aim was to represent the actual UTW test section on which the wheel was moving along the edge of the longitudinal joint. It should be pointed out that although the actual pressure distribution at the contact area between the tire and the pavement is non-uniform, it was assumed uniform for the purposes of this model. The elliptical load area of the tire was approximated by two rectangular areas as shown in Figure 6.2 model. Each of the areas was loaded by a constant pressure of 0.83 MPa (120 psi), which was the tire pressure of the APT test wheel. In determining the size of the rectangular areas, the total load on the wheel $(20,000 \mathrm{lbs})$ was divided by the tire pressure on the testing wheel (120 psi) thus yielding a contact area of $20,000 / 120=$ 167.7 sq. in. This area was further divided into two patches, each equal to 83.3 sq. in., to represent the dual tire of the loading wheel. To further approximate the actual imprint of the test wheel and to conform to the grid size of the surface mesh, the two patches were separated by a gap of $150 \mathrm{~mm}\left(6^{\prime \prime}\right)$ and their area was reduced to 80 sq. in. each.

This patch load was moved over the surface of the model pavement along the longitudinal joint to simulate the moving wheel. The wheel load was modeled using the uniform contact pressure option in ABAQUS. The load was placed $50 \mathrm{~mm}(2 ")$ away from the location of the longitudinal joint, as was the case for the wheel during the APT test. Figure 6.2 shows the configuration of the wheel. 


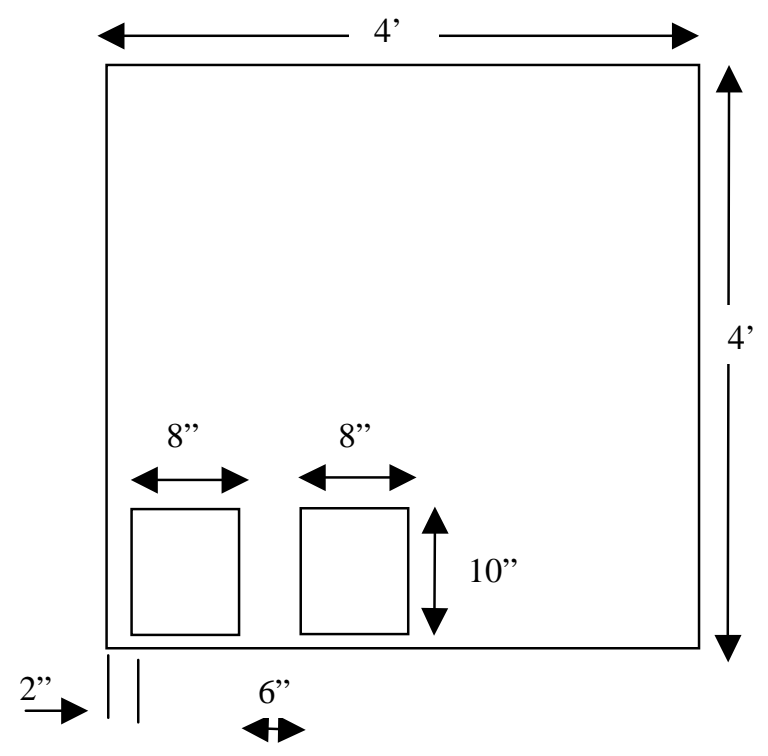

Figure 6.2 Plan view of loading area on the surface of the UTW panel

The simulation of the boundary conditions for the UTW pavement was one of the most important and complex tasks in the modeling. As already mentioned, for the sake of simplicity, the transverse joints were not included in the FEM model. The main boundary condition occurred at the interface of the concrete and asphalt where the degree of bonding is unknown. Since the UTW works as a composite structure, there has to exist some degree of bonding between the concrete and the asphalt surface. It was assumed that the concrete and the asphalt were fully bonded at the interface. This was modeled by strain continuity at the interface but a stress discontinuity at the asphalt surface. This allowed for the simulation of stress concentration that occurs at the asphalt surface, which may be one of the leading causes of the debonding of the composite layer. Since only one lane (representing the length of four panels) was modeled using FEM, the effects of the longitudinal joint and the load transfer to the adjacent lane were neglected. 
The subgrade support conditions were modeled as a stiff and completely rigid surface at the bottom of the asphalt layer, restrained with respect to all six degrees of freedom. This was a good approximation of the conditions existing at the APT facility because of the presence of a strong base below the asphalt layer. This base consisted of a thick reinforced concrete slab on top of 60 " of p-gravel. This provided an exceptionally strong and stiff subgrade with practically no deflections.

\subsubsection{Material properties}

Most of the existing finite element methods assume that the paving materials are linear and elastic. The material properties are represented by Young's modulus and Poisson's ratio. As determined during the course of accelerated testing, the pavement strains and deflections were relatively small and the dynamic strains were recoverable. Larger loads might produce stresses above a given material's yield stress causing irrecoverable deformation. In such cases, material models accounting for behavior after yielding must be utilized. Since the FEM analysis used in the present study was aimed at estimating the strains in the concrete and at the asphalt interface due to the motion of the wheel (dynamic load) on the pavement, it did not involve analysis of permanent deformations and creep. Therefore, a linear elastic model was chosen to represent the materials. The Young's modulus of concrete and asphalt was assumed to be $31 \mathrm{GPa}$ $(450,0000 \mathrm{psi})$ and $2 \mathrm{GPa}(300,000 \mathrm{psi})$, respectively. A Poisson's ratio of 0.20 and 0.38 was assumed for the concrete and asphalt, respectively. 


\subsection{Execution of the FEM program}

The FEM problem was modeled as a $4.8 \mathrm{~m}$ x $1.2 \mathrm{~m}\left(16^{\prime} \mathrm{x} 4^{\prime}\right)$ pavement that was $200 \mathrm{~mm}(8$ ") thick. The cross sectional area of the element was $50 \mathrm{~mm}$ x $50 \mathrm{~mm}$ (2"x 2") and its thickness was $25 \mathrm{~mm}(1$ "). In all, there were eight layers of elements: the top four being concrete and the bottom four being asphalt. The number of elements in this problem was $18432(96 \times 24 \times 8)$. The total number of nodes defined was 21825 . A linear static analysis was carried out which used the "sparse solver" component of ABAQUS. The wheel load was modeled by a patch load placed at various locations in the pavement along the wheel path. Since the response of the model was linear, the application of loads at various locations simulated a dynamic approach to the problem, which was similar to the motion of the wheel. The strains and stresses at the edge of the test lane were calculated at the locations where the actual strain gages were located in the UTW pavement.

The results of the simulation were stored in a data file generated by ABAQUS. The pavement deflections and the stress-strain levels at various locations in the model are stored in a data file. ABAQUS/POST, which provides graphical post processing of ABAQUS analysis result files, uses this data file to create various plots such as deformed shape plots, and contour plots of various parameters.

\section{$\underline{6.5 \text { Analysis of FEM results of UTW model }}$}

The following subsections discuss the stresses and strains obtained from the analysis of the FEM model. In addition, the results obtained from the modeling are compared to the experimental results obtained from the accelerated testing of the UTW 
section. Figure 6.3 shows the magnified plot of the deformed shape plot resulting from the wheel load.

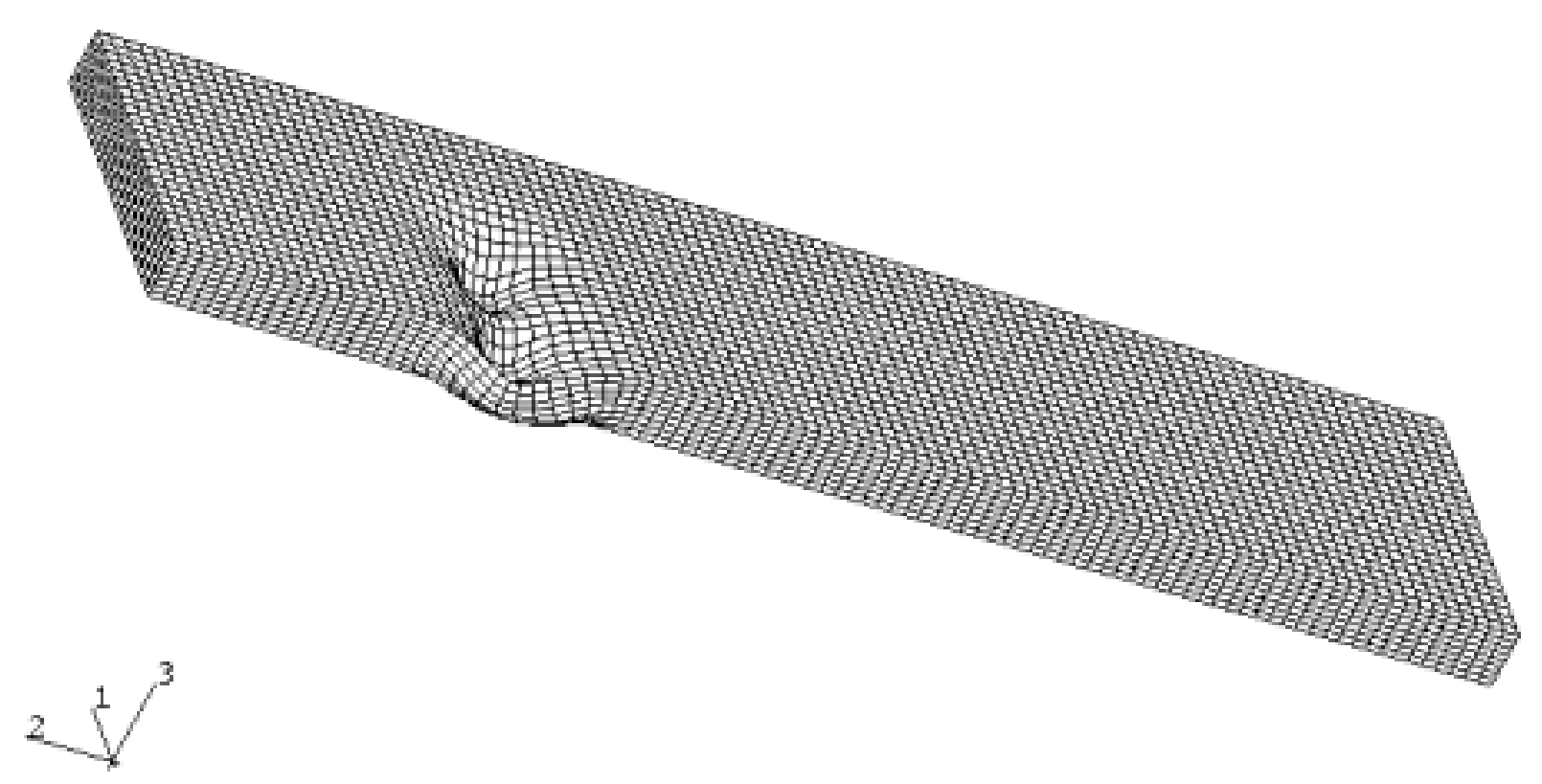

Figure 6.3 Magnified image of the deflection pattern due to the wheel load

\subsubsection{Analysis of stresses and strains}

Figure 6.4 shows the longitudinal stress distribution in the UTW section as computed by the model. The maximum tensile stress occurs at the interface of the concrete overlay and the asphalt layer. It can be seen that the stress at the top of the overlay is compressive in nature with the magnitude around $0.83 \mathrm{MPa}$ (120 psi), which is equal to the tire pressure applied at the top of the overlay. The stress becomes tensile at the interface of the asphalt and the concrete overlay with a maximum magnitude of around $0.66 \mathrm{MPa}(95 \mathrm{psi})$. Below the interface, the stress becomes compressive again and its value is about $0.14 \mathrm{MPa}(20 \mathrm{psi})$. This discontinuity in the stress distribution 
indicates that there is a stress concentration at the interface. This could be a possible cause for the deterioration of the bond as postulated earlier.

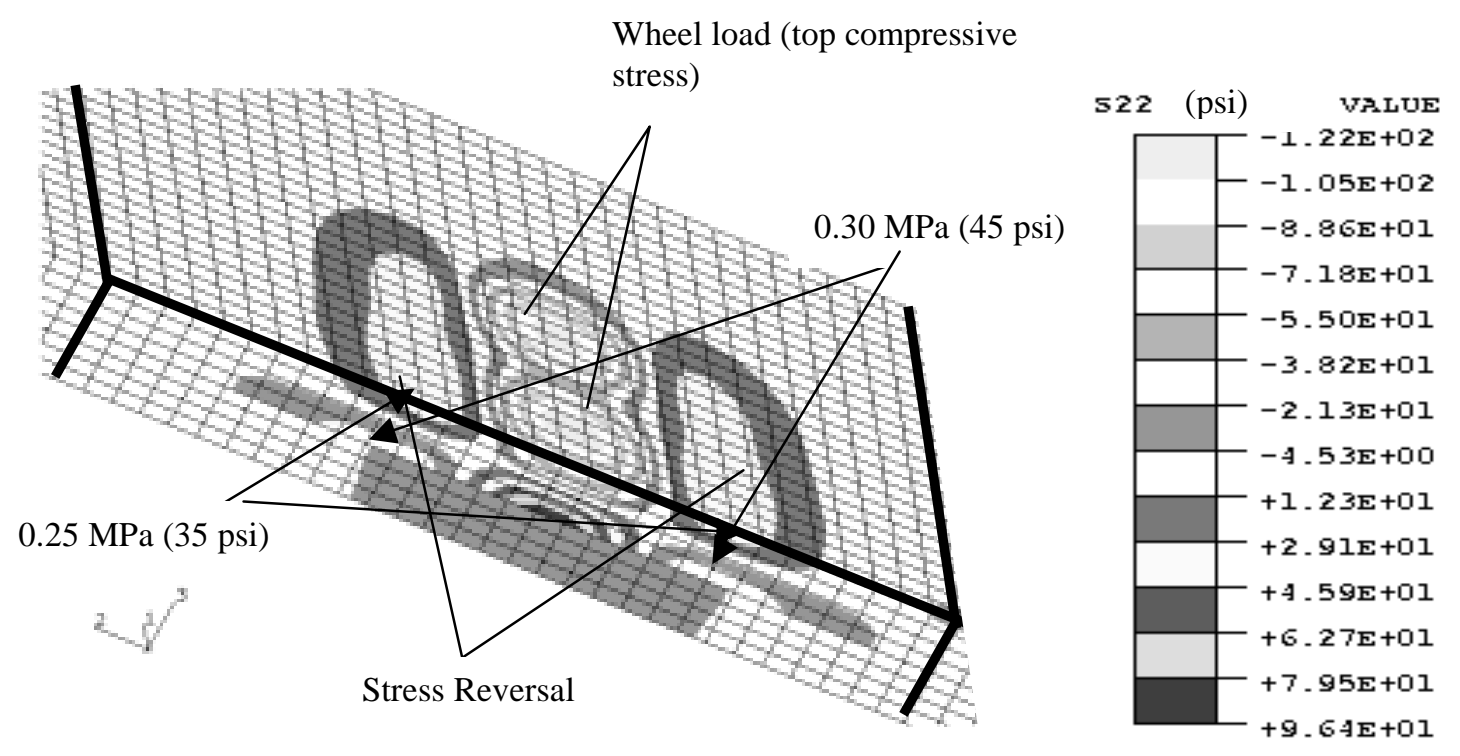

Figure 6.4 Surface contour of the stress due to the wheel load

Another interesting phenomenon observed is a stress reversal due to the load. At the point of loading, the stresses are compressive at the top and tensile at the bottom of the overlay, but a reversal of this is observed in the areas in front and behind the wheel load, where there is a compressive stress at the bottom and a tensile stress on top of the overlay. The top of the overlay experiences a tensile stress of around $0.25 \mathrm{MPa}$ (35 psi) and the bottom of the overlay shows a compressive stress of around $0.30 \mathrm{MPa}$ (45 psi). This corroborates the observations of strain reversal observed during the experimental test at the APT facility.

The longitudinal strains produced under the wheel traveling along the edge of the UTW section are shown in Figure 6.5. The strains produced at the top of the overlay 
(under the wheel load) were compressive in nature having a maximum value of around 20 microstrain. The strains become tensile at the interface with a maximum value of around 30 microstrain at the asphalt surface. Below the interface, the strains drop to about 20 microstrain over the depth of $50 \mathrm{~mm}(2 ")$. The high strain gradient indicates a stress concentration at the interface. The tensile strains further decrease through the asphalt layer reaching the value of about 10 microstrains at the bottom of the asphalt. The phenomenon of strain reversal is also noticeable from the figure. The areas just ahead of the wheel load and behind the wheel load experience a reversal in strain. The values of the strains caused by the reversal are around 10 microstrain (tensile) at the top of the slab and 15 microstrain (compressive) at the bottom of the overlay.
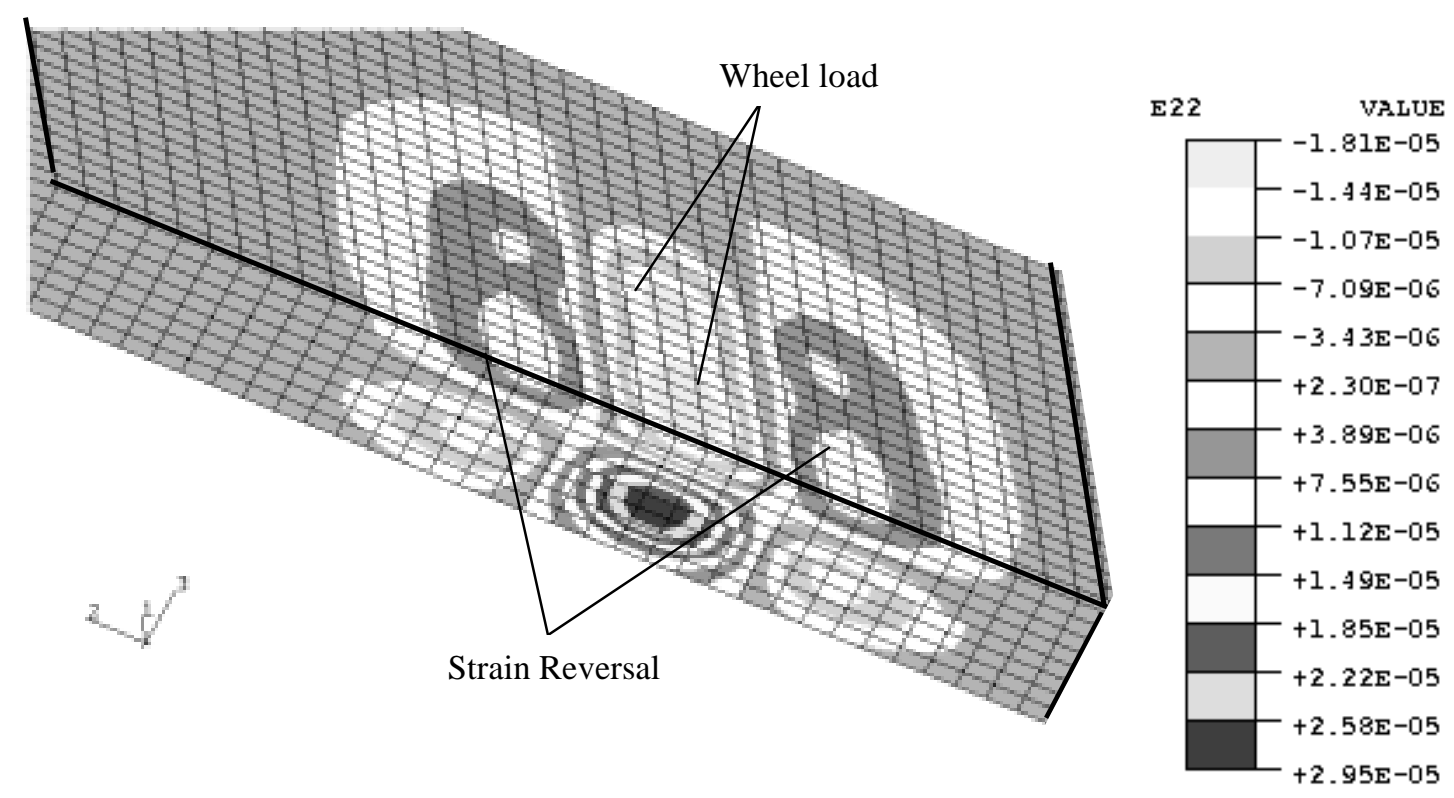

Figure 6.5 Surface contour of longitudinal strain distribution due to the wheel load 


\subsubsection{Comparison of FEM generated and experimental strain data}

Shown in Figure 6.6 is the comparison of the maximum strains generated by the model with the experimental strains collected from lane 1. The location of the critical strains for the model was at the interface of the concrete overlay and asphalt. This was true in most cases for the observed experimental values.

\section{Maximum strain in the UTW pavement under static wheel load of 20000 lbs.}

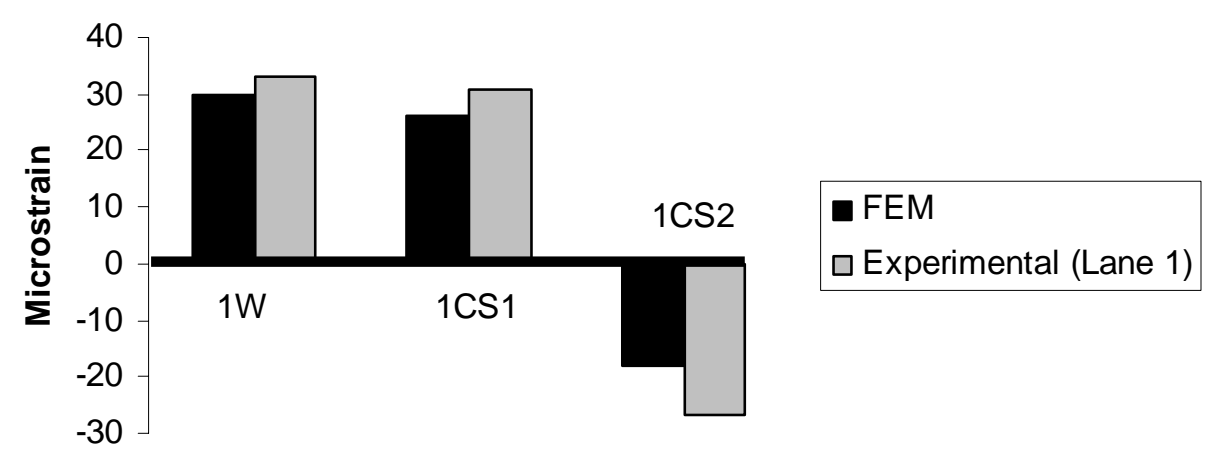

Figure 6.6 Comparison of maximum calculated and experimental strains in the UTW pavement of lane 1

(In some cases strain reversal caused a shift in the critical strains from the interface of the concrete overlay and asphalt to the top of the overlay as discussed in sections 4.2.1.2 and 4.2.3). The magnitude of the calculated strains at the top of the overlay was about -20 microstrain whereas the observed values (at the same location) were higher (around -30 microstrain). The values of both calculated and observed strains on the asphalt surface were very comparable (about +30 microstrain each. It can be hence be seen that the strains calculated from the model and the collected strains during the accelerated testing of the UTW section were similar in magnitudes. 
Figure 6.7 shows the comparison of the strain distribution at the asphalt surface for the model generated and the experimental strains. The model strains were generated after one pass of the wheel. The experimental strains were collected from lane 1 after 30,000 passes and 1000,000 passes, respectively. These values correspond to the first and the final pass with a 20,000 lbs load for lane 1 (since the testing for the first 30,000 passes for lane 1 was carried out at 12,000 lbs).

\section{Dynamic strain variation of gage 1WS under $20000 \mathrm{lbs}$ load}

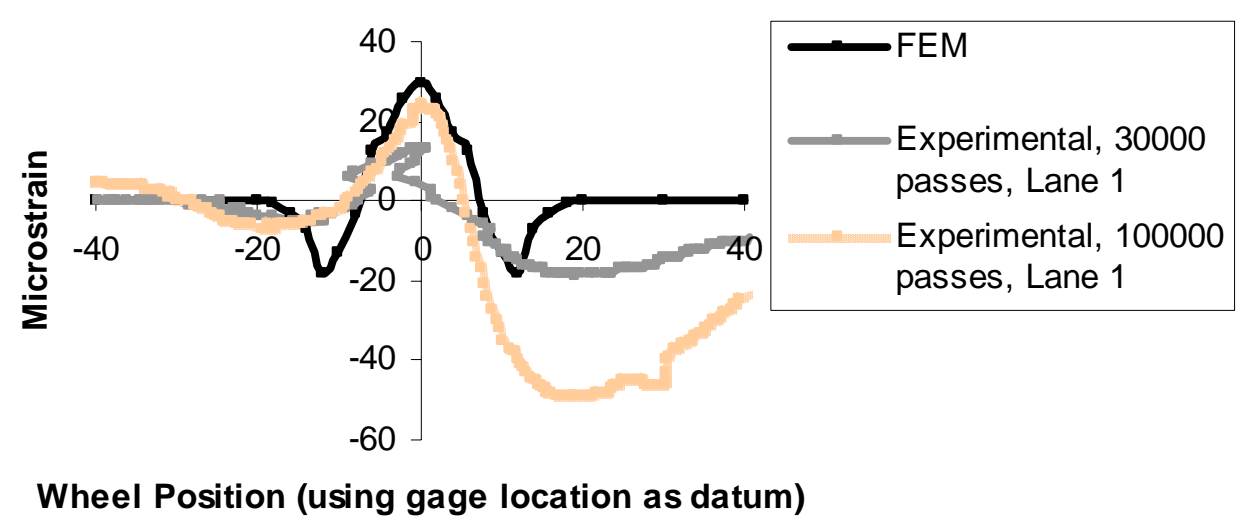

Figure 6.7 Dynamic strain variation at the asphalt surface under 20000lbs wheel load in lane1

Figure 6.8 shows a similar comparison of the strain distribution at the top of the concrete overlay for the model generated and the experimental strains as discussed above.

The strains for the FEM model were determined by placing the wheel load placed at different locations along the pavement and calculating the strains at a particular fixed location. It can be seen from these figures (Figures 6.7 and 6.8) that the FEM model also produced a strain reversal. Also the magnitudes of the strains for both the model generated and the experimental strains after 30,000 passes are reasonably similar. 


\section{Dynamic strain variation of gage1CM2 under 20000 lbs load}

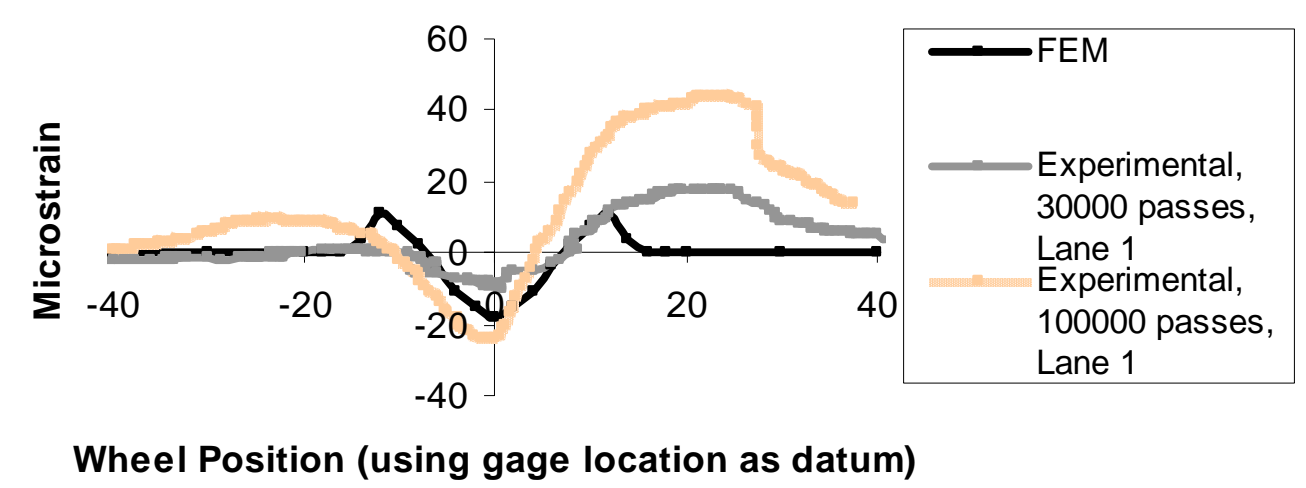

Figure 6.8 Dynamic strain variation at the top of the concrete under 20000lbs wheel load in lane1

Another interesting observation is the fact that the reversal of strains obtained from the FEM model is symmetric about the location of the gages. The transverse joints were not incorporated in the FEM model. Since the gages were located at the middle of the panel, the experimental strains ideally should also be symmetric. However, the experimental strains measured by the gage after the wheel has passed the gage location are higher than the strains measured by the same gage before the wheel reached the gage location. This asymmetry could be attributed to the fact that the joint preceding the gage could have been damaged less than the joint located after the gage. This is corroborated by the V-meter results on Lane 1. The time of flight data shown in Figure 5.4 clearly shows the joint following the gage is potentially less solid than the joint preceding the gage, which may explain the asymmetry of the experimental strains.

Figure 6.9 shows the variation of the strains through the thickness of the pavement for the FEM model. The model showed a trend of decreasing tensile strains 
inside the layer of asphalt. It is therefore postulated that the concrete overlay on top of the milled asphalt is able to absorb most of the stresses generated by the loading and thereby effectively reduces the strains within the asphalt. This has been compared to the variation of the strains within the overlay up to the milled surface of asphalt based on the experimental results. It can be seen (from Figure 6.9) that for both cases, the neutral axis is located about $1.75 "$ from the top of the overlay. The strain variation, through the overlay depth, observed experimentally is linear with depth. For the FEM model, however the strains decrease in the asphalt layer.

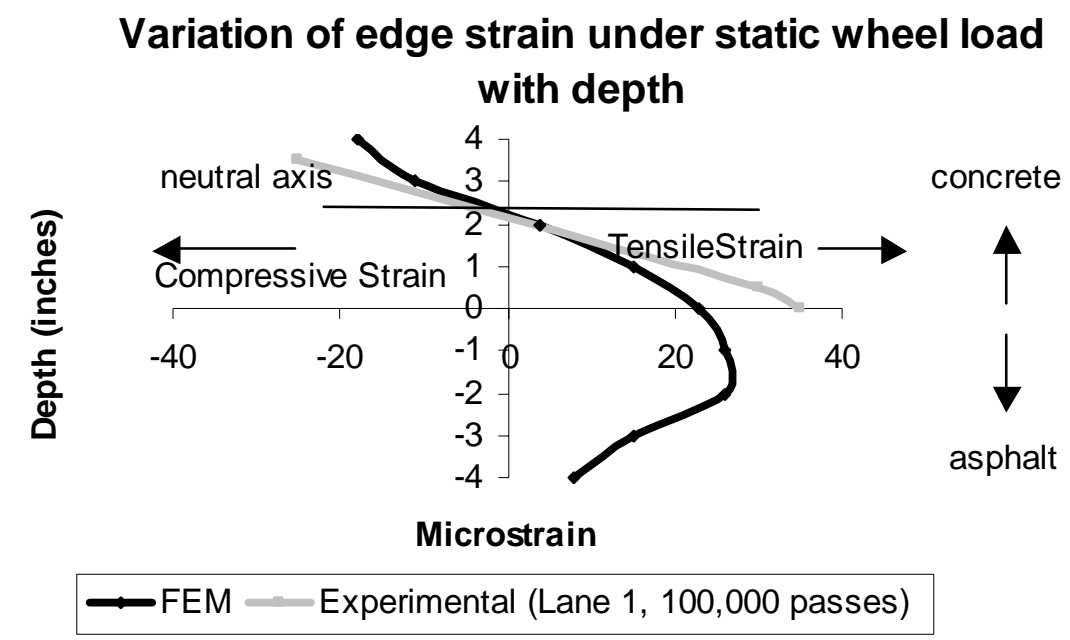

Figure 6.9 Strain variation through the depth of the pavement for the FEM model and experimental test.

\section{$\underline{6.6 \text { Summary }}$}

The following points could be made based on the results generated by the finite element analysis of the UTW model.

1. The calculated strains from the model and the observed experimental strains were very similar in magnitudes. The strains were compressive in nature at 
the top of the overlay and became increasingly tensile as the depth of the pavement increased.

2. The model predicted that the critical strains will develop at the interface of the asphalt and the concrete overlay. This was actually observed from the experimental results. The model also predicted that a stress concentration would develop at the interface. This stress concentration may in turn weaken the bond between the concrete overlay and the asphalt base.

3. The phenomenon of strain reversal was observed in the results produced by the FEM model. This phenomenon was validated by the data gathered during the experiment. The strain reversal predicted by the FEM model is symmetric with respect to the location of the gage. However, the experimental strains are not symmetric.

4. The variation of the strains through the depth of the overlay shows a linear trend for both the experimental and the calculated values of strain. However, the FEM model predicts a decrease in the strains within the asphalt layer. Since no strain gages were installed within the asphalt layer this observation could not be verified experimentally.

5. From the experimentally observed data, it could be concluded that the pavement behaved in a linear and elastic manner within the concrete overlay. However, the strains observed in the asphalt layer showed a non-linear trend. 


\section{CONCLUSIONS AND RECOMMENDATIONS}

\section{$\underline{7.1 \text { Summary }}$}

Since its inception in the early nineties, UTW has emerged as a fast growing technology for pavement rehabilitation. A number of research projects have been undertaken to gain an insight on the factors and conditions that affect the performance of a UTW pavement. The present research has employed a number of techniques like full scale accelerated tests, non-destructive tests and finite element modeling method to analyze the performance of pavements subjected to slow moving loads.

Accelerated Pavement Testing offers advantages for testing and evaluating Ultrathin Whitetopping. The predetermined loading, controlled environment, and rapid simulation of traffic loads can be used to accurately evaluate the factors influencing the UTW performance. The objective of the study included the analysis of strains and deflections caused by the wheel loads and the temperature gradient to get an insight into the pavement response of the UTW. This analysis gave an indication of the performance of the overlay on the asphalt surface. The non-destructive tests conducted on the pavement surface after the accelerated pavement testing revealed potential for the existence of some internal damage caused by the repeated loading. A three-dimensional finite element model based on ABAQUS was also used to conduct a simple linear static analysis of the pavement response of a UTW pavement subjected to a wheel load. This 
simple model uses reasonable pavement geometry, boundary and load conditions and material properties to study the effect of wheel load on the stress-strain distribution in a UTW pavement. The experimental and the modeling results did not show any significant difference. The model was useful in verifying the response as obtained by the experimental test at the APT facility.

\section{$\underline{7.2 \text { Conclusions }}$}

Several conclusions can be drawn from the results of the APT tests as well as the finite element model.

a) The performance of the UTW overlay, $100 \mathrm{~mm}$ (4") thick proved to be satisfactory under the heavy wheel load (of 20,000 lbs) as there were no significant strains and deflections even after 100,000 passes. Even the $63 \mathrm{~mm}$ $\left(2^{1} / 2^{\prime \prime}\right)$ thick overlay in lane 3 performed very well under the wheel load (of $12,000 \mathrm{lbs})$ as no permanent deflections and strains accumulated after 150,000 passes. In lane 4 also, 250,000 repetitions of the heavier wheel load (of 20,000 lbs) and elevated temperature effects did not cause structural damage to the pavement. From the results of the accelerated pavement test, it could be concluded that the joint spacing of $1.2 \mathrm{~m}$ (4') in all the lanes was sufficient. Overall, judging by the magnitude of deflections and the strains observed at the various lanes, it could be concluded that the performance of the UTW overlay in all the lanes was very effective.

b) The strain gages performed very well under the different environmental and loading conditions. Considering that the gages maintained an acceptable internal 
resistance throughout the test, had a low failure rate and the strain gage response agreed with the finite element calculations, the performance of the gages during these tests could be considered very effective. The techniques used to install the gages in the pavement structure could thus be deemed satisfactory.

c) The measured strain in the overlay was relatively proportional to the applied load. This suggests that the pavement response was linear within the overlay. The increase of temperature in lane 4 however affected the linearity of the pavement response, and the strains at the asphalt surface increased considerably because of the temperature gradient.

d) Dynamic measurements of longitudinal strain indicate that the concrete overlay experienced significant stress reversal as the wheel rolls over the pavement. As the wheel approaches a given point in the pavement, the top and the bottom of the overlay experiences a tensile and compressive strain respectively. When the wheel is exactly over the point, the strains quickly reverse causing the top of the slab to be in compression and the bottom to be in tension. These strains again quickly reverse as the wheel moves away from the given point. This phenomenon was also observed in the finite element model.

e) Non-destructive testing using Ultrasonic Pulse Velocity technique proved to be very effective in determining the potential locations of cracks within the panels. However, the width and depth of the cracks could not be determined using this technique.

f) The dynamic strain measurements indicated the existence of a good bond between the overlay and the underlying asphalt. It was also observed that the overlay 
thickness and the asphalt stiffness significantly affect the strains because of their influence on the location of the neutral axis. The bond strength tests on the cores confirmed the presence of a strong bond between the UTW and the asphalt.

\subsection{Suggestions for further research}

From the tests on the UTW sections, it can be concluded that the magnitude of strains was very low. In addition, there was no significant cracking observed on the test sections. Further tests on UTW would be needed to establish a criterion for an optimum overlay design. More tests should be performed to determine the effects of parameters like joint spacing. The performance of UTW should be monitored on a field installation, which would give an opportunity to determine additional factors such as the effect of environmental condition, effect of a greater joint spacing etc. that affect the overlay performance and life. The stress reversal phenomenon observed during the present tests should be further investigated. Further mechanistic analysis needs to be done to determine the reasons for this occurrence and its effect on the life of the pavement. Finite element modeling is a powerful tool to analyze these effects. The model incorporated in this study was a simple linear static model. Dynamic analysis of the pavement response could be carried out using more sophisticated finite element models. There is a need to generate more data on the UTW sections to establish a semi empirical model for the performance of UTW. Based on further analysis of data, design guidelines could be formulated for the performance prediction of UTW. 
LIST OF REFERENCES 


\section{LIST OF REFERENCES}

1. Mack, J. W, Hawbaker, L. D., and Cole, L.W, "Ultrathin Whitetopping State of the Practice for Thin Concrete Overlays of Asphalt", Transportation research record 1610, TRB, National Research Council, Washington D.C., pp. 39-43

2. Cole, L W., "Pavement Condition Surveys of Ultrathin Whitetopping Projects", Proceedings Sixth International Conference on Concrete Pavements, Volume 2, November 1997, Purdue University, West Lafayette, Indiana, pp. 175-187.

3. Mack, J. W., Cole, L.W., and Moshen, J.P., “Analytical Considerations for Thin Concrete Overlays on Asphalt", Transportation research record 1388, TRB, National Research Council, Washington D.C., 1993, pp. 167-173

4. Armaghani, J.M., and Tu, D., "Evaluation of Ultra-Thin Whitetopping in Florida", Paper for presentation at Transportation Research Board, National Council, Washington, D.C., 1996, pp. 15-20.

5. Armaghani, J.M., and Tu, D., "Rehabilitation of Ellaville Weigh Station with UltraThin Whitetopping", Presented at the Transportation Research Board, National Council, Washington, D.C., 1999.

6. Mack, J. W., Wu, C-L., Tarr, S., and Refai, T., "Model Development and Interim Design Procedure Guidelines for Ultra-thin Whitetopping Pavements", Proceedings, Sixth International Conference on Concrete Pavement Design and Materials for High Performance, Volume 1, November 1997, Indianapolis, Indiana, pp.189-206.

7. Cole, L.W., "Performance of Ultrathin Whitetopping Roadways" Proceedings of the Conference American Society of Civil Engineers, May 1999, Cincinnati, Ohio, pp. 583-590.

8. Cole, L.W., Mack, J.W., Packard, R.G., "Whitetopping and Ultrathin WhitetoppingThe US Experience", Proceedings American Concrete Pavement Association (ACPA), Skokie, Illinois, Volume 36, Number 2, pp.247 - 263.

9. Speakman, J., and Scott, N.H.III, "Ultra-Thin, Fiber-Reinforced Concrete Overlays for Urban Intersections", Transportation research record 1532, TRB, National Research Council, Washington D.C., pp. 15-20. 
10. Cole, L.W., Sherwood, J., and Qi, X., “Accelerated Pavement Testing of Ultrathin Whitetopping", Proceedings of the International Conference on Accelerated Pavement Testing, October 1999, Reno, Nevada, Paper number CS1c (b), 18 p.

11. Edwards, W.F., and Sargand, S.M., "Response of an Ultra-Thin Whitetopping Pavement to Moving Wheel Loads", Proceedings International Conference on Accelerated Pavement Testing, October 1999, Reno, Nevada, Paper Number CS1-4, $13 \mathrm{p}$.

12. Vandenbossche, J.M., and Rettner, D.L., "One-Year Performance Summary of Whitetopping Test Sections at the Mn/ROAD Test Facility", Proceedings International Conference on Accelerated Pavement Testing, October 1999, Reno, Nevada. Paper Number CS1c (a), 21 p.

13. Risser, R.J., LaHue, S.P., Voigt, G.F., and Mack, J.W., "Ultra-Thin Concrete Overlays on Existing Asphalt Pavements", American Concrete Pavement Association Record, ACPA, Skokie, Illinois, pp. 247-254.

14. Cole, L.W., Mohsen, J.P., "Ultrathin Concrete Overlays on Asphalt", Paper submitted for Presentation at the Prosperity Through Innovative Pavement Design Session, TAC Annual Conference, 1993, Ottawa, Ontario, Canada.

15. Yoder, E.J., and Witczak, M.W., Principles of Pavement Design, Second Edition, John Wiley and Sons Inc., New York, NY, 1975.

16. Huang, Y.H., Pavement Analysis and Design, Prentice Hall, Inc. 1993.

17. Van Deusen, D.A., Newcomb, D.E., and Labuz, J.L., A Review of Instrumentation Technology for the Minnesota Road Research Project, Report 92-10, Minnesota Department of Transportation, 1992, $120 \mathrm{p}$.

18. Baker, H.B., Ruth, M.R., and Van Deusen, D.A., Load Response Instrumentation Installation and Testing Procedures, Report 94-01, Minnesota Department of Transportation, 1994, 43 p.

19. Logan, D.L., A First Course in the Finite Element Method, International Thomson Publishing, 1992.

20. “ABAQUS, Finite Element Computer Program”, Version 5.8-18, Hibbit, Karlson and Sorensen Inc, 2000a

21. “ABAQUS, Finite Element Computer Program”, Theory Manual, Version 5.5, Hibbit, Karlson and Sorensen Inc., 1995b 
22. “ABAQUS, Finite Element Computer Program”, User Manual, Version 5.5, Hibbit, Karlson and Sorensen Inc., 1995c

23. Iowa Department of Transportation, Highway Division, "Method of Test for Determining the Shearing Strength of Bonded Concrete" 406-B, 1978. 